\title{
The role of online discussion forums in newcomers' labour market integration in Canada
}

by

\author{
Daniel Gulanowski
}

A thesis submitted to the Faculty of Graduate and Postdoctoral Affairs in partial fulfillment of the requirements for the degree of

Doctor of Philosophy

in

Management

Carleton University

Ottawa, Ontario

(C)2018

Daniel Gulanowski 


\begin{abstract}
This dissertation explores the phenomenon of increased use of online discussion forums by newcomers to Canada to access labour market knowledge. Drawing on extant literature on social support, knowledge exchange, and online technology affordances, I examine the role of online discussion forums in newcomers' labour market integration, through an inductive content analysis of 574 discussion threads. Results of this study suggest that the role of online discussion forums is to provide knowledge resources, in the form of information and advice support, which help newcomers make migration decisions and manage their expectations and preparedness, which in turn has the potential to help newcomers with adjustment and labour market integration in the new country.

This dissertation contributes to literature on newcomers' adjustment and labour market integration by describing the online discussion forum system and showing that it facilitates access to and exchange of online social support that can help newcomers with adjustment and integration in the new country's labour market. It also expands our understanding of the theory of knowledge exchange and the optimal matching model by examining them in the context of online discussion forums and newcomers' labour market integration. The findings also question the way we think of newcomers' labour market integration and newcomers' knowledge needs at different stages of settlement and suggest that we also need to include and focus more on the pre-arrival stage of migration and better understand online sources of social support. Moreover, I argue that advice support should be recognized as a separate type of social support.

This research also makes practical contributions by expanding our understanding of newcomers' interactions in online discussion forums which can inform government and community organizations tasked with supporting newcomers integrate in the labour market. The findings highlight the importance of pre-arrival training and support to migrants and the potential of better utilizing online technologies to reach future migrants and accelerate their adjustment and integration process. Pre-arrival online support facilitates preparation and more accurate expectations prior to migration, which in turn has the potential to facilitate migrants' adjustment and labour market integration.
\end{abstract}




\section{Acknowledgements}

I would like to thank my supervisor, Dr. Luciara Nardon, for her work in seeing this dissertation through. Her encouragement, insight and guidance has been critical to the development of this dissertation.

I would also like to thank my dissertation committee, Dr. Mike Hine and Dr. Diane Isabelle, for their encouragement and guidance at key points.

Lastly, I would like to thank and dedicate this dissertation to my parents for their endless patience, encouragement and optimism. 


\section{Table of Contents}

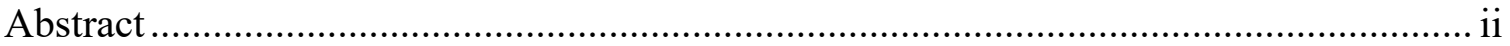

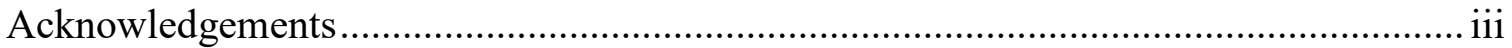

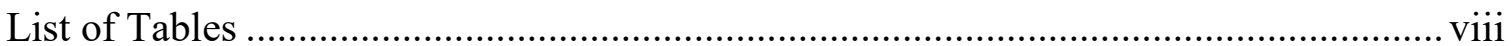

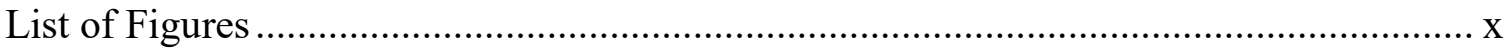

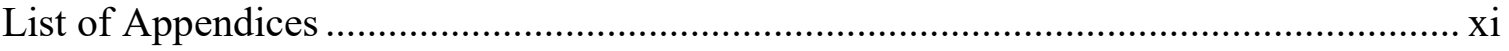

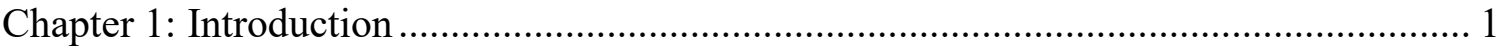

Global migration and labour market integration ........................................................ 2

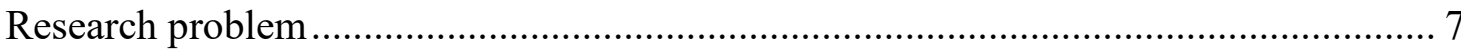

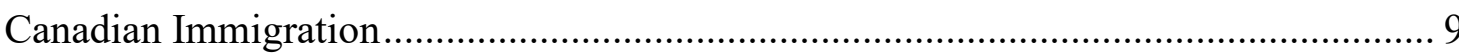

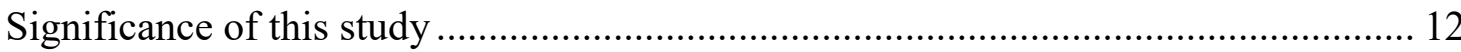

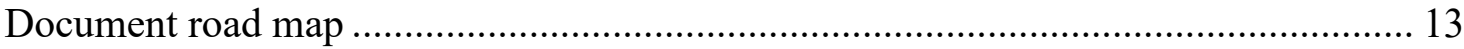

Chapter 2: Literature Review.................................................................................. 14

2.1. Labour market integration of newcomers ........................................................... 14

Labour market integration of newcomers - benefits ................................................. 16

Labour market integration of newcomers - challenges ............................................... 17

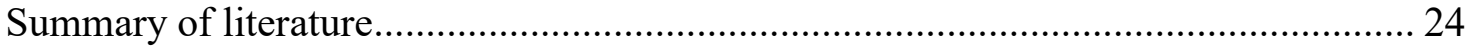

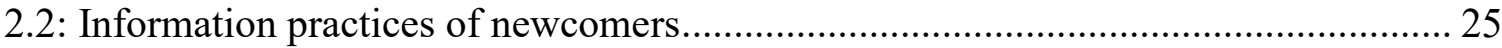

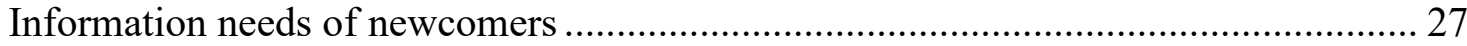

Information needs at different stages of settlement ............................................... 29

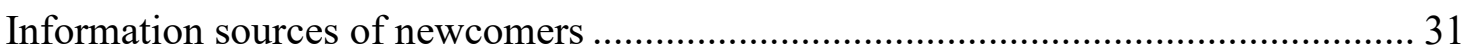

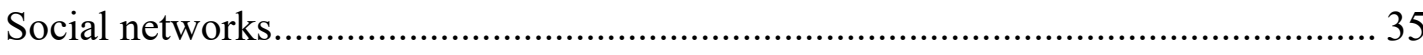

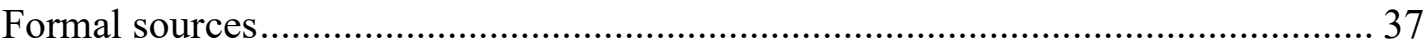

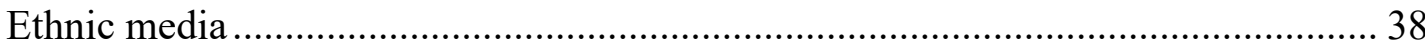

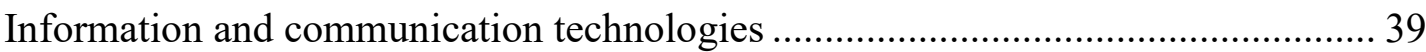

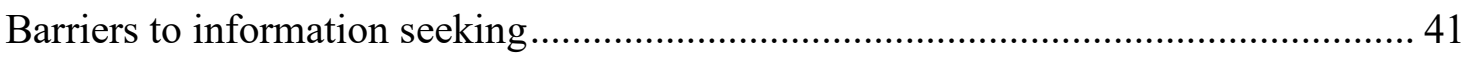

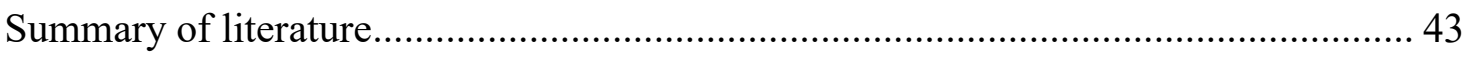

2.3. Internet technologies and employment information .................................................. 44

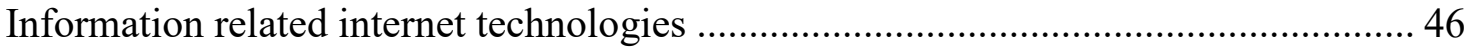

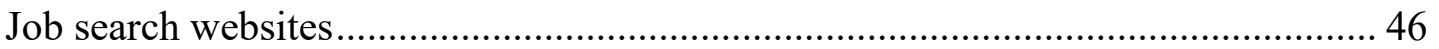

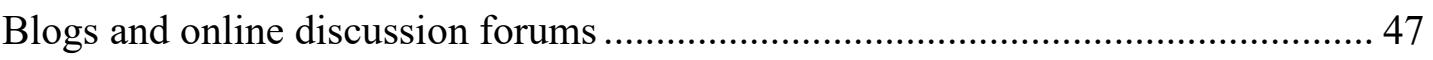

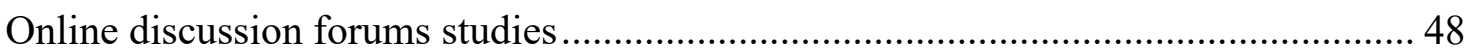




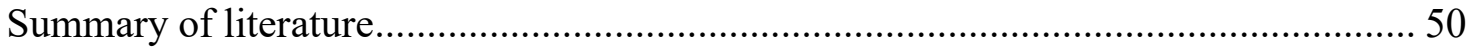

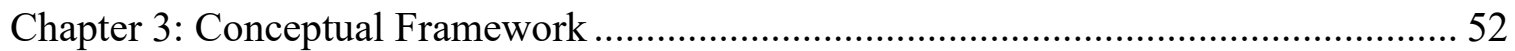

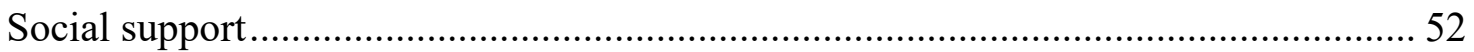

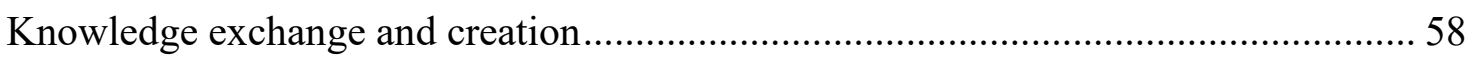

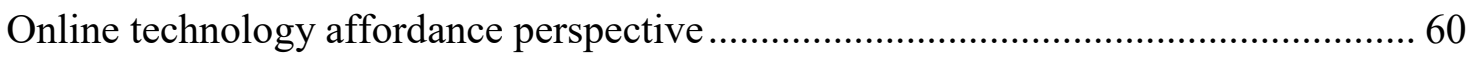

Chapter 4. Research Approach and Methodology …………….................................... 63

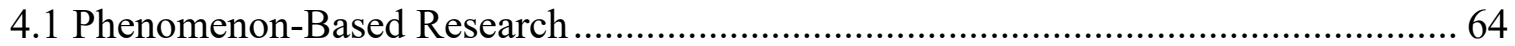

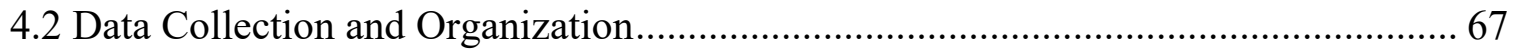

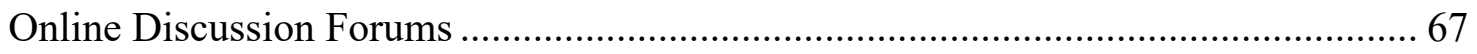

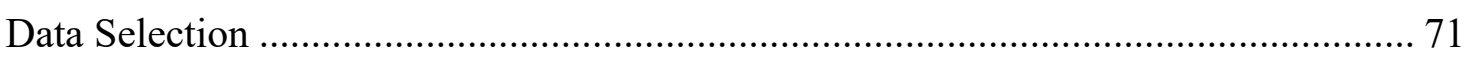

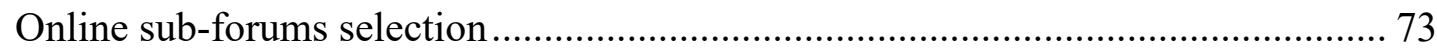

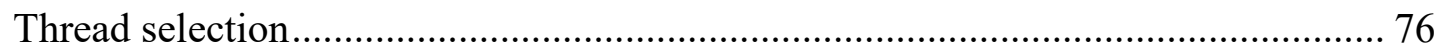

Summary of data collection and organization process............................................... 80

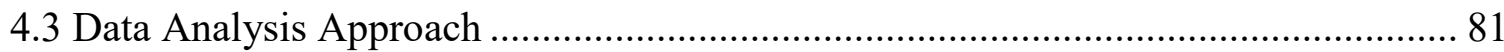

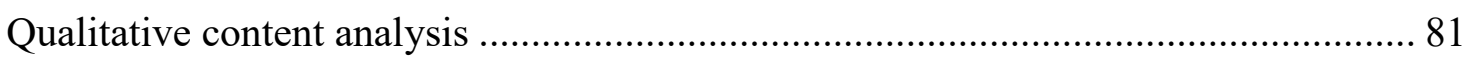

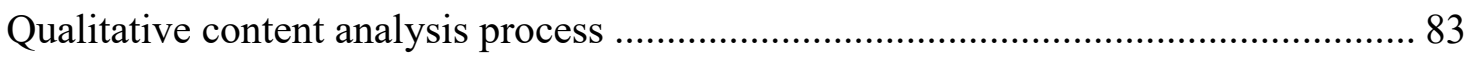

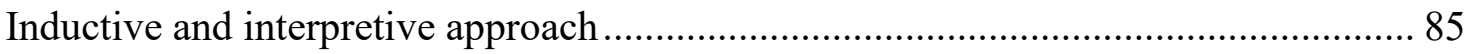

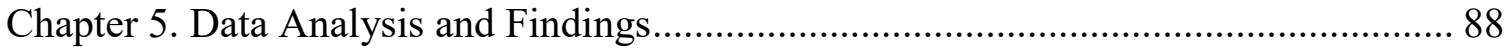

5.1. Research Question 1: What needs are newcomers trying to meet with online

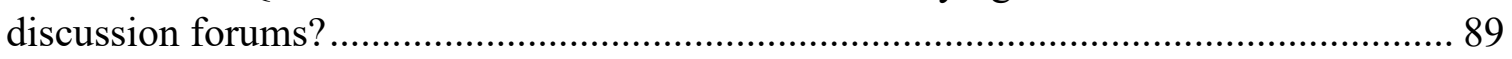

Summary of analysis and findings for research question 1 ......................................... 90

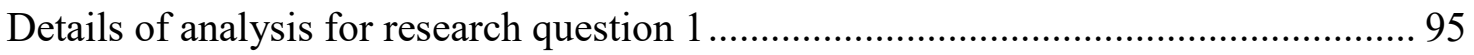

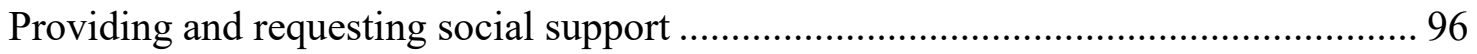

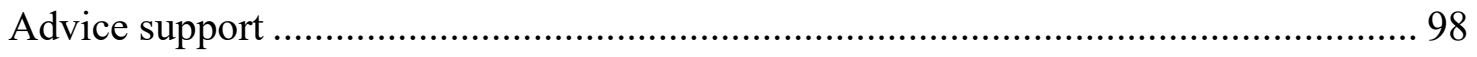

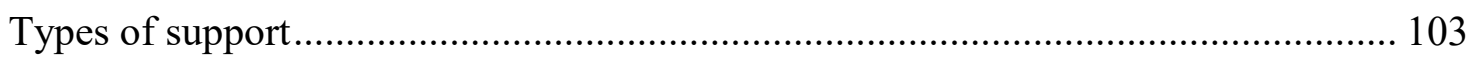

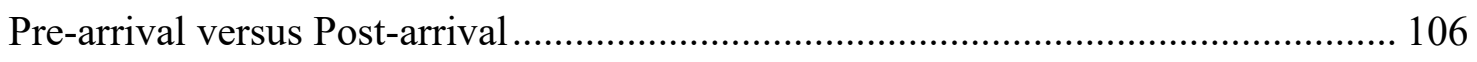

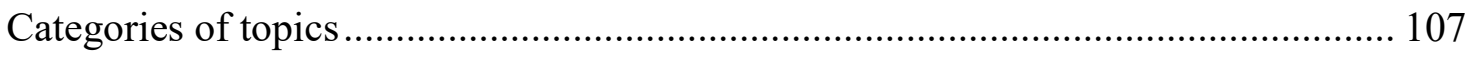

Forms of advice: opinion, guidance, and problem specific........................................ 117

5.2. Research Question 2: To what extent are these needs met in online discussion

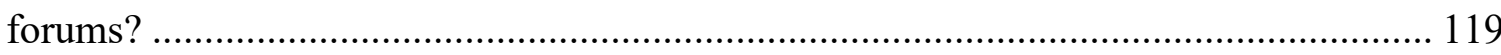

Summary of analysis and findings for research question 2..................................... 120

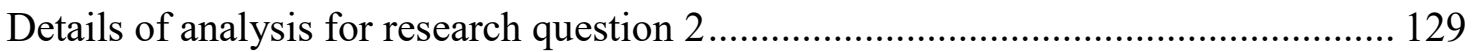

Needs met outcomes for various categories of topics of needs requested .................. 133 
Support needs requested versus support needs provided 136

Needs met in pre-arrival and post-arrival initial posts threads................................... 138

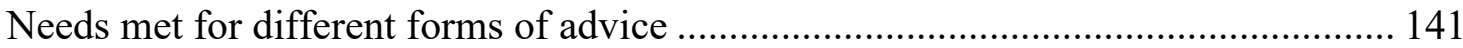

5.3. Research Question 3: What are the characteristics of threads in which needs are not

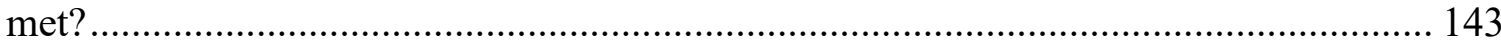

Summary of analysis and findings for research question 3..................................... 143

Details of analysis for research question 3 ....................................................... 148

Needs not met in various categories of topics requested in initial posts ................. 150

Needs not met in pre-arrival and post-arrival initial posts ..................................... 152

Needs not met for different forms of advice........................................................ 154

Time since the initial posts' posting date ……………......................................... 155

Initial posts with high number of replies and needs met versus no replies ............. 155

Participation in computer mediated communications ................................................. 157

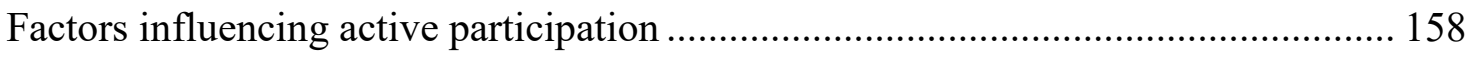

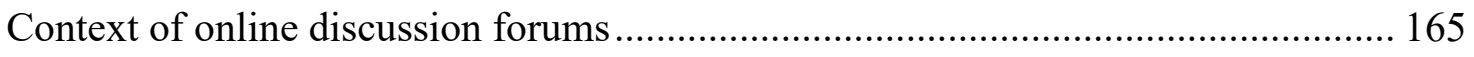

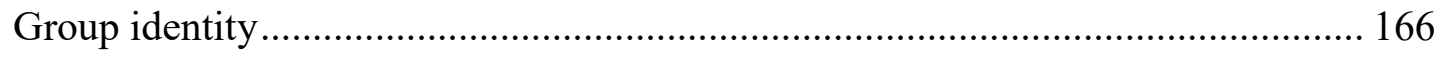

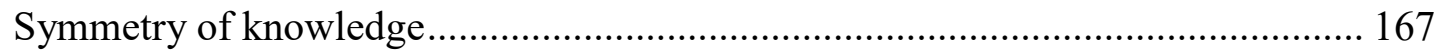

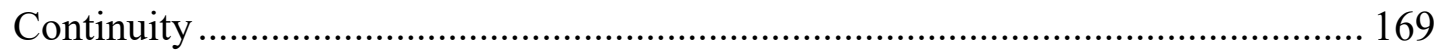

5.4. Research Question 4: What role do online discussion forums play in facilitating and/or hindering newcomers' labour market integration? ............................................ 170

The online forum technology system and the exchanges of knowledge support

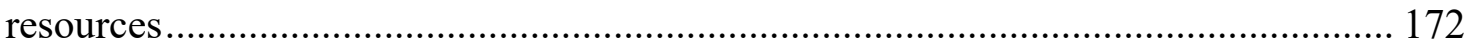

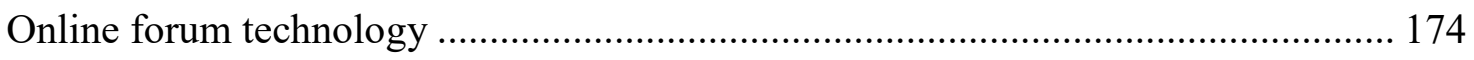

Initial post author's contributions: initial posts providing and requesting support..... 175

Online forum participants' contributions: replies providing and requesting support . 176

Online discussion forum knowledge support resources: information and advice....... 181

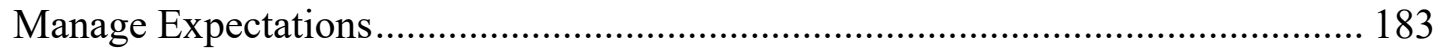

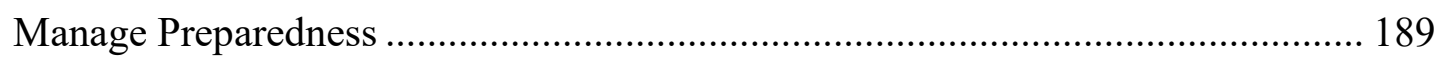

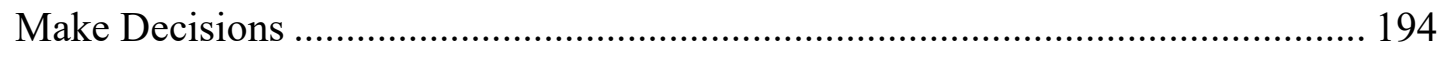

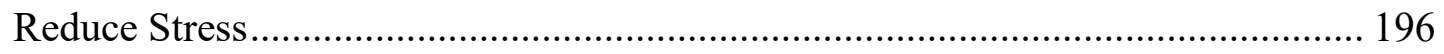

Adjustment and Labour Market Integration.............................................................. 197

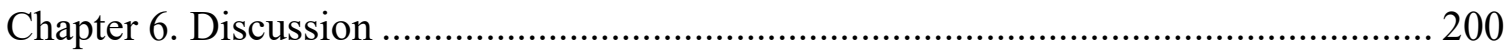

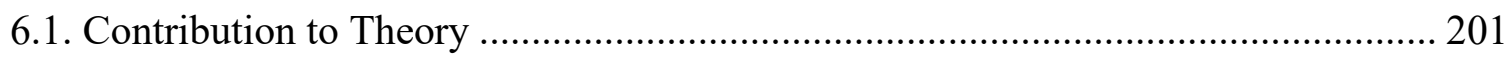




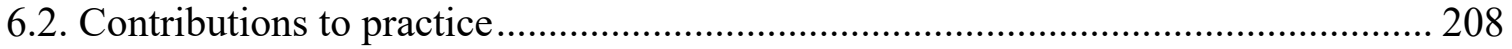

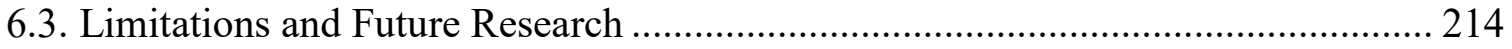

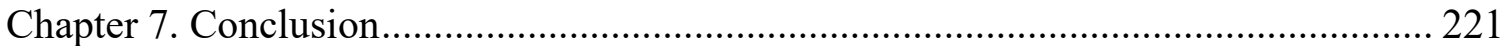

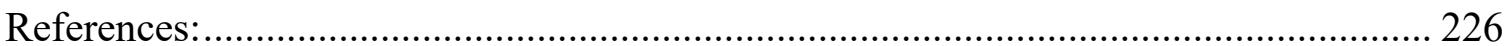

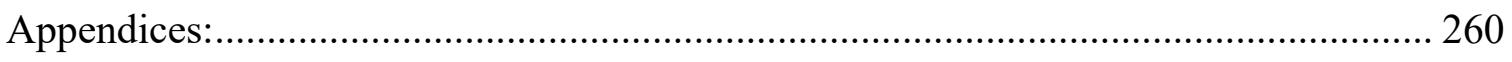




\section{List of Tables}

\begin{tabular}{|c|c|c|}
\hline Table & Name & Page \\
\hline 1 & Registered members, threads and posts in Canada Visa forum & 8 \\
\hline 2 & Annual immigrant admission to Canada by class & 11 \\
\hline 3 & $\begin{array}{l}\text { Research strategies given the growth stages of research on the } \\
\text { phenomenon }\end{array}$ & 66 \\
\hline 4 & $\begin{array}{l}\text { Search terms and the corresponding returned results in Google search } \\
\text { engine }\end{array}$ & 71 \\
\hline 5 & Selected online discussion forums & 72 \\
\hline 6 & Canada Visa and Road to Canada forums statistics & 73 \\
\hline 7 & Canada Visa forum structure & 74 \\
\hline 8 & Selected sub-forums statistics & 75 \\
\hline 9 & Summary of the threads selection & 79 \\
\hline 10 & Types of social support requested and provided in the initial posts & 97 \\
\hline 11 & Types of support provided in the 41 providing initial posts & 104 \\
\hline 12 & Types of support needs requested in the 533 requesting initial posts & 105 \\
\hline 13 & Ten final categories of topics identified in initial posts & 107 \\
\hline 14 & $\begin{array}{l}\text { Topics requested in the } 380 \text { information and } 144 \text { advice initial posts } \\
\text { (real figures) }\end{array}$ & 111 \\
\hline 15 & $\begin{array}{l}\text { Topics requested in the } 380 \text { information and } 144 \text { advice initial posts } \\
\text { (percentages) }\end{array}$ & 112 \\
\hline 16 & $\begin{array}{l}\text { Examples for topics requested in the } 380 \text { initial posts requesting } \\
\text { information }\end{array}$ & 114 \\
\hline 17 & Examples for topics requested in the 144 initial posts requesting advice & 116 \\
\hline 18 & $\begin{array}{l}\text { Forms of advice and categories of topics requested in advice initial } \\
\text { posts }\end{array}$ & 118 \\
\hline 19 & Categories and examples of support needs met outcomes & 131 \\
\hline 20 & $\begin{array}{l}\text { Support needs met outcomes for information and advice support needs } \\
\text { requested }\end{array}$ & 132 \\
\hline
\end{tabular}




\begin{tabular}{|c|c|c|}
\hline Table & Name & Page \\
\hline 21 & Needs met outcomes in the initial posts requesting information support & 133 \\
\hline 22 & Needs met outcomes in the initial posts requesting advice support & 134 \\
\hline 23 & $\begin{array}{l}\text { Needs met versus not met across } 10 \text { categories of information and } \\
\text { advice needs requested }\end{array}$ & 135 \\
\hline 24 & $\begin{array}{l}\text { Support needs requested in the initial posts versus support needs } \\
\text { provided in the threads }\end{array}$ & 136 \\
\hline 25 & $\begin{array}{l}\text { Needs met in the pre-arrival and post-arrival initial posts requesting } \\
\text { information }\end{array}$ & 138 \\
\hline 26 & $\begin{array}{l}\text { Needs met in the pre-arrival and post-arrival initial posts requesting } \\
\text { advice }\end{array}$ & 139 \\
\hline 27 & $\begin{array}{l}\text { Needs met in the pre-arrival and post-arrival initial posts requesting } \\
\text { support }\end{array}$ & 140 \\
\hline 28 & Needs met in different forms of advice and across categories of topics & 142 \\
\hline 29 & $\begin{array}{l}\text { Threads with needs not met across categories of topics of needs } \\
\text { requested }\end{array}$ & 150 \\
\hline 30 & $\begin{array}{l}\text { Needs not met in pre-arrival and post-arrival initial posts requesting } \\
\text { information }\end{array}$ & 152 \\
\hline 31 & $\begin{array}{l}\text { Needs not met in pre-arrival and post-arrival initial posts requesting } \\
\text { advice }\end{array}$ & 153 \\
\hline 32 & $\begin{array}{l}\text { Needs not met for initial posts requesting information and three forms } \\
\text { of advice }\end{array}$ & 154 \\
\hline 33 & Examples of initial posts with high number of replies and no replies & 156 \\
\hline 34 & Online community versus Online exchange & 169 \\
\hline
\end{tabular}




\section{List of Figures}

\begin{tabular}{|c|c|c|}
\hline Figure & Name & Page \\
\hline 1 & Information needs of newcomers across four stages of settlement & 30 \\
\hline 2 & Information sources of newcomers at different settlement stages & 33 \\
\hline 3 & Modes of the knowledge creation & 59 \\
\hline 4 & Initial posts and replies structure in an online forum & 77 \\
\hline 5 & Data collection and organization process & 80 \\
\hline 6 & Summary of the qualitative content analysis process & 83 \\
\hline 7 & Main steps in the analysis of research question 1 & 90 \\
\hline 8 & Summary of the examination of requesting initial posts & 92 \\
\hline 9 & Ten categories of topics in initial posts requesting information & 93 \\
\hline 10 & Eight categories of topics in initial posts requesting advice & 94 \\
\hline 11 & Main steps in the analysis of research question 2 & 120 \\
\hline 12 & Percentage of support needs meet with online discussion forums & 121 \\
\hline 13 & Needs met outcomes for requesting initial posts & 122 \\
\hline 14 & $\begin{array}{l}\text { Needs met for the ten topics in initial posts requesting information } \\
\text { and advice support }\end{array}$ & 124 \\
\hline 15 & $\begin{array}{l}\text { Needs met in pre-arrival and post-arrival initial posts requesting } \\
\text { information support }\end{array}$ & 126 \\
\hline 16 & $\begin{array}{l}\text { Needs met in pre-arrival and post-arrival initial posts requesting } \\
\text { advice support }\end{array}$ & 127 \\
\hline 17 & Main steps in the analysis of research question 3 & 143 \\
\hline 18 & Needs not met for different forms of support requested in initial posts & 144 \\
\hline 19 & Needs not met in the ten categories of topics & 145 \\
\hline 20 & A schematic model of a text-based CMC cycle & 164 \\
\hline 21 & The online discussion forum system & 173 \\
\hline
\end{tabular}




\section{List of Appendices}

\begin{tabular}{|c|c|c|}
\hline Appendix & Name & Page \\
\hline $\mathbf{A}$ & Relational perspective on newcomers' capital mobilization & 261 \\
\hline B & $\begin{array}{l}\text { Examples of types of support provided in the } 41 \text { providing initial } \\
\text { posts }\end{array}$ & 265 \\
\hline $\mathbf{C}$ & $\begin{array}{l}\text { Examples of types of support needs requested in the } 533 \\
\text { requesting initial posts }\end{array}$ & 267 \\
\hline $\mathbf{D}$ & Initial 24 and final 10 categories of topics & 269 \\
\hline $\mathbf{E}$ & $\begin{array}{l}\text { Examples for topics requested in the } 380 \text { initial posts requesting } \\
\text { information }\end{array}$ & 270 \\
\hline $\mathbf{F}$ & $\begin{array}{l}\text { Examples for topics requested in the } 144 \text { initial posts requesting } \\
\text { advice }\end{array}$ & 276 \\
\hline $\mathbf{G}$ & Examples of needs met outcomes & 281 \\
\hline
\end{tabular}




\section{Chapter 1: Introduction}

This study contributes to the sub-field of global mobility within International Business by exploring the recent real-world phenomenon of increasing use of online discussion forums by newcomers to Canada to access job related knowledge. In this study, the term 'newcomers' broadly refers to individuals who are in the process of immigrating, recently immigrated, or self-expatriated to Canada, and it includes all types of international workers. Given the focus on labour integration, organization assignees who do not need to find a job are not represented in this study.

Newcomers constitute a very important part of the global talent pool and their labour market integration benefits organizations and receiving societies (Cascio and Boudreau, 2016; Vaiman et al., 2015). Moreover, newcomers need employment in the local market to successfully settle, integrate, and fully function in the new society (Al Ariss and Syed, 2011; Alexander, 2017; Fang et al., 2013). Knowledge of local labour market and information environment are critical for employment integration (Farh et al., 2010; Khoir et al, 2015). However, newcomers typically lack relevant local knowledge and are increasingly turning to internet technologies, such as online discussion forums to meet their information needs (Ahmed and Veronis, 2017; Janta and Ladkin, 2013).

In the remaining sections of this chapter, I discuss the global migration and labour market integration and, Canadian immigration, and explain the research problem and significance of the study. At the end of this chapter, I also include a document roadmap for the remaining sections of this dissertation. 


\section{Global migration and labour market integration}

Global migration is on the rise due to decreasing restrictions to international mobility and costs of international travel, as well as demographic changes, skilled labour shortages, and an increasingly integrated global labour market and economy (Al Ariss and Syed, 2011; Alexander, 2017; Guo and Al Ariss, 2015; Hajro et al., 2017; Sidani and Al Ariss, 2014). It is estimated that the number of migrants worldwide reached 258 million in 2017, rising by over 105 million since 1990 (UN International Migration Report, 2017). The primary sources and recipients of migrants are Europe, Asia and North America and migrants typically are moving from less developed countries (e.g., India, China and Mexico) to the first world countries such as the United States, Germany, Australia and Canada (UN International Migration Report 2017: Highlights, 2017; UN International Migration Wallchart, 2017).

International business and management scholars have identified the need to better understand issues related to global mobility in general and migration in particular as a key area for investigation (Al Ariss et al., 2014; Caligiuri and Bonache, 2016; Cascio and Boudreau, 2016; Doh et al., 2016; Hajro et al., 2017; Sidani and Ariss, 2014; Zikic and Richardson, 2016). Substantial research in business and organizations has examined issues concerning mobile professional workers, especially expatriates (Caligiuri and Bonache, 2016). Traditionally, business scholars were mainly focused on organization-initiated expatriation (e.g., Delios and Bjorkman, 2000; Farh et al., 2010; Mezias and Scandura, 2005), but more recently there is also a growing interest in studying self-initiated expatriates (e.g., Al Ariss, 2010; Al Ariss and Özbilgin, 2010; Howe-Walsh and Schyns, 2010; Ramboarison-Lalao et al., 2012; Tharenou, 2015) and skilled migrants (Al Ariss and 
Crowley-Henry, 2013; Aten et al., 2016). These different types of mobile workers are discussed in more detail in chapter 2 and referred to generally as "newcomers."

We need to better understand newcomers' labour market integration in the receiving country, because labour market integration is good for organizations and society, as well as for newcomers' settlement and integration. Newcomers, especially skilled newcomers, constitute an important part of the global talent pool that contributes to the competitive advantages of international companies, as well as receiving countries (Al Ariss and Syed, 2011; Carr et al., 2005; Cerdin et al., 2014; Guo and Al Ariss, 2015; Sidani and Al Ariss, 2014; Syed, 2008; Syed and Murray, 2009; Tarique and Schuler, 2010; Tung, 2016). For example, in the U.S., 44 out of 77 companies valued at over $\$ 1$ billion were founded by immigrants (Treurnicht, 2017). In Canada, there are also substantial and growing shortages of skilled workers (Pohlmann, 2017) and an aging Canadian population will lead to lower economic growth and more labour and skill shortages (Alexander, 2017). By 2035, Canada will need about 350,000 newcomers annually to meet its labour market needs and almost $100 \%$ of Canada's net population growth will come from immigration (Alexander, 2017). Labour market integration of newcomers can be very beneficial for receiving countries like Canada, as newcomers can bring new and complementary skills, foreign market expertise, increase cultural diversity and innovation in organizations, and reduce overall skill shortages (Cerdin et al., 2014; Crowley-Henry et al., 2016; Dietz et al., 2015; Downie, 2010; Pholphirul and Rukumnuaykit, 2016; Pohlmann, 2017; Turchick Hakak and Al Ariss, 2013; Zikic et al., 2010; Zikic and Richardson, 2016). 
It is well established that newcomers need to find suitable employment to fully function in the new country (Dietz et al., 2015; Fang et al., 2013; Frank, 2013; Frijters et al., 2005; Reitz, 2001; Reitz et al., 2014; Wang and Sangalang, 2005). Research has shown that integration of newcomers in the new country's labour market is critical for their settlement, adjustment and integration in the receiving society, culture and environment (Bevelander and Pendakur, 2014; Caidi et al., 2010; Frank, 2013; Hansen, 2012; Lundborg, 2013; Reitz, 2007a, 2007b; Sambasivan et al., 2017; Singh and Mahmood, 2017; Wang and Sangalang, 2005). Employment grants newcomers a sense of belonging, recognition, and acceptance in the new society (Dietz et al., 2015; Frank, 2013; Hansen, 2012; Reitz et al., 2014). In addition, research has shown that employed individuals have significantly higher levels of physical and psychological health than unemployed individuals (Korpi, 2001; Paul and Moser, 2009; Wanberg, 2012). However, the above advantages are not utilized in a reciving country when newcomers are not fully integrated in the country's labour market (Dietz et al., 2015; Fang et al., 2013).

The newcomers' countries of origin and reciving countries typically differ economically, socially and culturally, and newcomers need local information to successfully adjust, function, and integrate in a new environment (Cox, 2004; Farh et al., 2010; Mahajan and Toh, 2014; Mezias and Scandura, 2005). The main challenge for newcomers in getting jobs is a lack of relevant knowledge of local labour market, information practices (e.g., how and where to find jobs), and information sources (e.g., local social networks) (Caidi et al., 2008, 2010; Khoir et al., 2015, 2017; Savolainen, 2016; Zikic, 2015). Newcomers generally lack essential information about the destination country's culture, customs, and work environment among other things, and hence they have to manage higher levels of 
uncertainty, stress, and ambiguity about their economic wellbeing (Adelman, 1988; Nardon et al., 2015; Reitz, 2007a, 2007b; Reitz et al, 2014; Turchick Hakak and Al Ariss, 2013; Wang and Sangalang, 2005). To function in the new environment, they need to find and access needed knowledge. The top three information needs of newcomers typically include information about language training, housing and employment (Caidi et al., 2010, 2014; Savolainen, 2008, 2016). While information about language training and housing are both important and pursued in early and intermediate stages, employment knowledge is one of the main information needs of newcomers across all stages of settlement (i.e., early, intermediate, and integration) (Caidi et al., 2008, 2010; 2014; To, 1995). This study focuses primarily on employment related knowledge.

Newcomers typically lack relevant knowledge of the new country's labour market and lack local sources of support. As a result, more and more newcomers are turning to the Internet (e.g., job search websites and online discussion forums) to seek information and to connect with experienced people with the relevant knowledge (Fang et al., 2013; Khoir et al., 2015, 2015b; Turchick Hakak and Al Ariss, 2013). Recently, increasing number of newcomers use online discussion forums and this study focuses on the examination of this phenomenon (Caidi et al., 2014; Janta and Ladkin, 2013). Online discussion forums are websites or parts of websites where individuals with similar interests can connect, communicate, discuss, seek, and exchange information through posting initial messages or replying to existing messages (Azevedo et al., 2011; Figer and de Torres, 2012). Online forums are a very popular type of internet technology. For example, in the USA, about $20 \%$ of online users regularly use online forums (Pendry and Salvatore, 2015). Online forums differ from traditional websites and passive web searches in that they allow interactive communication 
and exchange of information with other users (Griesbaum et al., 2015), facilitate collaborative learning and knowledge creation (DeSanctis et al., 2003; Hall and Graham, 2004; Rabbany et al., 2014; Sundararajan, 2010), and enable the formation of virtual communities which can provide emotional support (Kim and Yoon, 2012; Kim and Sundar, 2016; Tabor and Milfont, 2013).

Although an increasing number of newcomers are using online discussion forums, very little is known about the needs that newcomers are trying to meet through online discussion forums and whether these needs are being satisfied (Caidi et al., 2014; Janta and Ladkin, 2013). The objective of this study is to explore the use of online discussion forums by newcomers' seeking labour market integration in Canada through a qualitative, inductive analysis of a set of online discussion forums. Given the limited understanding of the role of online forums in newcomers' labour market integration, an exploratory, qualitative study is most appropriate (Eisenhardt, 1989). Moreover, qualitative descriptions of unexplored phenomena are very valuable as they can "stimulate the development of theory and other insights" (Hambrick, 2007: 1350).

This study draws on extant literature on newcomers' adjustment and labour market integration (e.g., Adelman 1988; Black et al., 1991; Farh et al., 2010; Guo and Al Ariss, 2015; Sidani and Al Ariss, 2014; Tung, 2016), information practices of newcomers (e.g., Caidi et al., 2008, 2010; Savolainen, 2007, 2008, 2016), online knowledge exchange, sharing and construction (e.g., Chalkiti and Sigala, 2008; Griesbaum et al., 2015; Nonaka, 1994; Nor et al., 2010), social support (e.g., Cutrona, 1990; Cutrona and Russell, 1990; Farh et al., 2010; Podsiadlowski et al., 2013; Stroppa and Spieß, 2011; Van Bakel et al., 
2017), and online technology affordances (e.g., Majchrzak et al., 2013; Treem and Leonardi, 2012) to contribute to an emerging literature concerned with online technology use and newcomers' adjustment (e.g., Mikal et al., 2013, 2015; Nardon et al., 2015) and international careers (e.g., Al Ariss et al., 2013, 2014; Al Ariss and Syed, 2011; Cascio and Boudreau, 2016; Fang et al., 2013; Farh et al., 2010; Kuhn and Mansour, 2014).

\section{Research problem}

Online forums are a new way for newcomers to connect and communicate, and more and more newcomers are using online discussion forums (Caidi et al., 2014; Chien, 2005; Janta and Ladkin, 2013, Tabor and Milfont, 2013). Online forums are internet-based discussion boards that allow users to search for information relevant to a forum community and to connect and interact with people with relevant knowledge and experience (Burri et al., 2006; Figer and de Torres, 2012; Hwang et al., 2013; Jansen and Saint Onge, 2015). For example, there are several online discussion forums dedicated to the discussion of subjects concerning immigration and Canada, and the largest online forum, Canada Visa (Canadavisa.com), has over a half a million registered members. Primary users of the Canada Visa forum are newcomers, and the forum includes discussions on a variety of topics such as visa application, settlement, work, housing, and education. There are also many other international online forums discussing issues concerning immigration to other countries. As shown in Table 1 below, between March 21, 2016 and January 21, 2018, the total number of registered members in the Canada Visa Forum increased by 114,081, which is by over $25 \%$. The number of threads (i.e., discussion topics) and posts (i.e., replies) increased by about $37 \%$ and $31 \%$ respectively as well. 
Table 1. Registered members, threads and posts in Canada Visa forum.

\begin{tabular}{|l|l|l|l|l|}
\hline & March 21, 2016 & January 21, 2018 & \multicolumn{2}{|c|}{$\begin{array}{c}\text { Change } \\
\text { (\# and \%) }\end{array}$} \\
\hline Registered members & 452,387 & 566,468 & 114,081 & $25.2 \%$ \\
\hline Threads & 265,299 & 364,604 & 99,305 & $37.4 \%$ \\
\hline Posts & $4,738,820$ & $6,201,254$ & $1,462,434$ & $30.9 \%$ \\
\hline
\end{tabular}

Online discussion forums have been examined in several areas of research, including education (e.g., Griesbaum et al., 2015; Seethamraju, 2014), health (e.g., Brady et al., 2016; Lee, 2017; Kim and Sundar, 2016; Moore and Ayers, 2017; Pan et al., 2017), and psychology (e.g., McKiernan et al., 2017; Tabor and Milfont, 2013; Zhao and Basnyat, 2018). Although the process of global migration and importance of employment on newcomers' adjustment has been researched extensively and for several decades (e.g., Boyd, 1989; Choldin, 1973; Crowley-Henry, 2013; Dietz et al., 2015; Guo and Al Ariss, 2015; Hansen, 2012; Massey et al., 1993; Reitz et al., 2014; Taylor, 1999), there is a lack of international business research using data from online forums and our understanding of the role of online forums in newcomers' labour market integration in a new environment is very limited (Caidi et al., 2014; Tabor and Milfont, 2013). This lack of global migration research using online forum data and our limited understanding of the phenomenon constitutes a substantial research gap that this study addresses.

We know that newcomers are using online discussion forums to seek information concerning occupation integration in the local market. For instance, on the Canada Visa 
Forum, there are over three thousand topics (discussions) and fifteen thousand posts concerning employment in Canada. However, we do not know, for example, what employment needs newcomers are trying to satisfy using online discussion forums, whether these needs are met, and what other needs newcomers are trying to satisfy using online discussion forums.

To better understand the role of online discussion forums in labour market integration of newcomers, this study examined the following four research questions:

1. What needs are newcomers trying to meet with online discussion forums?

2. To what extent are these needs met in online discussion forums?

3. What are the characteristics of threads in which needs are not met?

4. What role do online discussion forums play in facilitating and/or hindering newcomers' labour market integration?

\section{Canadian Immigration}

Since the year 2000, Canada has been welcoming between 221,000 and 280,000 immigrants annually and, in 2016, Canada admitted almost 300,000 immigrants, the highest number of immigrants in a single year since 1913 (Boyd and Vickers, 2000; Government of Canada, 2014, 2017). About one in five Canadians are foreign-born and about 1.2 million individuals are recent immigrants (Statistics Canada, 2016, 2017a). Recent immigrants are defined as individuals who immigrated to Canada in the last five years (Statistics Canada, 2013). In Toronto, for example, over half of the total population is foreign born (Treurnicht, 2017). 
Canada is the seventh country in the world with the largest number of international immigrants (UN International Migration Report, 2017). About 52\% of immigrants to Canada in 2016 originated from five source countries: Philippines (14\%), India (13\%), Syria $^{1}$ (12\%), China (9\%), and Pakistan (4\%) (Government of Canada, 2017a). Although the immigrants to Canada come from very different cultural, political and economic environments, there are commonalities in their needs for job related information (Caidi et al., 2010; George and Mwarigha, 1999; Silvio, 2006; Srinivasan, 2007). Research has shown that the lack of relevant employment information is detrimental for newcomers' successful integration in the new country's labour market (Caidi et al., 2008, 2010; Khoir et al., 2015, 2017; Reitz et al., 2014).

There are different types of immigrants as people migrate internationally for various reasons, including economic (e.g., to pursue better occupation and economic opportunities), environmental (e.g., due to natural disasters and climate changes in their home country), political (e.g., due to discrimination, internal conflict and war in their home country), and family (e.g., to reunite with relatives) (Hagen-Zanker, 2008; Massey et al., 1993). Canadian immigration policy differentiates immigrants eligible for admission into three main classes: the economic class, the family class, and the refugee class. The economic class are immigrants "selected for their skills and ability to contribute to Canada's economy" (Government of Canada, 2017b), such as skilled workers, provincial and territorial nominees, or business individuals (e.g., investors, entrepreneurs, and the self-employed). Economic class immigrants are individuals selected with a point-based

\footnotetext{
${ }^{1}$ The large number of immigrants from Syria in 2016 was due to the unique case of the Syrian refugee resettlement initiative (Government of Canada, 2017c).
} 
system that awards points for specific criteria, such as financial capacity to invest, level of education, age, and experience (Caidi et al., 2010). The family class includes family members (e.g., parents, children, spouse) sponsored to immigrate to Canada by a Canadian permanent resident or citizen (Government of Canada, 2017b). The refugee class includes individuals admitted based on refugee resettlement criteria (Government of Canada, 2017b). Refugees are immigrants who have been found to flee their country of origin because their lives, freedom or safety have been threatened by factors such as internal conflicts, foreign aggression, or violations of human rights (Caidi et al., 2010; International Organization for Migration, 2017). In Canada, the large majority of immigrants are economic immigrants, at about 53\% in 2016 (Government of Canada, 2017a, 2016). Table 2 below shows the number of immigrants in each class admitted to Canada in 2015 and 2016, and the projected figures for the years 2017 and 2018 (based on data from Government of Canada, 2016, 2017a). In this study, the term "newcomers" is used to refer to foreign-born individuals seeking work in Canada and include individuals admitted through these three different classes.

Table 2. Annual immigrant admission to Canada by class

\begin{tabular}{|l|c|l|l|l|}
\hline Classes of Immigrants & $\mathbf{2 0 1 5}$ & $\mathbf{2 0 1 6}$ & $\mathbf{2 0 1 7}$ & $\mathbf{2 0 1 8}$ \\
\hline Economic & $\begin{array}{l}170,384 \\
(62.7 \%)\end{array}$ & $\begin{array}{l}155,994 \\
(52.6 \%)\end{array}$ & $\begin{array}{l}172,500 \\
(57.5 \%)\end{array}$ & $\begin{array}{l}177,500 \\
(57.3 \%)\end{array}$ \\
\hline Family & $\begin{array}{l}65,490 \\
(24.1 \%)\end{array}$ & $\begin{array}{l}78,004 \\
(26.3 \%)\end{array}$ & $\begin{array}{l}84,000 \\
(28 \%)\end{array}$ & $\begin{array}{l}86,000 \\
(27.7 \%)\end{array}$ \\
\hline Refugee and Humanitarian & $\begin{array}{l}35,971 \\
(13.2 \%)\end{array}$ & $\begin{array}{l}62,348^{2} \\
(21.1 \%)\end{array}$ & $\begin{array}{l}43,500 \\
(14.5 \%)\end{array}$ & $\begin{array}{l}46,500 \\
(15 \%)\end{array}$ \\
\hline Total number of immigrants & $\mathbf{2 7 1 , 8 4 5}$ & $\mathbf{2 9 6 , 3 4 6}$ & $\mathbf{3 0 0 , 0 0 0}$ & $\mathbf{3 1 0 , 0 0 0}$ \\
\hline
\end{tabular}

\footnotetext{
${ }^{2}$ In 2016, Canada has admitted the largest number of refugees in a single year since 1978 (Statistics Canada, 2016; UNHCR, 2017).
} 


\section{Significance of this study}

Considering (a) the critical role of employment in newcomers' successful settlement and integration, (b) the key role of local knowledge in newcomers' labour market integration, and (c) newcomers increasing use of online discussion forums to discuss information concerning labour market integration, it is imperative to study online forum data to better understand the role of online forums in newcomers' labour market integration in Canada. This phenomenon-guided study enhances our understanding of the under-researched phenomenon of increasing online forum use by newcomers. Specifically, it explores and describes the phenomenon and discusses the role of the online discussion forum system in facilitating labour market integration.

This study advances international business research by contributing to global migration and international careers research, which have been identified as key areas for investigation by international business scholars (Caligiuri and Bonache, 2016; Doh, 2015a, 2015b, 2017). In particular, this study contributes to literatures on newcomers' adjustment and labour market integration (e.g., Farh et al., 2010; Guo and Al Ariss, 2015; Sidani and Al Ariss, 2014; Sambasivan et al., 2017; Tung, 2016), newcomers' adjustment and online technology use (e.g., Mikal et al., 2013, 2015; Nardon et al., 2015), and newcomers and social support (e.g., Podsiadlowski et al., 2013; Stroppa and Spieß, 2011; Van Bakel et al., 2017) by showing that online discussion forums facilitate exchange of social support online, which can help newcomers with adjustment and integration in the new country's labour market. 
This study is also significant for the Canadian economy and makes important practical and policy implications. Studies concerning newcomers' integration in a new labour market are of great importance, especially for countries like Canada with a long tradition of welcoming and integrating hundreds of thousands of newcomers in its society every year. The findings suggest that policymakers should focus more on the pre-arrival stage of migration to facilitate adjustment and labour market integration post-migration, taking advantage of online technologies such as discussion forums.

\section{Document road map}

Relevant background literature for this study is discussed in Chapter 2. Considering that the focus is on newcomers and labour market integration, section 2.1 discusses literature on newcomers' adjustment and the role of employment. Section 2.2 examines literature concerning information practices of newcomers as extant research suggests that information plays a critical role in newcomers' labour market integration. Since this study investigates the role of online discussion forums, section 2.3 reviews relevant literature on various online technologies used by newcomers, in particular research concerning online discussion forums. The conceptual framework for this study is based on three different areas of literature (1) social support perspective; (2) knowledge exchange; and (3) online technology affordances. The conceptual framework and the relevant theories used in this study are discussed in Chapter 3. The phenomenon-guided research, approach and methodology are discussed in detail in Chapter 4. Four research questions are examined and discussed in detail in Chapter 5. Contributions to theory and practice, as well as limitations and future research are described in Chapter 6. A summary of the study and conclusion are presented in Chapter 7. 


\section{Chapter 2: Literature Review}

This chapter contains three main sections. The first section provides review of research relating to newcomers' labour market integration, including newcomers' integration benefits and challenges. The second section discusses literature on information practices of newcomers, in particular research on information needs and sources of newcomers, and various barriers to newcomers' information seeking. The third section focuses on research on internet technologies and labour market integration, in particular research relating to online discussion forums.

\subsection{Labour market integration of newcomers}

Issues concerning international skilled workers have been the focus of international business and management scholarship for over 50 years (e.g., Adams, 1970; Borrmann, 1968). However, these scholars were primarily preoccupied with the examination of the organization-assigned expatriates (Caligiuri and Bonache, 2016; Guo and Al Ariss, 2015).

In the last decade, issues concerning other types of international workers such as selfinitiated expatriates and immigrant professionals are increasingly receiving more attention (Al Ariss et al., 2014; Boese, 2015; Cerdin et al., 2014; Cao et al., 2012; Crowley-Henry et al., 2016; Lundborg, 2013; Tharenou, 2015). In recent business and management studies, several terms are used to describe various types of international workers, including selfinitiated expatriates, immigrant professionals, skilled immigrants, international mobile skilled professionals, and qualified immigrants (e.g., Al Ariss and Crowley-Henry, 2013; Bahn, 2015; Cerdin et al., 2014; Dietz et al., 2015; Fang et al., 2009; Silvanto et al., 2015; 
Tharenou, 2015). For example, immigrant professionals are typically defined as immigrants who completed at least a bachelor's degree or equivalent in their home country (Fang et al., 2009). Self-initiated expatriates are individuals who move to new countries voluntarily and independently of any employer without an explicit intention of staying in the foreign country (Al Ariss, 2010; Al Ariss et al., 2014), whereas traditional expatriates (i.e., organization-initiated expatriates) typically move at the request of their employer(s) (Carr et al., 2005; Guo and Al Ariss, 2015). Skilled migrants are defined as highly experienced and educated individuals (Al Ariss, 2010; Bahn, 2015). Aten and colleagues (Aten, Nardon, and Isabelle, 2016) have questioned the usefulness of these categorizations as they are more a reflection of the researchers' understandings than the way individuals understand their relationship with the new country.

Notwithstanding the differences in terminologies and definitions of various types of international workers, and differences in newcomers' countries of origin, there is an important commonality in that newcomers need to find employment (with the exception of traditional expatriates who typically have jobs prior to migrating) to fully function and integrate in the country of destination (Cerdin et al., 2014; Crowley-Henry et al., 2016; Dietz et al., 2015; Fang et al., 2013; Frank, 2013; Guo and Al Ariss, 2015; Reitz, 2007a, 200b; Reitz et al., 2014). Integration of newcomers in the local labour market is critical for their successful settlement and adjustment, and overall wellbeing (Dietz et al., 2015; Hansen, 2012; Khoir et al., 2015b; Mahajan and Toh, 2014; Paul and Moser, 2009; Reitz et al., 2014; Wang and Sangalang, 2005). 


\section{Labour market integration of newcomers - benefits}

International business and management research (e.g., Cascio and Boudreau, 2016; Cerdin et al., 2014; Dietz et al., 2015; Reitz et al., 2014; Sidani and Al Ariss, 2014; Tarique and Schuler, 2010; Tung, 2016) increasingly recognizes the importance and benefits of labour market integration of newcomers for receiving countries' economies and organizations. Newcomers are recognized as an important part of the global talent pool (Al Ariss and Syed, 2011; Alexander, 2017, Cascio and Boudreau, 2016; Cerdin et al., 2014; Treurnicht, 2017; Tung, 2016; Vaiman et al., 2015). For example, experienced and educated newcomers bring valuable skills and experience and can be an important source of competitive advantage for organizations (Cascio and Boudreau, 2016; Cerdin et al., 2014; Hajro et al., 2017a; Hernandez, 2014; Vaiman et al., 2015). Foreign employees can also offer important international experience and knowledge of international markets that they gained by working and living in other countries (Al Ariss and Syed, 2011; Vaiman et al., 2015). Newcomers can also reduce the receiving country's skills shortages (Dietz, 2010; Dietz et al., 2015; Reitz et al., 2014) and increase the receiving country's overall level of innovation and competitiveness (Downie, 2010; Pholphirul and Rukumnuaykit, 2016). For example, Downie (2010) found that foreign employees can increase innovation, creativity and competitive advantage, as well as improve client relationships and corporate culture in their organizations.

It is well recognized that newcomers bring many benefits to organizations and receiving countries, but the full benefits are attained only when the newcomers are fully integrated in the new country's labour market (Dietz et al., 2015; Fang et al., 2013; Reitz, 2001, 2011; Reitz et al., 2014). In Canada, many highly skilled and educated newcomers (e.g., doctors 
and engineers) are delivering pizzas, driving taxis and waiting tables (Alexander, 2017; Reitz, 2011). This problem of underutilization of skills and experience is known as "brain waste" and its cost to the Canadian economy totals several billion dollars annually and is increasing (Reitz, 2011, Reitz et al., 2014). In Canada, the total lost earnings from unemployment and under-employment of newcomers (due to unrecognized skills and education of newcomers) were estimated at about $\$ 4.8$ billion in 1996, $\$ 6$ billion in 2001, and between $\$ 13$ and $\$ 17$ billion in 2015 (Alexander, 2017; Pohlmann, 2017; Reitz et al., 2014). Therefore, better understanding of issues concerning labour market integration of newcomers is of great importance for the advancement of international business and management research (Crowley-Henry et al., 2016; Davoine and Ravasi, 2013; Guo and Al Ariss, 2015), as well as for Canadian economy and society (Alexander, 2017; Dietz, 2010; Dietz et al., 2015; Reitz, 2007a, 2007b, 2011, Reitz et al., 2014).

\section{Labour market integration of newcomers - challenges}

Newcomers often face a number of challenges and barriers to full integration in the receiving labour market, and they typically attain lower career results relative to local citizens (Al Ariss et al., 2013; Crowley-Henry et al., 2016; Dietz et al., 2015; Hawthorne, 2008; Reitz, 2001, 2001; Turchick Hakak and Al Ariss, 2013). Research has established that the lack of relevant knowledge and social networks of relationships often puts newcomers in a disadvantageous position when seeking employment in the receiving country (Barrett et al., 2012; Caidi et al., 2010; Dietz et al., 2015). Newcomers generally are among the most vulnerable members of society (Hajro et al., 2017b). They typically earn less (Barrett et al., 2012; DelCampo et al., 2011; Frenette and Morissette, 2005; Picot et al., 2007; Reitz, 2001), face higher unemployment rates than local citizens (Binggeli et 
al., 2013; Dietz, 2010; Dietz et al., 2015; Petersen and Dietz, 2005; Turchick Hakak and Al Ariss, 2013), and are generally the first to lose their jobs in the event of an economic recession (UN International Migration Report 2017: Highlights). Moreover, they tend to accept jobs for which they are overqualified as their skills and foreign education and experience are often undervalued, underutilized, and non-recognized (Aten et al., 2016; Bauder, 2003; Dietz et al., 2015; Frank, 2013; Reitz, 2001, 2011; Reitz et al., 2014; Wald and Fang, 2008; Watt and Bloom, 2001). Newcomers face higher unemployment rates and accept jobs for which they are overqualified in part due to their lack of knowledge of the new country's information environment (e.g., what employment information sources are available and how to access them) and the lack of local social networks (e.g., personal ties with influential and knowledgeable locals) (Caidi and Allard, 2005; Caidi et al., 2008, 2010; Khoir et al., 2015; Savolainen, 2007, 2008, 2016; Wang and Sangalang, 2005).

This study investigates newcomers' increasing use of online discussion forums for knowledge concerning integration in the destination country's labour market. To help us better understand types of employment information needs sought by newcomers in online forums, the following sections examine various employment related challenges and barriers newcomers face in the new country that are identified and discussed in business and management literature are discussed below.

\section{Discrimination}

Newcomers often face employment discrimination in the destination country's labour market and experience higher underemployment rates relative to locals (et al., 2004; Binggeli et al., 2013; DelCampo et al., 2011; Reitz, 2011; Reitz et al., 2014). Employment 
discrimination is defined as an unfair differential treatment of current or potential employees merely based on their demographic or social group membership (Dietz et al., 2015). Underemployment refers to underutilization of the individual's expertise and skills (Al Ariss, 2010).

Research shows that newcomers' skills are regularly undervalued and underutilized (Dietz et al., 2015; Pearson et al., 2012; Ramboarison-Lalao et al., 2012; Turchick Hakak and Al Ariss, 2013; Wald and Fang, 2008). Local organizations generally treat foreign work experience, education and qualifications as less worthy than local education, qualification and work experience; but when qualified newcomers apply for jobs that require lower qualification, their prospect of getting these jobs are also low because organizations often view them as overqualified for the positions (Benson-Rea and Rawlinson, 2003; Petersen and Dietz, 2005; Syed, 2008). In Canada for example, a 2009 survey of 1,425 Peel region residents (i.e., Mississauga, Brampton and Caledon, Ontario) indicates an income gap between newcomers and local citizens and underutilization of newcomers' skills and foreign education (The Region of Peel and The Diversity Institute, 2009). In addition, years of foreign work experience are valued only at about one-third of Canadian work experience, and the financial value of foreign education is discounted to about $70 \%$ of Canadian education (Alboim et al., 2005; Alexander, 2017; Dietz, 2010; Turchick Hakak et al., 2010). Newcomers, and particularly highly skilled newcomers, also face higher unemployment rates compared to local citizens (Alexander, 2017; Ramboarison-Lalao et al., 2012; Turchick Hakak and Al Ariss, 2013). In Canada, for individuals with university degrees, there is about an $11.1 \%$ gap between employment rates for locals $(90.9 \%)$ and immigrants (79.8\%) (Dietz et al., 2015). 
Employment discrimination of newcomers is not limited to Canada. For example, International Labour Organization (ilo.org) studies found that about $35 \%$ of qualified newcomers face discrimination in Western industrialized countries, and that the rates of discrimination vary among the countries (e.g., $33 \%$ in Belgium, $19 \%$ in Germany, $37 \%$ in Netherland, $36 \%$ in Spain, and $41 \%$ in Italy) (Allasino et al., 2004). In the USA, the discrimination rates for Hispanic and Black job applicants were found to be $33.2 \%$ and 19.4\% respectively (Syed, 2008). A study of 17 Malagasy physicians in France (Ramboarison-Lalao et al., 2012) has shown that only 10 out of the 17 physicians were eventually able to work in their original profession in France, while the remaining 7 turned to nursing. In a study involving 43 skilled Lebanese immigrants in France, Al Ariss (2010) also found that immigrants felt discriminated against in their schooling and in the hiring process, as well as when working in organizations.

\section{Inequality}

Research also indicates inequality in wages between immigrants and local citizens (e.g., Al Ariss et al., 2013; Barrett et al., 2012; Dietz et al., 2015; Frenette and Morissette, 2005; Picot et al., 2007). In the European Union, for example, average earnings of newcomers are typically between $10 \%$ and $18 \%$ lower relative to local citizens (Barrett et al., 2012). In Canada, newcomers earn only about 64 cents for every $\$ 1$ of what local citizens earn, and immigrants continue to earn on average between $20 \%$ and $25 \%$ less in the long-term relative to local citizens (Alexander, 2017). In addition, the average earnings between locals and newcomers differ more for highly skilled, educated and experienced individuals and less for individuals who do not hold degrees (Dietz et al., 2015; Picot et al., 2007). This phenomenon is also called the skill paradox: the more skilled immigrants are the more 
likely they are targets of employment discrimination (Dietz et al., 2015). Although the difference is especially high for recent newcomers (i.e., individuals who came in the last five years), it is still substantial even for relatively established immigrants who arrived more than 10 years ago (Alexander, 2017; Picot et al., 2007).

\section{Institutional and legal barriers}

Immigrants are also vulnerable to influences of various other factors such as government policies and agencies (Al Ariss, 2010; Al Ariss and Özbilgin, 2010; Bjerregaard, 2014; Fang et al., 2009; Hawthorne, 2008; Tatli et al., 2012; Zikic et al., 2010), recruitment agencies (Fang et al., 2013), professional associations, accreditation organizations, and other official gatekeepers (Alberti et al., 2013; Bauder, 2003; Khan, 2007; Kustec et al., 2007; Li, 2001; Salaff et al., 2002; Turchick Hakak and Al Ariss, 2013) when seeking labour market integration in the new country. For example, in an examination of economic selection policy on labour market outcomes for highly educated newcomers in Canada and Australia, Hawthorne (2008) found that the newcomers in Australia integrated into the labour market more easily and achieved greater professional growth compared to newcomers in Canada. This is because in Australia, degrees and accreditations of potential skilled immigrants are evaluated for transferability before the immigrants leave their home countries (Hawthorne, 2008). In addition, Canadian professional associations often limit immigrants' labour market integration opportunities by not recognizing foreign education and credentials (Bauder, 2003; Khan, 2007; Kustec et al., 2007). Fang et al. (2013) also found that newcomers seeking jobs using recruitment agencies in Canada often face substantial challenges and barriers to finding relevant employment opportunities. Recruitment agencies typically perceive newcomers as 'riskier' compared to local citizens, 
and hence they prefer to offer newcomers more temporary assignments and fewer higherpaid employment opportunities (Catano et al., 2005; Fang et al., 2013).

\section{Lack of local language proficiency}

Limited or lack of local language proficiency is also a substantial barrier for newcomers seeking employment in the local market (Al Ariss and Syed, 2011; Fang et al., 2013; Syed, 2008; Syed and Murray, 2009; Turchick Hakak and Al Ariss, 2013). Lack of local language proficiency limits newcomers' employment opportunities, for example, by impacting the quality of their job applications (e.g., cover letters, resumes, and interview process) and by limiting their access to local information sources (Fang et al., 2013, Khoir et al., 2015b; Sirikul and Dorner, 2016). Research on newcomers in English-speaking countries showed substantial income differences between newcomers from English speaking and nonEnglish speaking backgrounds (Syed, 2008; Syed and Murray, 2009). Moreover, research showed that higher language competency leads to better job outcomes, and that local employers view poor language skills as the key barrier for hiring skilled newcomers (Zikic, 2010, 2015).

\section{Lack of local knowledge and networks of relationships}

Research has shown that individuals with greater labour market knowledge make better career decisions and are more likely to succeed in the new country's labour market environment. (e.g., Murray, 2010; Oliver and Spokane, 1988; Reitz, 2005; Reitz et al., 2014; Turchick Hakak and Al Ariss, 2013; Whiston et al., 1998). However, newcomers typically come from countries that differ significantly socially and culturally, and they generally lack the necessary knowledge about how to go about getting a job and fully 
function in the new country's environment (Adelman, 1988; Reitz, 2007a, 2007b; Reitz et al, 2014; To, 1995). Research indicates that the lack of local knowledge is one of the greatest challenges that newcomers face when seeking labour market integration in the receiving country (Al Ariss and Syed, 2011; Caidi and Allard, 2005; Fang et al., 2013; Frijters et al., 2005; Reitz, 2005; Reitz et al., 2014; Turchick Hakak et al., 2010; Turchick Hakak and Al Ariss, 2013).

Getting a job is not an easy task for local citizens, and it is an especially challenging task for newcomers who typically lack relevant local market knowledge and local social networks (Frijters et al., 2005; Krause and Liebig, 2011; Mattingly, 1999). Social networks in the destination country are important sources of information about that country's environment, culture, employment market, and other relevant aspects; social networks typically consist of personal relationships with family members, coworkers, and friends (Fang et al., 2013; Khoir et al., 2015; Reitz, 2005; Turchick Hakak et al., 2010; Vacca et al., 2016). Those relationships in the new country are valuable because they inform newcomers about various work opportunities and introduce and connect newcomers to relevant information sources and influential others (Hagan, 1998; Nakao, 2004; Turchick Hakak et al., 2010; Vacca et al., 2016). Studies have shown that newcomers perceive lack of social ties with influential people in the new country as a considerable barrier to their successful labour market integration (Caidi et al., 2016; Turchick Hakak et al., 2010).

Newcomers also typically lack knowledge of local informational environment (e.g., where and how to seek information) and the means to get it (e.g., local social networks ties) (Turchick Hakak et al., 2010, Turchick Hakak and Al Ariss, 2013). Knowledge of the 
informational environment is critical for successful integration of newcomers in the destination country's labour market (Caidi et al., 2010; Krause and Liebig, 2011; Shahiri and Osman, 2015; Turchick Hakak and Al Ariss, 2013; Wang and Sangalang, 2005). Getting a job in the new country requires relevant knowledge about how to go about looking for a job, such as knowledge of how and where to search for information about available jobs, knowledge of how to apply for those jobs (e.g., prepare CV and cover letter), knowledge about the job search process (e.g., interviews), and knowledge about the process of educational and professional accreditation.

\section{Summary of literature}

Labour market integration in the new country is critical for newcomers' successful adjustment and settlement, and it also has many benefits for the local organizations, economy, and society (Al Ariss and Syed, 2011; Turchick Hakak and Al Ariss, 2013). Although newcomers constitute a very important part of the global talent pool for global organizations and receiving countries, the issues concerning labour market integration of newcomers are still under-researched (Al Ariss et al., 2013, 2014; Guo and Al Ariss, 2015). Newcomers often face several challenges (as discussed in the sections above) when seeking employment in a new country. Research has shown that lack of local knowledge is a substantial barrier to newcomers' labour market integration and newcomers need local knowledge to successfully integrate in the local labour market (Caidi et al., 2010; Farh et al., 2010; Khoir, 2015). Considering the critical role of local information for successful labour market integration of newcomers, the following section (Chapter 2.2) examines literature concerning the information practices of newcomers. 


\section{2: Information practices of newcomers}

Newcomers seek relevant information using some common information practices (Caidi et al., 2010; Savolainen, 2008). Information practice refers to "a set of socially and culturally established ways to identify, seek, use, and share the information available in various sources such as television, newspapers, and the Internet" (Savolainen, 2008:2-3). Information practices are embedded in everyday contexts and include three modes: information seeking, information sharing, and information use (Savolainen, 2006, 2008). Of the three modes, information seeking has received the uppermost attention from migration and information system scholars (Caidi et al., 2010; Mao, 2015; Newell et al., 2016; Savolainen, 2008).

McKenzie (2003) identifies different types of information practices including both active information seeking and also less-directive actions (e.g., active scanning, non-directed monitoring, and by proxy). Examples of active information seeking practices include "specifically seeking out a previously identified source, conducting a systematic, knownitem search, asking a pre-planned question" (p. 26). Active scanning practices, for example, include browsing in likely locations such as libraries or bookstores. Non-directed monitoring refers to unexpectedly encountering and recognizing a source (e.g., finding a book) in a not likely place or while not seeking information at all (e.g., chatting with a friend). An example of by proxy is "being referred to a source through a gatekeeper or intermediary" (p. 27). Active information seeking is the type that we can observe in the online discussion forums. 
Information practices of newcomers have received increasing attention from scholars, particularly in the areas of immigration and library and information science (Caidi and Allard, 2005; Caidi et al., 2010). Research has shown that information plays a critical role in newcomers' lives (e.g., Caidi and MacDonald, 2008; Farh et al., 2010; Jensen, 2002; Mao, 2015; Mehra and Papajohn, 2007; Savolainen, 2008) and that people seek information every day in a variety of ways and from a variety of sources to manage their daily lives (Savolainen, 1995, 2006, 2007, 2008, 2016).

Newcomers may have unique information needs depending on their individual circumstances (Baran et al., 2017; Yoon, 2017; Yoon and Chung, 2017). Information need refers to "a gap in a person's knowledge that, when experienced at the conscious level as a question, gives rise to a search for an answer" and "if the need is urgent, the search may be pursued with diligence until the desire is fulfilled" (Reitz, 2004: 357). In order to adjust and integrate in the new environment, newcomers need information about various aspects of the new country (e.g., housing, employment opportunities, education, settlement services, etc.) and when newcomers do not have easy access to the essential information, their settlement in the new environment can be very challenging (Baran et al., 2017; Caidi et al., 2010; Caidi and Allard, 2008; Mao, 2015; Newell et al., 2016).

Information seeking is an essential part of the immigration and settlement process (Caidi et al., 2010; Mao, 2015; Shoham and Strauss, 2007). To function in the new environment, newcomers need to quickly establish information practices; they need to regularly seek, identify and develop relevant information sources, and learn how to function in the destination's country information environment (Alam and Imran, 2015; Caidi et al., 2008, 
2010; Mao, 2015). The following sections focus on examination of research concerning information practices of newcomers to help us better understand newcomers' needs in and use of online discussion forums. In particular, they discuss newcomers' information needs and sources, and various information barriers newcomers face.

\section{Information needs of newcomers}

Newcomers need information to function in the new environment and they use different information seeking approaches to satisfy their individual information needs (Alam and Imran, 2015; Khoir et al., 2015, 2017). Savolainen (2008) differentiated the information seeking into two types: orienting information seeking and problem-specific information seeking. Orienting information seeking refers to the daily media habits (e.g., reading the newspapers, watching television, listening to radio, or routinely checking emails) that individuals engage in to continuously monitor everyday-life events. Problem-specific information seeking refers to search of practical information that may be used for solving the individual's problems or performing specific tasks (Savolainen, 2008: 83-84). The two types of information seeking can also be intertwined (Caidi et al., 2010; Savolainen, 2008). For example, consistent seeking of orienting information may help an individual acquire information that may help with solving a specific problem (Caidi et al. 2010; Savolainen, 2008). For instance, when reading the newspapers an individual may find an article or advertisement containing relevant employment information that may be useful to solve the individual's specific employment problem.

Newcomers generally lack the essential information resources (e.g., access to relevant social networks) and skills (e.g., knowledge of where and how to find information) to fully 
function in the new environment and hence they face very substantial information needs to resolve many orienting and problem-specific activities (Caidi and Allard, 2005; Caidi et al., 2008, 2010). For a detailed list of information needs see Caidi et al., (2008) and Caidi et al., (2010).

Orienting information needs of newcomers may include information about the new culture and the way of life in the new country (George and Mwarigha, 1999), local religious and cultural events (Jeong, 2004; Su and Conaway, 1995), and broader societal contexts such as identity (e.g., cultural, individual, professional) (Caidi and MacDonald, 2008; Srinivasan and Pyati, 2007). Orienting needs may also include current news and political information about the new country, as well as the homeland (Fisher et al., 2004b; Silvio, 2006).

The main problem-specific information needs of newcomers typically include information about employment in the new country (e.g., where and how to apply for a job or how to prepare a cover letter) (George, 2002; Jensen, 2002; Silvio, 2006), language (e.g., translation and interpretation services, language training) (George and Mwarigha, 1999; Su and Conaway, 1995), and housing (George and Tsang, 2000). Other problem-specific information needs may also include information about making connections in the local community (e.g., connecting to professional associations and community organizations) (Caidi et al., 2008), health (e.g., medical services), local laws, education, and transportation (Chu, 1999; Jensen, 2002; Silvio, 2006; Su and Conaway, 1995), as well as banking (Shoham and Strauss, 2007) and workplace safety (Jensen, 2002; Prock, 2003). 
Newcomers may seek orienting information in different ways and from different sources, depending on what their primary information seeking habits were in the country of origin (e.g., watching television, reading newspapers, reading news online) and specific conditions in the new environment (e.g., availability of specific information sources, such as radio or the Internet) (Ahmed and Veronis, 2017; Caidi et al., 2010; Yoon, 2017). Similarly, the way newcomers seek problem-specific information may also differ depending on how familiar newcomers are with their new environment (e.g., knowledge of where and whom to ask).

Newcomers typically face numerous challenges when seeking orienting information in the new environment. For instance, they may need to overcome information overload and identify appropriate sources with relevant, credible and accessible information (Caidi et al., 2010; Savolainen, 2008). Similarly, when seeking problem-specific information, newcomers need to identify and gain access to relevant sources with the essential information (Caidi et al., 2010; Yoon, 2017).

\section{Information needs at different stages of settlement}

Information needs of newcomers vary at different stages of settlement (Caidi and Allard, 2005; Caidi et al., 2008; 2010; Mwarigha, 2002). Caidi and Allard (2005) identified three main settlement stages: immediate, intermediate, and integration (i.e., long-term). Based on the examination of twelve studies, Caidi et al. (2008) expanded the framework into four stages and identified main information needs of newcomers across these stages. Research found that, at the early stages, newcomers generally need information on how to deal with their immediate needs, such as language barriers, employment, and where to find food and 
shelter (e.g., Caidi and Allard, 2005; Caidi et al., 2008, 2010; Mwarigha, 2002). At the intermediate stage, newcomers seek information about long term housing, access to various municipal services, health services and employment. At the long-term integration stage, the information needs vary depending on a newcomer individual's needs (e.g., sponsoring family member, inclusion in various cultural, political and social networks). It is also important to note that the stages are overlapping and some of the information needs may be present at multiple stages (Caidi et al., 2008, 2010; Mwarigha, 2002). Employment information, for example, is a critical information need of newcomers across early, intermediate, and long-term stages. Figure 1 below shows the main information needs of newcomers across four stages of settlement.

Figure 1. Information needs of newcomers across four stages of settlement (based on Caidi et al. 2008, 2010).

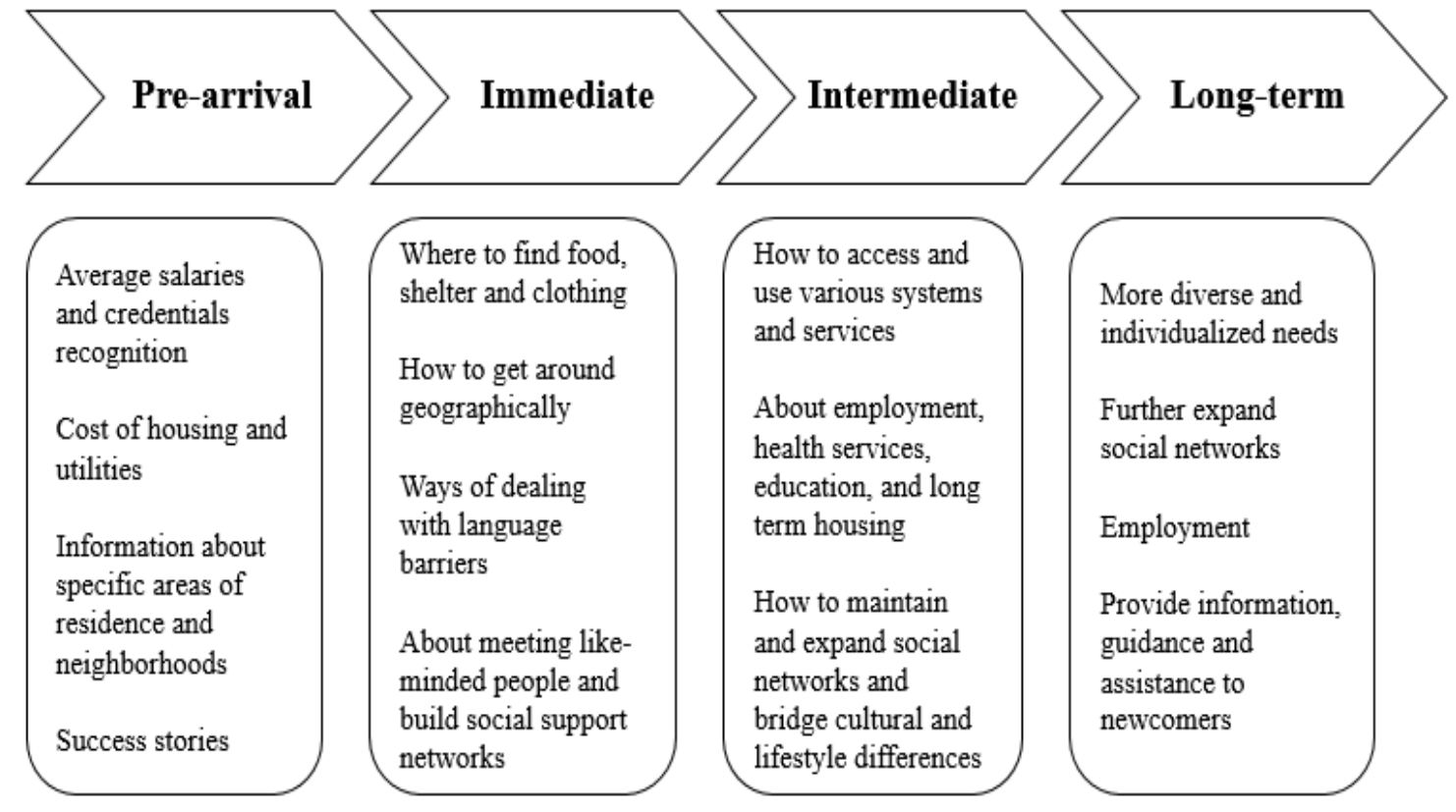


Newcomers with insufficient pre-arrival information typically face higher levels of anxiety and uncertainty, and greater difficulties with the settlement process (Benson-Rea and Rawlinson, 2003; Shoham and Strauss, 2007). The top settlement information needs of newcomers include language information (e.g., language training, translation services), housing information (e.g., about specific neighborhoods, cost of housing), and employment information (e.g., job searching skills) (Caidi et al., 2010; Khoir et al, 2015; Silvio, 2006; To, 1995).

\section{Information sources of newcomers}

This section discusses various information sources that newcomers may access to seek information about the new environment to investigate the preferred information sources. In addition, this section examines availability and access to, as well as types of information sought in different sources. Better understanding of various information sources of newcomers can help with the investigation of the role of online discussion forums in newcomers' seeking of employment information.

Newcomers typically use multiple sources of information and these sources can vary across different stages of settlement as their needs change (Caidi et al., 2008, 2010; Shoham and Strauss, 2007). The sources can also vary according to newcomers' individual circumstances (e.g., availability of personal contacts in the destination country) (Mao, 2015; Yoon and Chung, 2017), as well as availability and access to different information sources (e.g., ethnic media, newspapers, television, and the Internet) in the local environment (Ahmed and Veronis, 2017; Veronis and Ahmed, 2015; Caidi et al., 2010). Furthermore, newcomers typically use different types of media in a complementary fashion 
to meet their various needs (Ahmed and Veronis, 2017; Veronis and Ahmed, 2015). For instance, newcomers generally prefer to seek information prior and during the immigration process from friends and family members that have already immigrated to the destination country (Khoir et al., 2015; Wong and Salaff, 1998). Family members and friends in the destination country are important sources of information and they may also help newcomers gain access to critical information sources that otherwise would not be available or would be very difficult for newcomers to find and access (Courtright, 2005; Khoir et al., 2015; Savolainen, 2016). However, research indicates that newcomers typically lack well established social networks (e.g., friends and relatives) in the new country and they increasingly turn to information and communication technologies such as the Internet to seek information (Caidi et al., 2010; Khoir et al., 2015; Mao, 2015; Yin, 2015; Yoon, 2017). Shoham and Strauss (2007) found that the Internet was the most used information source of newcomers during the pre-arrival stage.

Newcomers can seek information on the Internet using both passive internet searches (e.g., Google search engine) and interactive websites such as blogs, online forums, and social media (e.g., Facebook). Online discussion forums are particularly interesting information sources as they allow both passive searches of existing topics as well as active interaction with other members in the forum. Online forums are topic centered and focus on cooperative information exchanges, whereas blogs are individual-centered and focus on an individual (e.g., the blog creator) (Miyazoe and Anderson, 2010; The University of New South Wales, 2017). Moreover, information in online forums tends to grow with time as users contribute to the online forums by starting new topics for discussions and/or replying 
to existing discussions. For example, some of the threads in the Canada Visa Forum have started over a decade ago and have maintained an active discussion for several years.

Since information needs of newcomers vary at different stages of settlement, newcomers typically seek information that is the most relevant to their current stage. For example, at the early stages of settlement, newcomers are more likely to seek and read specific instructional information (e.g., about language training and finding employment) than general information (e.g., novels, leisure material) (Cuesta, 1990; To, 1995). Lack of local language proficiency is a substantial barrier for newcomers seeking information online (Mao, 2015; Yoon and Chung, 2017). However, there are language specific online forums as well (e.g., polcan.fora.pl; bbs.51.ca/forum-50-1.html). This study examines online discussions in English, under the assumption that English proficiency is a pre-requisite for employment in many regions of Canada outside of Quebec.

Whereas Figure 1 above shows the main information needs of newcomers, Figure 2 below shows the main information sources used by newcomers across the four stages of settlement. 
Figure 2. Information sources of newcomers at different settlement stages (based on Caidi et al., 2008, 2010).

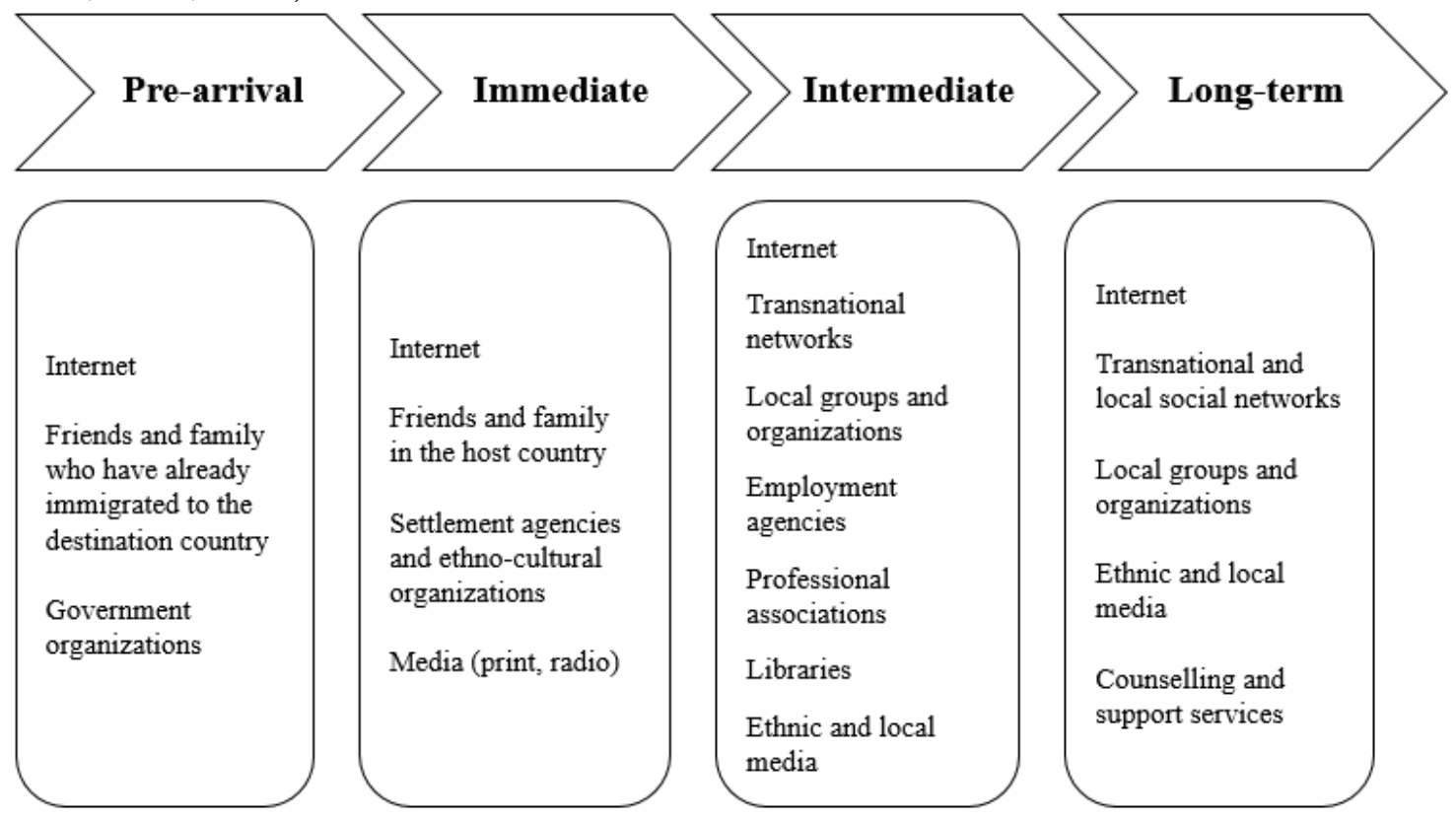

Newcomers turn to the Internet for information at all settlement stages. However, the information they seek online varies based on their needs. For example, when seeking employment information, in the pre-arrival stage, they may be more interested in employment information about average salaries and general job opportunities in the new country, and in the immediate stage, how to find work. Moreover, in intermediate and longterm stages they may be more interested in information about career advancement strategies and seeking better and long-term employment opportunities.

The various information sources can be grouped into four main categories: social networks (e.g., friends and family), formal sources (e.g., government organizations), media (e.g., ethnic television), and information and communication technologies (e.g., the Internet) (Caidi et al., 2008, 2010; Podsiadlowski et al., 2013; Van Bakel et al., 2017). The following sections discuss each of the four categories in more details. 


\section{Social networks}

When available and accessible, social networks are typically one of the most desirable and likely information sources that newcomers will use to seek relevant information (Hoye et al., 2009; Turchick Hakak and Al Ariss, 2013). Newcomers generally prefer to seek information from other individuals whom they trust and with whom they have strong and close personal relationships, such as family members, friends and coworkers (Courtright, 2005; Jeong, 2004; Silvio, 2006; Turchick Hakak and Al Ariss, 2013). However, newcomers do not rely only on strong social ties. Especially in the initial stages of migration, newcomers often do not have well developed strong social networks in the new country (e.g., local friends) and have to rely on whatever social networks available to them, if any (Caidi et al., 2010; Farh et al., 2010; Reitz, 2005; Van Bakel et al., 2017). Newcomers generally have to seek information from both strong and weak ties as the strong ties often do not have all the needed information that weak ties (e.g., government employees) do have (Caidi et al., 2010; Courtright, 2005). However, strong ties can often help newcomers identify or connect with the relevant weak ties that can in turn provide the needed information (Courtright, 2005; Khoir et al., 2015).

Ethnic gatekeepers are also an important information source for newcomers in the new country, especially in very ethnically diverse communities (Caidi et al., 2010; Chu, 1999; Jeong, 2004; Metoyer-Duran, 1993). Ethnic gatekeepers are individuals who are regarded as knowledgeable in the local community, who can operate in multiple speech communities (e.g., they are able to speak the native language of the newcomer group and the official language of the destination country), and who can connect those communities by providing information (e.g., translation, dissemination of information, connect and direct newcomers 
to relevant information sources) or obstruct the flow of information (Caidi et al., 2008, 2010; Chu, 1999; Jeong, 2004; Metoyer-Duran, 1993). There are various types of ethnic gatekeepers, including translator, affiliated gatekeeper, unaffiliated gatekeeper, broker, impeder, information professional, and leader-executive (Caidi et al., 2010; Jeong, 2004; Metoyer-Duran, 1991, 1993). For example, translator gatekeepers are individuals who translate information and/or explain various linguistic terms and concepts and differences (Caidi et al., 2010). Affiliated gatekeepers are individuals who have formal affiliations to local institutions and they can formally connect newcomers to organizations, agencies and institutions (Metoyer-Duran, 1991). Although unaffiliated gatekeepers lack formal affiliations, they can still connect newcomers to various agencies and organizations (Metoyer-Duran, 1991). Broker gatekeepers function in two cultures and connect the two groups, but without adding extra value (Metoyer-Duran, 1991). Impeder gatekeepers (e.g., clergyman) control and limit the flow of information, and they can also provide inaccurate information, often to maintain traditional or cultural values (Jeong, 2004; Metoyer-Duran, 1993). Information professional gatekeepers (e.g., immigration lawyers) can provide specialized professional information, whereas leader-executive gatekeepers (e.g., community leader) can lead and facilitate change in the community (Arns, 2016; MetoyerDuran, 1991, 1993).

Research (e.g., Fisher et al., 2004a, 2004b; Silvio, 2006) also suggests that trust plays a very important role in social network information seeking, as newcomers prefer to rely on trusted information sources, such as relatives and friends who immigrated to the destination country earlier than on individuals with whom they have weak ties only. In the preimmigration stages, friends and relatives living in the destination country (also referred to 
as transnational ties) can be a very important information sources for newcomers (Kennedy, 2004; Vacca et al., 2016; Wang and Salaff, 1998). However, studies show that newcomers often lack relevant transnational social networks in the destination country and they increasingly rely on other information sources (e.g., the Internet) to seek information (Caidi et al., 2010, 2014; Khoir et al., 2015; Lucić, 2016; Shoham and Strauss, 2007).

\section{Formal sources}

Formal sources of information for newcomers include government organizations and agencies, libraries, schools, ethno-cultural organization, immigrant organizations, employment centers, language training centers, and other service providers (Bordonaro, 2006; Caidi et al., 2008, 2010; Chu, 1999; Fisher et al., 2004b; George and Mwarigha, 1999; George and Tsang, 2000; Pokorny, 2003; Prock, 2003; Shoham and Rabinovich, 2008). Formal sources are very important sources of information for newcomers and they also facilitate both formal and informal information sharing among newcomers, as well as the development of social networks in the destination country, by providing places for newcomers to meet and interact (Caidi et al., 2010; Khoir et al., 2017; Pettigrew, 1999; Shoham and Rabinovich, 2008). In addition, research has shown that places where newcomers come together, such as libraries (e.g., Bordonaro, 2006; Chu, 1999; Fisher et al., 2004a; Khoir et al., 2017) and community centers (e.g., Dechief, 2006) also act as information grounds for newcomers. Information grounds refer to places that provide area for people to meet and that facilitate spontaneous and unanticipated information sharing among participants (Caidi et al., 2008, 2010; Fisher et al., 2004a, 2004b). In libraries, for example, newcomers may unexpectedly meet, interact and exchange information on 
various topics (e.g., employment opportunities, job search strategies, where and how to access specific government services) with library employees, locals, and other newcomers.

Public libraries help newcomers build social networks and relationship (e.g., with library staff and other newcomers), acquire and enhance practical skills (e.g., language, computer, and citizenship training courses offered at the libraries), and connect with their friend and relatives back home (e.g., using library computers) (Fisher et al., 2004a, 2004b; Khoir et al., 2017; Pokorny, 2003; Sirikul and Dorner, 2016). University libraries also help international students to practice and develop their language skills (Bordonaro, 2006). Moreover, community organizations and public library services help newcomers develop local social networks and adjust to the new environment (Dechief, 2006; Jensen, 2002; Khoir et al., 2017).

\section{Ethnic media}

Examples of ethnic media information sources for newcomers include local ethnic newspapers, radio and television, homeland television and print, as well as international websites (Caidi and MacDonald, 2008; Caidi et al., 2010; Chen, 2015; Karanfil, 2007; Lee, 2004; Lin and Song, 2006; Mitra, 2006; Moon and Park, 2007; Su and Conaway, 1995; Yin, 2015). Newcomers, and especially those with limited or no understanding of the destination country's language, often use ethnic media sources to seek relevant information about both the homeland and the new country (Caidi et al., 2010; Karanfil, 2007, Lin and Song, 2006; Yin, 2015). Research also suggests that newcomers prefer to use ethnic media to keep track of events in both their country of origin as well as in the local receiving country (Karanfil, 2007; Lee, 2004). 
Newcomers also use ethnic media to maintain their ethno-cultural identity (Kehoe, 2015; Mitra, 2006; Wenjing, 2005; Yin, 2015) and ethnic and cultural knowledge (Chen, 2015). For example, newcomers maintain their ethno-cultural identity by connecting with others within their ethno-cultural group through e-mail, chat rooms, newsgroups, online newspapers, and other Web-based media (Caidi et al., 2008, 2010, Mao, 2015; Mitra, 2006 Yoon, 2017). Research suggests that use of ethnic media by newcomers for maintenance of ethno-cultural identities is common across different ethno-cultural groups such as Chinese, Indian, Somali, and Latin American (Ahmed and Veronis, 2017; Caidi et al., 2010; Mitra, 2005; Wenjing, 2005; Yin, 2015) ethno-cultural groups. Although various ethno-cultural groups use various types of ethnic media, research shows that they tend to favor digital media, and in particular the Internet (Ahmed and Veronis, 2017). In their study examining the use of different types of ethnic media (i.e., internet technologies, television, radio, and print newspapers) in four ethnic communities in Ottawa, Ahmed and Veronis (2017) found that digital media had the highest levels of use across the four communities, ranging $60-80 \%$ for internet technologies, $25-42 \%$ for television, $20-30 \%$ for print newspapers, and only 9-19\% for radio.

\section{Information and communication technologies}

Traditionally newcomers relied mainly on reading print publications (e.g., books, newspapers, magazines) and social networks for information (Caidi et al., 2008, 2010). In recent decades, however, information and communication technologies (ICT) are becoming increasingly accessible and available (e.g., high speed Internet, mobile smartphones), and more and more newcomers are turning to various information and 
communication technologies to satisfy their information needs (Ahmed and Veronis, 2017; Du and Haines, 2017; Falco and Rotondi, 2016; Khoir et al., 2015; Lucić, 2016; Vilhelmson and Thulin, 2013). For example, about $88.5 \%$ of the population in Canada had access to the Internet at home in 2016, compared to only 51.3\% in 2000 (Internet Live Stats, 2016). In addition, about $88 \%$ of the population in Canada used Internet every day in 2016 (Statista, 2017).

Although there are several types of information and communication technologies available (e.g., the Internet, mobile phones, digital media and television), newcomers tend to favor the Internet (Ahmed and Veronis, 2017; Caidi et al., 2007, Caidi and McDonald, 2008; Mehra and Papajohn, 2007; Shoham and Strauss, 2007; Sirikul and Dorner, 2016). Internet technologies (e.g., Google search, job search sites, online discussion forums, social network sites, blogs, and wikis) tend to be the main information sources for newcomers in the early stages of migration (Shoham and Strauss, 2007; Sirikul and Dorner, 2016). Additionally, the role of the Internet as one of the primary information sources for newcomers across all stages of settlement, increased substantially in the last decade and continues to rise (Ahmed and Veronis, 2017; Caidi et al., 2010; Du and Haines, 2017; Khoir et al., 2015). A recent study of Thai newcomers in New Zealand has shown that the Internet was the main information source used by newcomers (Sirikul and Dorner, 2016). Thai newcomers used the Internet because it was easily accessible, quick, available at any time, convenient, and time saving (Sirikul and Dorner, 2016).

The Internet is a very important information source for newcomers and it plays a critical role in shaping newcomers' decisions (Du and Haines, 2017; Falco and Rotondi, 2016; 
Sirikul and Dorner, 2016; Vilhelmson and Thulin, 2013). It offers newcomers relatively easy and inexpensive access to relevant information about the destination country and on how to settle and integrate into the new culture and society (Caidi et al., 2007, 2010; Falco and Rotondi, 2016). For example, the Internet allows newcomers to search for specific information (e.g., with Google search), access to various media (e.g., online newspapers, internet sites, and newsgroups) to keep track of events in both the destination and homeland country, access to formal information (e.g., government websites) and specialized websites (e.g., real estate websites), and enables newcomers to communicate with others worldwide (e.g., with Skype, e-mail, Facebook) (Du and Haines, 2017; Khoir et al., 2015; Mao, 2015; Yoon, 2017).

Furthermore, research has shown that the Internet plays a vital role in facilitating newcomers' adjustment to a foreign environment, access to social support, job search, and creation of social network (Chen and Choi, 2011; Chu et al., 2012; Cox, 2004; Kuhn and Mansour, 2014; Mikal et al., 2013, 2015; Nardon et al., 2015; Stroppa and Spieß, 2011). It also allows newcomers to maintain contact with relatives and friends back home (Hertlein, 2012; Yoon, 2017), participate in the political and civic events of their homeland (Guarnizo et al., 2003), and develop social networks and share information with others (Chien, 2005, Hiller and Franz, 2004; Khoir et al., 2015). Various internet technologies are further discussed in the section 2.3.

\section{Barriers to information seeking}

Literature shows that newcomers often face various barriers to information seeking and the barriers can be differentiated into two main types: structural barriers and socio-cultural 
barriers (Caidi et al., 2008, 2010; Savolainen, 2016). Examples of structural barriers are: lack of language proficiency, lack of understanding of the information environment and sources in the destination country, and limited access to information sources arising from newcomers' immigration status (Caidi et al., 2010). Socio-cultural barriers can include social isolation (e.g., lack of social capital), communication problems, and differences in understandings (e.g., due to different social norms and cultural values) (Al Ariss and Syed, 2011; Caidi et al., 2010; Katila and Wahlbeck, 2012; Savolainen, 2016).

Insufficient language proficiency of the new country's language is often one of the most significant information seeking barriers faced by newcomers as it limits their access to information sources (Caidi et al., 2010; Fisher et al., 2004b; Jeong, 2004; Silvio, 2006). Newcomers also tend to lack sufficient knowledge and familiarity of the destination country's environment, where and how to seek desired information, and what information sources are available (Caidi and Allard, 2005; Caidi et al., 2008, 2010; Shoham and Struss, 2008). Newcomers' immigration status can also be a barrier, for example newcomers typically have a restricted access to some of the public services, such as public health care in the early stages of immigration (Caidi et al., 2010). Newcomers generally lack trusted social networks (e.g., friends and relatives) in the destination country and hence often feel socially isolated, do not know whom they can trust and where to seek information (Caidi and MacDonald, 2008; Caidi et al., 2010). In addition, newcomers often face communication and misunderstanding problems resulting from differences in social norms and cultural values. For example, they lack understanding of appropriate ways to communicate and seek information in the new environment, what type of information is 
accessible from various sources, from whom and how to ask for information (Caidi et al., 2010; Savolainen, 2016).

\section{Summary of literature}

Newcomers need information to fully function in the new environment and they use specific information practices to seek, access, and gather needed information (Caidi et al., 2008, 2010; Mao, 2015; McKenzie, 2003; Savolainen, 2008). There are multiple information sources available to newcomers, such as social networks in the new country (e.g., friends, family), government organizations (e.g., community centers, public libraries), ethnic media (e.g., ethnic newspapers, radio and television), and various information and communication technologies (e.g., the Internet, smartphones) (Ahmed and Veronis, 2017; Caidi et al., 2010; Chen, 2015; Frijters et al., 2005; Hoye et al., 2009; Jeong, 2004; Khoir et al., 2015, 2015b, 2017; Yin, 2015).

However, compared to local citizens, newcomers tend to lack relevant local networks in the local market and knowledge of the new country's labour market, and have limited access to and knowledge of sources and individuals with the needed knowledge (Caidi et al., 2008, 2010; Khoir et al., 2014, 2015; Sirikul and Dorner, 2016; Turchick Hakak and Al Ariss, 2013) resulting in an increasing reliance on internet sources for information (Caidi et al., 2010; Khoir, 2015). The Internet is increasingly becoming the main information source of newcomers as it is increasingly available and accessible, online searching is relatively low cost and available at any time, and online sources are more up to date than printed material (Ahmed and Veronis, 2017; Du and Haines, 2017; Sirikul and Dorner, 2016; Yoon, 2017). 
While more and more newcomers are turning to online discussion forums for employment information, there is a lack of international business research examining this phenomenon. The following section (2.3) examines literature concerning the Internet and employment information and extant literature on online discussion forums and newcomers.

\subsection{Internet technologies and employment information}

Newcomers typically need to function in a foreign new environment detached from longstanding social relationships and family and friends who stayed behind in the home country (Caidi and Allard, 2005; Fang et al., 2013; Khoir et al., 2015; Turchick Hakak et al., 2010). However, in the last two decades, the Internet is becoming increasingly accessible and available and more and more newcomers are turning to various internet technologies (e.g., online search websites, online discussion forums, social media) to seek needed information (Ahmed and Veronis, 2017; Du and Haines, 2017; Fang et al., 2013; Feldman and Klaas, 2002; Fountain, 2005; Khoir et al., 2015; Shahiri and Osman, 2015; Yoon, 2017). Searching information in traditional ways (e.g., visiting employment agencies, libraries, reading print) is costly and the information is not always accessible or timely (e.g., agencies are typically open Monday to Friday only, newspapers with job postings are typically printed weekly and have limited number of jobs, and employers have also shifted their recruitment to online). In comparison, online search is relatively low cost and the information is generally available online all the time (Kroft and Pope, 2014; Sirikul and Dorner, 2016; Yoon, 2017). Furthermore, studies have shown that newcomers favor the Internet among various media information sources (e.g., radio, print, television) (Ahmed and Veronis, 2017; Sirikul and Dorner, 2016). 
Business research relating to the Internet and labour market integration has been predominantly concerned with studying job search outcomes. For example, research has shown that individuals who use the Internet for employment information search typically experience better employment outcomes and shorter unemployment duration than comparable individuals who searched offline only (Beard et al., 2012; Kuhn and Mansour, 2014; Kuhn and Skuterud, 2000, 2005; Shahiri and Osman, 2015; Suvankulov et al., 2012). A study examining German and South Korean job seekers (Suvankulov et al., 2012) found that individuals who used the Internet for job search found employment sooner (in both countries) and they had a higher probability of being re-employed $(7.1 \%$ higher in Germany and $12.7 \%$ in South Korea) in the next 12 months. Research has also established that individuals who use the Internet for job search have a greater chance to find employment, are less likely to cease their job search, and are more likely to find employment sooner than individuals who only use traditional job search methods (e.g., newspaper job listing) (Beard et al., 2012; Feldman and Klaas, 2002; Fountain, 2005; Kuhn and Mansour, 2014; Kuhn and Skuterud, 2000, 2005; Shahiri and Osman, 2015; Stevenson, 2009; Suvankulov et al., 2012). For instance, unemployed individuals who seek work online are about $50 \%$ less likely to cease their job search and find employment about $25 \%$ faster than comparable individuals who do not seek work online (Beard et al., 2012; Kuhn and Mansour, 2014).

However, the focus of this study is not on job search outcomes, but on the examination of employment knowledge needs of newcomers in online discussion forums. Therefore, the 
following sections discuss several online technologies available to newcomers seeking employment information.

\section{Information related internet technologies}

Newcomers may use different internet technologies to seek and access different types of employment information. For example, they may use online search websites (e.g., Google) to search for specific employment information (e.g., information about specific companies, find job search websites), social network sites (e.g., Facebook, LinkedIn, Google+) to draw on their social capital (i.e., who do I know?), job search websites (e.g., Monster, Workopolis, Job Bank, and Indeed) to find available jobs (i.e., what jobs are available?), and they may look at online discussion forums for the how-to information (i.e., how to go about searching for and getting a job?) (Du and Haines, 2017; Fang et al., 2013; Janta and Ladkin, 2013; Khoir et al., 2015; Kim and Yoon, 2012; Shahiri and Osman, 2015; Yoon, 2017). This study examines online discussion forums technology because the 'how-to' information is one of the hardest to obtain and because not everyone has social networks in the new country.

\section{Job search websites}

The examination of the role of job search websites has received a considerable attention of researchers in the last two decades (e.g., Kuhn and Mansour, 2014; Kuhn and Skuterud, 2000, 2005; Shahiri and Osman, 2015; Stevenson, 2009; Thomsen and Wittich, 2010). For example, research shows that compared to non-Internet searches (e.g., searching newspaper job ads), online job search sites allow users an easier and less costly way to search vacancies and apply for available jobs (Kuhn and Mansour, 2014; Shahiri and 
Osman, 2015; Suvankulov et al., 2012). In addition, individuals tend to find more information about available jobs online than with print outlets (Shahiri and Osman, 2015; Van Rooy et al., 2003). Online job search websites also allow users to filter available jobs by specifying job location, required experience, pay level and education level, and enable users to apply to an unlimited number of positions (Shahiri and Osman, 2015; Suvankulov et al., 2012).

\section{Blogs and online discussion forums}

There are very few studies examining more interactive internet technologies frequently used by newcomers such as blogs (e.g., Nardon and Aten, 2016; Nardon et al., 2015; Takeda, 2013) and online discussion forums (e.g., Caidi et al., 2014; Tabor and Milfont, 2013). Online discussion forums and blogs are changing the way individuals seek information and interact with others (Majchrzak et al., 2013; Miyazoe and Anderson, 2010; Nardon et al., 2015; Treem and Leonardi, 2012; Ye, 2006; Yoon, 2017). They provide newcomers not only new ways to search, access and gather relevant information about a local new environment, but also allow newcomers to seek, connect and interact with individuals with the relevant knowledge (Caidi et al., 2014; Nardon et al., 2015; Tabor and Milfont, 2013).

For example, research indicates that the blogging system (i.e., the blogging technology, bloggers, discussants, and co-created online discussions) creates online adjustment resources that can be accessed by the blogging technology users (Nardon et al., 2015). Researchers have also shown that newcomers' blogs provide rich, longitudinal personal accounts of newcomers' daily feelings, concerns, experiences, reflections and events, 
which are the foundation of newcomers' adjustment (Nardon et al., 2015; Takeda, 2013). In addition, newcomers can use blogs to make sense of the new environment (Nardon and Aten, 2016).

Limited extant research on online forums and newcomers in non-business literature suggests that online forums allow newcomers to form a virtual community, engage in discussions and exchange information (e.g., offer opinions, share stories and experiences) (Caidi et al., 2014; Chien, 2005; Kim and Yoon, 2012), as well as receive emotional support (e.g., with encouraging posts) (Tabor and Milfont, 2013). However, there remains a lack of international business research concerning newcomers' use of online discussion forums for labour market integration.

\section{Online discussion forums studies}

Although there is a lack of international business research concerning online discussion forums and newcomers, online discussion forums have been examined in many other research areas, such as education (e.g., Davies and Graff, 2005; Johnson, 2007; Kling and Courtright, 2003; MacPherson, 2010; Tan and Seah, 2011; Wang and Woo, 2008), health (e.g., Brady et al., 2016; Rains and Wright, 2016; Steuber and Haunani Solomon, 2008), information systems and technology (e.g., Assimakopoulos and Yan, 2006; Coles and West, 2016; Gao et al., 2013; Li, 2004; Li and Cox, 2016; Saade and Huang, 2009), law (e.g., Ring and Oei, 2016), marketing (e.g., Bickart and Schindler, 2001), media (e.g., Bourgonjon et al., 2016), psychology (e.g., McKiernan et al., 2017), rural studies (e.g., Golding, 2014), total quality management (e.g., Sheng and Hartono, 2015), and others. In

the last decade, more and more researchers are examining various aspects of online 
discussion forums and analysing the data collected from online discussion forums. The following sections discuss several key findings, from the extant literature studying online discussion forums that are relevant to this study.

\section{Information exchange, learning and knowledge creations}

Studies have demonstrated that online discussion forums can facilitate information exchange and collaborative learning and co-creation of knowledge (e.g., Chalkiti and Sigala, 2008; Ellis et al., 2007; Nor et al., 2010; Rabbany et al., 2014; Schau et al., 2017). For example, students interacting and exchanging information in online forum discussions showed better understanding of the material (e.g., Badia et al., 2011; Griesbaum et al., 2015; Zhu, 2006). Jahnke (2010) also suggests that interactions in online forums can facilitate students' collaborative learning and improve their learning outcomes. In a study involving Chinese speaking customers learning about the US marketplace, Schau et al. (2017) showed that interactions in online forums can facilitate acculturation: for example, participants showed better understanding of the American culture over time. In a study of an online discussion forum for breast cancer sufferers, Keeling et al. (2013) found that online forums can also facilitate information transfer and construction of new knowledge, and that online forum participants developed rich understandings of their health through exchanges of experiences.

\section{Virtual community formation and engagement}

Research has shown that online discussion forums can facilitate community formation and engagement (e.g., Caidi et al., 2014; Chien, 2005; Fang et al., 2013; Figer and de Torres, 2012; Kim and Sundar, 2016). Online forums can contribute to formation of virtual social 
networks where individuals interact with others on the subjects relevant to the particular community (Caidi et al., 2014; Chien, 2005; Janta and Ladkin, 2013; Ruhleder, 2002). Studies examining Filipino migrants in Japan suggest that interactions in online discussion forums can create, maintain and enhance users' social networks (Figer, 2014; Figer and de Torres, 2012). For example, through the interaction in online forums, Filipinos got to know each other and increased their feeling of national identity and belonging to a community.

\section{Emotional support}

Online forums also enable offering and receiving of emotional support (McKiernan et al., 2017; Tabor and Milfont, 2013). For example, a study of online forum communities concerning migrants to New Zealand suggests that online discussion forums facilitate exchanges of emotional and tangible support (Tabor and Milfont, 2013). They showed that members acted in altruistic ways to benefit the community, shared personal experiences and offered encouragements. In addition, the exchanges of experiences fostered normalization of risk and reduction of uncertainty.

\section{Summary of literature}

The Internet allows newcomers relatively easy, inexpensive and quick access to information that is available 365 days a year and can be accessed worldwide (Noorani, 2017). However, newcomers often do not understand the local information environment (e.g., where to search for relevant information and whom to and how to ask) (Caidi et al., 2008, 2010; Farh et al., 2010; Khoir et al., 2015; Savolainen, 2016). In addition, relevant information is not always available online, or newcomers may lack necessary knowledge of where to find and how to access needed information online (Janta and Ladkin, 2013; 
Kim and Yoon, 2012; Noorani, 2017; Tabor and Milfont, 2013; Yoon, 2017). Recently, an increasing number of newcomers are turning to online discussion forums to seek information. Online forums are important information sources for newcomers as they allow not only searching for specific information, but also enable interactive discussions and exchanges with other users by posting specific questions or topics for discussion in online discussion forums and by replying within extant discussions. This allows newcomers to connect and seek needed information and advice from users with the relevant local knowledge and experience (Caidi et al., 2014; Chien, 2005; Griesbaum et al., 2015; Kim and Yoon, 2012). To a certain extent, online forums can be regarded as virtual social networks where users communicate and develop virtual ties (Caidi et al., 2014; Chien, 2005; Kim and Sundar, 2016). Research also shows that online discussion forums can facilitate emotional support, learning and co-creation of new knowledge. Online forum users also perceive the information in online forums as accurate, credible and trustworthy, and in occasional instances when the provided information was inaccurate, it was typically identified and corrected or updated by other members in the online community (Armstrong et al., 2012; Brady et al., 2016; Esquivel et al., 2006; Hajli et al., 2015; Mudry and Strong, 2013; van Berkel et al., 2015).

Although online discussion forums have been studied in several research areas there is a lack of international business studies concerning newcomers' labour market integration and online forums. This study examines the role of online discussion forums in newcomers' labour market integration to advance international business research concerning global mobility and international careers. 


\section{Chapter 3: Conceptual Framework}

In this section, I briefly review three bodies of literature that have informed this study in its present form: (a) a social support perspective (Adelman, 1988; Cutrona, 1990; Cutrona and Russell, 1990; Farh et al., 2010; Podsiadlowski et al., 2013; Stroppa and Spieß, 2011; Van Bakel et al., 2017); (b) knowledge creation and sharing (Nonaka, 1994; Polanyi and Sen, 2009); and (c) technology affordances perspective (Majchrzak et al., 2013; Treem and Leonardi, 2012).

In line with inductive research, I came to realize the utility of these concepts as I engaged with the data. For clarity, and to spare readers the ambiguity inherent in grounded research, I discuss this literature prior to presenting the analysis and results. However, as I will explain in the methods section, I examined and incorporated these concepts and related literature into this study as the analysis suggested its relevance. At the time of my proposal, I expected that a relational perspective on newcomer's capital mobilization (Al Ariss and Syed, 2011; Syed, 2008) would be most useful (the relational perspective is discussed in Appendix A). However, as I examined the data, I noticed that only cultural capital was present in online discussion forums, limiting the utility of the framework. In addition, examination of the online discussions suggested users were exchanging social support resources, which required a revision of the original conceptual framework.

\section{Social support}

This study focuses on social support in computer mediated communications. Social support refers to the provision of resources by local contacts (e.g., information, money, emotional comfort) that can help individuals cope with uncertainty and manage stresses (Adelman, 
1988; Stroppa and Spieß, 2011; Van Bakel et al., 2017). Computer mediated communications refer to interactions carried out by the use of Internet based technologies that facilitate interactions between individuals or among groups, such as online discussion forums, blogs, social network sites (e.g., Facebook), e-mail, and instant messaging (Rains, 2016; Rains and Wright, 2016). In the context of computer mediated communication and newcomers' labour market integration in the new country, social support refers to communication that helps individuals manage uncertainty and ambiguity about the new country's labour market environment and increases their perceptions of control regarding life through online interactions (Albrecht and Adelman, 1987; Goldsmith and Albrecht, 2011; Lin et al., 2016; Pan et al., 2017; Rains et al., 2016). Social support mitigates the uncertainty, ambiguity and anxiety, which are key barriers to newcomers' adjustment to foreign environments. Research also suggests that social support is an important element in newcomers' adjustment, job performance, well-being, and ability to contribute to the new society (e.g. Boese, 2015; Farh et al., 2010; Salgado and Bastida, 2017; Stroppa and Spieß, 2011; Van Bakel et al., 2017).

Four types of social support are commonly identified in the literature: informational support, instrumental support, emotional support, and companionship support (Cohen and Wills, 1985; Van Bakel et al., 2017). Informational support refers to help in explaining and understanding, and provision of information and guidance to help cope with problems; instrumental support (also called tangible support) refers to provision of material resources or economic aid, and/or required services; emotional support refers to provision of reassurance, encouragement, comfort, and information that a person is accepted and esteemed; and companionship support refers to provision of a sense of social belonging, 
spending of time and engaging in social and leisure activities with others (Chib et al., 2013; Cohen and Wills, 1985; Van Bakel et al., 2017; Van der Laken et al., 2016). In offline contexts (e.g., face-to-face interactions), companionship support is often a prerequisite for and starts provision of other types of support, and thus it is typically the most frequent type of social support offered by local contacts (Van Bakel et al., 2017).

Research has established that social support resources (e.g., informational, instrumental) can help newcomers adjust, as well as manage and mitigate various challenges in a foreign new environment, such as finding employment (Al Ariss and Syed, 2011; Bahn, 2015; Farh et al., 2010; Kuhn and Mansour, 2014; Mahajan and Toh, 2014). Research suggests that newcomers can seek social support from various sources, including family, friends, and co-workers (Hynie et al., 2011, Simich, 2003), ethnic communities (Makwarimba et al., 2013; Stewart et al., 2008), co-workers and locals (Boese, 2015; Farh et al., 2010; Podsiadlowski et al., 2013; Stroppa and Spieß, 2010; van Bakel et al., 2017), and government organizations (Darrow, 2015; Pittaway et al., 2015). However, newcomers typically lack the relevant knowledge of local information environment and social support sources in new and largely unfamiliar labour market environments (Dietz et al., 2015; Khoir and Koronios, 2015b; Kilpatrick et al., 2015; Stroppa and Spieß, 2011). In addition, when newcomers migrate to a foreign country they typically leave behind a very large part of their social networks (e.g., friends, family, co-workers), which are important sources of various types of social support in their homelands (Farh et al., 2010; Stroppa and Spieß, 2011; Van Bakel et al., 2017). The remaining social networks in their homelands diminish and/or cease to exist completely over time and hence newcomers need to seek new sources of relevant knowledge and support in the new countries (Van Bakel et al., 2017; Wang 
2002). Research shows that seeking and accessing relevant knowledge in a new country takes more time and requires greater effort and resources offline than online, and more and more newcomers are turning to online technologies (e.g., blogs, online discussion forums, social media websites) to seek and access needed knowledge (Ahmed and Veronis, 2017; Fang et al., 2013; Noorani, 2017; Sirikul and Dorner, 2016; Turchick Hakak and Al Ariss, 2013; Yoon, 2017) and social support (Mikal et al., 2013, 2015; Nardon et al., 2015).

The studies on online social support have been primarily conducted in the contexts of health and education (e.g., Haythornthwaite et al., 2000; Hrastinski. 2008; Kim et al., 2017; Lee et al., 2016; Wright et al., 2013; Zhang, 2017). Research on online social support in the context of health is quite extensive and these studies show that more and more individuals turn to online technologies for social support (Naslund et al., 2017; Rains and Tsetsi, 2017). In the United States, for example, data show that in 2010 almost one in five adult Internet users have gone online to search for health-related peer support and in 2012 the number increased to almost one in four (Fox, 2011; Fox and Duggan, 2013). More recently, several studies also examined the computer mediated support in the context of cultural adaptation (e.g., Chen and Choi, 2011; Kim et al., 2009; Mikal et al., 2013). However, there is a lack of research examining social support in the context of newcomers' labour market integration and online discussion forums. Several scholars argue that there is a need for more research on online social support in different contexts to enhance our understanding of the use and importance of online support in general and in other contexts (Rains et al., 2015, 2016; Rains and Wright, 2016). 
This study examines social support in the context of newcomers to Canada and online discussion forums. Specifically, it examines types of social support sought after, available and exchanged in online discussion forums. It is important to note that online discussion forums are only one type of media within a media rich environment that are accessible and available to newcomers and that newcomers can use multiple media sources depending on their individual needs and strategies and preferences to use these media (Ahmed and Veronis, 2017; Veronis and Ahmed, 2015).

I draw on the optimal matching model as a theoretical framework, which is often used to examine why and when some types of support messages are more or less common in different computer mediated support contexts (Green-Hamann and Sherblom, 2014; Rains et al., 2015, 2016). The optimal matching model was developed mainly in offline health context, and more recently it has been used to study computer mediated social support in the context of health (Rains et al., 2015; Rains and Wright, 2016). The optimal matching model proposed by Cutrona and her colleagues in 1990 (Cutrona, 1990; Cutrona and Russell, 1990) suggests that different types of social support may be more or less helpful in different situations. In this model, different types of social support messages are grouped into two categories: action-facilitating and nurturant. Action-facilitating types of support (e.g., instrumental and informational) help mitigate and manage a stressor, while nurturant types of support (e.g., emotional, companionship) help cope with a stressor.

The model suggests that action-facilitating types of support are typically more optimal when dealing with controllable problems, while nurturant types of support are better for coping with uncontrollable problems (Cutrona and Russell, 1990; Cutrona and Suhr, 1992). 
Uncontrollable problems are those over which individuals typically have very limited or no control to evade or to mitigate the stressors' consequences. Controllable problems are those that individuals can manage and control with relevant resources, such as information and money. For example, when dealing with more uncontrollable problems, such as terminal illness, individuals generally seek companionship and emotional support (Mikal et al., 2013, 2015; Rains and Wright, 2016; Tabor and Milfont, 2013). However, to manage and mitigate more controllable problems, such as finding work, school projects, and buying a house, individuals typically seek informational and instrumental (e.g., money and service) support (Al Ariss and Syed, 2011; Griesbaum et al., 2015, Hwang et al., 2013; Podsiadlowski et al., 2013).

Recent research examining computer mediated social support in the context of health also shows that the extent of action-facilitating and nurturant types of support vary for the health problems that are more or less controllable (Buis and Whitten, 2011; Coursaris and Liu, 2009; Fukkink, 2011; Moore and Ayers, 2017; Mo and Coulson, 2008; Pan et al., 2017; Rains et al., 2015; Zhao and Basnyat, 2018). A review and examination of 41 studies that used content analysis to study computer mediated social support messages in the context of health also shows that the messages with nurturing types of support (e.g., emotional and companionship) are more prevalent when the illness is less controllable (e.g., terminal illness or health condition with a higher probability for death), while the messages with action facilitating types of support (e.g., informational and instrumental) are more common when the health conditions are more controllable (e.g., chronic or long term) (Rains et al., 2015). The review also proposes that emotional and companionship types of support help 
with coping of emotional consequences of a stressor, whereas informational and tangible types of support help to manage and mitigate a stressor (Rains et al., 2015).

Newcomers' labour market integration in the new country's labour market is a controllable problem as newcomers can use relevant social support resources (e.g., information) to manage their job search and integration in the local labour market. Examined literature on social support and the optimal matching model suggests that, in the context of labour market integration, newcomers are more likely to seek informational and instrumental support rather than emotional and companionship support in online discussion forums.

\section{Knowledge exchange and creation}

There are two types of knowledge: tacit and explicit (Polanyi and Sen, 2009). Explicit knowledge or codified knowledge is relatively easy to transmit and share in formal, systematic language, while tacit knowledge is difficult to share because it is "deeply rooted in action, commitment and involvement in a specific context" (Nonaka, 1994:16).

Nonaka (1994) proposes a dynamic theory of knowledge creation suggesting that there are four possible different patterns of interactions between explicit and tacit knowledge. The four patterns are shown in Figure 3 below. The theory suggests that these patterns represent four different ways in which transfer of extant knowledge in a social interaction between individuals, can result in the creation of new knowledge, as discussed below. The theory also suggests that the development of new knowledge tends to increase with the number of participants in the interaction (Nonaka, 1994). 
Figure 3. Modes of the knowledge creation (Nonaka, 1994: 19).

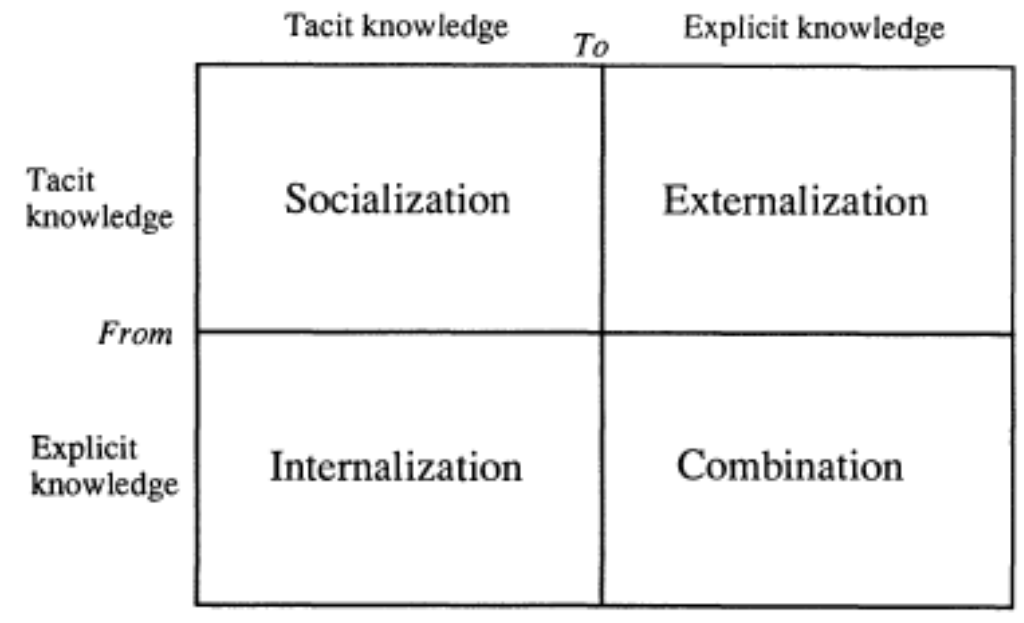

Socialization refers to the process of creation of tacit knowledge from tacit knowledge, typically through shared experience (e.g., observation, imitation, and practice) and not through language, because it is very difficult to transfer tacit knowledge without some form of shared experience.

Combination refers to the process of creation of explicit knowledge from explicit knowledge. Individuals can exchange and combine their knowledge through various exchange mechanisms, such as meetings, telephone conversations, and computer technologies (e.g., email, chat). These combinations and exchanges of information reconfigure existing information, (e.g., reorganise, add, and re-contextualize), which can lead to new knowledge.

Internalization refers to the process of conversion of explicit knowledge into tacit knowledge. This process is similar to the process of 'learning by doing' and experimentation. In the process of trial and error, explicit concepts are articulated and developed until they appear in a concrete tangible form. 
Externalization refers to the process of conversion of tacit knowledge into explicit knowledge. This process typically involves the use of complex 'metaphors' to articulate individuals' perspectives and expose hidden tacit knowledge that is otherwise very difficult to codify and communicate.

The four modes represent the four possible ways in which tacit and explicit knowledge can interact (Nonaka, 1994). Internalization and externalization modes are very complex as they include both tacit and explicit knowledge and hence they involve not only transfer of information, but also conversion of one type of knowledge into a very different type of knowledge. Transfer of tacit knowledge, socialization, requires shared experience and it is typically very difficult to transfer in an online environment. Online forums are particularly suitable to the combination mode of knowledge creation as it relies on explicit knowledge.

\section{Online technology affordance perspective}

Social media technologies such as online discussion forums, blogs, and wikis afford new ways of communication, which are very different from traditional personal interactions (Aichner and Jacob, 2015; Majchrzak et al., 2013; Treem and Leonardi, 2012). Treem and Leonardi (2012) identified four universal affordances enabled by social media technologies: visibility, persistence, editability, and association. Technology affordances are defined as technology capabilities that enable an actor the potential for a specific action (Faraj and Azad, 2012; Majchrzak et al., 2013). 


\section{Visibility}

Online discussion forums allow users to make their behaviour, preferences, communication network connections, and knowledge visible to others (Treem and Leonardi, 2012). For example, individuals can view users' posts, status updates, comments, votes, and personal profiles.

\section{Persistence}

Online discussion forums allow users' communication (e.g., posts) to remain accessible in its original display form, and the information remains available to users and does not expire or disappear (Treem and Leonardi, 2012). Persistence of previous communications allows information to be put in context (e.g., users can find and access previous communications) and provide people with the time to use, examine, and gain better understanding of the conversation over time. Persistence also allows the contributed knowledge to develop and remain available and accessible over time. Moreover, online discussion forums provide nearly limitless space for users' communications that facilitates the persistence and growth of content over time through the addition of new threads and posts.

\section{Editability}

Online discussion forums allow users to edit their communications after posting. They permit users to modify or revise content of previous communications or delete the content. Editability affordance allows users to edit content of their communications, for example, fix typological errors, provide additional context information, and increase message comprehension. Other technologies, such as email, do not provide this affordance. For example, the content of email communication cannot be edited after sending. 


\section{Association}

Online discussion forums also allow users to make connections between individuals (e.g., see social ties) and between individuals and content. For example, in online discussion forums, people can view with whom individuals communicate. In addition, people can easily connect individuals with specific content or communication as the posts in online discussion forums are tagged with the author's name and data and time of the post. Online forums also allow people to quickly connect users to all their previous communications, and view their status, ranking, and other available information.

The four online discussion forums affordances allow newcomers' new ways of interaction, which may provide newcomers' new means of accessing, exchanging, and combining information concerning labour market integration, which could also result in the creation of new relevant knowledge. 


\section{Chapter 4. Research Approach and Methodology}

This study is a phenomenon-based research investigating the role of online discussion forums in newcomers' labour market integration in Canada. I used a conventional qualitative content analysis method to study threads and posts collected from five online discussion sub-forums that focus on topics related to labour market integration of newcomers in Canada to examine (a) newcomers' employment needs requested in online discussion forums, (b) whether these needs are met, (c) the characteristics of threads in which needs are not met, and (d) how online discussion forums facilitate or hinder newcomers' labour market integration. The main objective of this study is to qualitatively explore the phenomenon and set a stage for future theorizing and not to test hypotheses or relationships. Considering the research approach, the objectives of this study, and the rich contextual data being examined, the study is primarily exploratory and descriptive. Moreover, in line with inductive research, I iteratively examined and described the collected data using concepts and literature that analysis suggested to be relevant.

This chapter contains three main sections. The first section discusses the phenomenonbased research; the second section explains the data collection and organization process; and the third section discusses the data analysis approach. 


\subsection{Phenomenon-Based Research}

This study investigates the phenomenon of increasing use of online discussion forums by newcomers seeking information concerning labour market integration in the Canadian labour market. Phenomenon-based research focuses on the phenomenon first and then identifies theory or theories that can inform the reality observed (Doh, 2015a; 2017; Wrona and Gunnesch, 2016). The primary objective of phenomenon-based research is to identify, explore, describe, document, and conceptualize a phenomenon (Von Krogh et al., 2012). Phenomenon-based research is about discovery of new relationships, patterns and facts that help us better understand the phenomenon, and these discoveries may in turn lead to new avenues for future theory development (Cheng et al., 2011; Doh, 2015a, 2017; Miller, 2007; Von Krogh et al., 2012). In phenomenon-based research, the initial primary focus needs to be on the questions about the phenomenon and researchers should not focus too much on theory and theoretical contributions initially as this may prevent discovery of new and rich details about the phenomenon (Hambrick, 2007; Helfat, 2007; Von Krogh et al., 2012).

Several international business scholars have called for more phenomenon-based research in International Business to examine new phenomena that are relevant to organizations and management (e.g., Cheng et al., 2011; Doh, 2015a, 2015b, 2017; Hambrick, 2007; Helfat, 2007; Von Krogh et al., 2012; Wrona and Gunnesch, 2016). International business and management scholars argue that the international management research is running out of new interesting ideas and that the research increasingly examines topics and uses data sets, concepts, and methods borrowed from other business fields, such as strategy (Buckley, 
2002; Shenkar, 2004). In addition, these studies typically focus on testing and expanding on existing theories, rather than developing new theories (Cheng, 2007). Scholars argue that there is a need for more phenomenon-based research to discover and investigate new big ideas as the field of international management is increasingly losing its uniqueness in knowledge development (Buckley, 2002; Cheng et al., 2011). There is also an increasing need for more research examining new phenomena that have implications not only for theory, but also for practice (Doh, 2015a, 2015b, 2017; Von Krogh et al., 2012).

Von Krogh et al. (2012) propose different phenomenon-based research strategies (e.g., distinguish, explore, design, theorize, and synthesize) given the growth stages of research concerning the phenomenon (e.g., embryonic, growth, and mature) and argue that researchers need to employ different research strategies based on the stage of research on a phenomenon. For example, they argue that when there is limited or no extant research about the phenomenon (i.e., embryonic stage) scholars need to focus more on exploration of the phenomenon, whereas when research on a phenomenon increases to a level where studies show predictable and consistent results (i.e., mature stage), the focus should be more on theorizing and synthesizing of research (Von Krogh et al., 2012). Table 3 illustrates phenomenon-based research strategies given the growth stages of research on the phenomenon under study. The primary research strategies for each research stage are indicated with grey shading. 
Table 3. Research strategies given the growth stages of research on the phenomenon (based on Von Krogh et al., 2012).

\begin{tabular}{|l|l|l|l|}
\hline \multirow{2}{*}{ Research Strategy } & \multicolumn{3}{|c|}{ Research Stages } \\
\cline { 2 - 4 } & Embryonic & Growth & Mature \\
\hline Distinguish & & & \\
\hline Explore & & & \\
\hline Design & & & \\
\hline Theorize & & & \\
\hline Synthesize & & & \\
\hline
\end{tabular}

There is a lack of international business research concerning newcomers' increasing use of online discussion forums and the very limited research in other research areas, such as information systems (e.g. Caidi et al., 2014; Chien, 2005) and psychology (e.g., Tabor and Milfont, 2013), suggests that research on newcomers' use of online discussion forums is at an embryonic stage. Given the phenomenon-based focus of this study and an embryonic stage of extant research, an exploratory qualitative approach is appropriate (Edmondson and McManus, 2007; Eisenhardt, 1989; Gligor et al., 2016). A qualitative method allows examination of contextual patterns in data and reporting of findings with rich descriptions embedded in real context (Miles and Huberman, 1994; Miles et al., 2014). 


\subsection{Data Collection and Organization}

The following sub-sections below discuss data collection and organization. Specifically, they present online discussion forums and the data selection and organization process.

\section{Online Discussion Forums}

Data for this study was collected from multiple online forums. An online forum is a form of online discussion board where individuals communicate, discuss and debate various subjects through posting messages with new topics for discussions or replying to previously posted messages (Figer, 2014; Figer and de Torres, 2012; Im and Chee, 2012; Seethamraju, 2014). Online forums not only offer users new and easy ways to communicate, seek and exchange information, and connect with individuals from various communities across the world, but also provide researchers new opportunities for novel research (Li and Cox, 2016; Kim and Sundar, 2016; Omidvar et al., 2014; Pendry and Salvatore, 2015).

Data from online forums also offers important advantages for research. For example, one of the main advantages of using online forum data over other methods of data collection, such as interviews and surveys, is that online forums typically allow non-obtrusive observations of naturally occurring behavior and collection of data (Griesbaum et al., 2015; Jansen and Saint Onge, 2015; Kozinets, 2002; Seethamraju, 2014). That is because online forums typically make all discussions publicly visible and accessible (i.e., individuals do not have to join a particular online forum community to view the discussions), allowing researchers continuous, unrestricted and non-obtrusive observation of various communities 
and discussions (Hwang et al., 2013; Jansen and Saint Onge, 2015; Kozinets, 2002; Weber, 1990). In addition, online forum participants create discussions independently of any expectations of future analysis and awareness of being analyzed, minimizing the risk that the researcher or the act of measurement itself will influence the observed process and confound the data (Weber, 1990). This non-obtrusive observation and examination of naturally occurring behavior may provide new understandings and reveal information that are not available through more traditional data sources such as surveys, interviews, or focus groups (Hwang et al., 2013; Im and Chee, 2006, 2012; Kozinets, 2002; Nor et al., 2010; Takeda, 2013). Moreover, ease of access and availability of multiple relevant online forums provide researchers with an opportunity to collect and examine large quantities of contextually rich data from multiple relevant sources, which can offer new and unique understandings and perspectives on the phenomenon under study (Chu, 2009; Im and Chee, 2006, 2012; Kaiser and Bodendorf, 2012).

Although study of online forums is a relatively recent phenomenon, with the majority of research published in the last decade, more and more studies use data collected from online forums. For example, data collected from online forums have been used in many different areas, including education (e.g., Griesbaum et al., 2015; Loncar et al., 2014), marketing (e.g., Hajli et al., 2015; Schau et al., 2017), healthcare (e.g., Jansen and Saint Onge, 2015; Kim and Sundar, 2016), tourism (e.g., Chalkiti and Sigala, 2008; Hwang, et al., 2013), information systems and technologies (e.g., Caidi et al., 2014), law (e.g., Ring and Oei, 2016), media (e.g., Bourgonjon et al., 2016), psychology (e.g., Tabor and Milfont, 2013) and others. However, there is lack of international business research investigating issues concerning global mobility using data from online forums. Studies that focus on 
newcomers' labour market integration in the new country's environments typically study data collected with surveys (e.g., Barrett and Duffy, 2008; Connor and Koenig, 2013; DelCampo et al., 2011; Fang et al., 2013; Kogan, 2011) and interviews (e.g., Al Ariss, 2010; Al Ariss et al., 2013; Al Ariss and Syed, 2011; Ramboarison-Lalao et al., 2012). Scholars argue that to provide new insights about the phenomenon and to advance research, studies need to use new data sets and methods (Cheng et al., 2011; Shenkar, 2004). Thus, this study examines contextually rich online forum data to increase our understanding of the role of online forums in newcomers' labour market integration and to advance international business research, in particular research concerning global mobility and international careers.

Global mobility is rising and millions of newcomers worldwide are turning to online discussion forums for information about the destination country's environment. For example, the Canada Visa forum, the largest online discussion forum dedicated to discussion of various topics related to newcomers to Canada, has more than half a million registered members. Considering that not all visitors to this online forum become registered members, as registration is not required to view the discussions, the actual number of people using this particular forum is expected to be much larger. In addition, there are several other online forums available to newcomers seeking information about Canada, and many more online forums concerning immigration to other countries, such as Australia, the United States, and Germany.

This study focuses primarily on the examination of online discussion forums concerning labour market integration of newcomers and it examines forums in English only. English 
proficiency is a pre-requisite for professional employment in most Canadian regions outside of Quebec and focusing on English discussion forums eliminates the potential issue of lack of language abilities. In addition, this is consistent with the extant research using online forums as studies typically examine online forum data collected from English only discussion forums (e.g., Caidi et al., 2014; Chien, 2005; Tabor and Milfont, 2013). Considering the above and that the focus is on the issues concerning employment and not language proficiency, using English only discussion forums is appropriate. Furthermore, although newcomers with limited English proficiency can't fully participate in English forums, there are online discussion forums available for newcomers to Canada speaking other languages, such as Polish (e.g., polcan.fora.pl) and Chinese (e.g., bbs.51.ca/forum50-1.html).

Although newcomers turn to online discussion forums for various reasons and needs, this study focuses primarily on issues concerning newcomers' labour market integration. Specifically, this study examines online forum data collected from sub-forums primarily discussing topics concerning newcomers' employment in Canada. Research has shown that labour market integration of newcomers in the new country's labour market plays a critical role in newcomers' integration in the new country's society, culture and environment (Bevelander and Pendakur, 2014; Dietz et al., 2015; Frank, 2013; Hansen, 2012; Lundborg, 2013). Moreover, the labour market integration of newcomers is critical for newcomers' successful settlement and adjustment in the new country and it can also be very beneficial for the local economy and society (Dietz et al., 2015; Pholphirul and Rukumnuaykit, 2016; Reitz et al., 2014). Numerous benefits of labour market integration of newcomers were discussed in the literature review (section 2.1). Research has also shown that newcomers 
typically lack relevant local market knowledge and access to local information sources, and an increasing number of newcomers are turning to internet technologies, such as online discussion forums for information (Khoir et al., 2015; Shahiri and Osman, 2015).

\section{Data Selection}

In line with research using online discussion forums (e.g., Burri et al., 2006; Fu et al., 2016; Griesbaum et al., 2015; Jansen and Saint Onge, 2015; Steuber and Haunani Solomon, 2008), relevant online forums were identified by searching multiple terms with the Google search engine. The Google search engine was chosen over other available Web search engines (e.g., Yahoo!, Bing, and Excite) as it is the most popular online search engine in use, with about $90 \%$ of global search engine market share (Statista, 2016). Since the primary focus of this study is on the role of online forums in immigrants' employment market integration in Canada, the searched terms include various combinations of the key words concerning Canada, immigrants, employment, and online forums. The ten terms entered in the Google search engine and their corresponding returned results are shown in Table 4 below.

Table 4. Search terms and the corresponding returned results in Google search engine.

\begin{tabular}{|l|l|c|}
\hline Search & Search Terms & $\begin{array}{c}\text { Returned Results } \\
\text { (in millions, August 10, 2016) }\end{array}$ \\
\hline 1 & Canada immigration forum & 25 \\
\hline 2 & Canada immigration discussion & 26 \\
\hline 3 & Canada discussion forum & 85 \\
\hline 4 & Jobs in Canada forum & 55 \\
\hline 5 & Work in Canada forum & 108 \\
\hline 6 & Employment in Canada forum & 33 \\
\hline 7 & Canada immigrant employment & 13 \\
\hline 8 & Canada immigrant jobs & 16 \\
\hline 9 & Canada immigrant work & 3 \\
\hline 10 & Canadian jobs forum & 47 \\
\hline
\end{tabular}


Research indicates that $97 \%$ of individuals view only the first 10 websites returned by search engines and the websites listed near the top of the first page are the most likely to be viewed, and very few individuals view websites listed on the second page (Eysenbach and Köhler, 2002; Fu et al., 2016). Considering the above, I examined the top 20 websites returned in each of the above ten searches. I examined the top 20 instead of only the top 10 websites to identify additional relevant online forums that might have not been included in the top 10 returned results. This resulted in 200 Websites.

Examination of the 200 Websites and elimination of duplicates resulted in 23 distinct online discussion forums. Next, I eliminated 1 non-English forum, 3 forums concerning Canadians and not newcomers, and 14 very small forums (forums with fewer than 1,000 threads). I also eliminated three forums that focus only on a very specific group of migrants such as British expatriates (e.g., British Expat) or Indian immigrants (i.e., Canadian Desi) as the focus of this study is on examination of issues concerning the general newcomer population and not a very specific group or type of immigrants. The remaining two online discussion forums are listed in Table 5 below.

Table 5. Selected online discussion forums.

\begin{tabular}{|l|l|l|}
\hline & Name & Link to Online Forum \\
\hline 1 & Canada Visa & $\begin{array}{l}\text { https://www.canadavisa.com/canada-immigration- } \\
\text { discussion-board/ }\end{array}$ \\
\hline 2 & Road to Canada & http://www.roadtocanada.com/forums/index.php \\
\hline
\end{tabular}

The Canada Visa forum was founded in 1996 and it is the largest online forum discussing topics concerning newcomers and Canada. The Road to Canada forum was founded in 2005. Some key statistics for the two selected forums are summarized in Table 6 below. 
Table 6. Canada Visa and Road to Canada forums statistics (as of May 12, 2017).

\begin{tabular}{|l|l|l|l|l|l|}
\hline & Forum & Sub-forums & Members & Threads (topics) & Posts (replies) \\
\hline 1 & Canada Visa & 33 & 516,805 & 322,840 & $5,597,460$ \\
\hline 2 & Road to Canada & 13 & 6,566 & 9,983 & 49,023 \\
\hline
\end{tabular}

\section{Online sub-forums selection}

As shown in Table 6 above, online forums can include several sub-forums. A sub-forum is a part of online discussion board and it contains threads (discussions) concerning a particular subject. The forum Canada Visa is much larger than the Road to Canada forum. For example, Canada Visa has more than 300 thousand threads grouped in 33 sub-forums while Road to Canada has only about 10 thousand threads in 13 sub-forums. Each subforum indicates a specific area or subject matter for discussion within the online forum. Some examples of sub-forums in the Canada Visa forum include "Education" (it contains discussions about the education system in Canada), "Resources for Finding a Canadian Job" (includes discussions about interview experiences, and tailoring resume and cover letter), and "Finding work in Canada" (discussions on how to find work in Canada). Subforums concerning 'similar' topics are also grouped together under a common category. For example, as shown in Table 7 below, topics about "temporary entry to Canada" are discussed in three sub-forums: foreign workers, international students, and visitors. Table 7 shows the structure of the Canada Visa forum, including sub-forums and their corresponding threads and posts. 
Table 7. Canada Visa forum structure (as of May 12, 2017).

\begin{tabular}{|l|r|r|}
\hline Sub-forums & Threads & \multicolumn{1}{c|}{ Posts } \\
\hline Immigration to Canada & & \\
\hline Express Entry / Expression of Interest & 35,697 & 540,457 \\
\hline Skilled Worker / Professional Immigration & 65,685 & $1,694,625$ \\
\hline Canadian Experience Class & 17,540 & 249,418 \\
\hline Provincial Nomination Program Immigration & 16,866 & 502,305 \\
\hline Quebec Immigration & 1,965 & 69,992 \\
\hline Family Class Sponsorship & 57,378 & $1,504,996$ \\
\hline Business Immigration & 953 & 5,803 \\
\hline IELTS - International English Language Testing Sys & 2,687 & 24,872 \\
\hline Refugees and Asylum & 663 & 8,799 \\
\hline General - All Canadian Immigration & 12,685 & 53,668 \\
\hline Moving to Canada from the U.S. & & \\
\hline Permanent Residence in Canada & 366 & 1,660 \\
\hline Temporary Residence in Canada (Work, Study, Visit) & 571 & 1,511 \\
\hline H-1B Holders in the U.S. & 40 & 326 \\
\hline Temporary Entry to Canada & & \\
\hline Foreign Workers & 16,433 & 170,708 \\
\hline International Students & 45,433 & 370,655 \\
\hline Visitors & 15,260 & 89,516 \\
\hline Settlement in Canada & & \\
\hline Settlement Issues & 4,323 & 29,276 \\
\hline Permanent Residency Obligations & 7,182 & 46,332 \\
\hline Citizenship & 10,108 & 179,524 \\
\hline Housing & 1,361 & 6,136 \\
\hline Education & 1,974 & 6,129 \\
\hline Health & 976 & 5,034 \\
\hline Working in Canada & & \\
\hline Finding Work in Canada & 2,602 & 12,711 \\
\hline Canadian Finance and Taxation & 994 & 3,951 \\
\hline Start Your Own Business in Canada - Self Employment & 321 & 1,316 \\
\hline Canadian Labour Legislation & 141 & 438 \\
\hline Resources for Finding a Canadian Job & 249 & 741 \\
\hline Canadian Visa Office & 534 & \\
\hline Visa Offices in North America & 46 & 4,513 \\
\hline Visa Offices in South America & 324 & 187 \\
\hline Visa Offices in Europe & 5,512 \\
\hline Visa Offices in Asia & $\mathbf{5 , 5 9 7 , 4 6 0}$ \\
\hline Visa Offices in Africa & \\
\hline Visa Offices in Oceania & & 1,314 \\
\hline & & \\
\hline
\end{tabular}


Although the two forums contain 46 sub-forums altogether, the majority of the sub-forums are not relevant to this study as they primarily focus on subjects not directly concerning newcomers' labour market integration in Canada, such as visa application, education, family sponsorship, citizenship, and others. For this study, only sub-forums that concern newcomers' labour market integrations in Canada were selected for analysis, such as, subforums containing discussions on how to go about searching and getting an employment in Canada. Sub-forums concerning other subjects, such as discussions about the immigration process, family sponsorship, studying in Canada, housing, or permanent residency application, were not included in the analysis. In the examination of the 46 sub-forums I identified 5 sub-forums that focus primarily on the discussion of topics concerning newcomers' labour market integration. The five sub-forums and their corresponding numbers of threads and posts are shown in Table 8 below.

Table 8. Selected sub-forums statistics (as of January 4, 2017).

\begin{tabular}{|l|l|l|l|}
\hline Forum & Sub-forums & Threads & Posts \\
\hline $\begin{array}{l}\text { Canada } \\
\text { Visa }\end{array}$ & Finding Work in Canada (CV21) & 2,441 & 12,905 \\
\hline & $\begin{array}{l}\text { Start Your Own Business in Canada - } \\
\text { Self Employment (CV22) }\end{array}$ & 308 & 1,253 \\
\hline & $\begin{array}{l}\text { Canadian Labour Legislation (CV23) } \\
\text { (CV24) }\end{array}$ & 133 & 412 \\
\hline $\begin{array}{l}\text { Road to } \\
\text { Canada }\end{array}$ & Settlement \& Employment (RC) & 246 & 1,479 \\
\hline Total & & $\mathbf{3 , 3 6 0}$ & $\mathbf{1 5 , 7 3 4}$ \\
\hline
\end{tabular}


This study examines data collected from five sub-forums, as data from multiple sources may provide a broader range of observations, richer and more complete information, and better insights about the phenomenon under study (Caidi et al., 2014; Tabor and Milfont, 2013). Studies using online forum data typically examine data collected from a single or two sub-forums only (e.g., Burri et al., 2006; Chalkiti and Sigala, 2008; Chien, 2005; Hwang et al., 2013; Jansen and Saint Onge, 2015). Examination of data from multiple subforums may also enrich the analysis and findings by allowing identification of various interesting trends and categories that may not all be present or observable in a single online sub-forum.

\section{Thread selection}

Sub-forums can include between a few and thousands of discussions. In online discussion forums, individual discussions are called threads or topics. Threads contain interactions and communications between community members on topics of interest to the members of the particular forum community (Azevedo, 2011; Hwang et al., 2013; Jansen and Saint Onge, 2015 Omidvar et al., 2014). A single thread is a topic posted on an online forum, and it typically contains an initial post and subsequent posts (replies) (Chien, 2005). A single post refers to a single reply in a thread discussion. The initial post is the first post in a discussion and the subsequent posts within threads are also called replies (Seethamraju, 2014). A general structure of initial post and replies in online forums is shown in Figure 4 below. 
Figure 4. Initial posts and replies structure in an online forum.

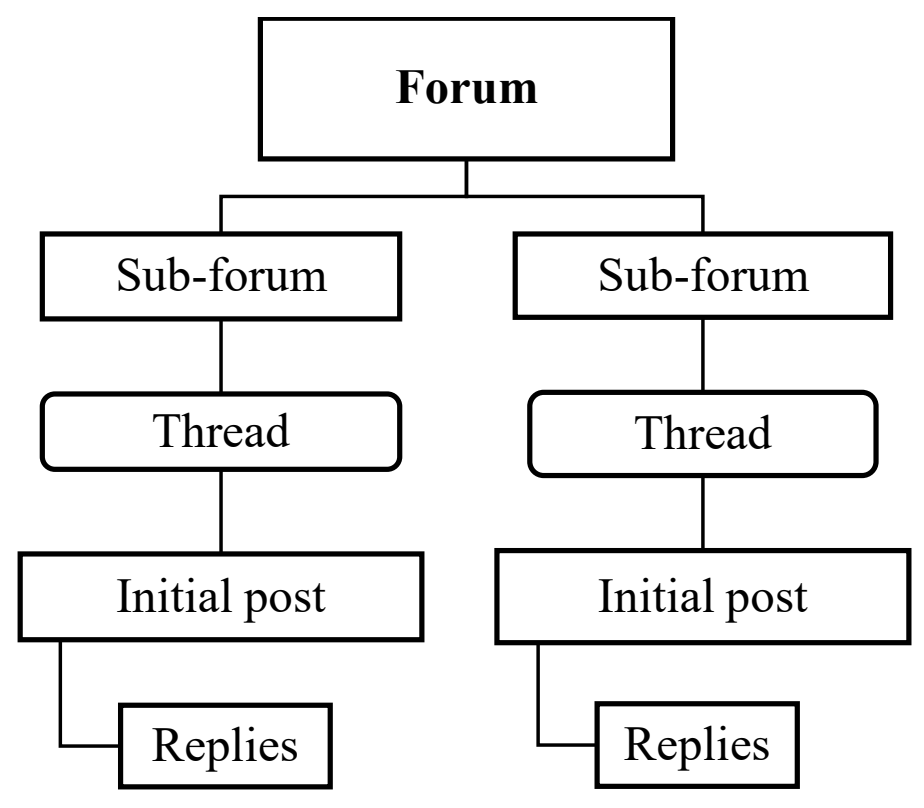

The number of replies within threads can vary: some threads may include hundreds or even thousands of replies while others include none. Individuals visiting a particular thread can choose to view the thread only or actively participate in a discussion by replying within the thread. The number of views for a typical thread tends to be several times greater than the number of replies as a majority of individuals visiting the thread do not actively participate in the discussions. For example, the thread "Alberta is where the work is" was viewed 9,449 times and has 68 replies, while the thread "Looking for a job in Canada with employer sponsorship" was viewed 7,342 times, but it has no replies (as of May 12, 2017). The two threads are in the same "finding work in Canada" sub-forum on Canada Visa forum. Moreover, a large number of threads do not include replies. For instance, in the selected five sub-forums there are 987 threads (i.e., 29.4\%) that contain no replies, that is, these threads contain only the initial posts. 
The selected five online sub-forums include threads that have been started several years ago and have not been discussed for a few years. Since the Canadian labour market environment is constantly changing, some of the older threads may concern subjects and information that are no longer valid or relevant today, and hence they are no longer discussed. To better understand the more up-to-date role of online forums, this study primarily focused on examination of threads that are relatively recent, that is, threads with the most recent replies posted on or after January 1, 2016.

The following steps were used to collect and select relevant threads for this study. First, a computer script was used to collect the 3,360 threads and 15,734 posts from the selected five sub-forums listed above. The threads and posts were collected in January 2017. Next, the individual threads and posts were organized and described using the Microsoft Excel software. Then, recent threads (with the most recent replies posted on or after January 1, 2016) were identified. In the five sub-forums, there are 574 recent threads, 139 of which contain no replies. The 574 threads contain 4,035 posts, of which 574 are initial posts and 3,461 are replies. The percentage of threads with no replies is very similar across the five sub-forums, between $21 \%$ and $25 \%$. Table 9 below summarizes the selected sub-forums and threads. 
Table 9. Summary of the threads selection.

\begin{tabular}{|l|l|l|l|l|l|l|}
\hline \multirow{2}{*}{ Relevant Sub-forum } & \multicolumn{5}{c|}{ Threads } \\
\cline { 2 - 8 } & \multicolumn{2}{|c|}{ Total } & \multicolumn{2}{c|}{ With replies } & \multicolumn{2}{c|}{ No replies } \\
\hline Finding Work in Canada & $\mathbf{4 2 4}$ & $73.9 \%$ & $\mathbf{3 1 7}$ & $75 \%$ & $\mathbf{1 0 7}$ & $25 \%$ \\
\hline $\begin{array}{l}\text { Start Your Own Business in Canada - } \\
\text { Self Employment }\end{array}$ & $\mathbf{7 1}$ & $12.3 \%$ & $\mathbf{5 6}$ & $79 \%$ & $\mathbf{1 5}$ & $21 \%$ \\
\hline Canadian Labour Legislation & $\mathbf{2 3}$ & $4 \%$ & $\mathbf{1 8}$ & $78 \%$ & $\mathbf{5}$ & $22 \%$ \\
\hline Resources for Finding a Canadian Job & $\mathbf{4 3}$ & $7.5 \%$ & $\mathbf{3 4}$ & $79 \%$ & $\mathbf{9}$ & $21 \%$ \\
\hline Settlement \& Employment & $\mathbf{1 3}$ & $2.3 \%$ & 10 & $77 \%$ & $\mathbf{3}$ & $23 \%$ \\
\hline & & & & & & \\
\hline
\end{tabular}

The final sample for this study is 574 threads. This number of threads is consistent with prior studies using online forum data and qualitative content analysis. For example, Hwang et al. (2013) examined only 220 initial posts collected from an online travel forum. Burri et al. (2006) studied 459 initial posts from an online forum aimed at recent ex-smokers. Jansen and Saint Onge (2015) examined 432 initial posts collected from a forum aimed at women seeking fertility treatment. Hajli et al. (2015) analyzed 156 posts from a single online health forum. Jean Harrison-Walker (2001) studied 551 posts from the United Airlines forum. Griesbaum et al. (2015) analyzed only 55 threads. Compared to the prior studies examining online forum data, this study is more extensive as it examines both the initial messages and the replies. In addition, in this study threads are collected from five sub-forums to increase data richness and chance of identification of occurrences that may not be present in a single sub-forum. 


\section{Summary of data collection and organization process}

Figure 5 below summarizes the data collection and organization.

Figure 5. Data collection and organization process.

Keyword search in Google search

Examine the top 20 websites returned in each search and eliminate duplicates

23 online forums

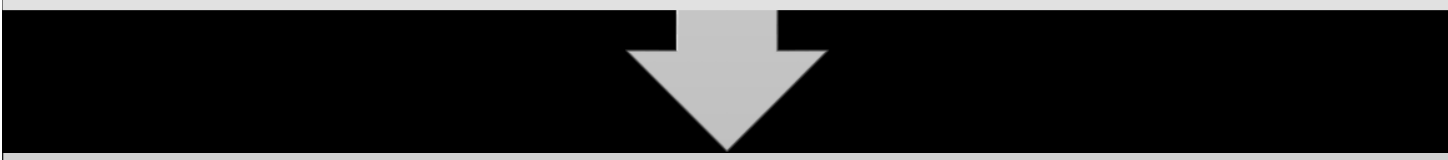

Eliminate 1 non English forum, 3 not relevant forums, 14 small forums with fewer than 1,000 threads, and 3 forums that focus primarily on a single group of migrants

2 online forums

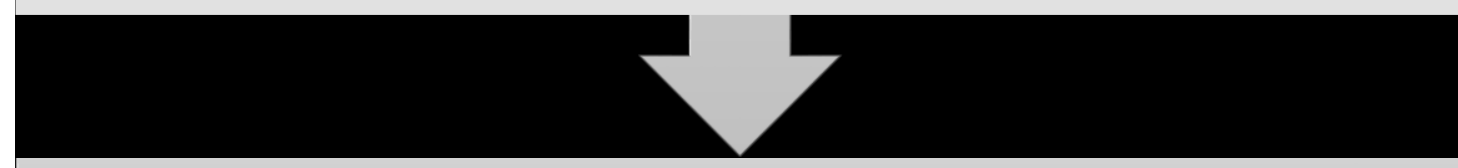

Identify relevant sub-forums

5 sub-forums

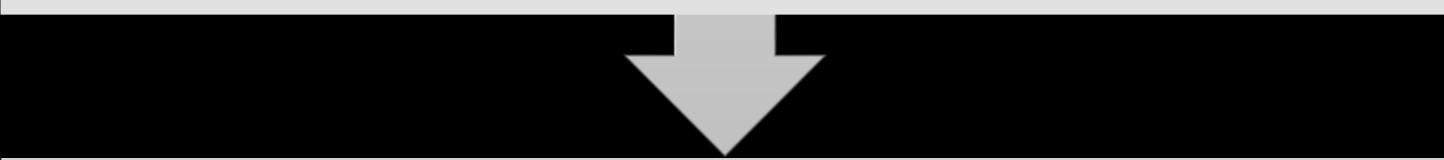

Collect all threads in the selected sub-forums

\section{3,360 threads}

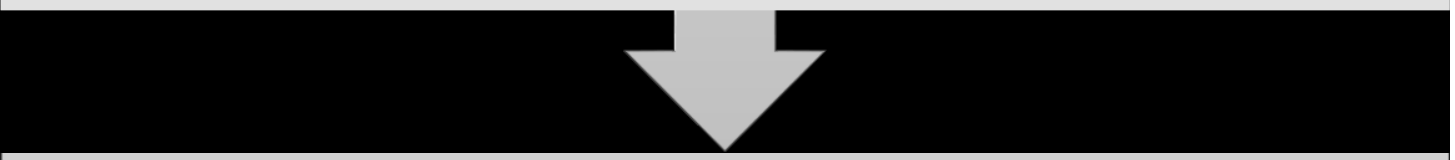

Identify recent treads

574 threads 


\subsection{Data Analysis Approach}

The following sub-sections describe the data analysis approach used in this study. In particular, they discuss the qualitative content analysis, process, units of analysis, as well as inductive and interpretive research philosophy.

\section{Qualitative content analysis}

From a methodological standpoint, this study examined the role of online discussion forums in newcomers' labour market integration using a qualitative content analysis.

Qualitative content analysis is a systematic research approach to make valid and replicable inferences from texts (e.g., print, multimedia, verbal, and pictures) with attention to the context in which the texts were used (Hsieh and Shannon, 2005; Krippendorff, 2012; Macnamara, 2005; Nandy and Sarvela, 1997; Webber, 1990). The inferences from text can be about the message itself, the viewers of the message, or the author of the message, and can vary based on the interest of the researcher (Webber, 1990).

Qualitative content analysis is a very popular research method for study of underresearched topics (Elo and Kyngäs, 2008; Hsieh and Shannon, 2005; Macnamara, 2005) and studies examining online forum data often use this method (e.g., Bourgonjon et al., 2016; Caidi et al., 2014; Marra et al., 2004; Rodriguez, 2014). The objective of content analysis is to increase our understanding and provide new knowledge about the phenomenon (Downe-Wamboldt, 1992). Qualitative content analysis is a research method that allows understanding of the meaning of a phenomenon through written communication 
materials (Cho and Lee, 2014). Qualitative content analysis also allows subjective interpretations of contextually rich text data using the systematic organization process of coding and grouping large amounts of data into a smaller number of categories that represent similar meanings and eventual themes (Corbin and Strauss, 2008; Elo, and Kyngäs, 2008; Gale et al., 2013; Hsieh and Shannon, 2005; Schreier, 2012). Considering the embryonic stage of extant research, the exploratory and descriptive focus of this study, and type of data being analyzed (i.e., contextually rich written communication materials from online forums), a qualitative content analysis is appropriate.

There are three distinct approaches to qualitative content analysis (i.e., conventional, directed, and summative) and the three approaches differ primarily with respect to origins of codes and coding schemes (Hsieh and Shannon, 2005). Conventional content analysis is typically used when existing research on a phenomenon is very limited. In this approach researchers derive coding categories directly from the data. Direct content analysis approach is usually used when prior research or existing theory about a phenomenon is incomplete. In the direct approach, researchers use existing relevant research and theory to identify initial coding schemes and categories. Summative content analysis usually starts with identification and quantification of certain content (i.e., keywords) in data to understand the context in which the content was used. This study used a conventional qualitative content analysis approach because of the limited extant research on a phenomenon (Hsieh and Shannon, 2005). Accordingly, the initial coding schemes and categories were derived directly from the data. 


\section{Qualitative content analysis process}

The qualitative content analysis process includes three main stages: "selecting the unit of analysis, creating categories, and establishing themes" (Cho and Lee, 2014:10). In qualitative content analysis, creating categories is a way to reduce a large number of items (e.g., initial posts) into a smaller number of categories (Cho and Lee, 2014; Thomas, 2006). The data with similar meanings and associations is grouped into mutually exhaustive and exclusive categories, and no data should be assigned into multiple categories or between categories (Cho and Lee, 2014; Weber, 1990). The qualitative content analysis process is summarized in Figure 6 below.

Figure 6. Summary of the qualitative content analysis process (based on Cho and Lee, 2014).

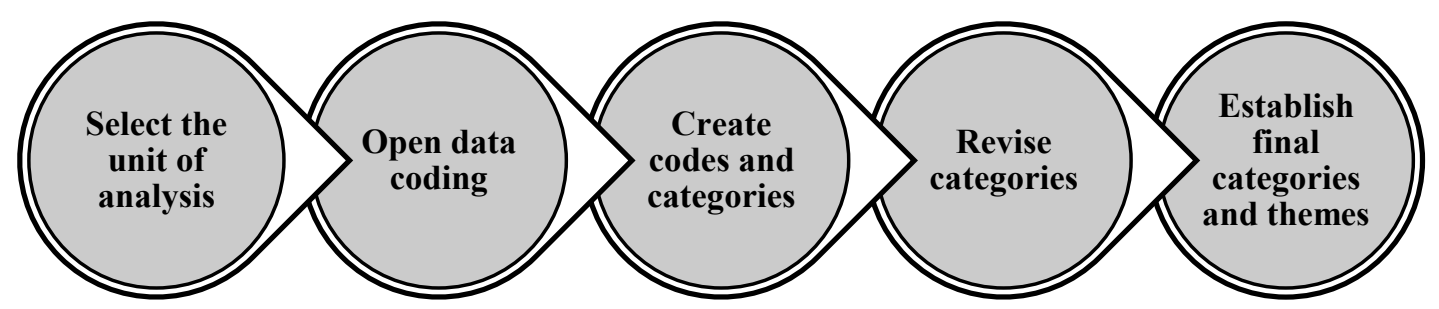

\section{Units of analysis and categories}

Depending on the research question, studies examine the data collected from online forums at the post level (e.g., Hwang et al., 2013) or thread level (e.g., Jansen and Saint Onge, 2015). Given this study investigates multiple research questions, the best way to understand them is by investigating them at different levels of analysis. For example, the data was examined at the post level to investigate research question \#1 (What needs are newcomers trying to meet with online discussion forums?), and at the thread level to investigate 
research questions \#2 (To what extent are these needs met in online discussion forums?) and \#3 (What are the characteristics of threads in which needs are not met?). Post level analysis and thread level analysis differ in that at the post level analysis only the initial posts are analyzed, whereas at the thread level analysis all conversations within threads are examined (e.g., to identify the overall outcomes of discussions).

As per the principles of conventional qualitative content analysis, the initial codes and categories are derived directly from the data, they are revised, grouped or divided, and new categories are added in the course of examination of the data (Cho and Lee, 2014; Hsieh and Shannon, 2005; Miles and Huberman, 1994; Miles et al., 2014). The final categories and themes emerge after multiple examinations of the data and revisions of coding and categories, and the data itself informs the final findings, interpretations and understanding of the phenomena (Bansal and Corley, 2012; Cho and Lee, 2014; Im and Chee, 2012; Miles and Huberman, 1994).

\section{Themes}

Themes are expressions of the underlying contents of the data and establishing a theme refers to a way to identify, describe, and connect the underlying meanings together (Cho and Lee, 2014; Graneheim and Lundman, 2004). In this study, qualitative content analysis was used to examine the selected threads and posts by reading, identifying, describing and coding various trends (e.g., types of information requested and provided). Then, the identified trends were examined further and similar items were grouped into relevant categories and eventual themes. The process involved coding the data in increasing degrees of integration, breadth, and understanding. 
In addition, in line with prior research (e.g., Chalkiti and Sigala, 2008; Nardon et al., 2015; Rodriguez, 2014), I used tables to organize and present the data (e.g., types of support, categories of topics) in order to identify trends in data that provided insights into the role of online discussion forums in newcomers' integration in Canadian labour market.

\section{Inductive and interpretive approach}

Given the limited extant research concerning newcomers' use of online discussion forums, this study is exploratory and it follows an inductive approach and interpretive research philosophy.

\section{Inductive approach}

The key difference between a deductive and inductive qualitative content analysis is in how initial codes and categories are developed (Cho and Lee, 2014; Elo and Kyngäs, 2008; Kondracki et al., 2002). In the deductive approach, initial codes, categories and even themes are developed from extant relevant theory or research, whereas in an inductive approach, initial codes and categories are developed directly from the data (Kondracki et al., 2002). The deductive approach is appropriate when the study aims to test the extant theory or existing data in a different context, whereas an inductive approach is more appropriate when extant knowledge about the phenomenon under study is limited (Cho and Lee, 2014). Given the limited extant research on the phenomenon under study, this study analyzed the data in accordance with principles of an inductive approach to qualitative content analysis, allowing initial analysis and findings to inform and focus subsequent iterations of data analysis (Cho and Lee, 2014). 


\section{Interpretive research philosophy}

From an ontological and epistemological standpoint, this study followed an interpretive research philosophy.

Positivism as a research philosophy views the researcher and reality as separate and suggests that there is only one distinguishable reality and the objective of positivist research is to predict and control. In contrast, interpretivism views the researcher and reality as inseparable and suggests that there are multiple realities that are dependent on individuals' interpretations (Lincoln et al., 2011; Meissner, 2016; Weber, 2004). A positivistic approach also suggests that objective knowledge about the phenomenon is obtainable and the results, relationships, and explanations should be general and independent of context, while an interpretive approach argues that the results are dependent on context and "the social world is constructed by people who carry out social actions and give meanings to them" (Johannesson and Perjons, 2014: 169). In other words, positivism argues that knowledge exists outside of the human mind, while interpretivism views knowledge as built through social constructions of the world (Weber, 2004).

Positivists consider the research to be reliable if results of the study can be replicated by other researchers, while interpretivists consider "that research is reliable if researchers can demonstrate interpretive awareness" (Weber, 2004: 9). That is, interpretive researchers acknowledge the subjectivity they introduce to the research process and take "steps to address the implications of their subjectivity" (Weber, 2004: 9). Therefore, in accordance with interpretive research, I tried to withhold any preconceptions when examining the phenomenon under study, remained open to alternative explanations of the phenomenon, 
focused on description before explanation, as well as regularly checked the rationality of alternative interpretations of the phenomenon (Sandberg, 2005; Weber, 2004).

In line with interpretive analysis (e.g., Nardon et al., 2015; Orlikowski and Gash, 1994; Shapiro et al., 2008), I assume that online discussion forum users act on their interpretations of their environments, specifically by posting in online forums by starting new discussions (new threads) and participating in discussions (replying within threads). I also assume that online users' interpretations are noticeable in their posts and that as a researcher I am able to identify and organize the data contained in online forum threads (both, initial posts and the resulting discussions), enabling me to figure out and establish final categories and themes in the data and the meaning of qualitative material (Cho and Lee, 2014; Gioia et al., 2013; Johannesson and Perjons, 2014). 


\section{Chapter 5. Data Analysis and Findings}

This study is a phenomenon-based research (Doh, 2017; Von Krogh et al., 2012) exploring the use of online discussion forums by immigrants. Research exploring newcomers' increasing use of online discussion forums related to labour market integration in the receiving country is limited and in an embryonic stage (Von Krogh et al., 2012). Following the research strategies for study of a phenomenon in an embryonic stage (Von Krogh et al., 2012), the analysis and findings primarily focus on description and exploration of the phenomenon.

This chapter is divided into four main sections, one section for each of the following four research questions:

1. What needs are newcomers trying to meet with online discussion forums?

2. To what extent are these needs met in online discussion forums?

3. What are the characteristics of threads in which needs are not met?

4. What role do online discussion forums play in facilitating and/or hindering newcomers' labour market integration?

In the first three sections, I examine, analyze, and organize the data using qualitative content analysis (Cho and Lee, 2014; Hsieh and Shannon, 2005) supported by Dedoose, a qualitative analysis software. In the fourth section, I draw on the results of the analysis of the first three research questions as well as relevant extant literature to elaborate on the role of discussion forums in newcomers' labour market integration. 
For ease of reading, in each of the sections, I summarize analysis and findings first and provide details of the analysis subsequently.

\subsection{Research Question 1: What needs are newcomers trying to meet with online discussion forums?}

To answer research question 1 , the data was systematically examined at the post level using the conventional inductive qualitative content analysis approach (Cho and Lee, 2014; Hsieh and Shannon, 2005). Following the conventional approach to qualitative content analysis, the initial coding and categories emerged from the data and final codes and categories were achieved through multiple iterations between the data and literature.

First, I categorized the initial posts into requesting and providing support, and types of support. Next, I coded initial posts for time of writing (e.g., pre-arrival and post-arrival). Subsequently, I categorized the posts by topics. Finally, I focused on the specific type of support "advice" to further understand the types and forms of advice support exchanged. The main steps taken to examine research question 1 are summarized in Figure 7 below. 
Figure 7. Main steps in the analysis of research question 1.

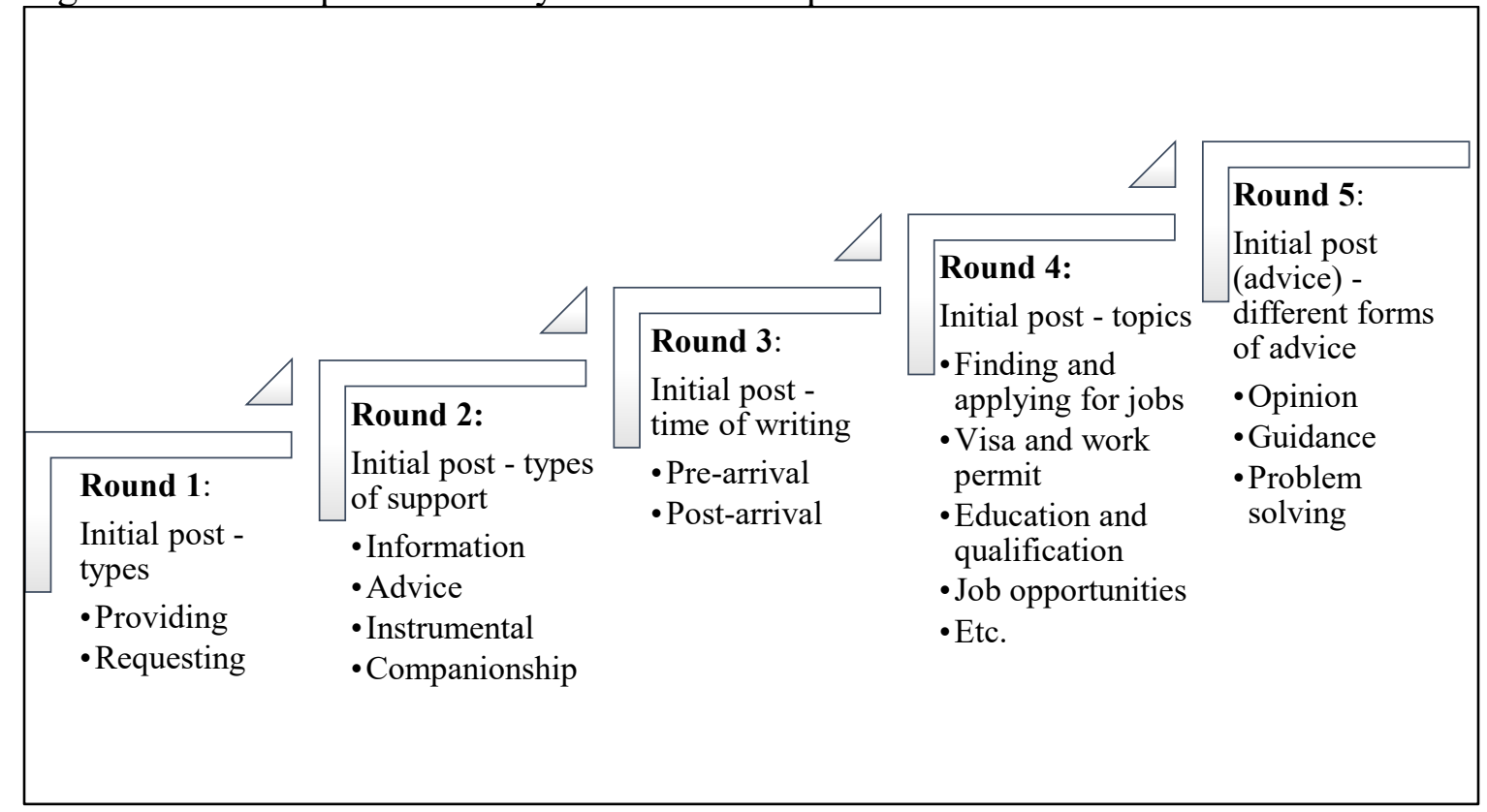

In the following sections below, I provide a summary of analysis and findings for research question 1 first then I discuss the analysis steps in detail.

\section{Summary of analysis and findings for research question 1}

What needs are newcomers trying to meet with online discussion forums?

Analysis of the initial posts revealed that online discussion forum members were primarily requesting $(93 \%)$ rather than providing $(7 \%)$ social support. In the examined sample of 574 threads, 533 initial posts requested support and only 41 provided support.

The analysis of the 533 requesting posts shows that newcomers were mainly trying to meet their information (383 initial posts, $72 \%$ ) and advice (144 initial posts, $27 \%$ ) social support needs with online discussion forums. In the examined data, there were only 5 initial posts requesting instrumental support, and 1 initial post requesting companionship support. 
In addition, the examination of initial posts authors' migration stage revealed that about $70 \%$ of initial posts authors were in the pre-arrival stage, and $30 \%$ were in the post-arrival migration stage. I was able to determine the migration stage for all, but three requesting initial posts.

Further examination and categorization of initial posts requesting advice support into categories of opinion, guidance and problem-solving advice revealed that newcomers were primarily trying to get opinion and guidance advice. Initial posts requesting problem solving advice account for less than $10 \%$ of all advice needs and less than $3 \%$ of the total requesting initial posts.

Figure 8 below summarizes the examination of requesting initial posts. Figure shows only 524 requesting initial posts as 9 initial posts have been excluded from the analysis (i.e., 5 initial posts requesting instrumental support, 1 initial post requesting companionship support, and 3 initial posts requesting information support for which it was not possible to determine the author migration stage at posting). 
Figure 8. Summary of the examination of requesting initial posts.

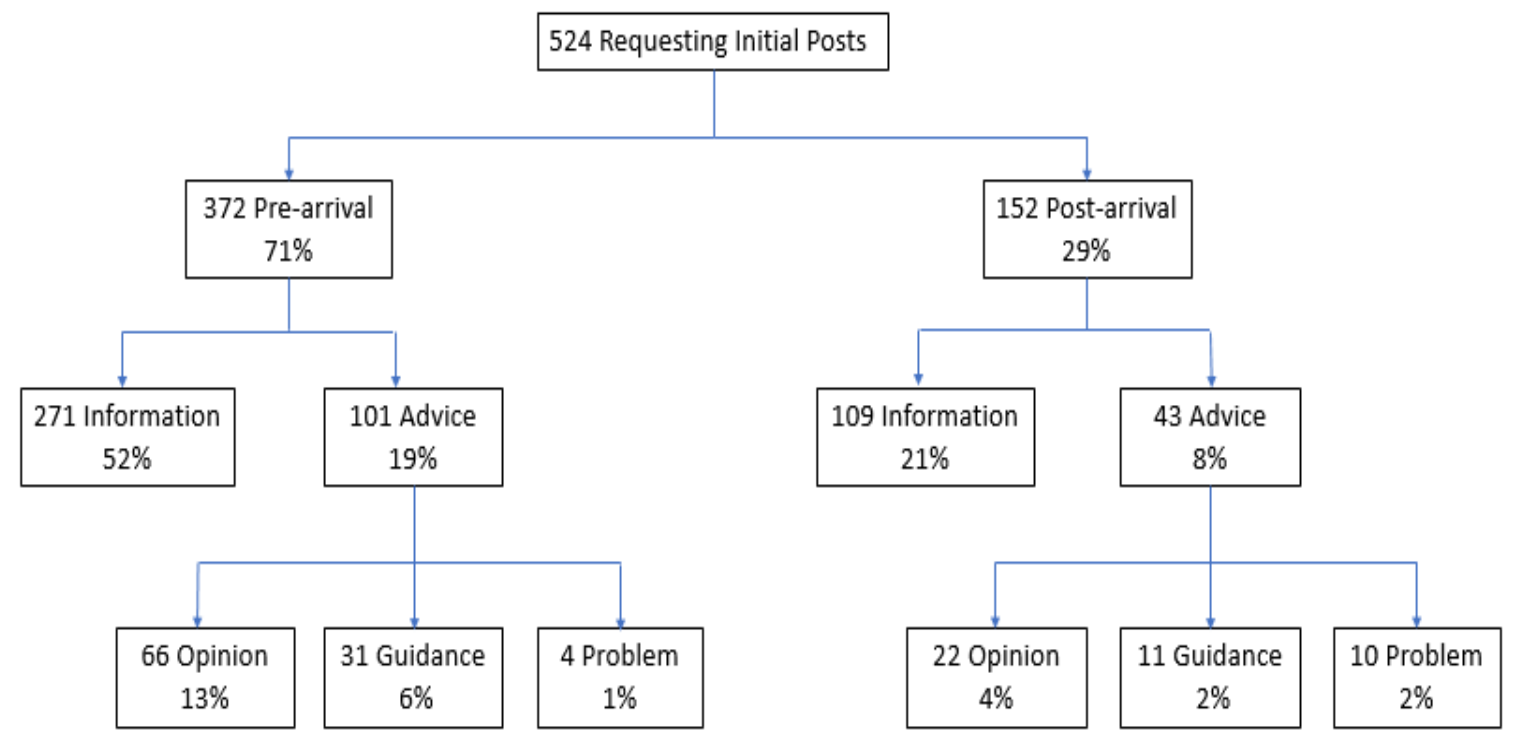

Analysis revealed that information was the most frequent support need that newcomers were trying to meet with online discussion forums. Out of the three advice forms, opinion was the most frequent advice support need. Together, information support and advice support represent about $97 \%$ of all the support needs requested in the examined online discussion forum data.

Overall, the top three categories of topics that newcomers were trying to meet with online forums were about finding and applying for jobs, job opportunities, and visa and work permit. Together these account for about $61 \%$ of all the needs requested in the initial posts. Moreover, two categories of topics (i.e., others' experiences and starting groups) were only presents in the initial posts requesting information support. That is, there were no initial posts requesting advice support about others' experiences and starting groups in the examined data. 
The number of initial posts in different categories of needs that newcomers are trying to meet with online discussion forums vary for information support and advice support, as well as for pre-arrivals and post-arrivals. For example, the top two most frequently requested categories of information support are about job opportunities and visa and work permit; together they account for almost $46 \%$ of all the information support needs. The most frequently requested category of advice support is about finding and applying for jobs, it accounts for about $41 \%$ of all the advice support needs requested in the examined online discussion forum data.

Figure 9 below summarizes the ten categories of topics requested in the 380 information initial posts and Figure 10 below shows the eight categories of topics requested in the 144 advice initial posts. In both figures, the initial posts are also separated into pre-arrival and post-arrival to illustrate main categories of topics in pre-arrival and post-arrival initial posts.

Figure 9. Ten categories of topics in initial posts requesting information.

Topics in initial posts requesting information

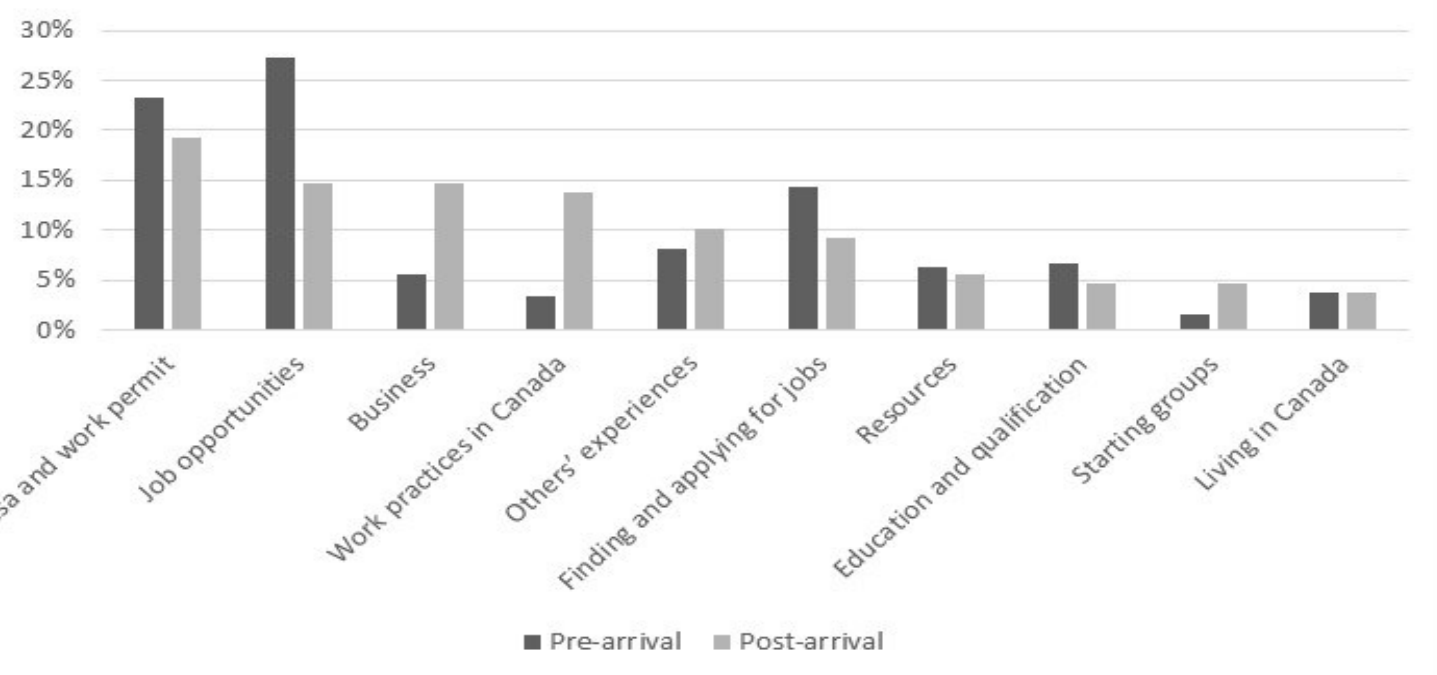


In the examined online discussion forums, pre-arrival newcomers were mainly trying to meet their information needs about job opportunities, visa and work permit, and finding and applying for jobs, whereas post-arrival newcomers were mainly trying to meet their information needs about visa and work permit, job opportunities, and business.

Figure 10. Eight categories of topics in initial posts requesting advice.

\section{Topics in initial posts requesting advice}

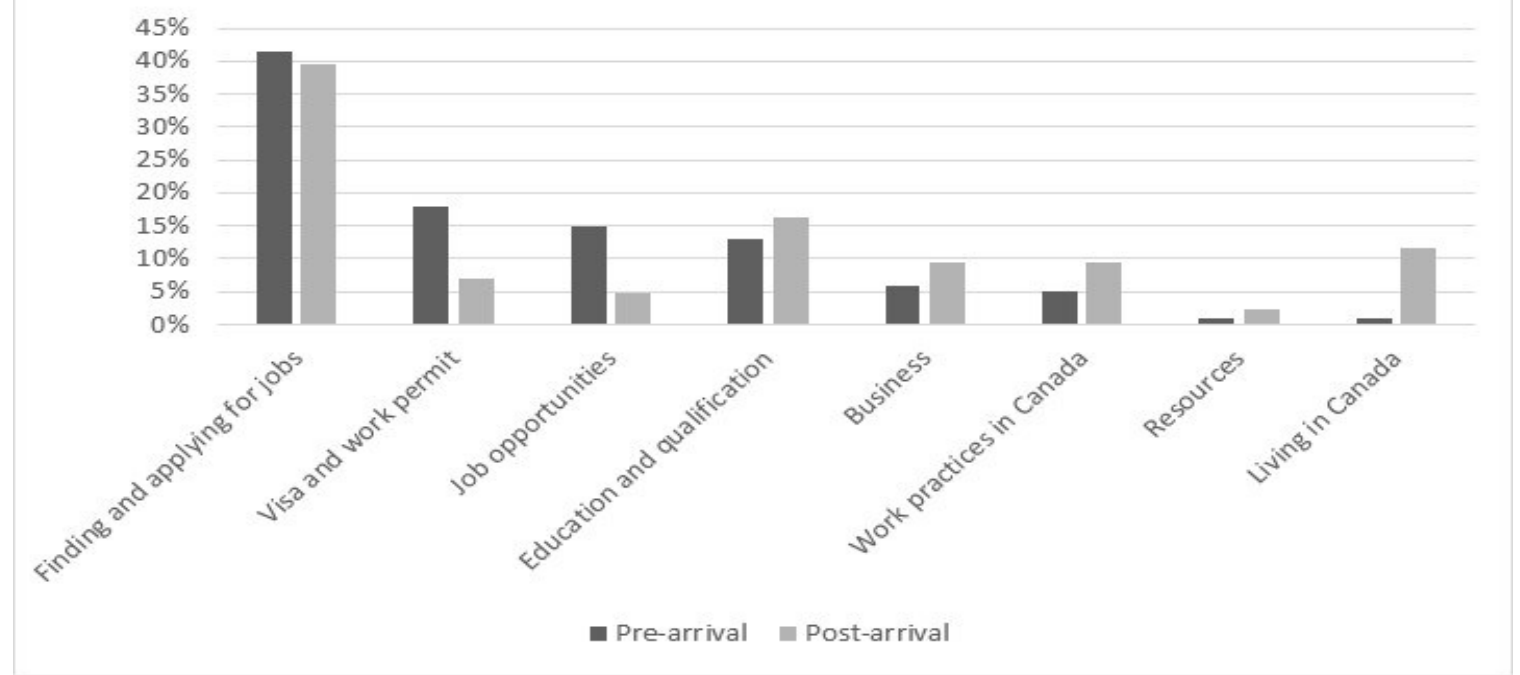

The analysis showed that pre-arrival newcomers were mainly trying to meet their advice needs about finding and applying for jobs, visa and work permit, and job opportunities, while post-arrival newcomers were mainly trying to meet their advice needs about finding and applying for jobs, education and qualifications, and living in Canada.

Question \#1: What needs are newcomers trying to meet with online discussion forums?

To sum up, in the context of labour market integration in Canada, newcomers were mainly trying to meet their information, opinion, guidance, and problem-solving support needs about topics such as finding and applying for jobs, job opportunities, and visa and work permit with online discussion forums. 
Further, about $70 \%$ of online discussion forum participants were in the pre-arrival migration stage. Pre-arrival individuals have limited or no prior knowledge and experience about the new country's labour market, suggesting that newcomers use online discussion forums as a means of preparation to migration. With online discussion forums, pre-arrival newcomers were trying to meet their social support resources needs to get more knowledgeable and ready for labour market integration in the new country's labour market prior to migration. Better preparation can help newcomers form more accurate expectations and adjust better in the new country's environment. Preparation, expectations and adjustment are discussed in more details in research question four and the discussion chapter.

\section{Details of analysis for research question 1}

At an initial stage, I examined all of the 574 initial posts to identify newcomers' various information needs concerning labour market integration in Canada. I coded and grouped initial posts focusing on topics (Charmaz, 2014; Nardon et al., 2015). Examples of the topics include: seeking information about job application, seeking information about work permit, asking questions about accreditation process, asking questions about work opportunities, seeking information about resources. However, in the process of examination and coding of the data, I realized that newcomers' initial posts are not only about information needs. For example, in online discussion forums newcomers seek not only factual information about various aspect concerning work, but also advice (e.g., opinions, guidance), instrumental help (e.g., samples of CVs and offer letters), and connection with others (e.g., seek friends). The examination of data and relevant literature 
on computer mediated communications (e.g., High and Solomon, 2011; Rains, 2016; Rains et al., 2015, 2016; Rains and Wright, 2016) suggest that newcomers are trying to meet their social support needs with online discussion forums.

Prior research has shown that social support is critical for newcomers' adjustment and wellbeing (Boese, 2015; Farh et al., 2010; Podsiadlowski et al., 2013; Van Bakel et al., 2017). Newcomers need social support to fully integrate, adjust and function in the receiving country and they find it online (Nardon et al., 2015; Rains and Wright, 2016). In this study, I used the social support framework to examine the online discussion forum data concerning newcomers' labour market integration.

In the following sub-section below, I describe and discuss the analysis process in detail. I also provide examples and organize the data with tables.

\section{Providing and requesting social support}

In the examined online discussion forum data, there are initial posts requesting support (533 posts, $93 \%$ ) and initial posts providing support (41 posts, $7 \%$ ). The prevalence of support requests is consistent with extant research on online health and education forum communities suggesting that most users seek rather than contribute resources (e.g., information, emotions) in online discussion forums (Kim and Sundar, 2016; Mo and Coulson, 2010).

Considering that newcomers' needs are about social support, I used a social support perspective to re-examine, code and categorize the initial posts. Through successive 
iterations and organizations of the forum data, I identified four types of social support being requested and/or provided in the initial posts: information support, advice support, instrumental support, and companionship support. Table 10 below summarizes the number of initial posts in each of the four identified types of social support requested and provided in the initial posts.

Table 10. Types of social support requested and provided in the initial posts.

\begin{tabular}{|l|l|l|l|l|l|l|l|l|l|l|}
\hline $\begin{array}{l}\text { Types of initial } \\
\text { post }\end{array}$ & \multirow{2}{*}{$*$} & $\mathbf{6}$ & \multicolumn{6}{|c|}{ Types of support requested / provided } \\
\cline { 4 - 11 } & & & Information & \multicolumn{2}{|c|}{ Advice } & \multicolumn{2}{|c|}{ Instrumental } & \multicolumn{2}{|c|}{ Companion } \\
\hline Requesting & 533 & $93 \%$ & 383 & $72 \%$ & 144 & $27 \%$ & 5 & $0.9 \%$ & 1 & $0.2 \%$ \\
\hline Providing & 41 & $7 \%$ & 31 & $76 \%$ & 5 & $12 \%$ & 5 & $12 \%$ & 0 & $0 \%$ \\
\hline Total / Average & $\mathbf{5 7 4}$ & $\mathbf{1 0 0} \%$ & $\mathbf{4 1 4}$ & $72.1 \%$ & $\mathbf{1 4 9}$ & $26 \%$ & $\mathbf{1 0}$ & $1.7 \%$ & $\mathbf{1}$ & $0.2 \%$ \\
\hline
\end{tabular}

Among the 533 requesting posts, 383 request information, 144 request advice, and 5 request instrumental support. In addition, there is only one initial post requesting companionship support. In comparison, among the 41 providing posts, 31 provide information, 5 provide advice, and 5 provide instrumental support.

In the examined data, no initial posts requested or provided emotional support. This suggests that in the context of labour market integration, newcomers are trying to meet their needs for information and advice support, rather than companionship and emotional support with online discussion forums. This is consistent with the research on offline social support (e.g., Podsiadlowski et al., 2013; Van Bakel et al., 2017) suggesting that different types of social support have different function (Podsiadlowski et al., 2013; Van Bakel et al., 2017). For example, information and instrumental support can help newcomers manage 
stresses by helping resolve instrumental problems (Cohen and Wills, 1985; Van Bakel et al., 2017). On the other hand, emotional support and companionship support can help with the basic needs of acceptance and belonging, and decrease feelings of loneliness, by enhancing self-esteem (Podsiadlowski et al., 2013; Van Bakel et al., 2017). Moreover, emotional support and companionship support are best suited to cope with uncontrollable problems (e.g., acculturation stress), while information support and tangible support are more helpful to cope with more controllable problems (e.g., searching for a new job) (Podsiadlowski et al., (2013). Therefore, the analysis and extant research on social support suggest that when dealing with controllable problems, such as labour market integration, newcomers are trying to mainly meet their information and advice support needs with online discussion forums. This is further discussed in research question four.

\section{Advice support}

Although scholars typically view both advice and information as informational support (Cohen and Wills, 1985; van Bakel et al., 2017), I argue that advice and information are two different types of support needs and that advice social support should be recognized as a new and distinct type of social support. This is because information support is more objective and factual, while advice support is more subjective and based on an individual's own perceptions, opinions, interpretations or experiences (Johnson and Johnson, 2017; MacGeorge et al., 2016; Mahajan and Toh, 2014; Rader et al., 2017; Russell et al., 2017). Consequently, the initial posts requesting information differ from the initial posts requesting advice. For example, when newcomers request information support about job opportunities in Canada they typically seek factual information about current job market 
and employment opportunities in a particular province or for a specific profession. However, when they request advice support about job opportunities, they typically request opinions about the best locations in Canada for a particular profession, or whether to seek work opportunities in Canada or in other countries. Similarly, when they request information support about visa and work permit they request factual information about the application process, application eligibility, and processing time. However, when they seek advice support about visa and work permit they typically request opinions about the best way to apply for a visa or work permit, or guidance about the application process.

\section{Forms of advice support}

In further examination of the initial posts requesting advice, I identified three different forms of advice (i.e., opinion, guidance, and problem-solving advice), which are defined and discussed below.

Definitions: Information is an objective non-opinion based fact or detail about something; opinion is an advice based on an individual's belief, view or judgment about something (i.e., it does not have to be based on facts of knowledge); guidance is an advice about process or direction aimed at resolving a difficulty with something; and, problem solving is an advice aimed at proving or finding a solution to a problem (Dictionary, 2017; Merriam-Webster Dictionary, 2017).

Initial posts requesting opinion advice typically request others' viewpoints or judgments about specific options, possibilities, or choices. Three examples below illustrate the typical initial posts requesting opinion advice in the examined data. 


\section{Example 1.}

"Has anyone taken the CSC course to get in the banking field in Canada? I heard it is very helpful to inquire information on the Canadian market for those who are in the financial field. I am in corporate banking as a relationships manager over 10 years' experience. Will this course help? Or is it a waste of time and money?" (CV21_21) ${ }^{3}$

\section{Example 2.}

"My brother is an actuary currently living in the UAE, and he's trying to decide which is a better place for his profession - Australia or Canada? Can someone please share their input regarding this if possible?" (CV21_11)

\section{Example 3.}

"How are the opportunities for Science (Physics and Chemistry) teachers in Canada. Which province will be the best suit for me." (CV21_220)

Initial posts requesting guidance advice typically request advice and directions about a process, such as advice on how to start applying for jobs or a visa. Authors of initial posts requesting guidance advice generally do not know how and/or where to begin the process.

\footnotetext{
${ }^{3}$ In this dissertation, I am referencing the initial posts and replies from online discussion forums using my archival codes. CV means Canada Visa and the first number indicates the sub-forum and the second number indicates the thread discussion. Likewise, RC indicates Road to Canada sub-forum. For example, (CV21_11) means $11^{\text {th }}$ thread from the Canada Visa's Finding Work in Canada sub-forum. The corresponding sub-forums are shown in Table 8.
} 
The following three examples below illustrate the typical initial posts requesting guidance advice in the examined data.

\section{Example 1.}

"I have a friend who is currently enrolled in courses at a local college in the field of child disabilities. She is working part time as a cashier to help pay for expenses. She would like to work at the hospital where I work, but she tells me that her visa is restricted and she cannot work with children or in health care. I can probably get her a job as a housekeeper or a porter, but she needs to have the restrictions lifted. What should she do to get this done???"(CV21_190)

\section{Example 2.}

"Received an offer letter in May 2014 from a reputed IT Company in Canada with joining date as Jan 2015 (for Canada location). They processed my VISA and I have received VISA in my hands. But they are continuously delaying my joining till date saying that currently they are not having work/requirement from their clients. Please suggest on how I should now proceed in this situation" (CV23_23)

\section{Example 3.}

"Hi, A school classmate of mine is in Canada and is planning to start a business by investing 1,000,000 CAD in his venture. He is interested in hiring me. Can you please advise on the procedure through which he can make me a job offer?" (CV21_205) 
Authors of initial posts requesting problem solving advice typically request advice on how to solve a particular problem they are unable to resolve. Three examples requesting a problem specific advice are included below.

\section{Example 1.}

"I've been searching for a job in the last three months, mainly in Montreal, Ottawa and Toronto, but to no avail. I'm growing more desperate now. I have a degree in Computer Engineering and advanced degrees in Electrical Engineering, but I cannot find a job neither in the industry nor in the academia. They all need 5+ years of experience on average, and I have none, which makes it even harder. Any advice?” (CV21_96)

\section{Example 2.}

"I've been in Canada since January 23. I'm an Environmental Engineer that's got 4-years work experience with a global firm in both the UK and UAE. I'm currently in Ontario and I'm struggling to find any work. It's been a real headache. I would really appreciate if anyone has any sort of advice for me?" (CV21_193)

\section{Example 3.}

"I am new immigrant in Canada, I am looking for good jobs since last few months but no luck yet? what do you think, what should be done to secure good job? any tips?" (CV21_20) 
Therefore, given that the advice support differs from information support, in this study, advice support and information support are viewed as two distinct types of support.

In the following four sub-sections, I analyze and discuss (1) types of support, (2) pre-arrival and post-arrival initial posts, (3) categories of topics, and (4) three forms of advice.

\section{Types of support}

Tables 11 below summarizes the three types of support provided in the initial posts and Table 12 summarizes the four types of support requested in the initial posts. The tables also include examples for each of the support types to illustrate the differences among different types of support. ${ }^{4}$ For more examples, please see Appendix B and Appendix C.

${ }^{4}$ Some of the spelling mistakes in the examples were corrected to improve readability. 
Table 11. Types of support provided in the 41 providing initial posts.

\begin{tabular}{|c|c|}
\hline $\begin{array}{l}\text { Type of } \\
\text { support } \\
\text { provided }\end{array}$ & Examples \\
\hline $\begin{array}{l}\text { Information } \\
31 \text { posts } \\
76 \%\end{array}$ & $\begin{array}{l}\text { "I just heard an interview on the news radio about Shopify setting up } \\
\text { a cell phone charging station and recruiting booth in Confederation } \\
\text { Park in Ottawa tomorrow. Apparently, there are multiple "poke-stops" } \\
\text { in the park, so they are hoping to capitalize on the number of tech } \\
\text { savvy/passionate people in the area and engage people in } \\
\text { conversations about employment. Note, Shopify is difficult to get into } \\
\text { and they use various out of the box strategies for recruiting. this one } \\
\text { seems pretty brilliant and I hope results in some good hires!!! They } \\
\text { didn't provide times, so perhaps the information is available on their } \\
\text { website or somewhere else on Google." (CV21_195) }\end{array}$ \\
\hline $\begin{array}{l}\text { Advice } \\
5 \text { posts } \\
12 \%\end{array}$ & $\begin{array}{l}\text { "Having been through hell and having spoken to many others sailing } \\
\text { in the same boat, here's a word of sincere advice for Newcomers } \\
\text { applying for registration as a Professional Engineer to the } \\
\text { Professional Engineers Association of Ontario (PEO). Here goes: } \\
\text { Before you decide to apply to PEO, STOP and research the } \\
\text { Registration Process for P. Eng. designation in all the other provinces } \\
\text { of Canada to enable you to make a decision as to which province has } \\
\text { a process that suits you. It is immaterial as to which Province you live, } \\
\text { in. You can apply for registration to any provincial association..." } \\
\text { (CV21_9) }\end{array}$ \\
\hline $\begin{array}{l}\text { Instrumental } \\
5 \text { posts } \\
12 \%\end{array}$ & $\begin{array}{l}\text { "Hi, just wanted to know if anyone moving into Canada on PR, in the } \\
\text { next few months between August - November and would be in the IT } \\
\text { industry, please don't hesitate to contact me on this post. Please leave } \\
\text { your email ID and what kind of skill set you have and years of } \\
\text { experience. I can see if I can help you out." (CV21_52) }\end{array}$ \\
\hline
\end{tabular}

Analysis shows that the most common type of support provided in the examined sample of initial posts is information support ( $76 \%)$. In addition, the initial posts providing advice and instrumental support constitute about $24 \%$ of the total number of providing posts. 
Table 12. Types of support needs requested in the 533 requesting initial posts.

\begin{tabular}{|c|c|}
\hline $\begin{array}{l}\text { Types of } \\
\text { support } \\
\text { requested }\end{array}$ & Examples \\
\hline $\begin{array}{l}\text { Information } \\
383 \text { posts } \\
71.9 \%\end{array}$ & $\begin{array}{l}\text { "Hi, I have a question, for the Egyptian bachelor degree of } \\
\text { Mechanical Engineer (From Alexandria University, Egypt). Do they } \\
\text { need a license to work as an engineer in Ontario?? If yes, can anyone } \\
\text { tell me where I can find more information about that?? and, can they } \\
\text { work as engineer assistance till they got the license?? appreciate } \\
\text { your help" (CV21_145) }\end{array}$ \\
\hline $\begin{array}{l}\text { Advice } \\
144 \text { posts } \\
27 \%\end{array}$ & $\begin{array}{l}\text { "I am 31, Mechanical Engineer living and working in Japan. My } \\
\text { work experience is so-so in terms of competency and skills. I have } \\
\text { PR and I am planning out strategies that would help me settle down } \\
\text { in Canada. Can you advise of some short-term courses ranging from } \\
3 \text { months to a year which could help me land me a Job in Canada?" } \\
\text { (CV21_19) }\end{array}$ \\
\hline $\begin{array}{l}\text { Instrumental } \\
5 \text { posts } \\
0.9 \%\end{array}$ & $\begin{array}{l}\text { "Could anyone please share a C++ Software Engineer } \\
\text { chronological resume after removing your personal details." } \\
(\mathrm{CV} 21 \text { 121) }\end{array}$ \\
\hline $\begin{array}{l}\text { Companionship } \\
1 \text { post } \\
0.2 \%\end{array}$ & $\begin{array}{l}\text { "hi to all forum participants. dear friends, I found this forum } \\
\text { amazing for friendship. I am looking for friends. I would share my } \\
\text { bio with friends, no problem. please answer." (CV21_132) }\end{array}$ \\
\hline
\end{tabular}

Analysis showed that information support is also the most common type of support requested in the initial posts, about $72 \%$, followed by advice support at about $27 \%$. Instrumental and companionship support constitute only about $1 \%$ of the total number of initial posts requesting support. 


\section{Pre-arrival versus Post-arrival}

Next, I examined and coded the data again to identify the immigration stages (e.g., prearrival, post-arrival) of the initial post authors at the time of writing their posts to see if newcomers' needs vary in pre-arrival and post-arrival initial posts.

In pre-arrival posts, authors generally indicate that they are not in Canada now or that they are planning to come to Canada in the future. For example:

"I'll be moving to Canada early 2017..." (CV21_110)

"I will be immigrating to Canada very soon as a permanent resident..." (CV21_183)

In post-arrival posts, authors indicate that they are already in Canada. For example:

"I landed in Canada and currently in NS and looking for job opportunities..." (CV21_148)

"I've been in Canada since January 23..." (CV21_193)

In unknown posts, authors do not provide sufficient information in their initial posts to determine their immigration stage at the time of writing. For example:

"what are the most requested skilled trades and labour jobs vs college, university jobs with decent incomes" (CV21_35)

In the examined 574 initial posts, 51 initial posts were coded as 'unknown' as they did not include explicit information about their authors' immigration stage. To identify the immigration stage for the authors of the 'unknown' initial posts, I examined the authors' other posts and replies in the collected data. This reduced the number of 'unknown' initial 
posts to only 3 . Since there are only 3 'unknown' initial posts, they were removed from further analysis. The 3 'unknown' initial posts are all requesting information support. Thus, the total number of initial posts requesting information support was reduced from 383 to 380 in the subsequent analysis.

Analysis shows that all 41 providing initial posts are post-arrival. In addition, in the 530 requesting initial post about $70 \%$ are pre-arrival and $30 \%$ are post-arrival.

\section{Categories of topics}

Next, I categorized the requests and provision of support by topic, such as finding jobs, applying for jobs, education, qualification, visa, work permit. In an initial coding I identified 24 categories, which were grouped into final 10 categories. The initial 24 categories of topics are listed in Appendix D and the final 10 categories of topics are listed in Table 13 and described below.

Table 13. Ten final categories of topics identified in initial posts.

\begin{tabular}{|r|l|}
\hline Number & Final ten categories of topics \\
\hline 1 & Business \\
\hline 2 & Education and qualification \\
\hline 3 & Finding and applying for jobs \\
\hline 4 & Job opportunities \\
\hline 5 & Living in Canada \\
\hline 6 & Others' experiences \\
\hline 7 & Resources \\
\hline 8 & Starting groups \\
\hline 9 & Visa and work permit \\
\hline 10 & Work practices in Canada \\
\hline
\end{tabular}


Each of the ten categories of topics listed in the Table 13 represents a distinct category of needs identified in the examined initial posts. For example, I grouped initial posts requesting support about finding jobs and applying for jobs into the finding and applying for jobs category. Similarly, I grouped initial posts requesting support about visa application process, visa types, visa requirements, and work permit eligibility into the visa and work permit category. In the same way, I grouped the initial posts requesting support about business opportunities in Canada, starting a new business process and business registration into the business category.

\section{Topics in the providing initial posts}

Among the 41 initial posts providing support, 31 provide information support about job opportunities (18), resources (8), and business (2), and share personal experiences (3). In addition, 5 initial posts provide advice support by sharing personal experiences, and 5 posts provide instrumental support by offering help with finding work and applying for jobs in Canada.

Considering that the focus of the research question 1 is on the needs that newcomers are trying to meet with online discussion forums, further analysis focuses primarily on the requesting initial posts.

\section{Topics in the requesting initial posts}

Among the requesting initial posts, there are only 6 initial posts requesting instrumental or companionship support. Before eliminating them from further analysis, I examined them in more detail below. 


\section{Instrumental support}

There are only 5 initial posts requesting instrumental support. These posts request samples of work experience letters and/or samples of resumes. Two of the 5 threads received no reply while the remaining three received information support rather than instrumental support. As the example below illustrates, the initial post (CV21_121) requests instrumental support, but it receives information support only.

Initial post (CV21_121)

"Could anyone please share a C++ Software Engineer chronological resume after removing your personal details."

Reply

"try a google image search"

The examined online forums do not allow users to post and exchange documents and other file attachments within the online forum. Considering the above and that there are very few initial posts providing and requesting instrumental support, one could argue that online discussion forums are not the preferred information and communications technology (ICT) for exchanging instrumental support in the context of newcomers' labour market integration.

\section{Companionship support}

Only one initial post requesting companionship support has been identified in the sample. In this initial post, the author is looking for friends. 
Initial post (CV21_132)

"I found this forum amazing for friendship. I am looking for friends. I would share my bio with friends, no problem."

Although this thread includes several replies, the replies inform the initial post author about alternative ICT platforms that are more suitable for the companionship support. A few examples of replies within this thread are included below.

Reply example 1 .

"If you want friends, connect over phone, or any social network..."

Reply example 2.

"This is a forum for immigration questions to Canada. If you are looking for friends, check out Tinder, Facebook or other relative media."

Reply example 3.

"If you have landed in Canada, join meetup.com I landed last week and already made friends... a lot of friends and activities. "

Considering that there is only one initial post requesting companionship support, one can argue that online discussion forums are also not a preferred source of companionship support in the context of labour market integration of newcomers in Canada.

Since there are only 5 initial posts requesting instrumental support and 1 post requesting companionship support, they were excluded from further analysis as well. 


\section{Information and advice support}

I identified all 10 categories of topics in the 380 initial posts requesting information support. However, I identified only 8 out of the 10 categories of topics in the 144 initial posts requesting advice support. Two categories of topics (i.e., other experiences and starting groups) are present only in the initial posts requesting information support. Table 14 below summarizes the number of initial posts requesting information and advice support for each of the 10 categories of topics as well as the number of pre-arrival and post-arrival initial posts in each of the categories.

Table 14. Topics requested in the 380 information and 144 advice initial posts (real figures).

\begin{tabular}{|l|l|l|l|l|l|l|l|}
\hline \multicolumn{2}{|c|}{ Topics requested in initial posts } & \multicolumn{3}{c|}{ Information } & \multicolumn{3}{c|}{ Advice } \\
\hline & $\#$ & Total & $\begin{array}{c}\text { Pre- } \\
\text { arrival }\end{array}$ & $\begin{array}{c}\text { Post- } \\
\text { arrival }\end{array}$ & Total & $\begin{array}{c}\text { Pre- } \\
\text { arrival }\end{array}$ & $\begin{array}{c}\text { Post- } \\
\text { arrival }\end{array}$ \\
\hline Finding and applying for jobs & $\mathbf{1 0 8}$ & 49 & 39 & 10 & $\mathbf{5 9}$ & $\mathbf{4 2}$ & $\mathbf{1 7}$ \\
\hline Job opportunities & $\mathbf{1 0 7}$ & $\mathbf{9 0}$ & $\mathbf{7 4}$ & 16 & 17 & 15 & 2 \\
\hline Visa and work permit & $\mathbf{1 0 5}$ & $\mathbf{8 4}$ & 63 & $\mathbf{2 1}$ & 21 & 18 & 3 \\
\hline Education and qualification & 43 & 23 & 18 & 5 & 20 & 13 & 7 \\
\hline Business & 41 & 31 & 15 & 16 & 10 & 6 & 4 \\
\hline Others' experiences & 33 & 33 & 22 & 11 & - & - & - \\
\hline Work practices in Canada & 33 & 24 & 9 & 15 & 9 & 5 & 4 \\
\hline Resources & 25 & 23 & 17 & 6 & 2 & 1 & 1 \\
\hline Living in Canada & 20 & 14 & 10 & 4 & 6 & 1 & 5 \\
\hline Starting groups & 9 & 9 & 4 & 5 & - & - & - \\
\hline Total & $\mathbf{5 2 4}$ & $\mathbf{3 8 0}$ & $\mathbf{2 7 1}$ & $\mathbf{1 0 9}$ & $\mathbf{1 4 4}$ & $\mathbf{1 0 1}$ & $\mathbf{4 3}$ \\
\hline
\end{tabular}

Table 14 above shows that job opportunities and visa and work permit are the two most frequently requested categories of information support (almost $46 \%$ of the initial posts requesting information support) and finding and applying for jobs is the most frequently requested category of advice support (about $41 \%$ of the initial posts requesting advice support). 
Overall, the top three categories of topics requested in online discussion forums are about finding and applying for jobs, job opportunities, and visa and work permit. These top three topics account for about $61 \%$ of the needs that newcomers are trying to meet with online discussion forums. In contrast, the three least frequently requested categories of needs that newcomers are trying to meet with online forums include starting groups, living in Canada, and resources. Together, they account for only about $10 \%$ of the requested needs in online forums.

Moreover, the most frequent information support needs that newcomers are trying to meet with online discussion forums in the pre-arrival stage are information about job opportunities in Canada and visa and work permit. Information about visa and work permit is also the most frequent information need that newcomers are trying to meet post-arrival.

The most frequent advice support need that newcomers are trying to meet in the pre-arrival and post-arrival immigration stage is advice about finding and applying for jobs.

Next, in Table 15 below I converted the pre-arrival and post-arrival figures from Table 14 into percentages to see if there are any other interesting trends in the data. 
Table 15. Topics requested in the 380 information and 144 advice initial posts (percentages).

\begin{tabular}{|l|l|l|l|l|l|l|l|}
\hline \multicolumn{2}{|c|}{ Topics requested in initial posts } & \multicolumn{3}{|c|}{ Information } & \multicolumn{3}{c|}{ Advice } \\
\hline & $\#$ & Total & $\begin{array}{l}\text { \% Pre- } \\
\text { arrival }\end{array}$ & $\begin{array}{c}\text { \% Post- } \\
\text { arrival }\end{array}$ & Total & $\begin{array}{c}\text { \% Pre- } \\
\text { arrival }\end{array}$ & $\begin{array}{c}\text { Post- } \\
\text { arrival }\end{array}$ \\
\hline Finding \& applying for jobs & 108 & 49 & $\mathbf{8 0}$ & 20 & 59 & $\mathbf{7 1}$ & 29 \\
\hline Job opportunities & 107 & 90 & $\mathbf{8 2}$ & 18 & 17 & $\mathbf{8 8}$ & 12 \\
\hline Visa and work permit & 105 & 84 & $\mathbf{7 5}$ & 25 & 21 & $\mathbf{8 6}$ & 14 \\
\hline Education and qualification & 43 & 23 & $\mathbf{7 8}$ & 22 & 20 & 65 & 35 \\
\hline Business & 41 & 31 & 48 & $\mathbf{5 2}$ & 10 & 60 & 40 \\
\hline Others' experiences & 33 & 33 & 67 & 33 & - & - & - \\
\hline Work practices in Canada & 33 & 24 & 38 & $\mathbf{6 3}$ & 9 & 56 & 44 \\
\hline Resources & 25 & 23 & $\mathbf{7 4}$ & 26 & 2 & 50 & 50 \\
\hline Living in Canada & 20 & 14 & $\mathbf{7 1}$ & 29 & 6 & 17 & $\mathbf{8 3}$ \\
\hline Starting groups & 9 & 9 & 44 & $\mathbf{5 6}$ & - & - & - \\
\hline Total / Average & $\mathbf{5 2 4}$ & $\mathbf{3 8 0}$ & $71 \%$ & $29 \%$ & $\mathbf{1 4 4}$ & $70 \%$ & $30 \%$ \\
\hline
\end{tabular}

Table 15 suggests that newcomers are trying to meet their information needs about finding and applying for jobs, job opportunities, visa and work permit, education and qualification, resources, and living in Canada mainly pre-arrival, and information needs about work practices in Canada, business and starting groups post-arrival. Similarly, newcomers try to meet their advice needs about finding and applying for jobs, job opportunities and visa and work permit pre-arrival and advice needs about living in Canada post-arrival.

Another interesting observation is that newcomers are typically trying to meet their information needs about living in Canada pre-arrival, while they are trying to meet their advice needs about living in Canada post-arrival.

In addition, I included two tables below to provide examples from the data for each category of topics in the initial posts requesting information and advice support. Table 16 provides examples for the 10 categories of topics identified in the initial posts requesting information and Table 17 provides examples for the 8 categories of topics identified in the 
initial posts requesting advice. The examples also illustrate the differences between initial posts requesting information and advice support. More examples of initial posts requesting information are included in Appendix $\mathrm{E}$ and examples of initial posts requesting advice in Appendix F.

Table 16. Examples for topics requested in the 380 initial posts requesting information.

\begin{tabular}{|c|c|}
\hline Topics & Examples \\
\hline $\begin{array}{l}\text { Job } \\
\text { opportunities } \\
90 \text { posts } \\
23.7 \%\end{array}$ & $\begin{array}{l}\text { "I am } 30 y \text { and have graduated in Mechanical Engineer in the best } \\
\text { South America University, Universidade de São Paulo, Brazil. I have } \\
\text { experience in small and big companies, like Embraer. I know I will not } \\
\text { be able to work as a P. Eng. while I am not licensed by PEO, or other } \\
\text { regulatory agency, but I would like to have a glance on how the } \\
\text { Canadian market is right now for Brazilian Mechanical Engineer. Can } \\
\text { anyone help me with updated information on that matter?" } \\
\text { (CV21_257) }\end{array}$ \\
\hline $\begin{array}{l}\text { Visa and } \\
\text { work permit } \\
84 \text { posts } \\
22.1 \%\end{array}$ & $\begin{array}{l}\text { "Hi, I am an IT professional and have } 11 \text { years of experience. I want to } \\
\text { work and live in Canada. I want to know how much the processing time } \\
\text { for is getting work visa in Canada, assuming I have received the offer } \\
\text { letter." (CV21_72) }\end{array}$ \\
\hline $\begin{array}{l}\text { Finding and } \\
\text { applying for } \\
\text { jobs } \\
49 \text { posts } \\
12.9 \%\end{array}$ & $\begin{array}{l}\text { "I am working in IT around } 12 \text { years in Teamcenter, Java, J2EE, C++, } \\
\text { C skill sets in India. Is it possible to search job in Canada from India? } \\
\text { I am applying for a Canadian PR." (CV21_300) }\end{array}$ \\
\hline $\begin{array}{l}\text { Others' } \\
\text { experiences } \\
33 \text { posts } \\
8.7 \%\end{array}$ & $\begin{array}{l}\text { "Anyone who had already landed in Saskatoon or Regina, please share } \\
\text { the real-time experiences in terms of job search, weather, atmosphere, } \\
\text { housing, etc." (CV21_156) }\end{array}$ \\
\hline $\begin{array}{l}\text { Business } \\
31 \text { posts } \\
8.2 \%\end{array}$ & $\begin{array}{l}\text { "I am planning to open a Latin-grocery store in Alberta, and I don't } \\
\text { have a clue from where to start. I do have my vendors already, but how } \\
\text { to set up the company, CRA, etc... so if anyone can give me a hand } \\
\text { would be greatly appreciated." (CV22_49) }\end{array}$ \\
\hline
\end{tabular}




\begin{tabular}{|c|c|}
\hline $\begin{array}{l}\text { Work } \\
\text { practices in } \\
\text { Canada } \\
24 \text { posts } \\
6.3 \%\end{array}$ & $\begin{array}{l}\text { "I just have a question about some companies that are not paying their } \\
\text { employees when they do OT. In some industry, it happens a lot. I was } \\
\text { thinking if it's that even legal at all. Some companies tell you work } 10 \\
\text { to } 12 \text { hrs. a day to meet the deadline without even paying you OT. Worse } \\
\text { case is you need to work free on weekend as well. This happens when } \\
\text { deadline is on the edge. I'm just curious if this situation is normal at } \\
\text { all." (CV23_7) }\end{array}$ \\
\hline $\begin{array}{l}\text { Education } \\
\text { and } \\
\text { qualifications } \\
23 \text { posts } \\
6.1 \%\end{array}$ & $\begin{array}{l}\text { "My wife is a bio-medical engineer in India, she works at a hospital } \\
\text { supporting patient diagnosing and treatment by installing, testing, } \\
\text { calibrating, and repairing biomedical equipment, training users, etc. } \\
\text { (We are already in the pool, expecting ITA very soon) Are there any } \\
\text { mandatory certifications/exams she has to pass in order to } \\
\text { find/apply/practice this occupation. If Yes, what are they." (CV21_18) }\end{array}$ \\
\hline $\begin{array}{l}\text { Resources } \\
23 \text { posts } \\
6.1 \%\end{array}$ & $\begin{array}{l}\text { "Hi Anyone help in finding resources to pass written examination for } \\
\text { license exam of physiotherapist in Canada" (CV24_13) }\end{array}$ \\
\hline $\begin{array}{l}\text { Living in } \\
\text { Canada } \\
14 \text { posts } \\
3.7 \%\end{array}$ & $\begin{array}{l}\text { "From what I understand, there is a 3-month waiting period for a new } \\
\text { resident of Ontario to quality for OHIP. And I also am aware that you } \\
\text { need to spend } 153 \text { of the first } 183 \text { days in Ontario to also qualify. My } \\
\text { question is for those first } 3 \text { months before you can qualify, do you need } \\
\text { to spend all days of those } 3 \text { months in Ontario otherwise the waiting } \\
\text { period resets? For example, if someone becomes a permanent resident } \\
\text { and settles in Ontario, they can't leave for the first } 90 \text { days if they want } \\
\text { to qualify for OHIP?" (RC_7) }\end{array}$ \\
\hline $\begin{array}{l}\text { Starting } \\
\text { groups } \\
9 \text { posts } \\
2.4 \%\end{array}$ & $\begin{array}{l}\text { "Guys, all those who have contacts with people working with Canadian } \\
\text { public sector at either municipal/provincial/federal level, please drop } \\
\text { in your contact number. I will create a Whats_pp group for networking } \\
\text { and to discuss the process to get government jobs. Thanks" (CV24_15) }\end{array}$ \\
\hline
\end{tabular}


Table 17. Examples for topics requested in the 144 initial posts requesting advice.

\begin{tabular}{|c|c|}
\hline Topics & Examples \\
\hline $\begin{array}{l}\text { Finding and } \\
\text { applying for } \\
\text { jobs } \\
59 \text { posts } \\
41 \%\end{array}$ & $\begin{array}{l}\text { "I've been searching for a job in the last three months, mainly in } \\
\text { Montreal, Ottawa and Toronto, but to no avail. I'm growing more } \\
\text { desperate now. I have a degree in Computer Engineering and advanced } \\
\text { degrees in Electrical Engineering, but I cannot find a job neither in the } \\
\text { industry nor in the academia. They all need 5+ years of experience on } \\
\text { average, and I have none, which makes it even harder. Any advice? } \\
\text { Thanks" (CV21_96) }\end{array}$ \\
\hline $\begin{array}{l}\text { Education } \\
\text { and } \\
\text { qualifications } \\
20 \text { posts } \\
13.9 \%\end{array}$ & $\begin{array}{l}\text { "Hello guys, kindly advise on best school option for a management } \\
\text { program based on my below criteria, am new to this forum I will really } \\
\text { need you guys' advice to apply for my January (2017) session } \\
\text { admission. Cheap tuition fee Availability of job while schooling in the } \\
\text { province No interest in writing GMAT, TOEFL etc. First degree holder } \\
\text { (Second Class lower division) ..." (CV21_312) }\end{array}$ \\
\hline $\begin{array}{l}\text { Visa and } \\
\text { work permit } \\
21 \text { posts } \\
14.6 \%\end{array}$ & $\begin{array}{l}\text { "Please note I am holding a multiple entry visit visa (v1) which is valid } \\
\text { until Nov } 2017 \text {. I have an active express entry profile and have a CSC } \\
\text { score of } 382 \text { points. I will get a job in Mississauga once I landed. So } \\
\text { please advise is it legal to work in Canada on V1 visa and while working } \\
\text { I can apply for my PR. Also, please advise the procedure to get work } \\
\text { permit too. I can come to Canada in February since my UAE residence } \\
\text { visa is valid until Feb 10th." (CV21_416) }\end{array}$ \\
\hline $\begin{array}{l}\text { Job } \\
\text { opportunities } \\
17 \text { posts } \\
11.8 \%\end{array}$ & $\begin{array}{l}\text { "I am a Semi Qualified Chartered Accountant (CA inter qualified, Final } \\
\text { remaining) from India. I have 2+ years of work ex in addition to } 3 \text { years } \\
\text { of internship in Audit firms. I am currently working in FIS global } \\
\text { business solutions as a Finance controller (engaged with the Statutory } \\
\text { reporting and audit team). Prior to this, I was working with SG } \\
\text { Analytics as an Analyst in investment research domain using IFRS and } \\
\text { US GAAP skills to analyze Financial Statements Besides I am also } \\
\text { pursuing CPA (US Chartered Accountant) and has certifications in } \\
\text { merger and acquisition from New York institute of finance. What are } \\
\text { my prospects of getting a job in Canada and which province / territory } \\
\text { should I go for?" (CV24_5) }\end{array}$ \\
\hline $\begin{array}{l}\text { Business } \\
10 \text { posts } \\
6.9 \%\end{array}$ & $\begin{array}{l}\text { "I have landed in Canada and not able get a good job yet, anyhow, I } \\
\text { have a good saving from my previous job so start to think about private } \\
\text { business, can anyone advise me on small business idea that cost less } \\
\text { than 150k, thanks all" (CV21_338) }\end{array}$ \\
\hline
\end{tabular}




\begin{tabular}{|c|c|}
\hline Topics & Examples \\
\hline $\begin{array}{l}\text { Work } \\
\text { practices in } \\
\text { Canada } \\
9 \text { posts } \\
6.3 \%\end{array}$ & $\begin{array}{l}\text { "What happens if my employer never paid me either the salary he } \\
\text { declared he would pay me on the LMO nor the 6\% vacation? I received } \\
\text { my PR a month ago, I asked for my first-year vacation that was never } \\
\text { paid and mentioned the LMO subject to him. A month later he laid me } \\
\text { off saying there is no work for me, when clearly, we have houses to } \\
\text { frame and lack of man power. He never gave me a two week notice after } \\
\text { working for } 21 / 2 \text { years for him. Just told me to grab my things and go } \\
\text { (he used the words laid off though). A day later I find a new job a and } \\
\text { when I asked for my record of employment he says I should help frame } \\
\text { those houses at least for } 2 \text { weeks??? what should I do? thank you" } \\
\text { (CV23_15) }\end{array}$ \\
\hline $\begin{array}{l}\text { Living in } \\
\text { Canada } \\
6 \text { posts } \\
4.2 \%\end{array}$ & $\begin{array}{l}\text { "Hi my Friends I was being away from this amazing website, right now } \\
\text { it is for a while I have lived in Canada. I have lived in } 3 \text { major cities in } \\
\text { Canada. My question is which of the cities in Canada are best to live in } \\
\text { warm weather. By my friend's advice I have lived in } 3 \text { different cities } \\
\text { Windsor, Montreal and Toronto and none of them were warm.by being } \\
\text { warm I mean no -20 Celsius over there. I experienced -39 in Windsor } \\
\text { which by internet data was one of the warmest and frequent-20 by wind } \\
\text { chill was there in Windsor, it was a cheap city but no jobs over there. I } \\
\text { wonder which place is best to ask this question. to me it is also crucial } \\
\text { to find a place which life is more affordable as well and I can apply for } \\
\text { jobs (reasonable job market)." (CV21_198) }\end{array}$ \\
\hline $\begin{array}{l}\text { Resources } \\
2 \text { posts } \\
1.4 \%\end{array}$ & $\begin{array}{l}\text { "Hello all Just received my COPR and my visa stamped and was } \\
\text { wondering if you would advise some recruitment websites that could } \\
\text { help find a job in pharmaceutical field before moving to Canada?" } \\
\text { (CV21_231) }\end{array}$ \\
\hline
\end{tabular}

\section{Forms of advice: opinion, guidance, and problem specific}

Next, I examined the 144 initial posts requesting advice and coded them into three distinct forms of advice (i.e., opinion, guidance, and problem solving) to see what the main forms of advice are requested in the advice initial posts and whether the numbers in categories of topics fluctuate for different forms of advice. The analysis is summarized in Table 18. 
Table 18. Forms of advice and categories of topics requested in advice initial posts.

\begin{tabular}{|l|l|l|l|l|l|l|l|l|}
\hline \multicolumn{3}{|c}{ Categories of advice needs requested } & \multicolumn{6}{c|}{ Forms of advice } \\
\cline { 5 - 11 } & & \multicolumn{3}{|c|}{ Opinion } & \multicolumn{3}{|c|}{ Guidance } & \multicolumn{2}{|c|}{$\begin{array}{c}\text { Problem } \\
\text { Solving }\end{array}$} \\
\hline & $\#$ & $\%$ & $\#$ & $\%$ & $\#$ & $\%$ & $\#$ & $\%$ \\
\hline Finding and applying for jobs & 59 & 41 & 28 & 47 & 20 & 34 & 11 & 19 \\
\hline Visa and work permit & 21 & 15 & 6 & 29 & 12 & $\mathbf{5 7}$ & 3 & 14 \\
\hline Education and qualification & 20 & 14 & 18 & $\mathbf{9 0}$ & 2 & 10 & - & - \\
\hline Job opportunities & 17 & 12 & 17 & $\mathbf{1 0 0}$ & - & - & - & - \\
\hline Business & 10 & 7 & 5 & 50 & 5 & 50 & - & - \\
\hline Work practices in Canada & 9 & 6 & 7 & $\mathbf{7 8}$ & 2 & 22 & - & - \\
\hline Living in Canada & 6 & 4 & 5 & $\mathbf{8 3}$ & 1 & 17 & - & - \\
\hline Resources & 2 & 1 & 2 & $\mathbf{1 0 0}$ & - & - & - & - \\
\hline Total / Average & $\mathbf{1 4 4}$ & $\mathbf{1 0 0} \%$ & $\mathbf{8 8}$ & $61 \%$ & $\mathbf{4 2}$ & $29 \%$ & $\mathbf{1 4}$ & $10 \%$ \\
\hline
\end{tabular}

The data shows that forms of advice vary for different categories of advice needs requested in the initial posts. For example, when requesting advice support in online forums about education and qualification, job opportunities, living in Canada, resources, and work practices in Canada, newcomers typically request them in the form of opinion advice. However, when requesting advice about visa and work permit, newcomers most frequently seek guidance advice. Moreover, when newcomers request advice about problem solving, the problems are mainly about finding and applying for jobs and visa and work permit.

Moreover, about $75 \%$ of initial posts requesting opinion advice and $74 \%$ of initial posts requesting guidance advice are pre-arrival initial posts. However, only $29 \%$ of initial posts requesting problem solving advice are pre-arrival. This suggests that when newcomers seek advice pre-arrival, they are typically seeking opinion and guidance advice. However, they need advice about specific problems post-arrival. 


\subsection{Research Question 2: To what extent are these needs met in online discussion forums?}

To examine research question 2 , the data was analyzed at the thread level to identify and categorize thread outcomes. Thread outcome refers to a degree to which a need in a requesting initial post has been met (Bishop, 2007; Sun et al., 2014). For example, I identified thread outcome as met when a specific support need requested in an initial post has been fully provided with the subsequent replies. Likewise, I identified and coded thread outcome as partial when a specific support need requested in an initial post has been only partially provided with the subsequent replies. Categories and examples of thread outcomes are provided and discussed in the details of analysis for research question 2 sub-section below.

For analysis of research question 2, I used the sample of 524 threads with requesting initial posts that were identified in the analysis of research question 1 above; that is, the 380 threads with initial posts requesting information support and 144 threads requesting advice support. The selected 524 threads contain 2,072 replies. On average, there are only about 4 replies per initial post. In addition, among the 524 threads, 127 threads contain no replies and only 42 threads contain 10 or more replies. The main steps in the analysis of research question 2 are shown in Figure 11 below. 
Figure 11. Main steps in the analysis of research question 2.

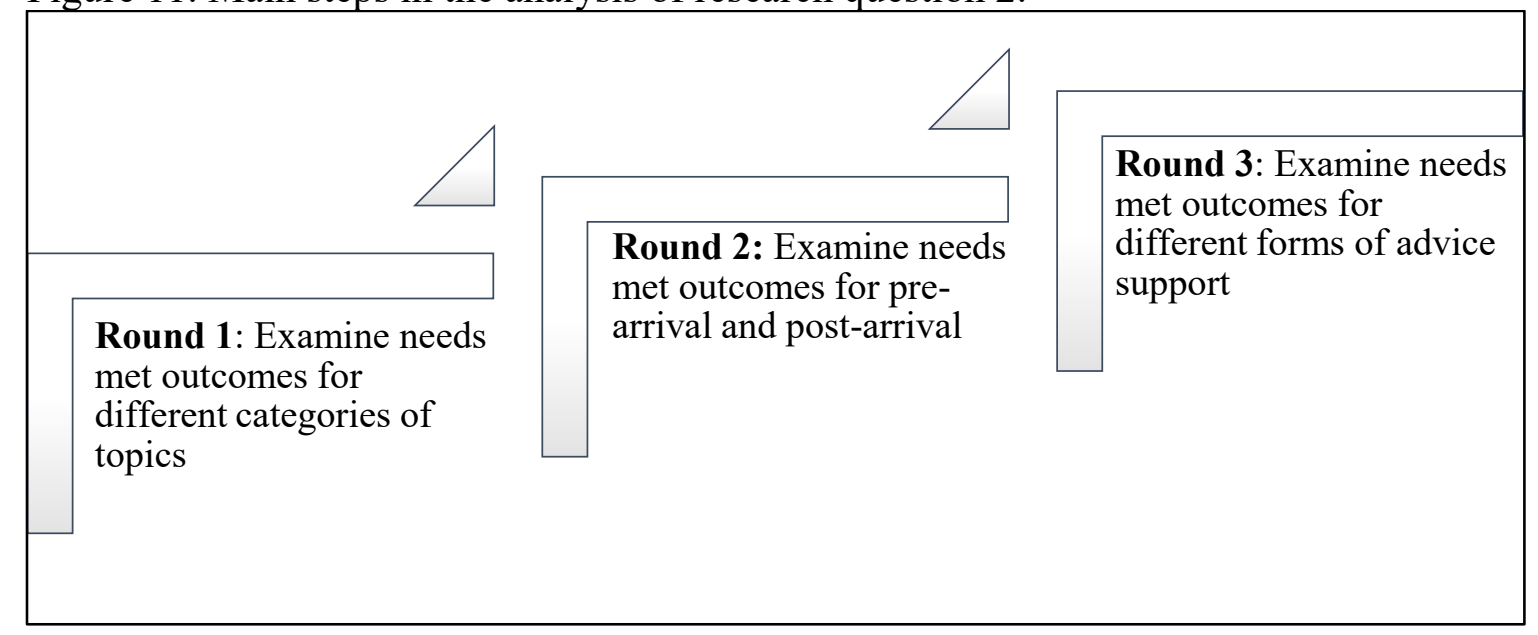

\section{Summary of analysis and findings for research question 2.}

To what extent are these needs met in online discussion forums?

Examination of online forum data showed that about $60 \%$ of needs requested in the initial posts were met in online discussion forums. In particular, about 59\% of information support, $66 \%$ of opinion advice support, $55 \%$ of guidance advice support, and $57 \%$ of problem solving advice support needs were met in the analyzed online discussion forums. Figure 12 below illustrates the percentages of needs met for different types of support requested in initial posts that newcomers are trying to meet with the examined online discussion forums. 
Figure 12. Percentage of support needs meet with online discussion forums.

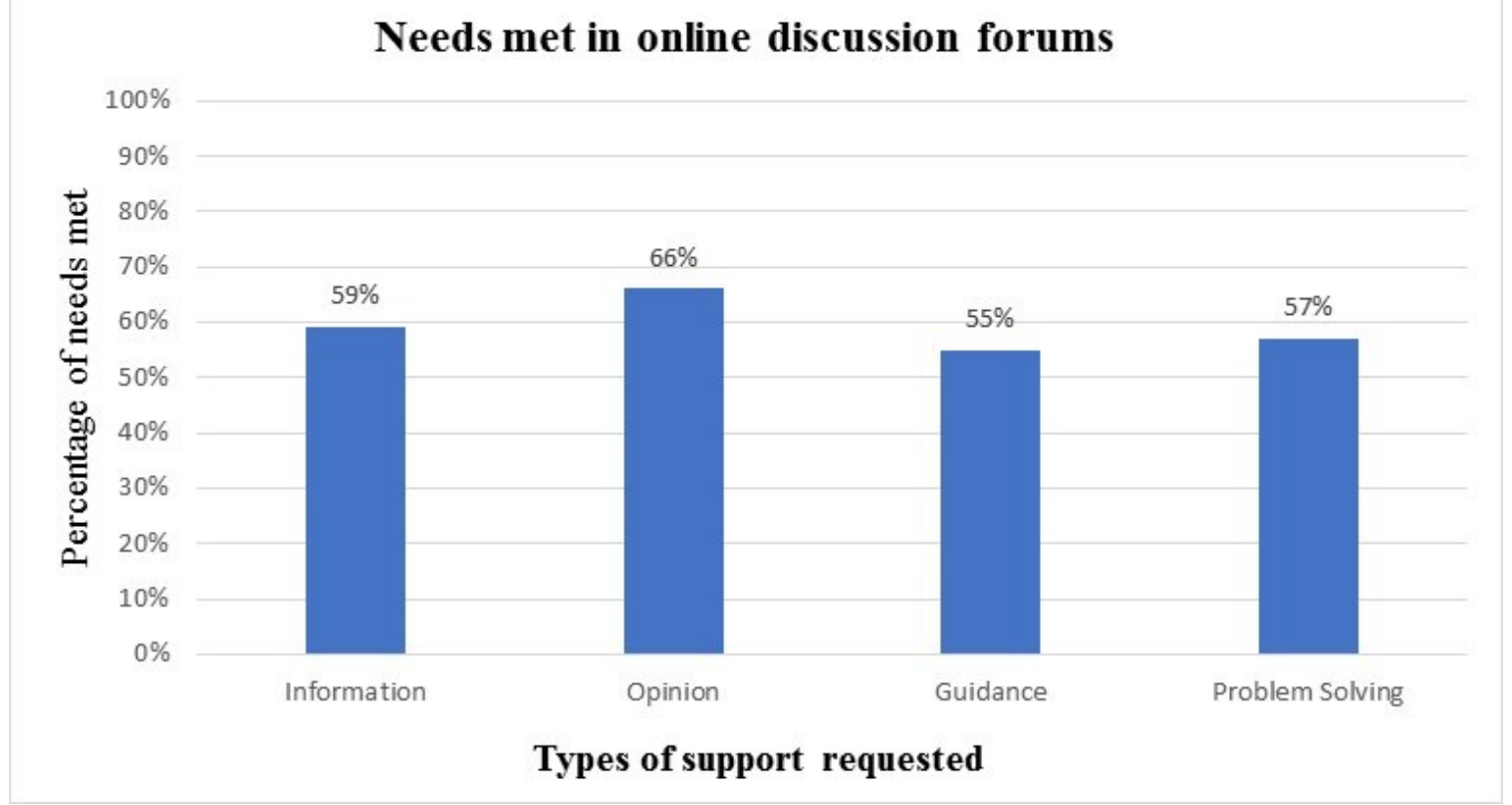

In this data, I found that newcomers were primarily requesting and meeting their information support and advice support needs. Analysis also showed that advice support needs were met with advice support, while information supports needs were met with information $(93 \%)$ or advice (7\%) support.

Although overall about $60 \%$ of requested needs were met in this sample of online discussion forums, the rates of needs met varies for pre-arrival and post-arrival initial posts as well as for different forms of social support needs requested. Figure 13 below summarizes needs met outcomes for requesting initial posts in this data. The percentages in the figure show the proportion of needs that were met. 
Figure 13. Needs met outcomes for requesting initial posts.

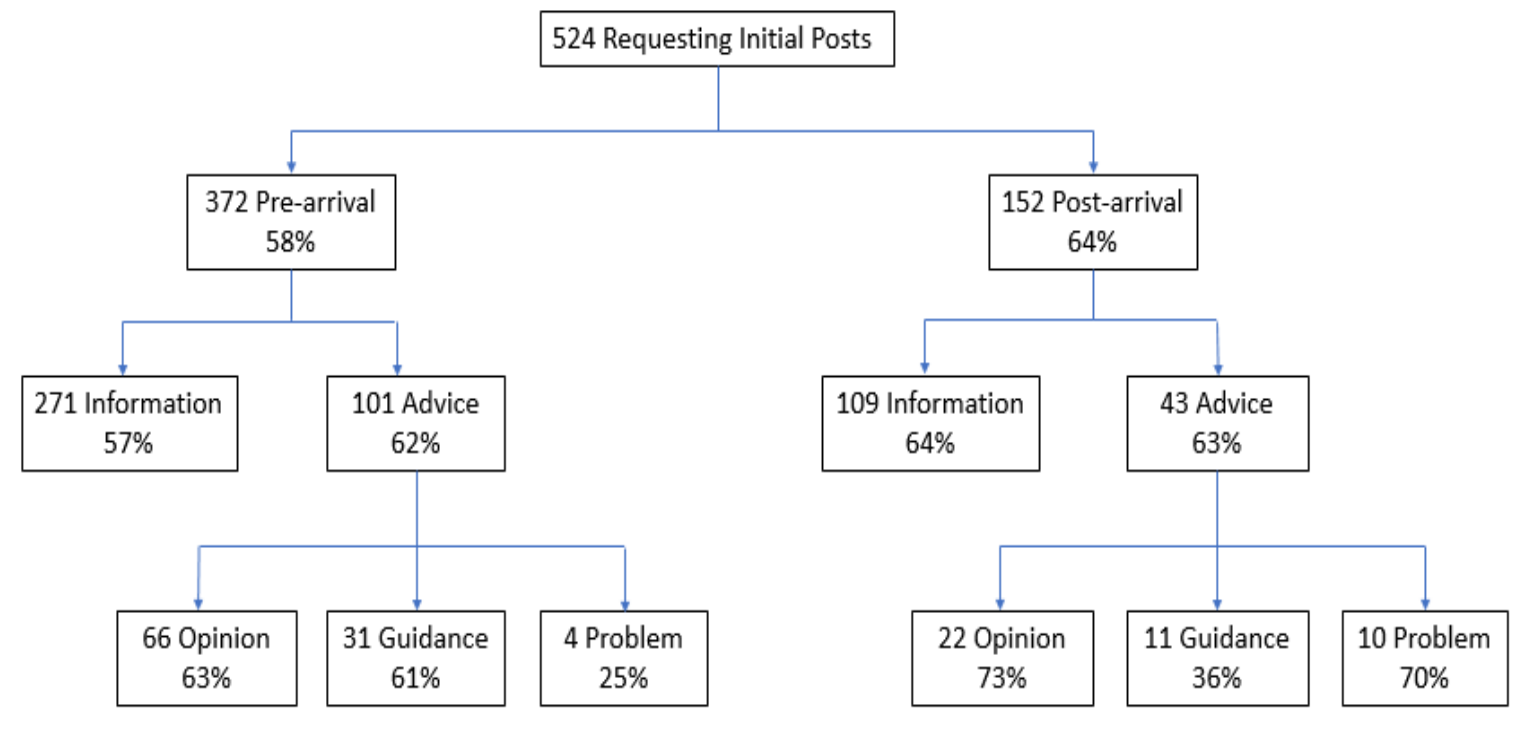

In this data, the overall rate of needs met was higher for post-arrival (64\%) than pre-arrival $(58 \%)$ initial posts. However, analysis showed that while post-arrival information, postarrival advice and pre-arrival advice support needs were met more than $60 \%$ of the time, the pre-arrival information needs are met only $57 \%$ of the time. Another interesting finding is that pre-arrival guidance advice needs were met $61 \%$ of the time while post-arrival guidance advice needs were met only $36 \%$ of the time. On the other hand, post-arrival problem solving advice needs were met at $70 \%$ while pre-arrival problem solving advice at only $25 \%$.

One of the probable reasons for lower rate of needs met in pre-arrival versus post-arrival initial posts requesting problem solving advice support is the asymmetry of knowledge about Canadian labour market between pre-arrival and post-arrival migrants. Pre-arrival migrants are still in their homelands and they lack relevant knowledge of the Canadian labour market to recognize what types of occupation integration problems are possible to 
solve. The authors of the three pre-arrival initial posts requesting problem solving advice that did not meet their needs were all trying to find work in Canada prior to migration, which in most cases is impossible without special sponsorship from a Canadian employer. On the other hand, post-arrival migrants are already in Canada, they have been trying to solve their specific problems for some time, and they typically had more knowledge about the types of problems that can be solved. The authors of the three post-arrival initial posts requesting problem solving advice support with needs not met were trying to find employment in professions with relatively scarce job prospects, such as geologist and software tester. However, the sample of initial posts requesting problem solving advice is too small (i.e., only 14 initial posts) to make inferences from the data. Future research should examine a much larger sample of initial posts requesting problem solving advice to see whether asymmetry of knowledge between pre-arrival and post-arrival migrants influences the needs met outcomes. 


\section{Categories of topics}

The rates of needs met also varied for different categories of topics requested in initial posts as shown in Figure 14 below.

Figure 14. Needs met for the ten topics in initial posts requesting information and advice support.

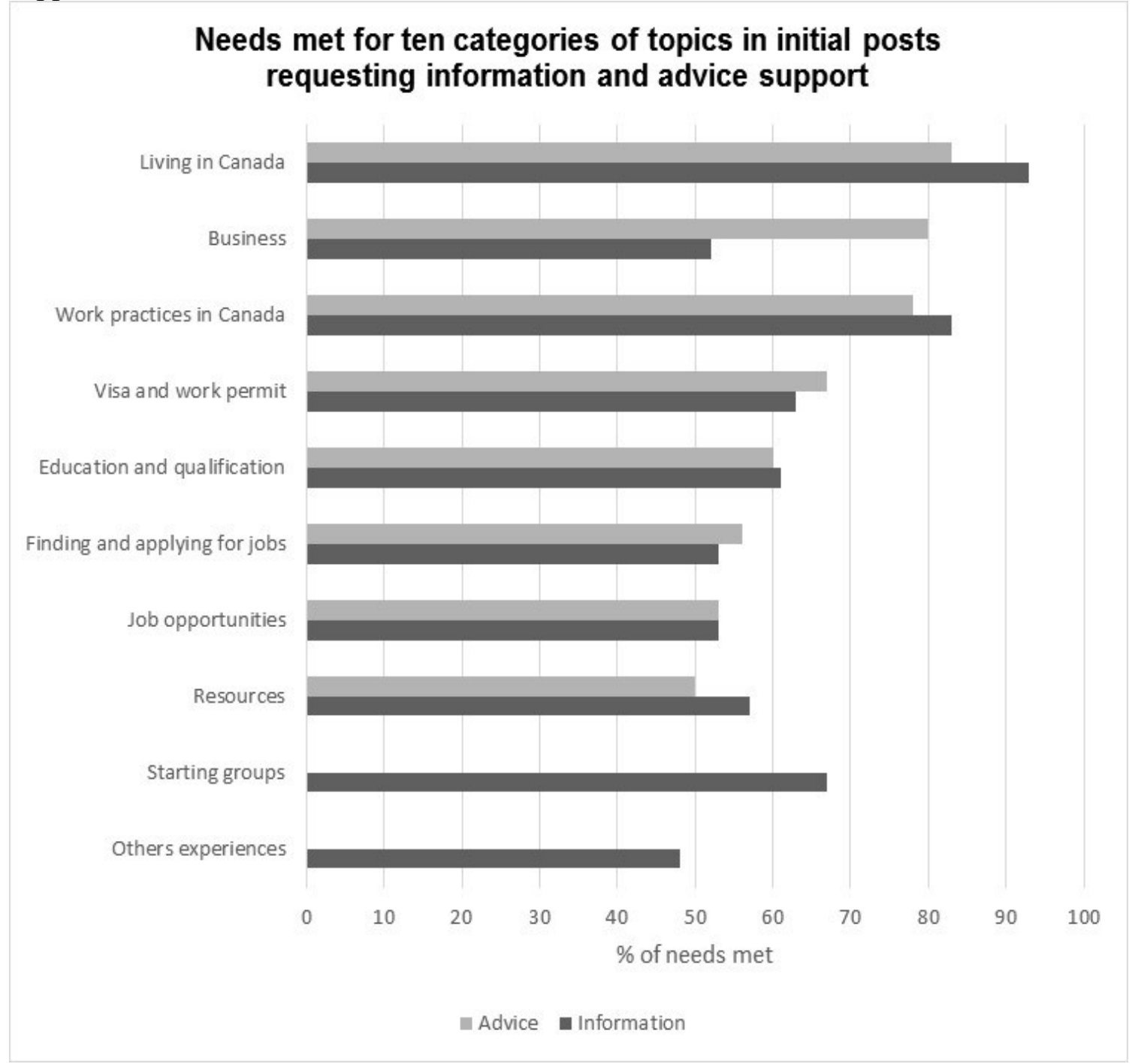

For example, the categories of topics with the highest rates of needs met (about $80 \%$ of the time) were about living in Canada and work practices in Canada. However, needs about others experiences, finding and applying for jobs, and job opportunities were met less than 
$60 \%$ of the time only. The ratio of needs met also varied between information support and advice support needs for some of the categories of topics. For example, advice needs about business were met at about $80 \%$ while information needs about business were met at about $50 \%$ only.

\section{Post-arrival versus pre-arrival}

Analysis of needs met outcomes also showed that the rates of need met varied for different categories of topics in the pre-arrival and post-arrival initial posts. For example, Figure 15 shows needs met outcomes for ten categories of topics in pre-arrival and post-arrival initial posts requesting information support. 
Figure 15. Needs met in pre-arrival and post-arrival initial posts requesting information support.

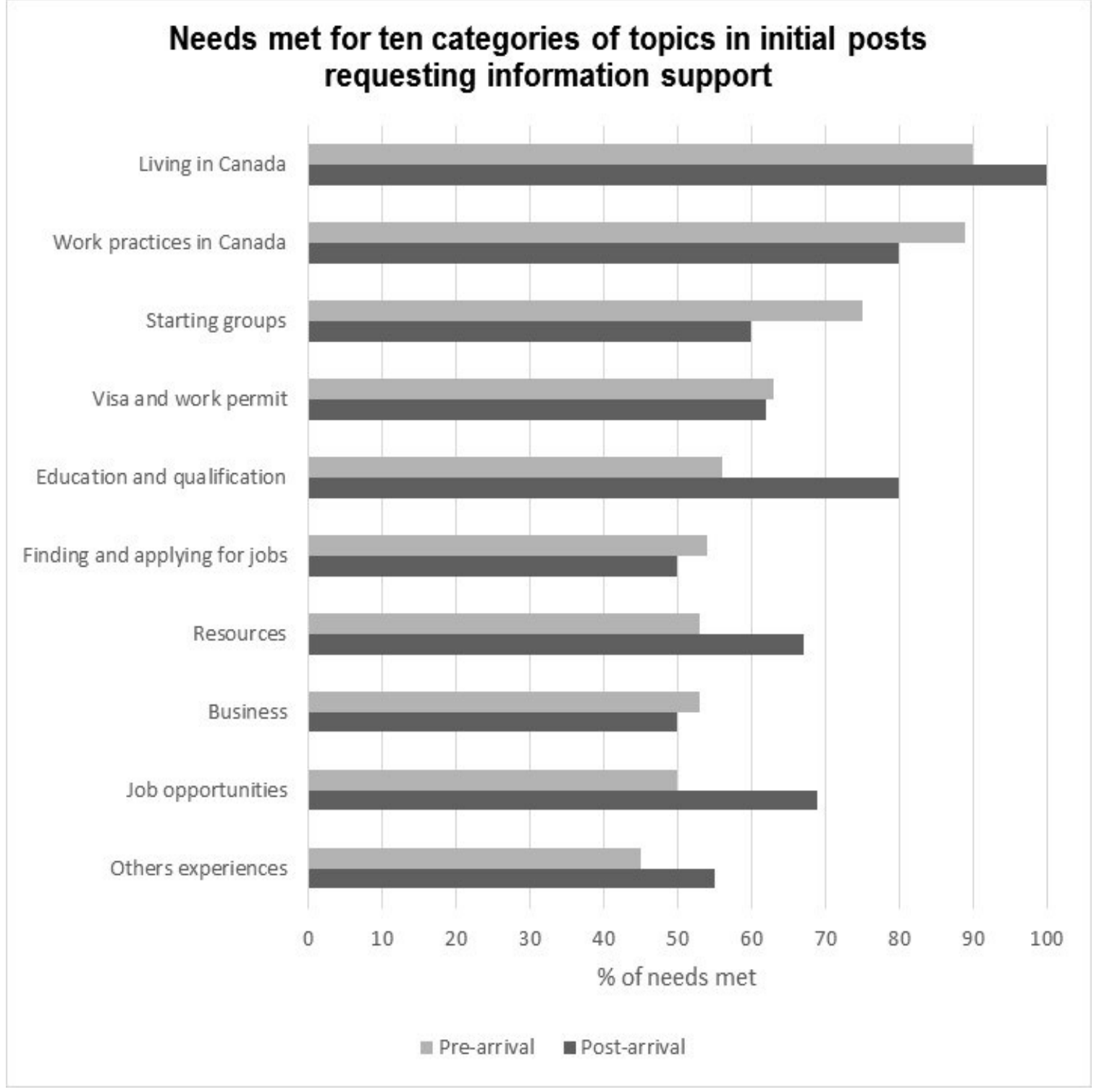

In this data, I found that information support needs about resources, education and qualification, and job opportunities had lower rates of need being met for pre-arrival than post-arrival initial posts. On the other hand, information needs about work practices in Canada and starting groups had higher rates of need being met for pre-arrival than postarrival initial posts. 
Similarly, Figure 16 below shows needs met in pre-arrival and post-arrival initial posts requesting advice support.

Figure 16. Needs met in pre-arrival and post-arrival initial posts requesting advice support.

\section{Needs met for ten categories of topics in initial posts requesting advice support}

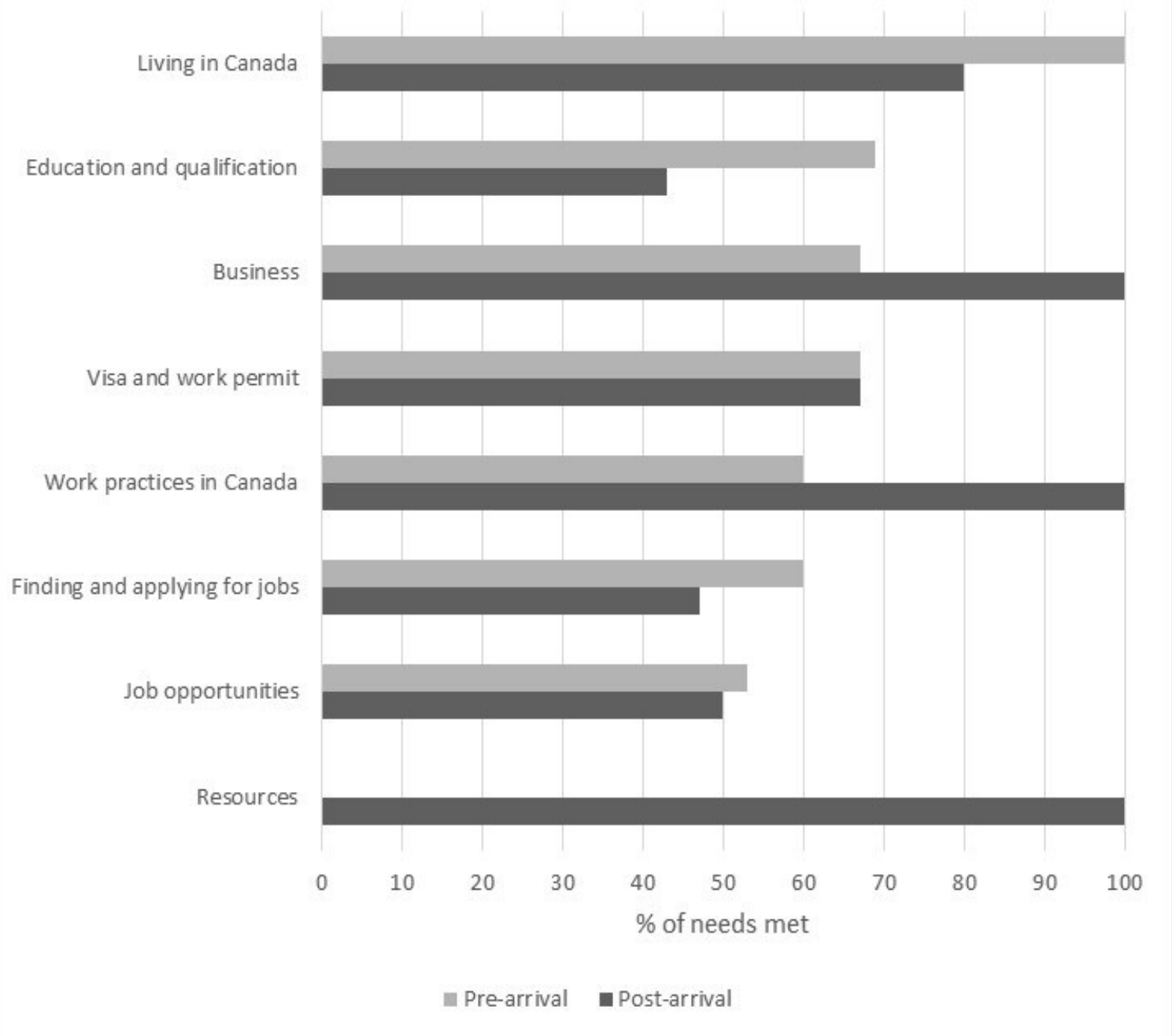

As shown in Figure 16, advice needs about education and qualification and finding and applying for jobs had higher rates of need being met for pre-arrival than post-arrival initial posts. However, advice needs about business and work practices in Canada had lower rates of need being met for pre-arrival than post-arrival initial posts. 


\section{Forms of advice}

Examination of needs met for the three forms of advice revealed that the rates on needs met varied substantially for some categories of topics across the three forms of advice support as well. For instance, opinion advice needs about finding and applying for jobs were met about $68 \%$ of the time while guidance advice and problem-solving advice about finding and applying for jobs were met only about $45 \%$ of the time.

\section{Question \#2. To what extent are these needs met in online discussion forums?}

In the context of labour market integration in Canada, newcomers were meeting about $60 \%$ of their needs in online discussion forums. As shown in the analysis, the rates of needs met varied for different categories of topics, types of support requested, as well as for prearrival and post-arrival initial posts.

Although some individuals may argue that the rate of $60 \%$ is not very high, one also has to consider the cost of obtaining online social support resources. While offline sources of social support, such as face-to-face interactions, may provide higher rates of needs met, the cost of seeking and gaining social support resources is much greater offline than online (Ahmed and Veronis, 2017; Rains and Wright, 2016). In addition, research (e.g., Caidi et al., 2010; Khoir et al., 2015; Savolainen, 2016; Yoon, 2017) has shown that newcomers (especially pre-arrival) typically do not understand the local information environment and often lack access to relevant local offline sources (e.g., friends, family, and knowledgeable locals). Studies have shown that an increasing number of newcomers are turning to the Internet, because it allows newcomers easy, inexpensive, and quick access to information 
sources that are available online and can be accessed worldwide at all times (Ahmed and Veronis, 2017; Kroft and Pope, 2014; Noorani, 2017; Sirikul and Dorner, 2016). Research on computer mediated social support in education and health contexts has also shown that seeking social support is easier and requires less effort online than offline (Rains et al, 2016; Rains and Wright, 2016).

Considering newcomers' limited access to offline support sources and the costs and benefits involved in seeking and gaining needed support resources online and offline, online discussion forums are very attractive sources of social support resources for newcomers. With very minimal cost and effort required, newcomers can seek and meet about $60 \%$ of their information and advice support needs in online discussion forums. Online discussion forums are particularly useful for pre-arrival migrants as they can meet their social support needs while still in their homelands. Gaining support pre-arrival can help newcomers better prepare for and form more realistic expectations pre-arrival, as well as help them better adjust post-arrival. The cost and benefit of obtaining social support online are further discussed in the research questions four and the discussion chapter. Detailed examination of differences is provided in the details of analysis section for research question 2 below.

\section{Details of analysis for research question 2}

First, I examined and coded the replies and responses to replies that followed each of the 524 requesting initial posts at the thread level. Specifically, I read all the replies following an initial post as a discussion or conversation and coded and categorized each discussion based on the overall outcome of the discussion. Through consecutive iterations of coding 
and organization of the data I identified and grouped the discussions into four categories of needs met outcomes: Yes, Partial, More questions, and No replies, which are described below.

I coded the outcome as Yes when the request in the initial post was met within the subsequent replies (i.e., discussion). Similarly, I coded the need met outcome as Partial when the request in an initial post was met in part only. That is, initial posts received relevant replies, but the replies did not fully meet the requested needs. I coded the outcomes as More questions when other online discussion forum users replied in a thread, but the need requested in the initial post was not met. Lastly, I coded the outcome as No reply when there was no reply to an initial post.

In Table 19 below, I summarize the four categories of needs met outcomes and provide examples for each of the outcomes to illustrate differences between the four categories of possible outcomes. More examples are included in Appendix G. 
Table 19. Categories and examples of support needs met outcomes.

\begin{tabular}{|c|c|}
\hline of & \begin{tabular}{|l|} 
Examples \\
\end{tabular} \\
\hline $\begin{array}{l}\text { Yes } \\
314 \text { threads } \\
60 \%\end{array}$ & $\begin{array}{l}\text { Initial post (CV21_7) } \\
\text { "I am planning to register to APEGBC, and their requirement is that } \\
\text { transcripts to be sent in a sealed envelope to their office by the } \\
\text { University. I want to know if they require certified / attested copies from } \\
\text { my university or they are asking for original transcripts to be sent by my } \\
\text { University. If anyone has experience with APEGBC, kindly shed some } \\
\text { light." } \\
\text { Reply } \\
\text { "First you need to apply for transcripts at the university from where you } \\
\text { obtained your degree, go to the university, fill the prescribed form, pay } \\
\text { the nominal charges, the clerk will tell you the time to come to receive } \\
\text { transcripts as it takes } 2 \text { to } 3 \text { weeks to prepare them. Don't give them extra } \\
\text { charges to get it immediately. Then go there at mentioned time, and } \\
\text { receive transcripts, which will be sealed by the university. Then send it } \\
\text { through courier to the destination." }\end{array}$ \\
\hline $\begin{array}{l}\text { Partial } \\
40 \text { threads } \\
7.6 \%\end{array}$ & $\begin{array}{l}\text { Initial post (CV24 43) } \\
\text { "Hi I will belong from USA to Canada. USA is known for low expenses } \\
\text { and low taxes while Canada has high living expenses and taxes. If I am } \\
\text { not wrong, tax is } 45 \text { percent and living is twice as expensive than USA. } \\
\text { So, when you got a job, did I get twice the salary you were getting in } \\
\text { USA? How did your new offer compared to USA? Are u making money } \\
\text { or losing money in Canada?" } \\
\text { Reply } \\
\text { "As to tax, see here: http://www.cra-arc.gc.ca/tx/ndvdls/fq/txrts- } \\
\text { eng.html As for salaries, Idon't know." }\end{array}$ \\
\hline $\begin{array}{l}\text { More } \\
\text { questions } \\
43 \text { threads } \\
8.2 \%\end{array}$ & $\begin{array}{l}\text { Initial post (CV2154) } \\
\text { "Hi. I will soon be getting my PR to come to Canada. I have done my } \\
\text { masters from India in biotech. I will be going to Vancouver, so I was } \\
\text { wondering how the job market is for international Biotech background } \\
\text { immigrants. Is it recommended to get my credentials evaluated? And, } \\
\text { which job boards might be useful for me relating to my biotech career? } \\
\text { And, what other fields can I look into if biotech careers are not surplus? } \\
\text { Thank you." } \\
\text { Reply } \\
\text { "Any luck on getting a Biotech Job in Vancouver, my wife is also } \\
\text { searching for an opening in Biotech as she as a Masters in Biotech from } \\
\text { India. Any help/insights here would be great." }\end{array}$ \\
\hline
\end{tabular}




\begin{tabular}{|l|l|}
\hline $\begin{array}{l}\text { Categories } \\
\text { of outcomes }\end{array}$ & Examples \\
\hline $\begin{array}{l}\text { No reply } \\
127 \text { threads } \\
24.2 \%\end{array}$ & $\begin{array}{l}\text { Initial post (CV21_367) } \\
\text { government? Are they paid? Are they hard to get?" } \\
\text { Reply } \\
\text { No reply }\end{array}$ \\
\hline
\end{tabular}

In this data, I found that about $60 \%$ of needs requested in the initial posts were met, $7.6 \%$ were partially met, $8.2 \%$ were not met (e.g., resulted in more questions), and $24.2 \%$ were not met (as the initial posts did not receive replies).

Next, in Table 20 below, I summarized the support needs met outcomes for the initial posts requesting information support and the initial posts requesting advice support to examine differences in needs met outcomes for different types of support needs requested.

Table 20. Support needs met outcomes for information and advice support needs requested.

\begin{tabular}{|l|l|l|l|l|l|l|l|l|l|}
\hline \multicolumn{1}{|c|}{ Support needs requested } & \multicolumn{8}{|c|}{ Support needs met } \\
\hline \multicolumn{1}{|c|}{ Types } & \multicolumn{2}{|c|}{ Yes } & \multicolumn{2}{|c|}{ Partially } & \multicolumn{2}{|c|}{ More questions } & \multicolumn{2}{c|}{ No reply } \\
\hline Information & 380 & 225 & $59.2 \%$ & 35 & $9.2 \%$ & 27 & $7.1 \%$ & 93 & $24.5 \%$ \\
\hline Advice & 144 & 89 & $61.8 \%$ & 5 & $3.5 \%$ & 16 & $11.1 \%$ & 34 & $23.6 \%$ \\
\hline Total / Average & $\mathbf{5 2 4}$ & $\mathbf{3 1 4}$ & $60 \%$ & $\mathbf{4 0}$ & $7.6 \%$ & $\mathbf{4 3}$ & $8.2 \%$ & $\mathbf{1 2 7}$ & $24.2 \%$ \\
\hline
\end{tabular}

Analysis of this sample of online forum data concerning labour market integration of newcomers in Canada suggests that newcomers met about $60 \%$ of both information support and advice support needs with online discussion forums. In addition, newcomers partially met about $9.2 \%$ of information support needs and about $3.5 \%$ of advice support needs. About $32 \%$ of information needs and about $35 \%$ of advice needs were not met (i.e., more 
questions or no replies). The threads with needs not met are discussed in more detail in the section examining research question 3.

\section{Needs met outcomes for various categories of topics of needs requested}

Next, I examined the needs met outcomes for the ten categories of topics that I identified in the initial posts requesting information and advice support in the research question 1 above to see whether needs met outcomes vary for different categories of topics. I summarized the data analysis with two tables below. Table 21 shows needs met outcomes for the 10 categories of topics in the initial posts requesting information support and Table 22 shows needs met outcomes for the 8 categories of topics in the initial posts requesting advice support.

Table 21. Needs met outcomes in the initial posts requesting information support.

\begin{tabular}{|l|l|l|l|l|l|l|l|l|l|l|}
\hline \multirow{2}{*}{$\begin{array}{c}\text { Categories of topics in initial posts } \\
\text { requesting information support }\end{array}$} & \multicolumn{9}{|c|}{ Needs met } \\
\cline { 4 - 13 } & & \multicolumn{3}{|c|}{ Yes } & \multicolumn{2}{c|}{ Partially } & \multicolumn{2}{c|}{$\begin{array}{c}\text { More } \\
\text { questions }\end{array}$} & \multicolumn{2}{c|}{ No reply } \\
\hline & $\#$ & $\%$ & $\#$ & $\%$ & $\#$ & $\%$ & $\#$ & $\%$ & $\#$ & $\%$ \\
\hline Job opportunities & 90 & 24 & 48 & 53 & 11 & 12 & 8 & 9 & 23 & 26 \\
\hline Visa and work permit & 84 & 22 & 53 & 63 & 3 & 4 & 4 & 5 & 24 & 29 \\
\hline Finding \& applying for jobs & 49 & 13 & 26 & 53 & 5 & 10 & 4 & 8 & 14 & 29 \\
\hline Others' experiences & 33 & 9 & 16 & 48 & 5 & 15 & 6 & 18 & 6 & 18 \\
\hline Business & 31 & 8 & 16 & 52 & 4 & 13 & 2 & 6 & 9 & 29 \\
\hline Work practices in Canada & 24 & 6 & 20 & 83 & 1 & 4 & - & - & 3 & 13 \\
\hline Education and qualification & 23 & 6 & 14 & 61 & 2 & 9 & 3 & 13 & 4 & 17 \\
\hline Resources & 23 & 6 & 13 & 57 & 3 & 13 & - & - & 7 & 30 \\
\hline Living in Canada & 14 & 4 & 13 & 93 & 1 & 7 & - & - & - & - \\
\hline Starting groups & 9 & 2 & 6 & 67 & - & - & - & - & 3 & 33 \\
\hline Total / Average & $\mathbf{3 8 0}$ & $\mathbf{1 0 0}$ & $\mathbf{2 2 5}$ & $59 \%$ & $\mathbf{3 5}$ & $9 \%$ & $\mathbf{2 7}$ & $7 \%$ & $\mathbf{9 3}$ & $25 \%$ \\
\hline
\end{tabular}

Analysis summarized in Table 21 above shows that needs outcomes varied among the various categories of topics in the initial posts requesting information support. For 
example, information needs about living in Canada and work practices in Canada were met over $80 \%$ of the time, whereas needs for information support about others' experiences, business, job opportunities, and finding and applying for jobs were met at about $50 \%$ of the time in this sample of online discussion forums.

Table 22. Needs met outcomes in the initial posts requesting advice support.

\begin{tabular}{|c|c|c|c|c|c|c|c|c|c|c|}
\hline \multirow{2}{*}{\multicolumn{3}{|c|}{$\begin{array}{l}\text { Categories of topics in initial posts } \\
\text { requesting advice support }\end{array}$}} & \multicolumn{8}{|c|}{ Needs met } \\
\hline & & & \multicolumn{2}{|c|}{ Yes } & \multicolumn{2}{|c|}{ Partially } & \multicolumn{2}{|c|}{$\begin{array}{c}\text { More } \\
\text { questions }\end{array}$} & \multicolumn{2}{|c|}{ No reply } \\
\hline & $\#$ & $\%$ & $\#$ & $\%$ & $\#$ & $\%$ & $\#$ & $\%$ & $\#$ & $\%$ \\
\hline Finding and applying for jobs & 59 & 41 & 33 & 56 & 2 & 3 & 9 & 15 & 15 & 25 \\
\hline Visa and work permit & 21 & 14.6 & 14 & 67 & 1 & 8 & 3 & 14 & 3 & 14 \\
\hline Education and qualification & 20 & 13.9 & 12 & 60 & - & - & 4 & 20 & 4 & 20 \\
\hline Job opportunities & 17 & 11.8 & 9 & 53 & 1 & 6 & - & - & 7 & 41 \\
\hline Business & 10 & 6.9 & 8 & 80 & 0 & 0 & - & - & 2 & 20 \\
\hline Work practices in Canada & 9 & 6.3 & 7 & 78 & 1 & 11 & - & - & 1 & 11 \\
\hline Living in Canada & 6 & 4.2 & 5 & 83 & - & - & - & - & 1 & 17 \\
\hline Resources & 2 & 1.4 & 1 & 50 & - & - & - & - & 1 & 50 \\
\hline Total / Average & 144 & $100 \%$ & 89 & $62 \%$ & 5 & $3 \%$ & 16 & $11 \%$ & 34 & $24 \%$ \\
\hline
\end{tabular}

Similarly, as shown in Table 22 above, needs outcomes varied for different categories of topics of advice support needs as well. For example, needs for advice support about living in Canada, business, and work practices in Canada were met about $80 \%$ of the time, whereas needs for advice about job opportunities and finding and applying for jobs were met at about $50 \%$ of the time in online discussion forums.

What is interesting is that advice needs about business were met $80 \%$ of the times whereas information needs about business were met about $50 \%$ of the time. In addition, analysis shows that requested needs about job opportunities, and finding and applying for jobs were met at about $50 \%$ only for both information and advice support. 
Next, in Table 23 below, I combined the figures for both information and advice support needs requested to examine the overall needs met outcomes across various categories of topics. In this table, I compare whether needs have been met (Yes) or not (No). Both More questions and No reply outcomes are included in the 'No' figures, because in both instances the needs have not been met. In addition, the 40 threads with partial needs met were excluded from this table as in these threads needs are neither fully met nor not met.

Table 23. Needs met versus not met across 10 categories of information and advice needs requested.

\begin{tabular}{|c|c|c|c|c|c|c|}
\hline \multirow{2}{*}{\multicolumn{3}{|c|}{$\begin{array}{l}\text { Categories of topics in initial posts } \\
\text { requesting advice and information support }\end{array}$}} & \multicolumn{4}{|c|}{ Needs met } \\
\hline & & & \multicolumn{2}{|c|}{ Yes } & \multicolumn{2}{|c|}{ No } \\
\hline & $\#$ & $\%$ & \# & $\%$ & \# & $\%$ \\
\hline Living in Canada & 19 & 4 & 18 & 95 & 1 & 5 \\
\hline Work practices in Canada & 31 & 6 & 27 & 87 & 4 & 13 \\
\hline Starting groups & 9 & 2 & 6 & 67 & 3 & 33 \\
\hline Visa and work permit & 101 & 21 & 67 & 66 & 34 & 34 \\
\hline Business & 37 & 8 & 24 & 65 & 13 & 35 \\
\hline Resources & 22 & 5 & 14 & 64 & 8 & 36 \\
\hline Education and qualification & 41 & 8 & 26 & 63 & 15 & 37 \\
\hline Job opportunities & 95 & 20 & 57 & 60 & 38 & 40 \\
\hline Finding and applying for jobs & 101 & 21 & 59 & 58 & 42 & 42 \\
\hline Others' experiences & 28 & 6 & 16 & 57 & 12 & 43 \\
\hline Total / Average & 484 & $100 \%$ & 314 & $65 \%$ & 170 & $35 \%$ \\
\hline
\end{tabular}

Analysis in Table 23 shows that needs about living in Canada and work practices in Canada were met most frequently (over $80 \%$ of the time) whereas needs about other experiences, finding and applying for jobs, are met least frequently (less than $60 \%$ of the time). 


\section{Support needs requested versus support needs provided}

Next, I examined and coded the thread discussions for the types of support provided (e.g., information support and advice support) to see if the support provided in the thread discussion replies matched the support needs requested in the corresponding initial posts. In other words, for example, if initial posts requesting information support received replies with information support or other types of support.

In Table 24, I show needs met outcomes and support needs provided for the information support and advice support needs requested. None category in this table indicates no support received and it includes both No replies and More questions outcomes.

Table 24. Support needs requested in the initial posts versus support needs provided in the threads.

\begin{tabular}{|c|c|c|c|c|c|c|c|c|c|c|c|}
\hline \multirow{2}{*}{\multicolumn{2}{|c|}{$\begin{array}{c}\text { Support needs } \\
\text { requested }\end{array}$}} & \multicolumn{10}{|c|}{ Support needs provided } \\
\hline & & \multicolumn{4}{|c|}{ Information } & \multicolumn{4}{|c|}{ Advice } & \multicolumn{2}{|c|}{ None } \\
\hline \multirow{2}{*}{\begin{tabular}{|c|} 
Types \\
Information
\end{tabular}} & \multirow{2}{*}{$\begin{array}{c}\# \\
380\end{array}$} & \multicolumn{2}{|c|}{ Yes } & \multicolumn{2}{|c|}{ Partial } & \multicolumn{2}{|c|}{ Yes } & \multicolumn{2}{|c|}{ Partial } & \multirow{2}{*}{\begin{tabular}{|c|}
$\#$ \\
120
\end{tabular}} & \multirow{2}{*}{\begin{tabular}{|r|}
$\%$ \\
$32 \%$
\end{tabular}} \\
\hline & & 213 & $56 \%$ & 29 & $8 \%$ & 12 & $3 \%$ & 6 & $2 \%$ & & \\
\hline Advice & 144 & 0 & $0 \%$ & 0 & $0 \%$ & 89 & $62 \%$ & 5 & $3 \%$ & 50 & $35 \%$ \\
\hline Total / Average & 524 & 213 & $41 \%$ & 29 & $5 \%$ & 101 & $19 \%$ & 11 & $2 \%$ & 170 & $32 \%$ \\
\hline
\end{tabular}

In the examined sample, out of the 524 initial posts requesting information or advice, about $68 \%$ met or partially met their needs with information support or advice support. The analysis shows that information supports needs were typically met with information support and advice support needs were met with advice support. What is interesting is that 
when the advice needs requested in the initial posts were met or partially met, they were all met with the advice support. However, when the information needs requested in the initial posts were met or partially met (in 260 out of the 380), they were met with information support (in 242 posts, 93\%) or advice support (in 18 posts, 7\%). In the information requesting threads that received advice support, the replies provided not only information, but advice as well. I included two examples from the data below to illustrate advice support provided when information support was requested.

Example 1. Initial post (CV21_247)

"Does anyone have any recommended, trustworthy job recruitment companies/website in Canada? I never know who to contact, or who to give my money to :( "

Reply

"You shouldn't be giving money to anyone. If someone is asking for money in exchange for a job - it's a scam. You're going to find that reputable recruitment companies in Canada only want to deal with people who are already PRs or citizens - or who already have open work permits. Your best option for finding a job outside of Canada is to search for jobs yourself on reputable job sites such as indeed.com."

Example 2. Initial post (CV21_75)

"Recently, I came across $w w w .$. for immigration-related help. The consultants help with securing temporary jobs as well as LMIA-based jobs, for a (what I thought was reasonable) fee. My question is, has anyone used their services? How did it go?" 


\section{Reply}

"usually when consultants ask for money promising "jobs" - it is assumed that it's a scam... jobs via LMIA are not easy to get BTW, and I wouldn't want to fall into a trap for "money for job"

\section{Needs met in pre-arrival and post-arrival initial posts threads}

Next, I examined the threads with needs met (i.e., Yes only) for the pre-arrival and postarrival initial post requesting information support to see whether there are differences in needs being met for different categories of topics in pre-arrival and post-arrival initial posts requesting information support. I summarized the analysis in Table 25 below.

Table 25. Needs met in the pre-arrival and post-arrival initial posts requesting information.

\begin{tabular}{|l|l|l|l|l|l|l|l|l|}
\hline \multicolumn{3}{|c|}{$\begin{array}{c}\text { Categories of topics in initial posts } \\
\text { requesting information support }\end{array}$} & \multicolumn{3}{c|}{ Pre-arrival } & \multicolumn{3}{c|}{ Post-arrival } \\
\cline { 4 - 10 } & Total & $\%$ & Total & $\#$ & $\%$ & Total & $\#$ & $\%$ \\
\hline Job opportunities & 90 & 24 & 74 & 37 & $\mathbf{5 0}$ & 16 & 11 & $\mathbf{6 9}$ \\
\hline Visa and work permit & 84 & 22 & 63 & 40 & 63 & 21 & 13 & 62 \\
\hline Finding and applying for jobs & 49 & 13 & 39 & 21 & 54 & 10 & 5 & 50 \\
\hline Others' experiences & 33 & 9 & 22 & 10 & 45 & 11 & 6 & 55 \\
\hline Business & 31 & 8 & 15 & 8 & 53 & 16 & 8 & 50 \\
\hline Work practices in Canada & 24 & 6 & 9 & 8 & 89 & 15 & 12 & 80 \\
\hline Education and qualification & 23 & 6 & 18 & 10 & $\mathbf{5 6}$ & 5 & 4 & $\mathbf{8 0}$ \\
\hline Resources & 23 & 6 & 17 & 9 & 53 & 6 & 4 & 67 \\
\hline Living in Canada & 14 & 4 & 10 & 9 & 90 & 4 & 4 & 100 \\
\hline Starting groups & 9 & 2 & 4 & 3 & 75 & 5 & 3 & 60 \\
\hline Total / Average & $\mathbf{3 8 0}$ & $\mathbf{1 0 0} \%$ & $\mathbf{2 7 1}$ & $\mathbf{1 5 5}$ & $57 \%$ & $\mathbf{1 0 9}$ & $\mathbf{7 0}$ & $64 \%$ \\
\hline
\end{tabular}

The overall rate of needs met was higher for post-arrival (about 64\%) than pre-arrival (57\%) initial posts requesting information support. As shown in Table 25, the rates of needs 
being met in pre-arrival and post-arrival discussions differed substantially for some of the categories of topics requested in the initial posts. For example, categories of topics about job opportunities and education and qualification showed higher rates of need being met for post-arrival than pre-arrival initial posts. However, the topics about work practices in Canada and starting groups showed higher rates of need being met for pre-arrival than post-arrival initial posts. Moreover, the rates of needs being met for topics about visa and work permit, finding and applying for jobs, and business were similar for pre-arrival and post-arrival initial posts.

Next, in Table 26 below I summarized the analysis for the pre-arrival and post-arrival initial posts requesting advice support.

Table 26. Needs met in the pre-arrival and post-arrival initial posts requesting advice.

\begin{tabular}{|l|l|l|l|l|l|l|l|l|}
\hline \multicolumn{2}{|c}{$\begin{array}{c}\text { Categories of topics in initial posts } \\
\text { requesting advice support }\end{array}$} & \multicolumn{3}{c|}{ Pre-arrival } & \multicolumn{3}{c|}{ Post-arrival } \\
\cline { 5 - 11 } & Total & $\%$ & Total & $\#$ & $\%$ & Total & $\#$ & $\%$ \\
\hline Finding and applying for jobs & 59 & 41 & 42 & 25 & $\mathbf{6 0}$ & 17 & 8 & $\mathbf{4 7}$ \\
\hline Visa and work permit & 21 & 15 & 18 & 12 & 67 & 3 & 2 & 67 \\
\hline Education and qualification & 20 & 14 & 13 & 9 & $\mathbf{6 9}$ & 7 & 3 & $\mathbf{4 3}$ \\
\hline Job opportunities & 17 & 12 & 15 & 8 & 53 & 2 & 1 & 50 \\
\hline Business & 10 & 7 & 6 & 4 & $\mathbf{6 7}$ & 4 & 4 & $\mathbf{1 0 0}$ \\
\hline Work practices in Canada & 9 & 6 & 5 & 3 & $\mathbf{6 0}$ & 4 & 4 & $\mathbf{1 0 0}$ \\
\hline Living in Canada & 6 & 4 & 1 & 1 & 100 & 5 & 4 & 80 \\
\hline Resources & 2 & 1 & 1 & 0 & 0 & 1 & 1 & 100 \\
\hline Total / Average & 144 & $\mathbf{1 0 0} \%$ & $\mathbf{1 0 1}$ & $\mathbf{6 2}$ & $61 \%$ & $\mathbf{4 3}$ & $\mathbf{2 7}$ & $63 \%$ \\
\hline
\end{tabular}


The overall rates of needs met were similar for post-arrival (about 63\%) and pre-arrival (61\%) initial posts requesting advice support. However, analysis shows that the rates of needs being met in pre-arrival and post-arrival discussions varied for some of the 8 categories of topics in initial posts requesting advice support. For instance, topics about education and qualification and finding and applying for jobs were met more frequently for pre-arrival than post-arrival initial posts. However, topics about business and work practices in Canada were met more frequently for post-arrival than pre-arrival initial posts. In addition, the rates of needs being met for topics about visa and work permit and job opportunities were very similar for pre-arrival and post-arrival initial posts.

Next, I combined the figures from Table 25 and Table 26 into Table 27 below to see whether needs met vary for different categories of topics in pre-arrival and post-arrival threads.

Table 27. Needs met in the pre-arrival and post-arrival initial posts requesting support.

\begin{tabular}{|l|l|l|l|l|l|l|l|l|}
\hline \multicolumn{2}{|c|}{$\begin{array}{c}\text { Categories of topics in initial posts } \\
\text { requesting support }\end{array}$} & \multicolumn{3}{c|}{ Pre-arrival } & \multicolumn{3}{c|}{ Post-arrival } \\
\cline { 5 - 10 } & Total & $\%$ & Total & $\#$ & $\%$ & Total & $\#$ & $\%$ \\
\hline Living in Canada & 20 & 4 & 11 & 10 & 91 & 9 & 8 & 89 \\
\hline Work practices in Canada & 33 & 6 & 14 & 11 & 79 & 19 & 16 & 84 \\
\hline Starting groups & 9 & 2 & 4 & 3 & $\mathbf{7 5}$ & 5 & 3 & $\mathbf{6 0}$ \\
\hline Visa and work permit & 105 & 20 & 81 & 52 & 64 & 24 & 15 & 63 \\
\hline Education and qualification & 43 & 8 & 31 & 19 & 61 & 12 & 7 & 58 \\
\hline Finding and applying for jobs & 108 & 21 & 81 & 46 & 57 & 27 & 13 & 48 \\
\hline Business & 41 & 8 & 21 & 12 & 57 & 20 & 12 & 60 \\
\hline Job opportunities & 107 & 20 & 89 & 45 & $\mathbf{5 1}$ & 18 & 12 & $\mathbf{6 7}$ \\
\hline Resources & 25 & 5 & 18 & 9 & $\mathbf{5 0}$ & 7 & 5 & $\mathbf{7 1}$ \\
\hline Others' experiences & 33 & 6 & 22 & 10 & 45 & 11 & 6 & 55 \\
\hline Total / Average & $\mathbf{5 2 4}$ & $\mathbf{1 0 0} \%$ & $\mathbf{3 7 2}$ & $\mathbf{2 1 7}$ & $58 \%$ & $\mathbf{1 5 2}$ & $\mathbf{9 7}$ & $64 \%$ \\
\hline
\end{tabular}


The overall rate of needs met was higher for post-arrival (about 64\%) than pre-arrival (58\%) initial posts requesting support. Analysis in the table above also shows that topics about livings in Canada and work practices in Canada had the highest rates of needs met in pre-arrival and post-arrival threads. However, the rates of needs met about starting groups were higher in pre-arrival than post-arrival threads. Then again, the rates of needs met about resources and job opportunities were higher in post-arrival than pre-arrival threads. What is interesting is that the rates of needs met for the other 7 categories (i.e., work practices in Canada, living in Canada, visa and work permit, education and qualification, finding and applying for jobs, business, and others' experiences) were fairly similar (within only 10\%) for pre-arrival and post arrival threads.

\section{Needs met for different forms of advice}

Next, I examined needs met for the three forms of advice to investigate whether needs met vary for various forms of advice and different categories of topics requested in the initial posts. I summarized the analysis in Table 28 below. In the table below, the '\#' symbols indicate the total numbers of initial posts requesting specific form of advice in each category. 'Met' indicates number of initial posts with needs met, and '\%' indicates percentages of initial posts with needs met. 
Table 28. Needs met in different forms of advice and across categories of topics.

\begin{tabular}{|l|l|l|l|l|l|l|l|l|l|}
\hline \multirow{2}{*}{$\begin{array}{c}\text { Categories of advice needs } \\
\text { requested }\end{array}$} & \multicolumn{8}{|c|}{ Forms of advice } \\
\cline { 2 - 12 } & \multicolumn{3}{c|}{ Opinion } & \multicolumn{3}{c|}{ Guidance } & \multicolumn{2}{|c|}{ Problem Solving } \\
\cline { 2 - 12 } & $\#$ & Met & $\%$ & $\#$ & Met & $\%$ & $\#$ & Met & $\%$ \\
\hline Finding and applying for jobs & 28 & 19 & $\mathbf{6 8}$ & 20 & 9 & 45 & 11 & 5 & 45 \\
\hline Visa and work permit & 6 & 3 & 50 & 12 & 8 & 67 & 3 & 3 & $\mathbf{1 0 0}$ \\
\hline Education and qualification & 18 & 12 & 67 & 2 & 0 & 0 & & & \\
\hline Job opportunities & 17 & 9 & 53 & & & & & & \\
\hline Business & 5 & 4 & $\mathbf{8 0}$ & 5 & 4 & $\mathbf{8 0}$ & & & \\
\hline Work practices in Canada & 7 & 6 & $\mathbf{8 6}$ & 2 & 1 & 50 & & & \\
\hline Living in Canada & 5 & 4 & $\mathbf{8 0}$ & 1 & 1 & $\mathbf{1 0 0}$ & & & \\
\hline Resources & 2 & 1 & 50 & & & & & & \\
\hline Total / Average & $\mathbf{8 8}$ & $\mathbf{5 8}$ & $66 \%$ & $\mathbf{4 2}$ & $\mathbf{2 3}$ & $55 \%$ & $\mathbf{1 4}$ & $\mathbf{8}$ & $57 \%$ \\
\hline
\end{tabular}

Analysis shows that needs met varied not only among different categories of topics of advice needs requested, but also for different forms of advice. For example, opinion advice needs were met about $66 \%$ of the times while guidance and problem-solving advice were met $55 \%$ and $57 \%$ of the time respectively. In addition, analysis shows that about $80 \%$ of opinion advice needs about business, work practices in Canada, and living in Canada were met in online discussion forums. However, only about 50\% of opinion advice needs about visa and work permit, resources, and job opportunities were met in online forums. Moreover, advice needs about finding and applying for jobs were met more frequently for initial posts requesting opinion advice than for initial posts requesting guidance and problem-solving advice. However, advice needs about visa and work permit were met more frequently for initial posts requesting problem solving advice than for opinion and guidance advice. 


\subsection{Research Question 3: What are the characteristics of threads in which needs are not met?}

To examine research question 3, I further analyzed the threads with initial posts with needs not met. Figure 17 below shows the main steps in the analysis of research question 3 .

Figure 17. Main steps in the analysis of research question 3.

\begin{tabular}{|c|c|c|c|c|c|}
\hline \begin{tabular}{l}
\multicolumn{1}{c}{$\Delta$} \\
Step 1: \\
Examine \\
needs not \\
met for \\
different \\
categories of \\
topics
\end{tabular} & \begin{tabular}{l}
\multicolumn{1}{c|}{$\Delta$} \\
Step 2: \\
Examine \\
needs not \\
met for pre- \\
arrival and \\
post-arrival \\
initial posts
\end{tabular} & \begin{tabular}{l}
\multicolumn{1}{c}{$\Delta$} \\
Step 3: \\
Examine \\
needs not met \\
for different \\
forms of \\
advice \\
support
\end{tabular} & \begin{tabular}{l}
\multicolumn{1}{c|}{$\Delta$} \\
Step 4: \\
Examine \\
time since \\
the initial \\
post posting \\
date
\end{tabular} & 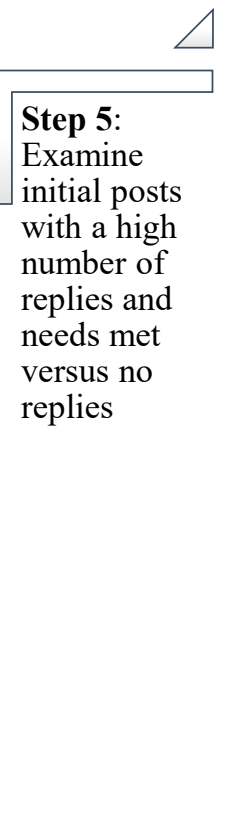 & $\begin{array}{l}\begin{array}{l}\text { Step 6: } \\
\text { Examine } \\
\text { factors }\end{array} \\
\text { influencing } \\
\text { active online } \\
\text { participation } \\
\text { - Reciprocity } \\
\text { - Member } \\
\text { ranking } \\
\text { - Context }\end{array}$ \\
\hline
\end{tabular}

\section{Summary of analysis and findings for research question 3.}

What are the characteristics of threads in which needs are not met?

Analysis of online forum data revealed that about one-third of the needs requested in the initial posts were not met (170 initial posts, 32.4\%) and that the rate of needs not met was higher for advice support needs (about 35\%) than for information support needs (about $32 \%)$. 
Further analysis of different forms of advice also showed that the rates of needs not met were higher for initial posts requesting guidance (about 38\%) and problem solving (about $43 \%)$ advice support than for initial posts requesting information support (32\%) and opinion advice support (32\%). This suggests that online discussion forums may be better for meeting newcomers' information and opinion support needs than guidance and problem-solving advice support needs.

Figure 18 below illustrates the percentages of needs not met for different forms of support requested in initial posts in online discussion forums concerning newcomers' labour market integration.

Figure 18. Needs not met for different forms of support requested in initial posts.

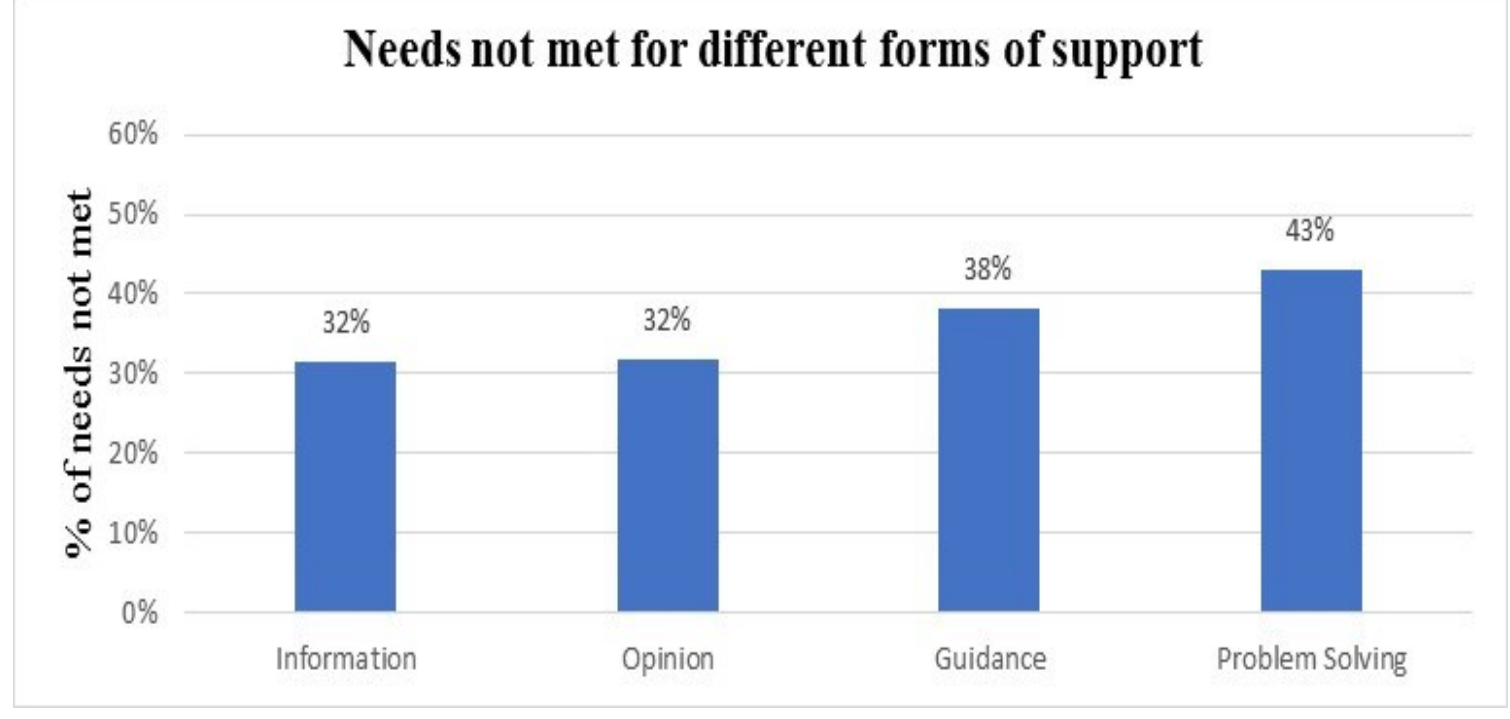

In this data, I found that the rates of needs not met varied for different categories of topics in the initial posts requesting information and advice support, as well as between pre-arrival and post-arrival initial posts. For example, the highest rates of needs not met for pre-arrival initial posts were found for information topics about others' experiences (41\%) and for 
advice topics about job opportunities (47\%). On the other hand, the highest rates of needs not met for post-arrival initial posts were found for information topics about business (44\%) and finding and applying for jobs (50\%) and advice topics about finding and applying for jobs (53\%) and education and qualification (57\%).

In the examined data, the top three categories of topics with the highest overall needs not met were about finding and applying for jobs (42 initial posts), job opportunities (38 initial posts), and visa and work permit (34 initial posts). These three categories of topics represent about $67 \%$ of all the initial posts with needs not met. Figure 19 below illustrates the number of initial posts in each of the ten categories of topics with needs not met.

Figure 19. Needs not met in the ten categories of topics.

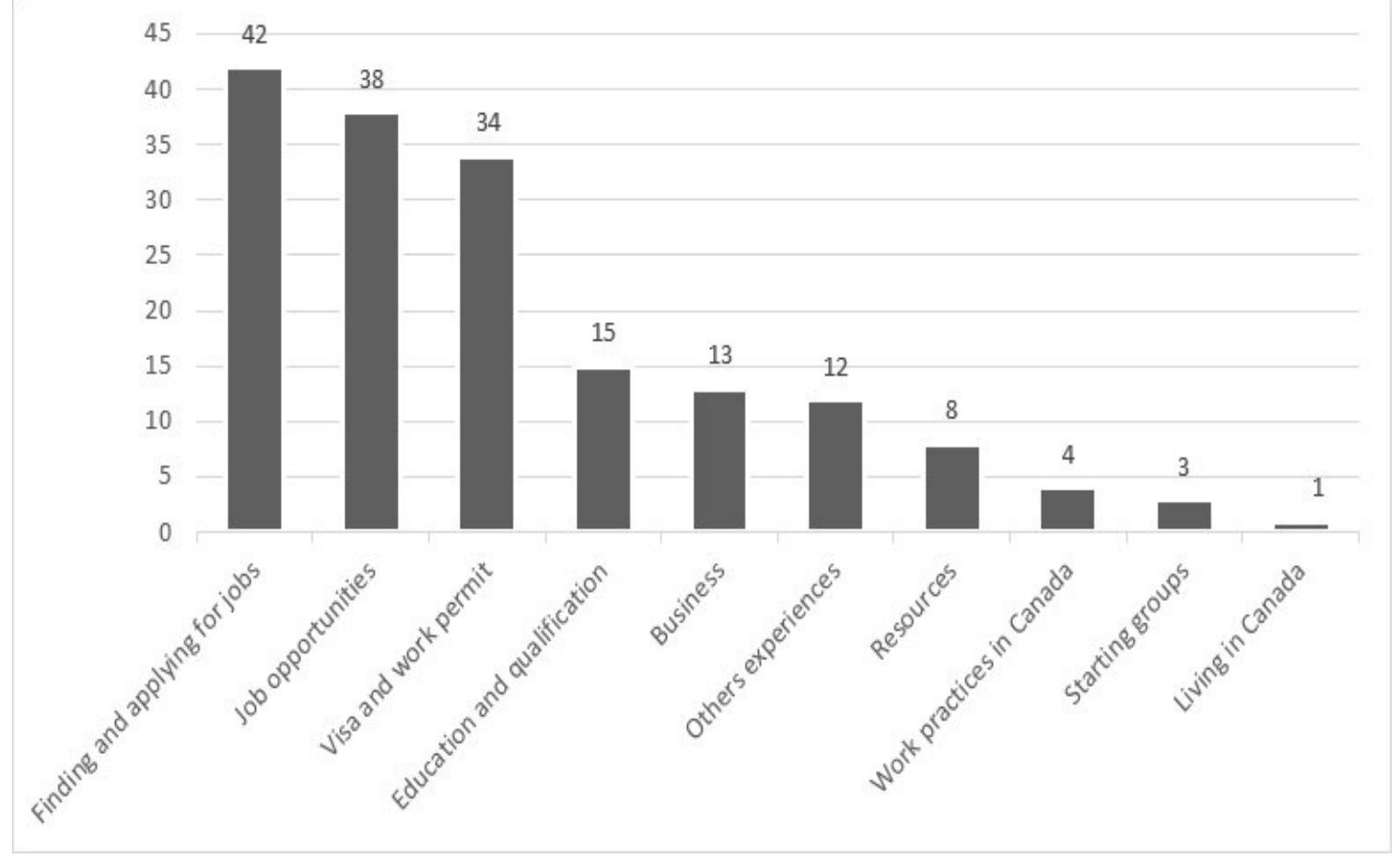


Question 3. What are the characteristics of threads in which needs are not met?

Analysis also suggests that the time passed since the initial post posting date does not seem to be a key factor influencing the rate of needs not met in online discussion forums. About $97 \%$ of initial posts with needs not met were posted on the discussion forum for at least 30 days before the data collection date.

Moreover, qualitative examinations and comparisons of texts in initial posts with a high number of replies and needs met and initial posts with no replies, using qualitative content analysis and Dedoose software, did not reveal any explicit differences between the initial posts with needs met and the initial posts with needs not met.

Examination of relevant extant research on online silence, lurkers, and online participation, as well as further examinations of the online forum data suggest that there may be several possible factors influencing higher no response rates in online discussion forums, including: usability, reciprocity, member ranking, online identity, group versus individual communication, asynchronous communications, and group identity (Feng et al., 2016; Gao and Zhou, 2017; Lim et al., 2013; Pan et al., 2017; Rains and Wright, 2016; Sun et al., 2014; Tang and Yang, 2012; van Mierlo, 2014; Zhang, 2010; Zhou, 2011). Although the literature suggests several possible factors, it was not possible to examine the role of many of these factors using the data collected for this study. Thus, future research should examine these factors using data collected from newcomers using online discussion forums with interviews, surveys, and focus groups. 
The two factors that I was able to examine using my data include reciprocity and member ranking. Essentially all authors of the initial posts with no replies were new members with very limited or no history of prior active participation in the online discussion forum. However, analysis and comparison of member rankings and prior participations of authors of initial posts with no replies and authors of initial posts with high number of replies revealed very little differences between the authors. This suggests that reciprocity and member ranking may not play critical roles on participation in the context of online discussion forums concerning newcomers' labour market integration.

Examination of data and relevant literature on online discussion forum communities suggests that online discussion forums concerning newcomers' labour market integration examined in this study are different from typical online health and education forum communities. The context of the newcomers' online forums is different and newcomers' interactions are quite different as well. The results suggest that the examined newcomers' forums have relatively low group identity, highly asymmetric knowledge among members, and very low rates of continued participation. These forums do not function like typical online communities. The interactions in the examined newcomers' online forums focus primarily on exchanging information and advice support rather than on developing long term connections and community. Thus, the results suggest that these forums are primarily online exchanges rather than online communities. This study introduces the new term online exchanges to describe and distinguish the newcomers' online discussion forums examined in this study from the typical online communities found in health and education contexts. These different contexts and online interactions in the examined newcomers' online forums may be the key factors influencing higher rates of no reply. 
Future research should further examine the online forum data using quantitative approaches (e.g., quantitative content analysis and text mining) to systematically extract and examine information from the initial posts texts as well as authors' online profiles with computer assisted text analysis techniques (e.g., Hoogeveen et al., 2018; Kuckartz, 2014; Momeni et al., 2016; Pennebaker et al. 2015; Zhai and Massung, 2016). Using a quantitative text analytic software will allow examination of a much larger sample of data and it may provide further insights into differences (e.g., structural, linguistic, and affective) between threads with initial posts with a high number of replies and needs met and threads with initial posts with not replies and needs not met. This is discussed in more detail in section four and the discussion chapter.

Future studies should also examine group identity and symmetry of knowledge using survey and/or interview data from newcomers participating in online forums to expand our understanding on these factors on participation in newcomers' online forums.

\section{Details of analysis for research question 3}

Based on the analysis for research questions 1 and 2, there are 127 threads with no replies in the 524 threads with requesting initial posts. Thus, about $24.2 \%$ of threads contain no replies. Among the 127 threads, 93 contain initial posts requesting information support and 34 requesting advice support. 
In the examined data, there are also 43 more questions threads. Although more questions threads include replies, the needs requested in their initial posts have not been met with the corresponding replies. I included five examples below to show the typical replies in the more questions threads.

\section{Example 1.}

"you got to be more specific" (CV21_243)

\section{Example 2.}

"I am really interested to know the answers of your question from any candidate or expert that face similar situation" (CV22_5)

\section{Example 3.}

“What are your updates? Could you find any job?” (CV21_84)

\section{Example 4.}

"I have the exact same query as that you have, for my Brother who has a similar experience but with 6+ years' experience. Let me know in case you got some leads in finding job for a Structural Engineer here in Canada. Your help is much appreciated." (CV21_316)

\section{Example 5.}

"Hi, did you get any option? I am also in same boat as you were two years back. Thanks" (CV21_194)

Considering that the needs are not met in both the no replies and more questions threads, further analysis will examine them together. 


\section{Needs not met in various categories of topics requested in initial posts}

First, I started my analysis by examining needs not met across the 10 categories of topics that I identified in research question 1 to see if the rates of needs not met varied for different categories of topics and for advice and information support. In Table 29, I summarized the threads with needs not met across various categories of information and advice needs requested in the initial posts.

Table 29. Threads with needs not met across categories of topics of needs requested.

\begin{tabular}{|l|l|l|l|l|l|}
\hline \multicolumn{2}{|c|}{ Categories of topics } & \multicolumn{3}{c|}{$\begin{array}{c}\text { Threads with needs not met } \\
\text { (no replies and more questions) }\end{array}$} \\
\cline { 3 - 7 } & \multicolumn{2}{|c|}{ Information } & \multicolumn{2}{c|}{ Advice } \\
\hline & Total & $\#$ & $\%$ & $\#$ & $\%$ \\
\hline Finding and applying for jobs & 108 & 18 & 37 & 24 & 41 \\
\hline Others' experiences & 33 & 12 & 36 & 0 & 0 \\
\hline Business & 41 & 11 & 35 & 2 & 20 \\
\hline Job opportunities & 107 & 31 & 34 & 7 & 41 \\
\hline Starting groups & 9 & 3 & 33 & 0 & 0 \\
\hline Visa and work permit & 105 & 28 & 33 & 6 & 29 \\
\hline Education and qualification & 43 & 7 & 30 & 8 & 40 \\
\hline Resources & 25 & 7 & 30 & 1 & 50 \\
\hline Work practices in Canada & 33 & 3 & 13 & 1 & 11 \\
\hline Living in Canada & 20 & 0 & 0 & 1 & 17 \\
\hline Total / Average & $\mathbf{5 2 4}$ & $\mathbf{1 2 0}$ & $32 \%$ & $\mathbf{5 0}$ & $35 \%$ \\
\hline
\end{tabular}

Needs were not met in 120 out of the 380 initial posts requesting information (about 32\%), and in 50 out of the 144 initial posts requesting advice (about 35\%). The ratio of needs not met is only $3 \%$ higher for advice than information support needs. In the examined data, the top three categories of topics with needs not met were requesting support about finding and applying for jobs (42 initial posts), job opportunities (38 initial posts), and visa and work 
permit (34 initial posts). These three categories represent about $67 \%$ (i.e., 114 out of 170 initial posts) of the requesting initial posts with needs not met.

In addition, there were some differences between various types of information and advice support needs requested in the initial posts. For example, comparison of the rates of needs not met between initial posts requesting information and advice support showed that categories of topics about education and qualification, resources and job opportunities had higher rates of needs not met for initial posts requesting advice support than information support. However, initial posts requesting information support about business had higher rate of needs not met than initial posts requesting advice support about business. The rates of needs not met were similar (within 5\% difference) for the other categories of topics (e.g., finding and applying for jobs, visa and work permit, and work practices in Canada) requested in information and advice initial posts. In addition, the rate of needs not met for information support about starting groups was about 33\%, which is close to the average of needs not met for the initial posts requesting information support (32\%) in this data.

Moreover, initial posts requesting others' experiences had a relatively high rate of needs not met, about $36 \%$. In the initial posts requesting others' experiences, authors are asking other members in the discussion forum to share their relevant personal experiences in Canada. Analysis of initial posts in research question 1 showed that about $70 \%$ of initial posts authors are pre-arrival. Pre-arrival users typically have no prior relevant experience in Canada. Therefore, since a large majority of online forums members lack prior experience in Canada, a higher rate of needs not met for others' experiences is to be expected as a majority of members have no relevant experience to share with others. 


\section{Needs not met in pre-arrival and post-arrival initial posts}

Next, I examined needs not met in the pre-arrival and post-arrival initial posts. First, in

Table 30 below I summarized the analysis for information needs.

Table 30. Needs not met in pre-arrival and post-arrival initial posts requesting information.

\begin{tabular}{|l|l|l|l|l|l|l|l|l|}
\hline \multirow{2}{*}{$\begin{array}{c}\text { Categories of topics in initial posts requesting } \\
\text { information support }\end{array}$} & \multicolumn{3}{c|}{ Pre-arrival } & \multicolumn{3}{c|}{ Post-arrival } \\
\cline { 4 - 11 } & & & $\begin{array}{c}\text { Needs not } \\
\text { met }\end{array}$ & & \multicolumn{2}{|c|}{$\begin{array}{c}\text { Needs not } \\
\text { met }\end{array}$} \\
\hline & Total & $\%$ & Total & $\#$ & \% & Total & $\#$ & $\%$ \\
\hline Job opportunities & 90 & 24 & 74 & 27 & $\mathbf{3 6}$ & 16 & 4 & 25 \\
\hline Visa and work permit & 84 & 22 & 63 & 21 & 33 & 21 & 7 & 33 \\
\hline Finding and applying for jobs & 49 & 13 & 39 & 13 & 33 & 10 & 5 & $\mathbf{5 0}$ \\
\hline Others' experiences & 33 & 9 & 22 & 9 & $\mathbf{4 1}$ & 11 & 3 & 27 \\
\hline Business & 31 & 8 & 15 & 4 & 27 & 16 & 7 & $\mathbf{4 4}$ \\
\hline Work practices in Canada & 24 & 6 & 9 & 1 & 11 & 15 & 2 & 13 \\
\hline Education and qualification & 23 & 6 & 18 & 6 & $\mathbf{3 3}$ & 5 & 1 & 20 \\
\hline Resources & 23 & 6 & 17 & 5 & 29 & 6 & 2 & 33 \\
\hline Living in Canada & 14 & 4 & 10 & 0 & 0 & 4 & 0 & 0 \\
\hline Starting groups & 9 & 2 & 4 & 1 & 25 & 5 & 2 & 40 \\
\hline Total / Average & $\mathbf{3 8 0}$ & $\mathbf{1 0 0} \%$ & $\mathbf{2 7 1}$ & $\mathbf{8 7}$ & $32 \%$ & $\mathbf{1 0 9}$ & $\mathbf{3 3}$ & $30 \%$ \\
\hline
\end{tabular}

The overall rates of need not met for pre-arrival (32\%) and post-arrival (30\%) initial posts are similar, within $2 \%$. However, the analysis showed that the rates of needs not met for information support topics about job opportunities, others' experiences, and education and qualification were higher for pre-arrival than for post-arrival initial posts. In addition, the rates of need not met for information support about finding and applying for jobs and business were lower for pre-arrival than post-arrival initial posts. Moreover, the rates of needs not met for information about visa and work permit, work practices in Canada, and resources were similar (within $4 \%$ difference) for pre-arrival and post-arrival. 
For pre-arrival initial posts, the highest rate of need not met was for a category about others' experiences (41\%), whereas for post-arrival the two categories with the highest rates of needs not met were about finding and applying for jobs (50\%) and business (44\%).

Similarly, I summarized the analysis for advice needs in Table 31 below.

Table 31. Needs not met in pre-arrival and post-arrival initial posts requesting advice.

\begin{tabular}{|l|l|l|l|l|l|l|l|l|}
\hline \multicolumn{3}{|c|}{$\begin{array}{c}\text { Categories of topics in initial posts } \\
\text { requesting advice support }\end{array}$} & \multicolumn{3}{c|}{ Pre-arrival } & \multicolumn{3}{c|}{ Post-arrival } \\
\cline { 4 - 11 } & & & $\begin{array}{c}\text { Needs not } \\
\text { met }\end{array}$ & & $\begin{array}{c}\text { Needs not } \\
\text { met }\end{array}$ \\
\hline Finding and applying for jobs & 59 & 41 & 42 & 15 & 36 & 17 & 9 & $\mathbf{5 3}$ \\
\hline Visa and work permit & 21 & 15 & 18 & 5 & 28 & 3 & 1 & 33 \\
\hline Education and qualification & 20 & 14 & 13 & 4 & 31 & 7 & 4 & $\mathbf{5 7}$ \\
\hline Job opportunities & 17 & 12 & 15 & 7 & $\mathbf{4 7}$ & 2 & 0 & 0 \\
\hline Business & 10 & 7 & 6 & 2 & $\mathbf{3 3}$ & 4 & 0 & 0 \\
\hline Work practices in Canada & 9 & 6 & 5 & 1 & 20 & 4 & 0 & 0 \\
\hline Living in Canada & 6 & 4 & 1 & 0 & 0 & 5 & 1 & 20 \\
\hline Resources & 2 & 1 & 1 & 1 & 100 & 1 & 0 & 0 \\
\hline Total / Average & $\mathbf{1 4 4}$ & $\mathbf{1 0 0} \%$ & $\mathbf{1 0 1}$ & $\mathbf{3 5}$ & $34 \%$ & $\mathbf{4 3}$ & $\mathbf{1 5}$ & $35 \%$ \\
\hline
\end{tabular}

The overall rates of needs not met for pre-arrival (34\%) and post-arrival (35\%) initial posts were again very similar. However, analysis showed that the rates of needs not met varied for different categories of topics in pre-arrival and post-arrival initial posts requesting advice support as well. For instance, the rates of needs not met for advice support about job opportunities and business were higher for pre-arrival than post-arrival initial posts. However, the rates of needs not met for advice support about finding and applying for jobs and education and qualification were lower for pre-arrival than post-arrival initial posts. Rates of needs not met were similar (within 5\%) for advice about visa and work permit for pre-arrival and post-arrival initial posts. 
Likewise, the highest rate of need not met for pre-arrival initial posts was for a category about job opportunities (47\%), whereas for post-arrival the two categories with the highest rates of needs not met were about finding and applying for jobs (53\%) and education and qualification (57\%).

\section{Needs not met for different forms of advice}

Next, I examined needs not met for different forms of advice to see if the rates of needs not met vary for different forms of advice as well. I summarized the results for the information and three forms of advice in Table 32 below.

Table 32. Needs not met for initial posts requesting information and three forms of advice.

\begin{tabular}{|l|c|c|c|c|}
\hline $\begin{array}{l}\text { Types of support } \\
\text { needs requested }\end{array}$ & Initial posts & $\mathbf{\%}$ & Needs not met & $\mathbf{\%}$ \\
\hline Information & 380 & 72.5 & 120 & 31.6 \\
\hline Opinion & 88 & 16.8 & 28 & 31.8 \\
\hline Guidance & 42 & 8 & 16 & 38.1 \\
\hline Problem solving & 14 & 2.7 & 6 & 42.9 \\
\hline Total / Average & $\mathbf{5 2 4}$ & $\mathbf{1 0 0 \%}$ & $\mathbf{1 7 0}$ & $32.4 \%$ \\
\hline
\end{tabular}

In this data, I found that the rates of needs not met for information support and opinion advice support were almost the same, about $32 \%$. However, the rates of needs not met were higher for guidance advice (about 38\%) and problem-solving advice (about 43\%). This suggests that online discussion forums are better for meeting newcomers' information support and opinion advice needs than for meeting their guidance and problem-solving advice needs. 


\section{Time since the initial posts' posting date}

Next, I examined the initial posts' 'posting dates' (posting date refers to the date when the initial post has been added to the forum) to see if sufficient time has passed, between the initial post posting date and the data collection date, for an initial post to receive a reply. Examination of posting dates revealed that only 4 out of the 170 threads with initial posts with needs not met have been posted within 30 days from the data collection date. In other words, 166 out of the 170 initial posts with needs not met (about 97\%) have been added and available in the online discussion forum for at least 30 days before the data collection date. Moreover, about 104 out of the 170 initial posts (about 61\%) were posted on the discussion forum for more than 6 months.

One can argue that 30 days is a sufficiently long time to receive a reply, especially considering that the large majority of initial posts with needs met received a reply the same day or within only few days after the posting date. Therefore, initial post posting date does not seem to be a key factor influencing the rate of needs not met in the context of online discussion forums concerning newcomers' labour market integration.

\section{Initial posts with high number of replies and needs met versus no replies}

Next, I examined and compared the initial posts with high number of replies and needs met with the initial posts with no replies, for various categories of topics of information and advice support. That is, for examples, I selected and examined initial posts requesting information support about job opportunities and compared the initial posts with a high number of replies and needs met to initial posts with no replies. To illustrate, in Table 33 
below I included six examples of initial posts requesting information about job opportunities, three with a very high number of replies and three with no replies.

Table 33. Examples of initial posts with high number of replies and no replies.

\begin{tabular}{|c|c|}
\hline High number of replies and needs met & No replies \\
\hline $\begin{array}{l}\text { (CV21_299) - } 70 \text { replies } \\
\text { "Folks, How's the Telecom Job } \\
\text { opportunity in Canada?" }\end{array}$ & $\begin{array}{l}\text { (CV21_122) - no replies } \\
\text { "Hi guys, I wish to immigrate Canada, } \\
\text { But I need to be cleared with job market. } \\
\text { Is there any scope for construction } \\
\text { planning engineers?" }\end{array}$ \\
\hline $\begin{array}{l}\text { (CV21_328) - } 25 \text { replies } \\
\text { "I am a Diploma holder and right now } \\
\text { doing Engineering in Electrical and } \\
\text { electronics engineering (bachelor } \\
\text { engineering) and after finishing my } \\
\text { degree I like to work in Canada is there is } \\
\text { any jobs available for people like me..." }\end{array}$ & $\begin{array}{l}\text { (CV21_371) - no replies } \\
\text { "I have } 3 \text { years of experience in Digital } \\
\text { Marketing and a bachelor's degree in } \\
\text { Arts, what are the job prospects for me" }\end{array}$ \\
\hline $\begin{array}{l}\text { (CV21_92) - } 16 \text { replies } \\
\text { "What sort of survival jobs are available } \\
\text { suppose I want to make } 3000 \$-\$ 4000 \text { a } \\
\text { month in Toronto? This is soon upon my } \\
\text { arrival" }\end{array}$ & $\begin{array}{l}\text { (CV21_47) - no replies } \\
\text { "hey guys, any idea about what the } \\
\text { market for Mechanical engineer oil gas in } \\
\text { SASK. is or for a project engineer - } \\
\text { mechanical" }\end{array}$ \\
\hline
\end{tabular}

As shown in the examples above, the initial posts with high number of replies and no replies are very similar. Qualitative examination of initial posts requesting information support and advice support did not reveal any apparent differences between initial posts with high number of replies and needs met and initial posts with needs no replies. 


\section{Participation in computer mediated communications}

Next, I examine relevant literature concerning participation in computer mediated communications to see whether extant research can provide some additional explanations for no responses in online discussion forums.

Research in the context of mental health showed that although an increasing number of individuals seek support online, the participation in offline communities, such as face-toface support groups, was considerably higher than in online support communities (DeAndrea, 2015; DeAndrea and Anthony, 2013). Studies also show that a large part of computer mediated communications does not receive responses (Sun et al., 2014; van Mierlo, 2014). In computer mediated communication literature, a lack of response (e.g., not receiving a reply to an-email or initial posts in an online forum) is referred to as 'online silence' (Kalman, 2007).

A substantial number of studies examined 'online silence' in e-mail communications (e.g., Barron and Yechiam, 2002; Lewis et al., 2004; Mark et al., 2005). However, there are relatively few studies examining the phenomenon of 'online silence' in other computer mediated communication technologies, such as virtual teams (e.g., Ter Bush, 2006), newsgroups (e.g., Joyce and Kraut, 2006), and online discussion forums (e.g., Hewitt, 2005). In addition, silence in online forums was primarily examined in the context of classroom and students, and in the context of health (Kalman, 2007; Sun et al., 2014).

Research has found that participation in online discussion forums is not symmetric and that typically a small number of members contribute in the discussions (Kalman, 2007). A 
larger number of online community members are 'lurkers', that is members who limit their participation to readings only (i.e., stay silent and never post or reply in an online community) (Lampe et al., 2010; Sun et al., 2014). The percentage of lurkers in an online community also varies (between 50\% and 90\%) for different communities (Kalman, 2007; Sun et al., 2014; van Mierlo, 2014; Yang et al., 2017). For example, examination of four online health social networks showed that the top $1 \%$ of most actively participating members created almost $74 \%$ of posts on average, while the bottom $90 \%$ of members created less than $2 \%$ of posts on average (van Mierlo, 2014).

\section{Factors influencing active participation}

Research identified several factors influencing active participation in computer mediated communications, including usability, reciprocity, member rankings, online identity, group versus individual communication, and asynchronous communications (Feng et al., 2016; Gao and Zhou, 2017; Pan et al., 2017; Rains and Wright, 2016; Sun et al., 2014; van Mierlo, 2014). These factors are briefly discussed below.

\section{Usability}

Studies suggest that usability (i.e. the ease of use) of the online community interface influences the participation as more complex interfaces generally discourage users from actively interacting and participating (Nonnecke et al., 2004; Preece et al., 2004). However, it is not possible to determine the ease of use of the particular online discussion forum interface to community members by studying the data collected in this study (e.g., thread discussion). 
Members of the online discussion forums examined in this study had to understand how to use the technology in order to actively participate in the discussions (e.g., create initial posts and/or replies). In order to participate in the online forum, one must first 'sign up' (i.e., register and create a unique login name and password). To sign up, one also needs a valid email address. After signing up, one needs to ' $\log$ in' into the online forum using the created login name and password. Even though one needs to sign up only once and that the registration process takes only a few minutes, it is impossible to examine the online discussion forum 'usability' for newcomers with the data collected for this study. Extant research typically examined usability of computer mediated communication by studying data collected with surveys. For example, Nonnecke et al. (2004) examined 1,188 online survey responses. Therefore, future research should investigate the role of usability on the participation in the context of online forums and newcomers' labour market integration by examining data collected with survey questionnaires and/or interviews.

\section{Reciprocity}

Studies suggests that individuals are more motivated to actively contribute in an online community when their contributions also receive replies and/or positive reaction (e.g., 'like', 'thumbs up', 'upvotes' and/or 'thanks') (Fan et al., 2009; Joyce and Kraut, 2006; Pan et al., 2017; Sun et al., 2014).

In online health discussion forums, Pan et al. (2017) found that social support is very selfgenerative and reciprocal. They found that the numbers of replies online forum members receive and sent out in online health forums are correlated. That is, members that sent out a higher number of replies typically also receive a higher number of replies. In addition, 
the greater the number of users one replied to, the greater the number of users they received replies from. Moreover, the average length of replies users sent out also correlates to the average length of replies they receive. In online health forums, users that provide more social support typically also receive more social support, and thus to get more social support one should try to provide more social support as well (Pan et al., 2017).

To study the role of reciprocity on participation, I examined the extent of prior active participation of the authors of the initial posts. In particular, I examined the collected data (i.e., all 574 thread discussions) and coded for the number of times each of the authors of initial posts with needs not met participated in the discussions (i.e., posted initial posts or replies) prior to creating the initial posts examined in this study. Analysis revealed that in the 170 threads with initial posts with needs not met, 107 (or 63\%) were started by authors who did not contribute in the online discussion forum before. That is, the initial posts were authors' first active contribution in the online forum. In the remaining 63 threads, 37 (or $22 \%$ ) authors contributed only once and 26 (or 15\%) authors contributed between 2 and 7 times ( 2 times on average) before posting their initial posts with needs not met. Moreover, they typically contributed by starting requesting threads or posting replies within their own threads. In addition, they typically participated within the same day they posted their initial posts.

Next, I examined and compared the figures for prior participation of authors of initial posts with high number of replies. In the examined data, there are only 42 requesting initial posts containing 10 or more replies, with about 24 replies on averages. The examination of the initial post authors' prior participation in the online forum revealed that the 42 authors 
contributed only about 4 posts on average. Although this is higher than the average prior contribution of authors of initial posts with no replies (i.e., only about 2 times on average), it is still quite low. Moreover, out of the 42 authors, 17 (about 40\%) did not participate prior to posting their initial posts. In addition, 7 authors (about 17\%) participated only once and 14 (about 33\%) participated up to 10 times before posting their initial posts. The remaining 4 (about 10\%) authors contributed 13,14,16, and 18 times respectively prior to posting their initial posts.

Analysis shows that the degree of prior participation of authors of requesting initial posts with no replies and authors with requesting initial posts with high number of replies are not that different. In both instances, the majority of authors contributed only once or not at all prior to posting their initial posts. This finding suggests that reciprocity may not be one of the key factors influencing participation in online discussion forums in the context of newcomers' labour market integration.

\section{Member ranking}

Member ranking refers to the author's status (e.g., newbies, star, hero, champion) in the online community (Gao and Zhou, 2017; Tang and Yang, 2012). It is typically based on the degree of active participation in the online community and the more one participates the higher his/her ranking is.

In the examined online discussion forums, users with fewer than 10 posts are ranked as newbies. Users gain a rank of member when they contribute between 10 and 20 posts and full member when they contribute at least 20 posts. 
Examination of the authors' ranks revealed that the authors of initial posts with needs not met are all ranked as newbies in the online forum community. In addition, the majority of the authors typically did not participate in the forum again. That is, their initial posts with needs not met were their first and typically the only participation in the online forum. This discovery supports findings in extant research suggesting that online members are more likely to post again when they receive responses (Joyce and Kraut, 2006; Pan et al., 2017). Since threads with no replies did not receive any responses, the authors of these threads are less likely to participate again. Future research should further examine the role of reciprocity and member ranking of initial posts authors on the response rates using a much larger sample and quantitative approaches to expand our understanding of the factors influencing needs not met in online discussion forums.

\section{Online identity}

Feng et al. (2016) also found that a seeker's and/or provider's online identity (e.g., using first name instead of nickname and profile with picture versus no picture) can influence support processes in online communications. They found, for example, that participants provided more polite and personalized support responses when the support seekers included first names and profile pictures.

In the particular forums examined in this study, users do not include profile pictures. In addition, only about $2 \%$ of users use first names instead of nicknames, and there is no way to determine if the first names used are actually their real first names. Lack of users' 'identity' in newcomers' online discussion forums may also be a factor influencing higher 
no response rates. Future research should study the role of identity on the response rate by examining users' surveys and/or interviews responses.

\section{Group versus individual communication}

Another probable reason for no response might be the nature of communication processes in online discussion forums. Research on silence in the context of e-mail found that e-mail requests addressed to several people received lower response rates than requests addressed to a single individual (Barron and Yechiam, 2002). Similarly, messages sent to a discussion group received a lower response rate than requests sent to individual members of the group (Yechiam and Barron, 2003). In online discussion forums, initial posts are typically directed at the entire online forum community and not specific individual members, which could also result in higher rates of no response. Future research should also investigate the role of group versus individual communications on the response rates in online forum communities.

\section{Asynchronous communications}

Studies have shown that computer mediated communication is different from typical offline face-to-face communication (Hrastinski, 2008; Rains and Wright, 2016; Tanis, 2008). For example, asynchronous online communications allow users more time to review text-based messages and to decide whether to respond to the messages (Eastin and LaRose, 2005; Kalman, 2007; Lampe et al., 2011; Lim et al., 2013; Rains and Wright, 2016; Trepte et al., 2015). 
Kalman (2007) proposed a model of a text-based computer mediated communication cycle. This model depicts seven main stages of communication and suggests that an individual may decide not to respond to the message at any of the seven stages which would result in no response to the original message. Figure 20 below shows the model proposed in Kalman's (2007) study.

Figure 20. A schematic model of a text-based CMC cycle (Kalman, 2007:73).

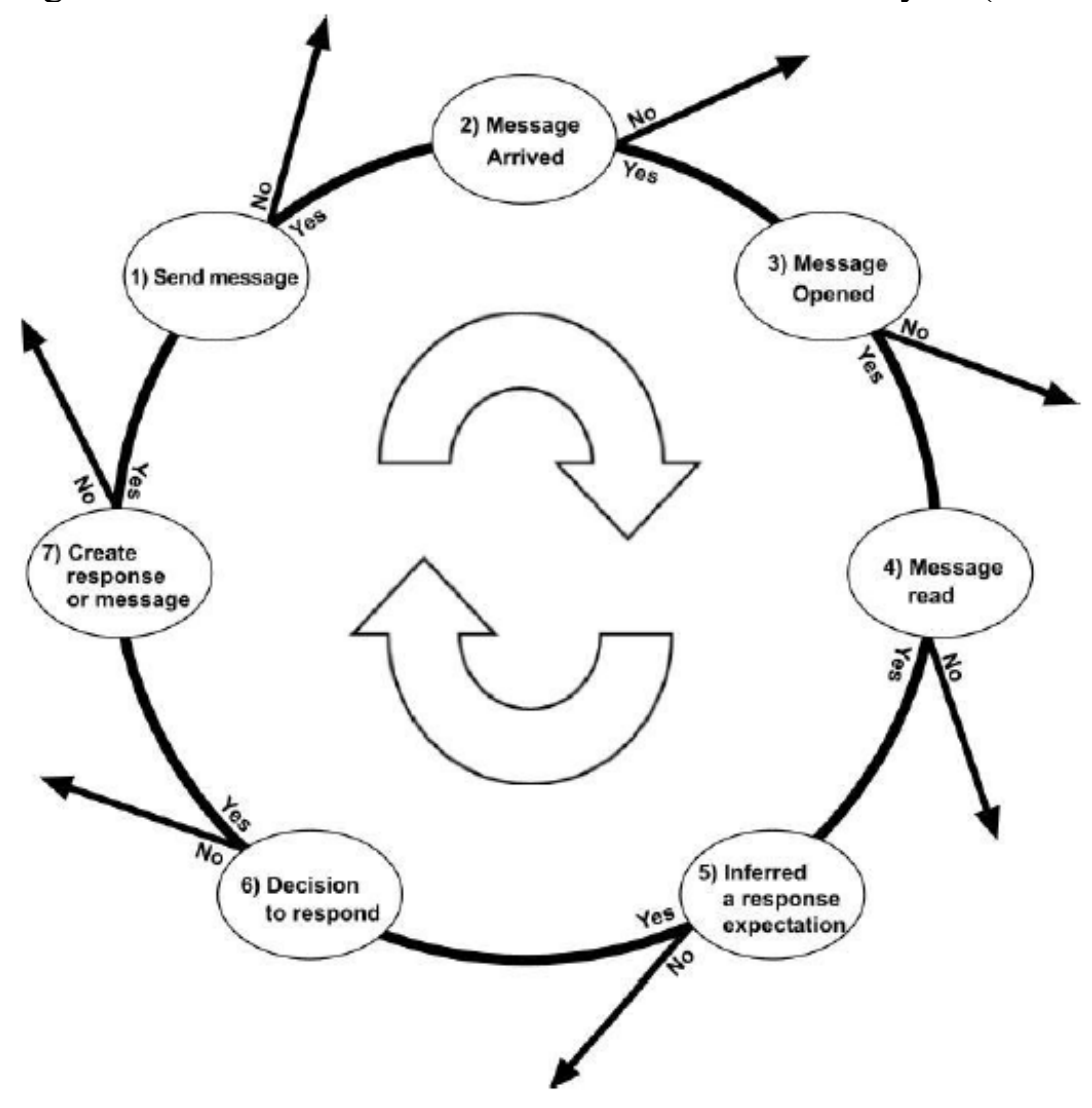

As shown in the figure above, online users have many opportunities to not respond to the message in asynchronous computer mediated communications such as online discussion forums. Before an initial post requesting support receives a relevant response in an online forum, the potential knowledgeable respondent has to find the thread with the initial post in the online forum, view and read the initial post, infer the response, decide to respond, 
create a response, and post the response in the thread. The potential respondent can decide not to respond to the initial post at any time in this process. Individuals have greater pressure to respond in face-to-face communication than in asynchronous online discussion forum communications. Online discussion forums provide users with more flexibility to not respond as well as greater anonymity, as initial post authors do not know whether particular community members visited their thread or not. They only see the total number

of views. Considering the above, one could argue that asynchronous communications may be one of the factors influencing no response rate in online communications as well. Future research should further investigate the role of asynchronous online communications on response rates.

\section{Context of online discussion forums}

Examination of the forum data and relevant literature on online communities suggest that the context may also be a factor influencing active participation. Participation in online forums was primarily examined in the context of education and the context of health (Kalman, 2007; Rains and Wright, 2016; Sun et al., 2014). However, the context of online discussion forums concerning labour market integration of newcomers in the destination country's labour market is different from the contexts of online discussion forums concerning health issues and education. The main types of support requested are different (e.g., emotional support in health forums), and the criteria for participation and effectiveness is different as well.

Education and health online forums are typically online communities (Rains and Wright, 2016; Yang et al., 2017; Zhou, 2011), whereas analysis in this study suggests that online 
forums concerning labour market integration of newcomers are more like 'online exchanges'. Online communities form closely around specific topics of interests (e.g., diabetes, smoking, fertility) and they involve online interactions of individuals with specific knowledge on the topics of interest (Haythornthwaite et al., 2000; Jansen and Saint

Onge, 2015; Oh et al., 2014; Zhang, 2010). A typical online community consist of group identity, symmetry of knowledge, and continuous interactions (Armstrong et al., 2012; Flickinger et al., 2017; Oh et al., 2014; Rising et al., 2017; Sheng and Hartono, 2015; Yang et al., 2017), which are discussed below.

\section{Group identity}

Research suggests that stronger group identity (i.e., common cognitive, moral and emotional connections) with a particular online community encourages greater active participation and online communities with stronger group identities typically have greater proportions of members actively participating (Haberstroh and Moyer, 2012; Holbrey and Coulson, 2013; Yang et al., 2017; Yli-Uotila et al., 2014; Zhang, 2010; Zhou, 2011).

In an online health community, individuals typically share very similar health challenges and experiences concerning a very specific health subject (e.g., fertility) (Lee, 2017). Interacting with others who share similar challenges and experiences also encourages a sense of belonging and empathy and increases perception of support available in the particular online communities (Nambisan, 2011; Oh et al., 2014; Rains and Wright, 2016). Similarly, in an education online community, individuals typically are members of a particular course, University, or program that they can also identify with, which can increase their overall group identity (Ruhleder, 2002). 
Analysis of online discussion forums concerning labour market integration of newcomers suggests that newcomers using online discussion forums come from very different countries, cultures, and often face different challenges (e.g., visa application, job search, education accreditation). In addition, about $70 \%$ of participants are pre-arrival, that is, still living in their homelands, and with very limited or lack of knowledge of Canada and the Canadian labour market. One could argue that newcomers, especially those still living in their homelands, generally will have relatively low group identity with other members in the online forum.

It is not feasible to study group identity by examining online discussion forums text data. The extant research studied group identity by examining responses to survey questionnaires (e.g., Zhang, 2010; Zhou, 2011). In addition, group identity in computer mediated communications was primarily examined in the context of education and University students. For example, Zhang (2010) examined 181 survey questionnaires collected from university students in the U.S.A. and Zhou (2011) studied responses to 450 survey questionnaires collected from university students in China. Future research should investigate the role of group identity on the participation rate in online discussion forums in the context of newcomers and labour market integration by examining data collected with survey questionnaires and/or interviews.

\section{Symmetry of knowledge}

In health and education online communities, members typically have some prior knowledge (e.g., attend the same course) and experiences (e.g., dealing with the same or similar health issues) about the subject of interest (Li, 2004; Ruhleder, 2002; Sheng and 
Hartono, 2015). This relative symmetry of knowledge enables members not only to request social support resources, but also to actively reciprocate and share some of their own knowledge and experiences on a particular subject (Griesbaum et al., 2015). Symmetry of knowledge enables not only exchange, but also collaboration and co-creation of online resources (Griesbaum et al., 2015; Sheng and Hartono, 2015). In the context of this study, co-creation refers to construction of new knowledge (e.g., information, advice) from exchanges and reconfiguration of existing knowledge (Griesbaum et al., 2015; Nonaka, 1994; Stewart Loane et al., 2015).

On the other hand, examination of online discussion forums concerning labour market integration of newcomers in Canada revealed that about $70 \%$ of initial posts were authored by individuals in the pre-arrival migration stage. These individuals generally lack relevant knowledge and experience about the new country's labour market and hence are unable to fully reciprocate. Substantial asymmetry of knowledge of pre-arrival migrants reduces the degree to which they can participate in online discussion forums.

The results suggest that newcomers generally used online discussion forums to seek and exchange social support only. However, in typical online communities, users not only seek and exchange support, but also co-create social support resources (e.g., Griesbaum et al., 2015; Seraj, 2012; Sheng and Hartono, 2015; Stewart Loane et al., 2015). Therefore, the examined online discussion forums concerning labour market integration of newcomers in the new country are more like online exchanges of 'social support' rather than typical online communities. 


\section{Continuity}

Continued participation is also an important aspect of online community and it can also enhance group identity and participants' rankings in online communities (Haythornthwaite et al., 2000; Oh et al., 2014; Zhou, 2011). However, analysis in this study found that newcomers typically do not participate continuously in online discussion forums. Generally, newcomers participate only very few times and within a very short time span. That is, they usually participate the same day only or within 1-2 days since their initial post. This suggests again that the newcomers' forums examined in this study act more like online exchanges of social support than online communities. Newcomers seem to turn to online discussion forums primarily to seek or request a particular support only and they rarely reciprocate or participate afterwards.

Table 34 below summarizes the main differences between online community and online exchange.

Table 34. Online community versus Online exchange.

\begin{tabular}{|l|l|}
\hline \multicolumn{1}{|c|}{ Online Community } & \multicolumn{1}{c|}{ Online Exchange } \\
\hline Group identity & Very limited or lack of group identity \\
\hline Symmetry of knowledge of members & Asymmetry of knowledge of members \\
\hline Continuity of interactions & $\begin{array}{l}\text { Infrequent use and minimum reciprocal } \\
\text { contributions }\end{array}$ \\
\hline
\end{tabular}




\subsection{Research Question 4: What role do online discussion forums play in facilitating and/or hindering newcomers' labour market integration?}

Examination of the 574 threads discussions written by newcomers to Canada suggests that, in the context of labour market integration, online discussion forums facilitate newcomers' labour market integration by facilitating the exchange of social support resources in the form of information and advice (Caligiuri et al., 2001; Kim and Tung, 2013; Takeuchi, 2010). Better preparation and more accurate expectations can in turn help newcomers with adjustment and integration in the new country's labour market (Harvey et al., 2012; Irving and Montes, 2009; Kraimer et al., 2016; Mähönen et al., 2013).

Analysis of different forms of advice also showed that online discussion forums are better at facilitating exchange of opinion and guidance than problem solving advice. There are very few requests for problem solving advice in the data (less than $3 \%$ of the requesting initial posts) and about $43 \%$ of these needs are not met.

In this data, about $60 \%$ of the needs requested in the initial posts have been met in online discussion forums. Although only $60 \%$ of needs were met, one has to also consider the cost of obtaining social support with online discussion forums. The effort and cost of seeking support is very minimal in online discussion forums compared to offline sources (Rains and Wright, 2016). Online discussion forums also provide specific technological affordances (Treem and Leonardi, 2012) that enable newcomers' new ways of seeking and gaining relevant support resources online. Newcomers can seek and access support online from anywhere in the world and at any time, and online support is visible (i.e., available 
and accessible to all users), persistent (i.e., does not expires and remains accessible at all times), and asynchronous (i.e., users have more time to examine text-based messages and to decide if and how to respond to the messages) (Kalman, 2007; Lim et al., 2013; Majchrzak et al., 2013; Treem and Leonardi, 2012).

Review of relevant literature and the high number of newcomers using online discussion forums before migration suggest that online forums are particularly useful for facilitating information and advice needs in the pre-arrival preparation stage. In this study, I found that about $70 \%$ of individuals participating in the examined online discussion forums were in the pre-arrival migration stage, that is, the individuals were still living in their country of origin. Research showed that newcomers (especially pre-arrival newcomers) generally lack knowledge and access to the offline sources of support in the country (Caligiuri et al., 2001; Kraimer et al., 2016) and they increasingly turn to online sources to mitigate their lack of traditional offline sources of support (Caidi et al., 2010; Chen and Choi, 2011; Chung, 2013). Consequently, this lack of relevant local knowledge and access to the country's offline sources of social support might also be one of the key factors influencing an increasing number of newcomers turning to online discussion forums for social support.

The dynamic theory of knowledge creation (Nonaka, 1994) suggests four possible ways in which interactions and exchanges between tacit and explicit knowledge can result in creation of new knowledge. In the examination of newcomers' online discussion forums data, I found that newcomers were primarily exchanging explicit knowledge and there was very limited evidence of co-creation of new knowledge. Analysis showed that participants were primarily pre-arrival migrants and the examination of online forum discussions 
suggests that the majority of participants lack or have very limited knowledge of the local destination country's labour market, which limits the extent to which the participants can reciprocate and contribute in online forum discussions.

Analysis of research question 3 also suggests that participants of online forums focusing on newcomers' employment are characterized by substantial asymmetry of knowledge, relatively low group identity, and low rates of continuous interactions. Moreover, not only are the interactions in newcomers' online forums different, but also the context of labour market integration of newcomers is very different from the contexts of health and education forums. Therefore, I argue that newcomers' online discussion forums function more like online exchanges than typical online discussion forum communities.

\section{The online forum technology system and the exchanges of knowledge support resources}

Based on the examination of the data and relevant literature, this study proposes a model of the online discussion forum technology system, which is depicted in Figure 21 and discussed in the sections below. 
Figure 21. The online discussion forum system.

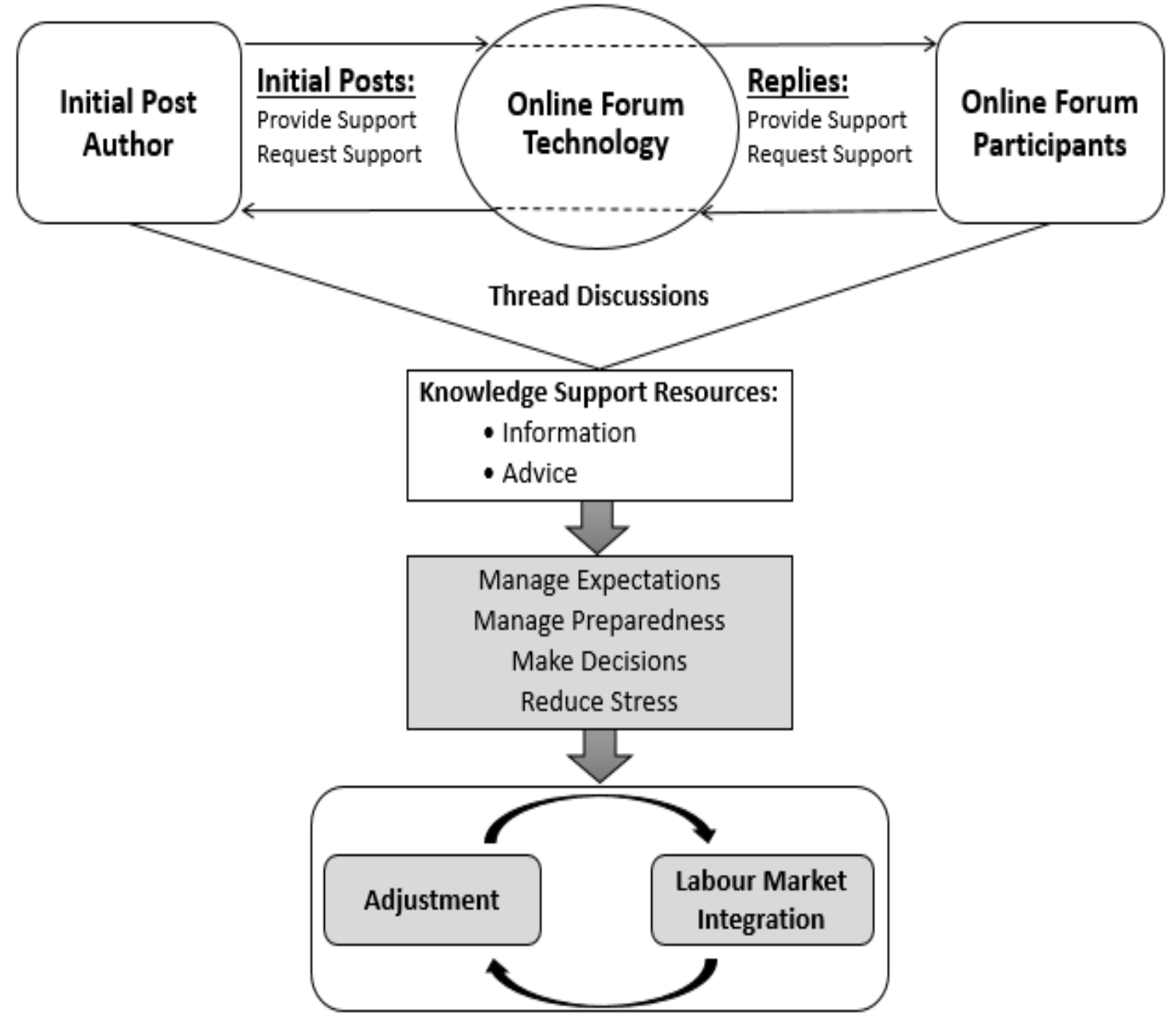

In this study, the online forum technology system is conceptualized based on the view of a technical subsystem (Alter, 2013; Chatterjee et al., 2017; Leonardi, 2012). A technical subsystem is also called a sociomaterial practice, and it refers to a space that includes technology and people artifacts, in which multiple material and human (social) agencies intersect and overlap (Alter, 2013; Leonardi, 2012). In this study, I found that the examined online discussion forum system included newcomers who were initial posts authors and online forum participants (members), online forum technology, and thread discussions. In addition, thread discussions included interdependent initial posts and replies. 
With online discussion forum systems, users developed electronic text-based discussions on specific topics of interests concerning newcomers' labour market integration in the new country. Initial post authors contributed to the online discussion forum system by starting new discussions (i.e., creating initial posts) and the online forum participants contributed by posting in the existing discussions (e.g., replying to the initial posts and/or others' replies within the thread discussion). These interactions (i.e., initial posts and replies) between users in online discussion forums generated more discussions that were also accessible and available to all users at all times. This study shows that the discussions were sources of online information and advice support resources, that can could also be viewed as knowledge resources.

\section{Online forum technology}

Online forum technology is comprised of software (e.g., web applications, server software) and hardware (e.g., computers and hosting servers) that enable the computer mediated text communications in online discussion forums (e.g., starting discussions with initial posts and replying in existing discussions). In the examined online discussion forums, users were able to access and view the discussions without joining the online discussion forums. That is, the examined forums did not require registration to access and view discussions. However, users needed to register to actively participate (i.e., create initial posts and replies). In addition, users were able to join and interact with other users in the online forums free of charge and at all times. 


\section{Initial post author's contributions: initial posts providing and requesting support}

In the examined online discussion forums, initial post authors contributed in the online discussion forum system by creating and starting new thread discussions (by way of posting initial posts) on a topic of interest to the particular online discussion forum. In this study, I found that about $93 \%$ of the initial posts requested and only about $7 \%$ of the initial posts provided social support resources. In the requesting initial posts, authors requested information support (71.9\%), advice support (27\%), instrumental support $(0.9 \%)$, and companionship support $(0.2 \%)$. About $99 \%$ of requesting initial posts requested information or advice support. In the providing initial posts, authors provided information support (76\%), advice support (12\%) and instrumental support (12\%). Again, about $88 \%$ of providing initial posts provided information or advice support. The types of support are discussed in detail of analysis for research question 1. In addition, several examples of each type of requesting and providing initial posts are included in Appendices B and C.

In addition, by examining different forms of advice, I found that initial posts typically requested or provided opinion or guidance advice. In this study, I found that only 14 initial posts requested problem solving advice and no posts provided problem solving advice. Examples and forms of advice are also discussed in the details of analysis for research question 1.

In this study, initial post authors provided and requested support on various topics relating to newcomers' labour market integration in Canada, such as finding and applying for jobs. I grouped the different topics into the 10 final categories of topics, which are discussed in 
the details of analysis for research question 1 section and shown in Appendix D. The top three categories of topics are about finding and applying for jobs, job opportunities, and visa and work permit in Canada, and they represent about 60\% (343 out of 574 initial posts) of the topics in the examined data.

\section{Online forum participants' contributions: replies providing and requesting support}

Online forum participants are individuals who view and read thread discussions (i.e., initial posts and extant replies) and make replies in the threads, developing conversation with the initial post author and/or other participants in the thread. Usually, online forum participants are also initial post authors as all users can create and post initial posts and start new threads. The examined data and relevant literature on online discussion forums suggest that the majority of online discussion forum users are lurkers who only view and read discussion and do not actively participate in the thread discussions (Sun et al., 2014; van Mierlo, 2014; Yang et al., 2017). Since lurkers do not do contribute in the discussions, they are not visible in the text data and hence they are not part of this study.

In this study, I found that the replies posted by online forum participants not only provided, but also requested support in the corresponding thread discussions. Replies providing support were discussed in the prior sections above. To illustrate the difference between replies providing and requesting support, I included three examples of each below. 


\section{Replies providing support}

Consider the three examples of replies providing support below:

\section{Example 1 (CV21_60)}

Initial post

"I am in a restoration period and I would like to know about the chances to get an LMIA through any kind of small retail stores. Can I be eligible to apply LMIA?"

\section{Reply}

"You don't apply for the LMIA - your employer is the one who has to apply for the LMIA. Yes - the LMIA can be submitted while you are in the restoration period. If the LMIA isn't approved before the 90 days are over - you should apply to change your status to visitor and apply to restore your status at the same time."

Example 2 (CV21_117)

Initial post

"Please advise what survival jobs at received after immigration in Canada?"

Reply

"Dishwasher, McDonalds restaurant, snow removal, window cleaning, convenience store clerk, waiter, bus boy" 


\section{Example 3 (CV21_148)}

Initial post

"I landed in Canada and currently in NS and looking for job opportunities. Must have sent my resumes to 15 job ads but no response. Is Canadian Experience being the barrier. I initially thought prior arrival that I would land a position easily with any employer. I have CPA, CGA, ACCA, DipIFR (ACCA/UK), MCSI (UK) and CFA L3 Candidate with over 6 years of foreign work experience."

\section{Reply}

“Do you have a CPA license from any Canadian province? If you don't, then landing a job that requires an accounting designation will be difficult - the CFA is the only recognized designation you have, and it's still work in progress. My advice... Work on obtaining a Canadian issued designation - the ACCA should make it easy for you. That said, Canadian experience may be a factor among other things, such as how well you write your cover letter and resume, the job market etc. As for the applications... Keep writing them! Most people write way more than that, in a week."

In all three examples above, the replies of online discussion forum participants provided relevant support to the support requested in the initial posts. 


\section{Replies requesting support}

The replies could also request support, as illustrated with the three examples of replies requesting support in threads below:

\section{Example 1 (CV21_58)}

Initial post

"Hi! I'd like to move to British Columbia via Express Entry. But the problem is I don't have enough points. Getting job offer guarantees you enough points but I don't know how to start looking for a job from my homeland. What's the algorithm of looking for a job except job fairs (or what are they called) outside Canada? What should I indicate in my resume? Labor Market Impact Assessment? required? Are there any useful sites with stats except governmental? What sites are most useful especially for immigrants (may be where employers expect to meet foreigners)? Are really employers interested in processing EE for a long time? (As far as I understand they should wait for me at least 6 months, may be better to hire local) Any advice will be much appreciated."

\section{Reply}

"Hello everyone I have been trying to secure a job in Canada before permanently moving there. I have mentioned local Toronto address on my resume and also bought a virtual telephone number which can route any incoming calls to my number in Japan. So far there has been no response. Just FYI I work with one of the world leading companies in Japan. Has anyone been able to secure job before permanently moving? If so please advise on how you did it." 
Example 2(CV21_316)

Initial post

"I have rich 4.5 years of experience as a structural engineer in the offshore oil and gas sector... I am looking for new roles and opportunities in Canada as a structural engineer/Civil engineer."

Reply

"I have the exact same query as that you have, for my Brother who has a similar experience but with $6+$ years experience. Let me know in case you got some leads in finding job for a Structural Engineer here in Canada."

Example 3 (CV24_37)

Initial post

"I am at my final stage of immigration... will be moving to Calgary in next 2-3 months. . . I am a flight operation officer/ Load Controller... I want to apply for the same job at Calgary Airport... Anyone has any idea where to apply for this job and what is the average salary for this position?"

Reply

"I'm FOO too here in Brazil. I work as a Flight operation officer on GOL Airlines. Don't you get a job yet? do you have a FFA registry?"

In all three examples above, both the initial posts and the replies of online discussion forum participants request support. 


\section{Online discussion forum knowledge support resources: information and advice}

The initial posts and replies discussed above produce online text discussions that are available and accessible to all users and at all times. As shown in the sections above, the online thread discussions created information support and advice support resources. In the context of newcomers, social support resources have been typically studied and considered as offline local social contacts and networks, such as local friends, family, coworkers, and government employees (Alam and Imran, 2015; Caidi et al., 2010; Farh et al., 2010; Stroppa and Spieß, 2011; Turchick Hakak and Al Ariss, 2013; Van Bakel et al., 2017). Studies show that seeking and getting social support requires more effort and time offline than online (Ahmed and Veronis, 2017; Noorani, 2017; Rains and Wright, 2016). In addition, newcomers typically lack relevant knowledge of local offline sources of social support (Dietz et al., 2015; Kilpatrick et al., 2015). Moreover, pre-arrival newcomers do not have access to offline support in the new country as they are still in their homelands. However, the discussions in online discussion forum systems are visible, persistent, searchable, and accessible from anywhere in the world and at all times.

This study shows that online discussion forums facilitate the exchange of social support resources in the form of information and advice. Both, information support and advice support can be viewed as knowledge support resources. Information support resources are objective non-opinion-based facts or details about something, while advice support resources are subjective opinions, viewpoints, or judgements that do not have to be based on facts. In this study, I also identified three forms of advice: opinion, guidance, and problem solving. 
Newcomers acknowledged accessing information support and advice support resources in their replies in the online discussion forum systems. Newcomers typically acknowledged accessing information support in their replies in the thread discussions by showing that they gained new information or learned new things about the Canadian labour market using thankfulness statements such as "thank you for the information, it is very helpful" (CV21_364) “useful information" (CV21_216), "I really appreciate the useful information you posted here" (CV21_135), "thank you very much, you've been very helpful" (CV21_415).

Expressing thanks for useful or helpful information was the most frequent form of acknowledgement of accessing information support. However, in rare instances, newcomers also acknowledged accessing information support by showing that they gained new understanding, as depicted in the example below:

Example (CV21_302)

Initial post

"Do employers have to show that no Canadian is available for the job before offering it to a permanent resident?"

Reply

"No. what you are describing here is the LMIA process for hiring a foreign worker."

Reply (initial post author)

"I thought certain government jobs gave priority to or were restricted to Canadian citizens." 
Similar to information support, newcomers typically acknowledged accessing advice support in their replies by expressing thanks and appreciation for the provided advice support using statements such as "thanks for sharing your experience” (CV21_9), "thank you so much... for guidance once again thanks" (CV21_135), "You are a life saver bro :) +1 for you” (CV21_296), "Thanks... for the guide!” (CV22_13). In the examined data, expressions of thanks and appreciations were similar for all three forms of advice: opinion, guidance, and problem solving.

These statements of appreciation and thankfulness for provided advice and information show that newcomers accessed new advice support and information support with online discussion forums. Moreover, these statements also show that newcomers found the provided support valuable and useful.

\section{Manage Expectations}

Studies suggest that information and advice support resources can enhance newcomers' relevant knowledge of the new country's environment and labour market (Caligiuri et al., 2001; Stroppa and Spieß, 2011; Van Bakel et al., 2017). Research also shows that greater relevant knowledge can help newcomers better manage their expectations and form more accurate and realistic expectations about the new country and their prospects of integration in the local labour market (Caligiuri et al., 2001; Harvey et al., 2007, 2012; Irving and Montes, 2009; Kraimer et al., 2016; Mähönen et al., 2013).

Porter and Steers (1973) introduced the concept of 'met expectations' in the organizational context. The concept of met expectations refers to the difference between what an 
individual expected to encounter and what the individual actually encountered in the way of negative and positive experiences. The concept has since expanded to several other areas, including migrants' adjustment which is more relevant for this study. In the context of newcomers, adjustment to a foreign environment refers to newcomers establishing a relatively stable and functional relationship with the new country environment (Farh et al., 2010; Sobre-Denton and Hart, 2008), so that they are able to predict and explain others' behaviors and proficiently interact in the new country (Gudykunst, 2005), as well as live their everyday lives with ease and with a sense of emotional comfort (Farh et al., 2010; Sobre-Denton and Hart, 2008; Ward et al., 1998).

When adjusting to a new environment, newcomers often experience cultural shock (Kim, 2008; Nardon et al., 2015). Research has shown that expectations about the new country can influence migrants' adjustment and job satisfaction in the new county (Harvey et al., 2012; Irving and Montes, 2009; Kim and Tung, 2013; Kraimer et al., 2016; Mähönen et al., 2013; Takeuchi, 2010). Extant studies on immigrants have shown that accurate expectations positively influence post-migration adjustment outcomes, such as job search and labour market integration (Awais Bhatti et al., 2014; Caligiuri et al., 2001; Harvey et al., 2012; Mähönen et al., 2013; Qureshi et al., 2017). Conversely, unrealistic expectations can result in a discrepancy between expectations and reality and typically the greater the difference between expectations and reality the greater the negative impact on the overall job satisfaction and adjustment (Harvey et al., 2012; Irving and Montes, 2009; Kim and Tung, 2013). Mähönen et al. (2013) also found that the more newcomers' expectations are exceeded, the better they adjust post-migration. 
Newcomers generally form their expectations about the destination country labour market prior to migrating, when they are still in their homelands (Caligiuri et al., 2001). In order to form realistic and accurate expectations, newcomers need sufficient and accurate relevant knowledge about the new country and its labour market (Caligiuri et al., 2001; Harvey et al., 2007). Research has also shown that greater relevant knowledge of the new country can help newcomers adjust and function more effectively in the new environment (Aycan, 1997; Caligiuri et al., 2001; Kraimer et al., 2016). However, it is very difficult to gain sufficient and accurate relevant knowledge about the destination country, especially in the pre-arrival stage, which typically results in very unrealistic expectations (Harvey et al., 2012; Irving and Montes, 2009).

In the absence of relevant knowledge, newcomers often use stereotypes to form their expectations (Caligiuri et al., 2001). Stereotypes can be defined as "cognitive structures that contain the perceiver's knowledge, beliefs, and expectations about a human group" (Hamilton and Troiler, 1986: 133). They are simplified ways to manage and understand complex and uncertain situations (Caligiuri et al., 2001; Genova, 2017). Studies suggest that expectations formed using stereotypes could also be very inaccurate (Bell et al., 2014; Genova, 2017). For example, Caligiuri et al. (2001) found that expatriates who spoke the destination country's local language expected easier adjustment in the destination country while those who did not speak the local language expected harder adjustment. However, their study found that expatriates' expectations were often inaccurate and not met. 
In the examined online forum discussions, there are examples of newcomers with very unrealistic expectations about the Canadian country local labour market, as shown in the two examples below:

Example 1 (21_402)

Initial post

"Recently, I had a debate with some friends since we all are studying computer science, about the salaries for a new grad student! Some said it's around 50k/year or maybe $60 \mathrm{k} /$ year maximum. While I thought that a new grad student can earn around $80 \mathrm{k} /$ year as a software developer. Does anybody have any information about the salaries here in Canada?"

Reply

"80K is not very realistic - although I'm sure there are some that do. $50 \mathrm{~K}$ - $60 \mathrm{~K}$ is more realistic for a new grad."

Reply (Initial post author)

"Thank you for your post. Do you think that 50k is sufficient for a cost-living?"

Example 2 (CV21_86)

Initial post

"What are the job prospects for a banking professional in Toronto? Will it be difficult to get a decent job in the above-mentioned professions once we immigrate? Is there a way in which before I leave my job in the home country, I finalize an offer in Toronto and then immigrate?" 


\section{Reply}

"Most likely not realistic to think that you can finalize a job offer before immigrating. You'll most likely need to immigrate first."

Reply (Initial post author)

"Thanks...Appreciate your response."

In the examined discussions, there are also examples where newcomers explicitly stated in their initial posts that they request information or advice support to manage their expectation, as shown in the two examples below.

\section{Example 1 (CV21_370)}

Initial post

"My work is in Software Development and I have heard and read that its comparatively easier to land IT related jobs, so I guess it will a bit easier for me just because of my career path. But I still want to plan ahead and have realistic expectations. So, anyone who already landed recently and went through with this, please share your experience."

Example 2(CV21_370)

Initial post

"I am just a candidate in pool of Express Entry. Recently applied for OINP. I haven't even received AOR/ITA. But I need to plan and start preparing myself now to help in job search later on (after landing if I get visa). I also need to keep my expectations straight. So, here's my question ..." 
In the data, there also are instances where online forum participants referred to the importance of managing expectations in their replies to the initial posts, as shown in the two examples below.

\section{Example 1 (CV21_324)}

Initial post

"Being an IT person, did you need to get any certification or even education to find a job in Canada, or your foreign education and experience was enough to find a job?"

Reply

“Canada-educated people find job easy Certifications help... but help little. If you are good enough and your expectations are realistic then that is enough."

Example 2(CV21_313)

Initial post

"I have interviewed for a job in Vancouver and been advised the salary is 80k CAD. I'm currently on $£ 30 k$ in Scotland in a very similar job. Is this salary enough to live reasonably in Vancouver?"

\section{Reply 1}

"It really depends on your definition of living reasonably. Vancouver is an expensive city. Will you be able to rent a place on that salary? Sure. Will you be able to buy a house? Nope... Keep in mind that $80 \mathrm{~K}$ won't be your take home. You will need to factor in what will go to taxes." 


\section{Reply 2}

"Vancouver has a reputation as being expensive but as long as you're not expecting to stay in a fancy condo right in the middle of the downtown core and eating out at the expensive restaurants all the time it's not really that much more expensive than the UK."

Reply (Initial post author)

\section{"Thanks guys, much appreciated"}

The several examples provided above illustrate that information support and advice support can help newcomers manage their expectations. This study also suggests that greater relevant knowledge can help newcomers form more accurate and realistic expectations, which in turn can help newcomers better adjust and integrate in the Canadian labour market.

\section{Manage Preparedness}

Research also suggests that relevant knowledge can also help newcomers better prepare culturally (e.g., how to go about getting a job), economically (e.g., prepare more money for probable unemployment in the first 6 months in the new country), and psychologically (e.g., get ready to accept a survival job initially) for various challenges they may face in the new country (Al Ariss and Syed, 2011; Caidi et al., 2010; Dietz et al., 2015; Fang et al., 2013; Harris and Brewster, 2002; Puck et al., 2008; Reitz et al., 2014; Salgado and Bastida, 2017; Turchick Hakak and Al Ariss, 2013; Zainol et al., 2013). In the context of newcomers' labour market integration in the new country's environment, preparedness can be viewed as making ready (prepare) for labour market integration challenges beforehand 
(Celaya and Swift, 2006; Harris and Brewster, 2002; Hurn, 2007; Zainol et al., 2013). Research also suggests that preparedness and expectations are to some extent interconnected. For example, the expectations that newcomers form about the new country's environment and labour market can influence newcomers' preparations (Chew, 2004; Littrell et al., 2006; Zainol et al., 2013).

The results suggest that the relevant knowledge, in the forms of information and advice support, that newcomers access with online discussion forums can help them better prepare to deal with the challenges in the new labour market environment. In addition, the more relevant knowledge newcomers have about the probable challenges in the new country, the more likely they will be better prepared to deal with those challenges.

In the examined online forum discussions, there were many examples of newcomers who migrated to Canada without making appropriate preparations for the probable challenges and were struggling to adjust and integrate in the local labour market, as shown in the three examples below:

\section{Examples 1 (CV21_193)}

Initial post

"I've been in Canada since January 23. I'm an Environmental Engineer that's got 4 years of work experience with a global firm in both the UK and UAE. I'm currently in Ontario and I'm struggling to find any work. It's been a real headache. I would really appreciate if anyone has any sort of advice for me?" 


\section{Reply}

"My suggestion -- find a minimum wage job that keeps you from depleting your savings and settle down for the long haul. It took me two years to find a professional job in Canada."

Reply (Initial post author)

"wow two years!! Yes, the economy in my field seems to be doing quite bad at the moment"

\section{Example 2 (CV21_96)}

\section{Initial post}

"I've been searching for a job in the last three months, mainly in Montreal, Ottawa and Toronto, but to no avail. I'm growing more desperate now. I have a degree in Computer Engineering and advanced degrees in Electrical Engineering, but I cannot find a job neither in the industry nor in the academia. They all need 5+ years of experience on average, and I have non, which makes it even harder. Any advice? Thanks"

\section{Reply}

“...it's important to adjust your resume to match the specifics of each job posting... recruiters are not looking for cookie cutter resumes anymore. they want specific information that shows them how you can bring value by making or saving money and match the requirements of the job they are recruiting for... getting a job is a full-time job. significant effort needs to be made to get the desired results. If you have already landed as a PR, then reach out to your local immigrant service organization and ask them for help with job placement services. They can help you get connected to the industry you 
are interested in and provide leads for how to successfully get a job. In Ottawa, the organization is called OCISO and they have fantastic referrals and programs. They also provide mentorship programs to qualified professionals to help build networks and find job opportunities..."

Reply (Initial post author)

"Thanks for your lengthy responses. I haven't heard of these agencies before. Good information. I'll try to reach out to them."

Example 3 (CV21_202)

Initial post

"I am a new Immigrant. Landed in Toronto couple of months back. It's been hard finding a job. I am SAP FI / PMP Certified, with over 5 years of experience. I have been tailoring my resume, and applying consistently, but still no luck. I feel that given the job market conditions here, the best way to get a job is through contacts. But being new to the country, it's hard. I am even willing to intern for few months or volunteer in my field, just to get back in the game... Savings are drying quickly, and winters will be approaching soon. Any help or advise will be appreciated?"

No replies

In the data, there also are instances where online forum participants referred in their replies to the importance of being prepared before coming to Canada, as shown in the examples below. 


\section{Example 1 (CV21_423)}

Initial post

“...But Canada I believe is a different style of life, more culture and yes, I will go in the country with another work that it doesn't belong to me, also I will travel with this job and leave my husband in my country for I don't know how much time until I can get him a job offer or get my residence. So, should I stay or should I go? Is Canada a really good place like to leave everything behind and start all over again?"

\section{Reply}

"The one thing I know for sure, is that no one should come unless they are prepared to try it for several years. Canada has NO immediate gratification. If you want that, stay put. If you want the possibility of delayed gratification, then come."

\section{Example 2(CV21_300)}

\section{Initial post}

"I am working in IT around 12 years in Teamcenter, Java, J2EE, C++, C skill sets in India. Is it possible to search job in Canada from India? I am applying for a Canadian PR. ”

\section{Reply}

"You can look at what's available in the job market on Job Bank Canada, Indeed, Monster, etc. any job listing sites. But it is very difficult to apply for a job outside of Canada, without a PR card. You should contact someone from the Indian communities and see if they can 
help you ask around about jobs in your field. That way, you can already be prepared when you get $P R . ”$

Example 3 (CV21_152)

Initial post

"How fast did you find a job as a newcomer? How was it?"

Reply

"Few of my friends were able to grab a job (contracting work with IT companies in most cases) within 2-3 months after landing. This totally depends on the field (technology/function) you're into and your experience. Personally, I will be prepared for 3 months (6 months worst case scenario)."

To summarize, greater relevant knowledge can help newcomers better prepare for possible challenges, which in turn can help newcomers better adjust and integrate in the destination country's labour market.

\section{Make Decisions}

In addition, examination of the data suggests that better knowledge of the Canadian labour market (e.g., job opportunities, accreditation requirements) may also help newcomers decide about migrating to the new country. In the examined online discussion forums, several pre-arrival migrants requested information and advice support about job opportunities and accreditation to assess whether they should migrate to Canada, to other countries, or stay in their homelands. I included three relevant examples of the initial posts below. 


\section{Example 1}

"My brother is an actuary currently living in the UAE, and he's trying to decide which is a better place for his profession -- Australia or Canada? Can someone please share their input regarding this if possible?" (CV21_11)

\section{Example 2}

"I need Feedback from people Who Already in Canada Subject: Confused to Decide to Migrate or Stay in India Am 38 Yrs. Old, already well Settled in India In Senior Management Role with Annual Income After Tax: 60000 CAD / Annum I Have a Daughter..." (CV21_101)

\section{Example 3}

"I am confused about my decision. Me \& my wife both having Government Job in India, having Rs. 80,000/- per month family income. Also have PR in Canada... It is really tough for me to choose the right one (INDIA or CANADA). Please suggest me expert advice, what is best for me \& my family. Right now, we both are 32 and have Bachelor's Degree in Electronic \& Electrical Engineering. ” (CV21_340)

In all three examples above, pre-arrival migrants sought information or advice support to help them decide whether to migrate to Canada. However, the sought-after support sources not only can help newcomers decide whether to migrate to Canada, but they can also help newcomers form more accurate expectations and better prepare if they eventually decide to migrate to Canada. Thus, these sought support resources can ultimately help newcomers better adjust and integrate in the destination country's local market as well. 


\section{Reduce Stress}

In recent years, the potential outcomes of seeking and receiving support in online health context have received increased attention from scholars (e.g., Feng and Hyun, 2012; Holbrey and Coulson, 2013; Liu and Yu, 2013; Oh et al., 2014; Wright et al., 2013; YliUotila et al., 2014). The research on the potential outcomes is mainly grounded on two general perspectives about the effects of social support on stress and coping: (1) supportive action and (2) perception of available support (Lakey and Cohen, 2000; Rains and Wright, 2016). The supportive actions perspective proposes that social support can directly improve individuals' coping resources and coping performance. For example, by receiving support (e.g., advice, information), the support seekers can better manage and cope with their stressors (Holbrey and Coulson, 2013; Rains et al., 2016). The perception of available support perspective suggests that the knowledge that support seekers have about available potential support providers can influence support outcomes by influencing support seekers' appraisal of stressful situations and stressors. For example, perceiving that one can easily access support providers online (e.g., in blogs, social networking sites, online discussion forums) can reduce one's view of the severity of the stressor, and can make the stressor appear more manageable than if the support providers were not perceived to be available (Feng and Hyun 2012; Rains and Wright, 2016; Yli-Uotila et al., 2014). Studies also show that by simply perceiving that support is available online can lower stress (Feng and Hyun 2012), increase life satisfaction (Oh et al., 2014) and enhance general well-being (Kaczmarek and Drążkowski, 2014; Rains and Keating, 2011). 
In the examined online discussion forums, newcomers can easily access support providers online at all times and from anywhere. In addition, newcomers can also easily request specific support resources in the examined online discussion forums by starting new threads. The perception of easily available and accessible online support and support providers can help newcomers reduce their stress and make the problems appear more manageable. These in turn, can help newcomers better adjust in the new country's environment (Eyou et al., 2000; Mikal et al., 2013; 2015; Noh and Avison, 1996; Turchick Hakak and Al Ariss, 2013).

\section{Adjustment and Labour Market Integration}

As discussed in the prior sections above, relevant knowledge can help newcomers manage their expectations, make migration decisions, and better prepare to deal with the probable challenges in the new country, which in turn can help newcomers better adjust and integrate in the local labour market. Please consider the example below:

\section{Example (CV21_400)}

Initial post

"I am PR of Canada and looking for the job of a sonographer (one who does ultrasound examination). I am certified with the American registry (which all jobs want) and have been applying for the jobs but I don't get any interviews. I happen to talk with one of the recruiters and she says that I don 't have Canadian work experience though I do have about 5-6 years' experience from my home country. I am kind of disheartened. how to crack the ice?" 


\section{Reply}

"Canadian experience matters in this country. Try to get involved in volunteer work to gain Canadian experience."

Reply (Initial post author)

"finally got a volunteer position after a wait of 5 months"

Reply

"Congrats! It is hard enough to get a volunteer position some times. But you made the first step. Keep on trying."

Reply (Initial post author)

"hi, sorry for the delayed reply. I have a full-time job as a sonographer now... god is great...”

In the example above, the initial post author could not find a job in Canada and he requested support in the online discussion forum by starting a new thread discussion with an initial post. Online forum participants provided relevant knowledge support in their replies. In his replies, the initial post author showed that he accessed and used the provided support (e.g., "got a volunteer position"). In addition, the initial post author showed that he actually integrated in the local labour market and got a full-time job in the profession that he was initially looking for (i.e., "as a sonographer").

Examination of the thread discussion and relevant literature suggests that, in the context of newcomers' labour market integration, adjustment and integration in the local labour 
market can influence each other (Awais Bhatti et al., 2014; Farh et al., 2010; Puck et al., 2017; Qureshi et al., 2017; Sambasivan et al., 2017; Singh and Mahmood, 2017; Takeuchi, 2010; Van Bakel et al., 2017). Studies suggest that a better adjustment in the new country's environment can help newcomers better integrate and perform in the local labour market (Awais Bhatti et al., 2017; Salgado and Bastida, 2017; Sambasivan et al., 2017; Singh and Mahmood, 2017). For instance, in the study of 108 Spanish expatriate managers, Salgado and Bastida (2017) found that adjustment positively influenced expatriate effectiveness in the new country. Extant research also suggests that integration in the local labour market can also help newcomers better adjust to the new environment (Farh et al., 2010; Puck et al., 2017; Qureshi et al., 2017).

This section proposed and discussed the online discussion forum system illustrating newcomers' interactions in the online discussion forum environment in the context of labour market integration in the new country. Examination of the online forum discussions and relevant literature suggests that online discussion forums facilitate newcomers' labour market integration by facilitating exchange of knowledge resources in the form of information and advice support. These knowledge resources can help newcomers make migration decisions and manage their expectations and preparedness, which in turn has the potential to help newcomers with adjustment and labour market integration in the new country. Moreover, examined literature also suggests that the perception of easily available and accessible online support and support providers in online discussion forums can help newcomers reduce their stress and view their problems as more controllable, which in turn can help newcomers better adjust in the destination country's environment. 


\section{Chapter 6. Discussion}

In this study, I examined online discussion forums concerning newcomers' labour market integration in Canada using qualitative content analysis. Specifically, I examined 574 discussions at both the post and thread levels of analysis to provide greater understanding of the role of online discussion forums in newcomers' labour market integration. I found that newcomers were mainly trying to meet their needs for information and advice support prior to migration and that the main categories of topics in initial requesting posts were about finding and applying for jobs, job opportunities, and visa and work permit. I also found that for this group of newcomers, online forums functioned as a space for online exchange of social support as opposed to an online community. The exchange nature of the interaction may explain the low rate of participation of newcomers in others' discussions as well as the low rate of met needs observed. In line with other research suggesting that online support is a valuable and efficient addition to traditional offline support for immigrants (e.g., Chen and Choi, 2011), in my study I also found that online discussion forums were important sources of online support, which was shown in prearrival migrants' acknowledgements of accessing support resources and statements that they viewed the provided support as useful and valuable.

This study also has important implications for theory and practice as will be discussed now. 


\subsection{Contribution to Theory}

This study contributes to literature on newcomers' adjustment and labour market integration (e.g., Farh et al., 2010; Guo and Al Ariss, 2015; Sidani and Al Ariss, 2014; Sambasivan et al., 2017; Tung, 2016), newcomers and social support (e.g., Podsiadlowski et al., 2013; Stroppa and Spieß, 2011; Van Bakel et al., 2017), and newcomers' adjustment and online technology use (e.g., Mikal et al., 2013, 2015; Nardon et al., 2015) by showing that online discussion forums facilitate access to and exchange of online social support that can help newcomers with adjustment and labour market integration in the new country. In particular, this study expands understanding of the phenomenon of increasing use of online discussion forums by newcomers by examining four questions that provide new insights about the role of the online forums in newcomers' labour market integration in Canada.

Specifically, this study found that the online discussion forum system affords newcomers new and easier ways to seek, access, and exchange knowledge support resources in the form of information and advice support. Online forum participants and initial post authors developed the knowledge support resources by starting new discussions with initial posts and by replying within the existing discussions in the online forums. This study shows that newcomers acknowledge accessing the knowledge support resources which can help them make more informed decisions about migration to the new country, better prepare for likely challenges, and form more accurate and realistic expectations about labour market integration in the new country. Based on extant research, I argue that more informed decisions, realistic expectations and better preparedness can help newcomers with adjustment and labour market integration in Canada. In addition, perceptions of easy access 
to online support resources and support providers that are available and accessible at all times and from anywhere in the world can help newcomers reduce stress and make the problems associated with migration and labor integration appear more manageable. These in turn, can also help newcomers with adjustment and integration in the destination country's labour market. Therefore, I argue that the availability of relevant knowledge resources in online discussion forums can help newcomers with adjustment and integration in the local labour market.

This study also contributes to the social support literature (e.g., Podsiadlowski et al., 2013; van Bakel et al., 2017) by expanding our understanding of advice social support and suggesting it is a distinct category of social support. In particular, results of this study suggest that advice support is qualitatively different from information support, and, as such, should be treated independently. Prior research examining online discussion forums in other contexts, such as health (e.g., Kim and Sundar, 2016; Kim, S., \& Yoon, 2012; Moore and Ayers, 2017; Pan et al., 2017) and education (e.g., Griesbaum et al., 2015; Seethamraju, 2014) showed that online discussion forums provide an environment of abundant information exchange. This study found that although information support is a major need that newcomers are trying to meet with online discussion forums (e.g., about $72 \%$ of initial posts), advice support constitutes a very important part of newcomers needs in this medium (e.g., about $26 \%$ of initial posts). Information and advice social support are typically grouped together as informational support (Cohen and Wills, 1985; Podsiadlowski et al., 2013; van Bakel et al., 2017). However, information is more objective and factual and advice is more subjective and based on individual's own perceptions, opinions, and interpretations (Johnson and Johnson, 2017; MacGeorge et al., 2016; Mahajan and Toh, 
2014; Rader et al., 2017; Russell et al., 2017). Moreover, as discussed in chapter 5, information support and advice support are different types of support needs.

In addition, this study provides additional support to the theory of knowledge creation (Nonaka, 1994) by examining the theory in the context of online discussion forums and newcomers' labour market integration. Examination of newcomers' interactions in this new context showed that online discussion forums can also facilitate knowledge exchange in the form of information support and advice support though computer mediated text interactions. Nonaka (1994) suggested four possible patterns of knowledge exchange between tacit and explicit forms of knowledge (i.e., socialization, combination, internalization, externalization) (discussed in Chapter 3). In this study, I found that newcomers were only exchanging explicit knowledge in the examined forums. Literature on computer mediated social support also suggests that online support interactions need to be more explicit because the interactions are primarily text based and lack social and nonverbal cues that are typically available in offline face-to-face interactions (Rains et al., 2015; Rains and Young 2009; Tanis, 2008). The theory of knowledge creation also suggests that the knowledge exchanges can lead to creation of new knowledge. In this study, I found that although thread discussions showed acknowledgements of access to and transfer of explicit knowledge between online discussion forum users, there was no evidence of new knowledge creation resulting from exchanges of explicit knowledge resources. Therefore, the results suggest that, in the context of newcomers' labour market integration and online discussion forums, computer mediated text interactions can facilitate exchange of explicit knowledge, but they do not facilitate creation of new knowledge. 
This study expands our understanding of the optimal matching model framework (Cutrona, 1990; Cutrona and Russell, 1990) by examining it in the context of newcomers' labour market integration and by adding a dimension of problem-support-medium fit. The optimal matching model was mainly examined in the context of health and the model talks only about the problem-support fit. In agreement with the optimal matching model and recent research on social support in online forums in the context of health (e.g., Moore and Ayers, 2017; Pan et al., 2017; Rains and Wright, 2016; Zhao and Basnyat, 2018) which suggests that different types of social support may be more or less helpful in different situations, I found that newcomers were mainly trying to meet their action-facilitating types of support with online discussion forum to deal with a controllable problem of integration in the destination country's labour market. Specifically, newcomers are trying to meet their needs for information support and advice support, which are critical for coping with and managing controllable problems, such as finding work in the new country (Podsiadlowski et al., 2013; Russell et al., 2017; Van Bakel et al., 2017). However, although the optimal matching model suggests that action-facilitating types of support (i.e., information and instrumental) are more optimal when dealing with the controllable problems, I found very few instances of instrumental support in my data. Among the 574 examined threads, there were only 10 initial posts providing or requesting instrumental support, which corresponds to less than $2 \%$ of the examined initial posts. In addition, I found that when the requests for instrumental support were met, they were met with information or advice support and not instrumental support. Literature on social support in the health contexts also suggests that offers of instrumental support are generally uncommon in online health forums (Rains et al., 2015). Considering the findings in this study as well as extant relevant literature on 
social support and online discussion forums in other contexts, this study proposes that online discussion forum technology is not the preferred medium for seeking and accessing instrumental social support online. The examined online discussion forums did not allow for sharing of files so inherently this medium is not a vehicle for instrumental support. Therefore, the optimal matching model should also include and consider the medium of support as one of the variables explaining the type of social support resource exchanged.

Moreover, based on the analysis in this study and examination of extant relevant literature in the context of health and online discussion forums, this study proposes that the more controllable the problem is (e.g., seeking a job), the more likely users are to seek information support and advice support, and the more uncontrollable the problem is (e.g., terminal cancer) the more likely users are to seek emotional support through online discussion forums. This study showed that, in the context of newcomers' labour market integration, which is a very controllable problem, information and advice were the primary types of social support exchanged in the examined forums. I found that requests for information and advice support accounted for about $98 \%$ of all the needs requested in the examined initial posts. Research has shown that online communities form tightly around specific topics (e.g., Hwang et al., 2013; Jansen and Saint Onge, 2015; Rains and Wright, 2016; Tabor and Milfont, 2013) and that types of social support sought online vary in different contexts (Green-Hamann and Sherblom, 2014). For example, in a study examining computer mediated support communications provided by three different support groups (i.e., cancer caregivers, transgender identity, and alcoholics anonymous), GreenHamann and Sherblom (2014) found that the group structure influences the types of social support provided. They showed that the transgender identity community provided mainly 
informational, companionship and encouragement support, while the cancer caregiver community provided mainly emotional support.

This study also expands our understanding of online communities (e.g., Armstrong et al., 2012; Chu, 2009; Flickinger et al., 2017; Oh et al., 2014; Rising et al., 2017; Sheng and Hartono, 2015; Yang et al., 2017) by articulating the difference between online exchange spaces and communities. This distinction is important because we often assume online groups to be communities, but that is not necessarily the case. A better distinction between these different groups will help researchers investigating online phenomena. Studies examining migrants' communications in online discussion forums in the context of information science and communication (Caidi et al., 2014; Chien, 2005; Figer, 2014; Figer and de Torres, 2012; Kim and Sundar, 2016) suggest that migrants can develop virtual ties in online forums. For example, studies examining online discussion forum interactions of Filipino migrants in Japan (Figer, 2014; Figer and de Torres, 2012) suggest that online discussion forums can create, maintain and enhance migrants' social networks, as well as increase migrants feeling of national identity and belonging to a community. However, analysis and findings in this study suggest that, in the context of newcomers' labour market integration, online discussion forums function more like online exchanges (online exchanges are discussed in section 5.3). Strong group identity, symmetry of knowledge among members, and continuity of interactions are important characteristics of online communities (Figer, 2014; Flickinger et al., 2017; Rising et al., 2017; Sheng and Hartono, 2015; Yang et al., 2017). For instance, Figer (2014) examined online discussion forum interactions of migrants who already migrated to Japan and came from the same country. One can argue that these migrants shared a similar group identity (e.g., Filipino migrants 
living in Japan) and gained some relevant knowledge by living in Japan. However, in this dissertation research, the examined online discussion forum data suggests that newcomers typically had limited group identity, substantial asymmetry of knowledge, and participated infrequently. The analysis in this study revealed that about $70 \%$ of participants were newcomers in the pre-arrival migration stage. Pre-arrival newcomers lack relevant knowledge of the destination country's labour market and access to local offline support sources as they are still in their homelands. Since the pre-arrival individuals lack relevant local knowledge, they are not able to fully reciprocate and contribute in online forum discussions. This asymmetry of knowledge among the members can influence their interactions and knowledge exchanges in online discussion forums. Therefore, I argue that the examined newcomers' online forums function more like online exchanges (i.e., members primarily seek and exchange social support resources), rather than typical health and education online communities (i.e., where members not only exchange, but also cocreate resources).

This study also questions the way we think of newcomers' labour market integration and their knowledge needs at different stages of settlement (e.g., Caidi et al., 2008, 2010; Farh et al., 2010; Mwarigha, 2002) and proposes that we also need to include and focus more on the pre-arrival stage and online sources of social support. Extant research on newcomers' labour market integration typically focuses on offline sources of knowledge and support and on newcomers who are already in the new country (post-arrival) (Caidi et al., 2008, 2010; Dietz, 2010; Dietz et al., 2015; Ramboarison-Lalao et al., 2012; Reitz, 2001; 2007a, 2007b, 2011; Reitz et al., 2014; Turchick Hakak and Al Ariss, 2013). However, in the last decade, more and more newcomers are using online technologies for 
knowledge and support. The examination of thread discussions in this study showed that online discussion forums allow newcomers to search and access social support resources prior to migration, when they are still in their homelands. In the examined data, about $70 \%$ of participants were in the pre-arrival stage. This study found that pre-arrival migrants sought information about average salaries, general job opportunities, and credential recognition in the new country, as suggested by the literature (e.g., Caidi et al. 2008, 2010), but this study also found that pre-arrival migrants were also seeking knowledge about how to find employment and prepare job applications. Therefore, I argue that, in the context of labour market integration, pre-arrival newcomers use online discussion forums to not only manage their expectations, but also to better prepare for labour market integration prior to migration.

\subsection{Contributions to practice}

This study also makes important contributions to practice. In particular, it expands our understanding about newcomers' interactions in online discussion forums and informs government and migrant supporting organizations about the importance and role of online discussion forums in newcomers' adjustment and labour market integration in the new country.

Before the emergence of computer mediated communication technologies, face-to-face interactions with knowledgeable individuals in a new country were the main sources of newcomers' knowledge. Newcomers had to find and gain access to individuals with relevant knowledge and interactions were typically limited to a particular time and place 
only. For example, to interact with a government employee with a needed knowledge, a newcomer had to travel to the specific government office that was only open and accessible during specific days (e.g., Monday to Friday) and hours (e.g., 9am to 5pm). This study shows that online discussion forum technology affords newcomers new, easier, and less costly ways to seek, access, and exchange knowledge support resources, and to seek and interact with knowledgeable others across time and space. The online discussion forum system affordances greatly reduce the costs of seeking and acquiring knowledge support as newcomers do no need to identify, travel to, and interact with specific individuals to access the resources available in the online discussion forums.

Moreover, newcomers can also easily view and access all knowledge resources present in online discussion forums, and search for the specific needed knowledge at all times and from anywhere in the world. For example, many online discussion forums do not require registration and active participation (e.g., creating initial posts and replies), member rankings, and profiles are visible to all and at all times. In addition, with online discussion forum technology, users can effortlessly and quickly search for discussions on a particular topic and all contributions made by a particular member. Furthermore, users can also make associations between online forum users and their content. For instance, other users can see with whom and how a particular user interacted with and all of his or her prior communications in the online forum. This is important, because it enables users to seek and identify specific individuals with a particular relevant knowledge or expertise. By accessing others' prior posts and replies, users can also learn about experiences and challenges that others' have been dealing with over time. 
In the examined online discussion forums, users were also able to choose to restrict the search to thread titles, selected sub-forums, threads newer than a selected date, and threads with a minimum number of replies. This affords users to easily search for specific needed social support resources and for users with a needed relevant knowledge and experience. The social support resources are also persistent in online discussion forums. That is, users' contributions remain accessible and available to all users at all times as the discussions do not disappear but may be outdated over time. This allows users to access older discussions, put the discussions in context and gain greater understanding of the provided and requested knowledge support resources. Persistence and search affordances also allow newcomers to interact across time. For example, newcomers can interact in recent thread discussions as well as search for and make replies in discussions that are several years old. In addition, online discussion forum technology provides ample space for users' discussions, which facilitates the persistence of extant discussions and growth of support resources over time through the additions of new initial posts and replies. This is important, because it allows newcomers to continuously request, add and exchange new resources in the online discussion forums.

Online discussion forum technology also enables users to edit their communications after posting. That is, users can update and revise their initial posts and replies, which allows users to add more details, context, and enhance the clarity of their messages. Other communication technologies, such as email and text-messages, do not allow users to edit their communication after sending. Traditional offline face-to-face interactions are synchronous and hence newcomers have a very limited time to understand the provided information and decide on the reply. However, in online discussion forums, newcomers are 
not restricted to synchronous communications and interactions with particular others at a particular point in time only. This allows newcomers more time to examine the extant discussions and to decide how, when, and whether or not to contribute to the discussions. In addition, face-to-face communications are typically limited to a small number of participants, whereas online discussion forums afford newcomers to easily interact and communicate with thousands of users. This is important as it allows newcomers to seek and request support from multiple potential providers at the same time.

Online discussion forum technology also affords newcomers to choose the level of participation that they feel comfortable with and that suits their particular needs. For example, newcomers can choose to view and read others communications only or to actively participate in the discussions by starting new thread discussions with the initial posts and/or making replies in the extant discussions. Online forums also allow newcomers to interact across geographic space. For example, they allow pre-arrival migrants to access and acquire needed knowledge resources in online discussion forums prior to migration to the new country, which can help them better prepare for labour market integration in the new country before migration. The online discussion forums technology affordances discussed above have important implications for newcomers' labour market integration and adjustment in the new country.

I argue that the social support resources exchanged and accessed in online forums can help newcomers make migration decisions, form more realistic expectations about the new country, and better prepare for the possible challenges. These in turn can help newcomers with better adjustment and integration in the destination country's labour market post 
migration. In addition, the continuous availability, visibility and access to social support and support providers can also greatly reduce newcomers' stress and help them view their problems as more manageable, which can also help them with adjustment in the destination country.

Considering examined relevant literature and findings of this study, I argue that government organizations, programs, and policies need to include and focus more on prearrival migrants and online sources of social support. Government and newcomer support organizations should reach out to migrants at the pre-arrival stage to facilitate their better adjustment and labour market integration post migration. In the examined online forums, I found that about $70 \%$ of users were pre-arrival migrants. Newcomers with insufficient prearrival knowledge generally face higher levels of anxiety and uncertainty, and greater difficulties with integration in the new country (Benson-Rea and Rawlinson, 2003; Shoham and Strauss, 2007). Literature shows that pre-arrival programs help migrants better adjust and integrate in the destination country's labour market post-migration (Hawthorne, 2008; Turchick Hakak and Al Ariss, 2013). For example, Hawthorne (2008) found that newcomers integrated more easily and achieved better professional growth in Australia than Canada, because accreditations and skills of migrants are evaluated for the transferability before migration to Australia. In the examined online forums, many prearrival newcomers were seeking information and advice support about accreditation in Canada. To help pre-arrival newcomers with adjustment and labour market integration, Canadian government organizations should also evaluate newcomers' skills and accreditations for the transferability pre-migration to Canada. I also argue that government organizations should use online tools to provide newcomers with low-cost alternative 
sources of relevant knowledge (e.g., advice support about job opportunities, accreditations, and finding and applying for jobs) which newcomers can easily access online at all times and from any place. Online tools can be especially valuable to pre-arrival migrants who are still in their homelands and do not have access to local offline sources of support. Therefore, government and newcomer support organizations should take advantage of online technologies to reach future migrants and accelerate their integration process by providing stronger pre-arrival training and support. The provided relevant online knowledge resources can improve pre-arrival migrants' adjustment and labour market integration outcome in the new country due to better preparation and more realistic/accurate expectations prior to migration.

This study also identified and examined types of social support needs, categories of topics, as well as rates of needs met for different categories of topics requested by newcomers in the examined online forums. For example, I identified ten categories of topics and found that the top three categories were about finding and applying for jobs, job opportunities, and visa and work permit, and they represented about $61 \%$ of all the needs requested. Detailed examination of data and findings in this study can help government organizations better focus and utilize online technologies to enhance newcomers' adjustment and labour market integration in the new country. For example, this study showed that newcomers need more pre-arrival information support and advice support about job opportunities and how to find and apply for jobs in the new country.

This study also found that newcomers are trying to meet not only information support, but also advice support needs with online discussion forums. In Canada, there exist 
government and migrant support organisations, some of which provide extensive online information websites and tools to assist newcomers with immigration and labour market integration. However, they focus mainly on providing information support. In this dissertation, I show that advice support is different from information support and I argue that government and migrant support organizations need to focus not only of providing information support, but also advice support. For example, employees of government and migrant support organizations could actively monitor and provide requested information and advice support in online discussions forum.

\subsection{Limitations and Future Research}

As with all studies, this exploratory phenomenon-based study has a number of limitations. First, this study examined 574 thread discussions using a conventional qualitative content analysis approach (Cho and Lee, 2014; Hsieh and Shannon, 2005). Qualitative content analysis is a descriptive method as it mainly identifies and describes observed patterns in data (e.g., what is there) and does not reveal or explain the reasons for the observed patterns (e.g., why), which other methods (e.g., text mining and analytic approaches) may reveal. However, given the embryonic stage of knowledge of this phenomenon (Von Krogh et al., 2012) an initial descriptive method is appropriate (Cho and Lee, 2014; Schreier, 2012; Von Krogh et al., 2012). Future research should examine a much larger sample of discussion threads using quantitative approaches, such as quantitative content analysis and text mining, to provide additional insights into the role of online discussion forums as well as examine the model proposed in this study. For example, examination of several thousands of thread discussions with quantitative text analysis software may provide new 
understandings into differences (e.g., affective, linguistic, and structural) between initial posts with a high number of replies and posts with no replies, between initial posts with needs met and needs not met, as well as between pre-arrival and post-arrival initial communications.

This study examined the data collected from online discussion forums concerning newcomers' labour market integration in Canada. Canada is one of the top immigration countries and has a very long history of welcoming and integrating hundreds of thousands of newcomers in its society annually (Government of Canada, 2017a; UN International Migration Report, 2017). This openness to newcomers may have also influenced newcomers' communication behavior in online discussion forums. Thus, newcomers' interactions in online discussion forums and the findings may be different in other countries. Likewise, the context of newcomers' labour market integration is different from the contexts of newcomers' family sponsorship, settlement (e.g., housing), and international students, which may influence the online forum communications and findings as well. Therefore, we do not know what happens in other countries and in other contexts. Future research should also investigate the use of online discussion forums by newcomers in different countries. It may be particularly interesting to investigate online discussion forums concerning countries that are not as open to newcomers as Canada, to examine the role of country openness on computer mediated communications and interactions in newcomers' online forums, as well as on the types of social support and categories of topics discussed in those online forums. Future research should also investigate online discussion forum interactions in different contexts, such as international students, to see, for example, whether the interactions and types of support vary in different contexts. 
The data examined in this study was collected from online discussion forums in English only. Accordingly, this data includes discussions written in English only and by newcomers who were able to communicate in English. Therefore, we do not know what happens in other languages. Considering that English proficiency is a pre-requisite for employment in Canada (outside of Quebec), examination of English only online forums is acceptable. However, bearing in mind the very important role of language proficiency for newcomers' successful labour market integration, future research should also examine the use of online discussion forums by newcomers in their native languages and compare the communication process and findings in these online forums to those where newcomers communicate in the official language of a new country. For example, there are several online discussion forums concerning newcomers to Canada where newcomers communicate in their native languages, such as Polish (e.g., polcan.fora.pl), and Chinese (e.g., bbs.51.ca/forum-501.html). It is possible that those online discussion forums would function more like online communities and have more emotional type of support. Future research should also investigate the role of language and ethnic identity in online discussion forums.

In the examined online discussion forums, authors do not always respond to the online discussion forum participants' replies and to their requests. Consequently, although the examination of thread discussions showed that the replies providing social support are available and accessible to all users at all times, and the examples included in the analysis and findings chapter showed that initial posts authors frequently acknowledged accessing the support, we do not know whether the provided support was always accessed by the initial post authors as not all initial posts authors post acknowledgements of received 
support. Moreover, we are not certain of the effect of the support on the initial post authors. That is, this data did not allow for an investigation of the impact of the accessed social support in the initial post authors' expectations, preparedness, and decisions about Canada and the local labour market. In addition, it was typically not possible to know from the examined data the long-term adjustment and labour market integration outcomes that may have resulted from newcomers accessing the social support resources in online discussion forums. Although this study showed that social support resources were available and accessible to all users and that they were accessed by newcomers in online discussion forums, this study could not examine the long-term outcomes of accessing the support with the collected thread discussions. Therefore, future research should also investigate the long-term outcome of accessing the social support resources in online forums by newcomers on their adjustment and labour market integration in the new country, for example, by examining interview and/or survey data.

Future research should also further examine what influences needs met and active participation in newcomers' online discussion forums. In this study, only about $60 \%$ of support needs requested in the initial posts were met with the subsequent replies and in about $25 \%$ of threads there were no replies. Although literature suggests several possible factors influencing extent of active participation in computer mediated communications (e.g., usability, reciprocity, member rankings, online identity, group versus individual communication, and asynchronous communications), the collected data and qualitative approach in this study allowed examination of only few of these factors. Therefore, future research should examine the other factors identified in this study, such as usability, online 
identity, group versus individual communication, and asynchronous communications, as well as symmetry of knowledge and group identity, using survey and interview data collected from newcomers using online discussion forums to expand our understanding on active participation and online silence in online discussion forums. Surveys and interviews are also the main types of data used when examining the above factors in other contexts (e.g., health and education).

In this study, given the nature of the data, we do not know participants' immigration class (i.e., economic, family, refugee). The interactions and needs that newcomers are trying to meet with online discussion forums may vary for different classes of immigrants.

Therefore, future research should also examine and compare the interactions and needs newcomers of different classes try to meet with online discussion forums.

In this conventional qualitative content analysis study, the initial codes and categories were derived directly from the data. The coding and organization of the data were open to subjective interpretation and probable bias. In accordance with interpretive research philosophy (Sandberg, 2005; Weber, 2004), I was aware of the possible subjectivity and made an effort to withhold any preconceptions and remain open to alternative explanations about the phenomenon. In addition, I regularly checked the rationality of the examination and alternative interpretations of the phenomenon with Dr. Luciara Nardon, a very knowledgeable scholar in the interpretive qualitative research.

There are several types of computer mediated communication technologies available to newcomers, including online discussion forums, blogs, social media (e.g., Facebook), 
email, mobile applications (e.g., WhatsApp, WeChat), and telecommunications application (e.g., Skype). This research examined online discussion forums only and in the context of newcomers' integration in the Canadian labour market. Future research should also investigate the role of other technologies (e.g., WeChat, Skype, Facebook, blogs, and others) on newcomers' labour market integration to expand our understanding of the roles of different computer mediated communication technologies on newcomers' online interactions, adjustment, and labour market integration in a new country.

The examined literature on social support in various online and offline mediums suggests that the medium of support can influence the types of support available and accessed. Social support literature is grounded on face-to-face interactions that do not problematize the issue of synchronicity (Rains, 2016; Rains and Wright, 2016). However, asynchronous computer mediated interactions are different from synchronous face-to-face interactions (Kalman, 2007; Rains and Wright, 2016). Research in the context of education showed that the types of support students seek online vary between asynchronous and synchronous computer mediated communications. For example, Hrastinski (2008) showed that although students exchanged mainly information in both synchronous and asynchronous communications, the expressions of emotional support, advice, and companionship, as well as negotiations and conflict resolutions were substantially more common when student used synchronous than asynchronous communication. In addition, research shows that individuals can use different online technologies to seek and access different types of social support. For example, they can use websites and websites' online communities to acquire informational support, and instant messaging applications to acquire emotional support (Feng and Hyun, 2012; Xie, 2008). Trepte et al. (2015) also showed that communications 
in online social network sites are better for facilitating information and advice support, but offline face-to-face communications are better for facilitating emotional and instrumental support. This study examined types of support available and accessible in the context of newcomers' labour market integration and asynchronous interactions in online discussion forums. Future research should also examine types of support available and accessible to newcomers in other contexts and in other online mediums to expand our understanding on the role of online mediums on types of support available and accessible.

Research in the context of health suggests that computer mediated communications facilitate the social support seeking process by providing an environment where individuals seeking support feel more comfortable and less stigmatized (e.g., HIV patients) when requesting support (as they can communicate anonymously and remotely) (Caplan and Turner, 2007; Flickinger et al., 2017; Moore and Ayers, 2017; Rains and Wright, 2016; Rising et al., 2017; Vanable et al., 2006). This study could not examine the role of stigma on newcomers' interactions with the collected data. Thus, future studies should also examine the role of stigma on newcomers' interactions in online discussion forums with survey and interview data. 


\section{Chapter 7. Conclusion}

This phenomenon-based study investigated the role of online discussion forum technology in newcomers' labour market integration through an inductive qualitative content analysis of online forum discussions concerning labour market integration of newcomers in Canada. The overarching question guiding this study was "What is the role of online discussion forums in newcomers' labour market integration?"

Results of this study suggest that the role of online discussion forums is to provide knowledge resources, in the form of information and advice support, which help newcomers make migration decisions, manage their expectations and preparedness, and reduce stress, which in turn has the potential to help newcomers with adjustment and labour market integration in the new county.

To expand our understanding of the role of online discussion forums in newcomers' labour market integration, this study examined four research questions.

\section{What needs are newcomers trying to meet with online discussion forums?}

Analysis showed that newcomers were mainly trying to meet their needs for information support (72\%) and advice support (27\%) with online discussion forums. In addition, newcomers were mainly requesting $(93 \%)$ rather than providing $(7 \%)$ social support. Moreover, $70 \%$ of newcomers were in the pre-arrival stage. The top three categories of topics that newcomers were trying to meet were about finding and applying for jobs, job opportunities, and visa and work permit and they account for $61 \%$ of all the topics requested in the examined forums. Furthermore, the top two most frequently requested 
categories of information support were about job opportunities and visa and work permit (about $46 \%$ of all the information support needs requested). The top two frequently requested categories of advice support were about finding and applying for jobs and visa and work permit (about $56 \%$ of all the advice support needs requested).

\section{To what extent are these needs met in online discussion forums?}

Examination of 524 threads with requesting initial posts showed that about $60 \%$ of needs requested in the initial posts were met in online discussion forums. The highest rate of need met $(66 \%)$ was for opinion advice support and the lowest (55\%) for guidance advice. In addition, the rate of needs met was higher for post-arrival initial posts $(64 \%)$ than prearrival initial post (58\%). Although the rate of $60 \%$ is not high, one also has to consider the cost and effort required to seek, access, and obtain social support resources, which are considerably lower in online discussion forums than in typical offline sources, such as faceto-face interactions.

\section{What are the characteristics of threads in which needs are not met?}

I found that requested needs were not met in about one-third $(32.4 \%)$ of the examined threads. The rate of needs not met were higher for guidance advice (38\%) and problemsolving advice (43\%) than for information (32\%) and opinion advice (32\%) support needs. In examination of extant literature, I identified several possible factors influencing higher no response rates in online discussion forums (i.e., reciprocity, member ranking, usability,

online identity, group versus individual communication, asynchronous communications, and group identity). However, with my data, I could only examine reciprocity and member 
ranking. The above factors are discussed in detail in section 5.3 of this dissertation. The analysis and examined literature suggest that the high rates of needs not met are due to low reciprocal participation and that the context and newcomers' interactions in the examined forums may be the main factors influencing higher rates of no reply. The context of the examined newcomers' online forums is different from typical online education and health forum communities. Moreover, the interactions in the examined newcomers' online forums were different from interactions in a typical online community. The participants in the examined online discussion forums focused mainly on exchange of information and advice support rather than on development of long term connections and community.

\section{What role do online discussion forums play in facilitating and/or hindering newcomers'} labour market integration?

In the context of labour market integration, online discussion forums facilitate newcomers' labour market integration by enabling the exchange of knowledge support resources in the form of information support and advice support across time and space. In the examined online discussion forums, newcomers exchanged information and advice support resources with the online discussion forum system, which includes online forum technology (hardware and software), initial post authors and online forum participants, and thread discussions (developed through making of initial posts and replies). Initial posts authors contributed by starting new thread discussions, whereas online forum participants contributed by replying in existing thread discussions. The online discussion forums also allow newcomers to access and gain relevant needed knowledge resources pre-arrival, which can help newcomers make migration decisions, form more accurate expectations about the labour market, better prepare for the possible challenges in the new country and 
reduce the stress of migration. More knowledgeable migration decisions, better preparation, accurate expectations, and reduced stress pre-arrival can help newcomers with adjustment and labour market integration post-arrival.

This study contributes to literatures on newcomers' adjustment, labour market integration, social support, and online technology use by showing that online discussion forums facilitate access to and exchange of online social support that can help newcomers with adjustment and labour market integration. More specifically, this study contributes to the social support literature by expanding our understanding of advice social support and suggesting it is a distinct category of social support. It also expands the optimal matching model framework which suggests the need of a problem-support fit, by adding the dimension of medium and suggesting that optimal social support comes from a problemsupport-medium fit. Moreover, it expands our understanding of the optimal matching model and the theory of knowledge creation by examining them in the new context of online discussion forums and newcomers' labour market integration in Canada. This study also expands our understanding of online communities by articulating the difference between online exchange spaces and communities. Lastly, this study also questions the way we think of newcomers' labour market integration in Canada and newcomers' knowledge needs at different stages of settlement and proposes that research also needs to include and focus more on the pre-arrival stage and online sources of social support.

This study also has several contributions to practice. First, it expands our understanding about newcomers' interactions in online discussion forums and informs government and migrant supporting organizations about the importance and role of online discussion 
forums in newcomers' adjustment and labour market integration in Canada. It also suggests that government and migrant supporting organizations should focus more on pre-arrival migrants and online support. In addition, it suggests that there is a need not only for provision of information support, but advice support as well.

With this dissertation, I hope to bring awareness to the phenomenon of increasing use of online discussion forums by newcomers and initiate a dialogue about the role of online technologies in newcomers' adjustment and labour market integration in the new country. I also hope that the findings and contributions made in this dissertation will lead to new avenues for future theory development on newcomers' adjustment and integration and online social support. Moreover, I hope that this study will inform and persuade government organizations and policy makers about the importance of online support and reaching out to migrants on pre-arrival stage to facilitate their adjustment and labour market integration post migration. 


\section{References:}

Adams, T. F. M. (1970). The world of Japanese business. Thunderbird International Business Review, 12(1), 5-7.

Adelman, M. B. (1988). Cross-cultural adjustment: A theoretical perspective on social support. International Journal of Intercultural Relations, 12(3), 183-204.

Ahmed, R., \& Veronis, L. (2017). Multicultural media use and immigrant settlement: A comparative study of four communities in Ottawa, Canada. Journal of International Migration and Integration, 18(2), 587-612.

Aichner, T., \& Jacob, F. (2015). Measuring the degree of corporate social media use. International Journal of Market Research, 57(2), 257-275.

Al Ariss, A. (2010). Modes of engagement: migration, self-initiated expatriation, and career development. Career Development International, 15(4), 338-358.

Al Ariss, A., \& Crowley-Henry, M. (2013). Self-initiated expatriation and migration in the management literature. Career Development International, 18(1), 78-96.

Al Ariss, A., \& Özbilgin, M. (2010). Understanding self-initiated expatriates: Career experiences of Lebanese self-initiated expatriates in France. Thunderbird International Business Review, 52(4), 275-285.

Al Ariss, A., \& Syed, J. (2011). Capital mobilization of skilled migrants: A relational perspective. British Journal of Management, 22(2), 286-304.

Al Ariss, A., Cascio, W. F., \& Paauwe, J. (2014). Talent management: Current theories and future research directions. Journal of World Business, 49(2), 173-179.

Al Ariss, A., Vassilopoulou, J., Özbilgin, M. F., \& Game, A. (2013). Understanding career experiences of skilled minority ethnic workers in France and Germany. The International Journal of Human Resource Management, 24(6), 1236-1256.

Alam, K., \& Imran, S. (2015). The digital divide and social inclusion among refugee migrants: A case in regional Australia. Information Technology \& People, 28(2), 344-365.

Alberti, G., Holgate, J., \& Tapia, M. (2013). Organising migrants as workers or as migrant workers? Intersectionality, trade unions and precarious work. The International Journal of Human Resource Management, 24(22), 4132-4148.

Alboim, N., Finnie, R., \& Meng, R. (2005). The discounting of immigrants' skills in Canada: Evidence and policy recommendations. IRPP Choices, 11(2), 1-26. Retrieved from http://irpp.org/wp-content/uploads/assets/research/diversity-immigration-andintegration/new-research-article-4/vol11no2.pdf

Alexander, C. (2017, May). Immigration in Canada's Economic Growth Equation. Conference Board of Canada. Retrieved from http://www.conferenceboard.ca/Libraries/CONF_PRES_PUBLIC/170065_cbocupdate_alexander.sflb 
Allasino, E., Venturini, A., \& Zincone, G. (2004). Labour market discrimination against migrant workers in Italy. International Labour Organization. Retrieved from https://www.researchgate.net/profile/Emilio_Reyneri/publication/242493353_Labour_M arket_Discrimination_Against_Migrant_Workers_in_Italy/links/546b3c300cf $2397 \mathrm{f} 7831 \mathrm{~b}$ 7d1.pdf

Alter, S. (2013). Work system theory: overview of core concepts, extensions, and challenges for the future. Journal of the Association for Information Systems, 14(2), 72121.

Armstrong, N., Koteyko, N., \& Powell, J. (2012). 'Oh dear, should I really be saying that on here?': Issues of identity and authority in an online diabetes community. Health, 16(4), 347-365.

Arns, J. W. (Ed.). (2016). Annual Review of Cultural Heritage Informatics: 2015. Rowman \& Littlefield.

Assimakopoulos, D., \& Yan, J. (2006). Sources of knowledge acquisition for Chinese software engineers. $R \& D$ Management, 36(1), 97-106.

Aten, K., Nardon, L., \& Isabelle, D. (2016). Making sense of foreign context: Skilled migrant's perceptions of contextual barriers and career options. International Journal of Cross Cultural Management, 16(2), 191-214.

Awais Bhatti, M., Mohamed Battour, M., Rageh Ismail, A., \& Pandiyan Sundram, V. (2014). Effects of personality traits (big five) on expatriates adjustment and job performance. Equality, Diversity and Inclusion: An International Journal, 33(1), 73-96.

Aycan, Z. (1997). Expatriate adjustment as a multifaceted phenomenon: Individual and organizational level predictors. International Journal of Human Resource Management, 8(4), 434-456.

Azevedo, B. F. T., Behar, P. A., \& Reategui, E. B. (2011). Qualitative analysis of discussion forums. International Journal of Computer Information Systems and Industrial Management Applications, 3, 671-678.

Badia, A., Barberà, E., Guasch, T., \& Espasa, A. (2011). Technology educational affordance: Bridging the gap between patterns of interaction and technology usage. Digital Education Review, 19(June), 20-35. Retrieved from http://revistes.ub.edu/index.php/der/article/view/11313/pdf

Bahn, S. (2015). Managing the well-being of temporary skilled migrants. The International Journal of Human Resource Management, 26(16), 2102-2120.

Bansal, P., \& Corley, K. (2012). Publishing in AMJ-Part 7: What's different about qualitative research?. Academy of management Journal, 55(3), 509-513.

Baran, B. E., Valcea, S., Porter, T. H., \& Gallagher, V. C. (2017). Survival, expectations, and employment: An inquiry of refugees and immigrants to the United States. Journal of Vocational Behavior. Available online 26 October 2017. https://doi.org/10.1016/j.jvb.2017.10.011 
Barrett, A., \& Duffy, D. (2008). Are Ireland's immigrants integrating into its labor market?. International Migration Review, 42(3), 597-619.

Barrett, A., McGuinness, S., \& O'Brien, M. (2012). The immigrant earnings disadvantage across the earnings and skills distributions: the case of immigrants from the EU's new member states. British Journal of Industrial Relations, 50(3), 457-481.

Barron, G., \& Yechiam, E. (2002). Private e-mail requests and the diffusion of responsibility. Computers in Human Behavior, 18(5), 507-520.

Bauder, H. (2003). "Brain abuse", or the devaluation of immigrant labour in Canada. Antipode, 35(4), 699-717.

Beard, T. R., Ford, G. S., Saba, R. P., \& Seals, R. A. (2012). Internet use and job search. Telecommunications Policy, 36(4), 260-273.

Bell, M. P., Marquardt, D., \& Berry, D. P. (2014). " Diversity," immigration, and the new American multi-racial hierarchy. Journal of Managerial Psychology, 29(3), 285-303.

Benson-Rea, M., \& Rawlinson, S. (2003). Highly skilled and business migrants: Information processes and settlement outcomes. International Migration, 4(2), 59-77.

Bevelander, P., \& Pendakur, R. (2014). The labour market integration of refugee and family reunion immigrants: A comparison of outcomes in Canada and Sweden. Journal of Ethnic and Migration Studies, 40(5), 689-709.

Bickart, B., \& Schindler, R. M. (2001). Internet forums as influential sources of consumer information. Journal of interactive marketing, 15(3), 31-40.

Binggeli, S., Dietz, J., \& Krings, F. (2013). Immigrants: A forgotten minority. Industrial and Organizational Psychology, 6(1), 107-113.

Bishop, J. (2007). Increasing participation in online communities: A framework for human-computer interaction. Computers in human behavior, 23(4), 1881-1893.

Bjerregaard, T. (2014). Engaging institutions in global careers: highly skilled self-initiated expatriates' journeys through a Nordic welfare state. European Management Journal, 32(6), 903-915.

Black, J. S., Mendenhall, M., \& Oddou, G. (1991). Toward a comprehensive model of international adjustment: An integration of multiple theoretical perspectives. Academy of management review, 16(2), 291-317.

Boese, M. (2015). The roles of employers in the regional settlement of recently arrived migrants and refugees. Journal of Sociology, 51(2), 401-416.

Bordonaro, K. (2006). Language learning in the library: An exploratory study of ESL students. Journal of Academic Librarianship, 32(5), 518-526.

Borrmann, W. A. (1968). The problem of expatriate personnel and their selection in international enterprises. Management International Review, 8(4/5), 37-48. 
Bourgonjon, J., Vandermeersche, G., De Wever, B., Soetaert, R., \& Valcke, M. (2016). Players' perspectives on the positive impact of video games: A qualitative content analysis of online forum discussions. new media \& society, 18(8), 1732-1749.

Boyd, M. (1989). Family and personal networks in international migration: recent developments and new agendas. International migration review, 23(3), 638-670.

Boyd, M., \& Vickers, M. (2000). 100 years of immigration in Canada. Canadian social trends, 58(2), 2-13.

Brady, E., Segar, J., \& Sanders, C. (2016). "You get to know the people and whether they're talking sense or not": Negotiating trust on health-related forums. Social Science \& Medicine, 162(August), 151-157.

Buckley, P. J. (2002). Is the international business research agenda running out of steam?. Journal of International Business Studies, 33(2), 365-373.

Buis, L. R., \& Whitten, P. (2011). Comparison of social support content within online communities for high-and low-survival-rate cancers. CIN: Computers, Informatics, Nursing, 29(8), 461-467.

Burri, M., Baujard, V., \& Etter, J. F. (2006). A qualitative analysis of an internet discussion forum for recent ex-smokers. Nicotine \& Tobacco Research, 8(Suppl 1), S13-S19.

Caidi, N., \& Allard, D. (2005). Social inclusion of newcomers to Canada: An information problem? Library \& Information Science Research, 27(3), 302-324.

Caidi, N., \& MacDonald, S. (2008). Information practices of Canadian Muslims post 9/11. Government Information Quarterly, 25(3), 348-378.

Caidi, N., Allard, D., \& Dechief, D. (2008). Information practices of immigrants to Canada: A review of the literature. Unpublished Report to Citizenship and Immigration Canada.

Caidi, N., Allard, D., \& Quirke, L. (2010). Information practices of immigrants. Annual review of information science and technology, 44(1), 491-531.

Caidi, N., Allard, D., Dechief, D., \& Longford, G. (2007). Including immigrants in Canadian society: What role do ICTs play? Unpublished Report to Human Resources and Social Development Canada (pp. 2-52). Retrieved from https://www.academia.edu/762788/Including_Immigrants_in_Canadian_Society_What Role_do_ICTs_Play_Draft_Report

Caidi, N., Komlodi, A., Abrao, A. L., \& Martin-Hammond, A. (2014). Collectively figuring it out: Foreign-trained health professionals and labor market integration. LIBRES: Library and Information Science Research Electronic Journal, 24(2), 118-131.

Caligiuri, P., \& Bonache, J. (2016). Evolving and enduring challenges in global mobility. Journal of World Business, 51(1), 127-141. 
Caligiuri, P., Phillips, J., Lazarova, M., Tarique, I., \& Burgi, P. (2001). The theory of met expectations applied to expatriate adjustment: The role of cross-cultural training. International Journal of Human Resource Management, 12(3), 357-372.

Canada Visa. (2017). Canada Immigration Discussion Board. Retrieved January 2017 from https://www.canadavisa.com/canada-immigration-discussion-board/

Cao, L., Hirschi, A., \& Deller, J. (2012). Self-initiated expatriates and their career success. Journal of Management Development, 31(2), 159-172.

Caplan, S. E., \& Turner, J. S. (2007). Bringing theory to research on computer-mediated comforting communication. Computers in human behavior, 23(2), 985-998.

Carr, S. C., Inkson, K., \& Thorn, K. (2005). From global careers to talent flow: Reinterpreting 'brain drain'. Journal of World Business, 40(4), 386-398.

Cascio, W. F., \& Boudreau, J. W. (2016). The search for global competence: From international HR to talent management. Journal of World Business, 51(1), 103-114.

Catano, V. M., Wiesner, W. H., Hackett, R. D., \& Methot, L. L. (2005). Recruitment and selection in Canada (3rd edition). Toronto, ON: Nelson.

Celaya, L., \& Swift, J. S. (2006). Pre-departure cultural training: US managers in Mexico. Cross Cultural Management: An International Journal, 13(3), 230-243.

Cerdin, J. L., Diné, M. A., \& Brewster, C. (2014). Qualified immigrants' success: Exploring the motivation to migrate and to integrate. Journal of International Business Studies, 45(2), 151-168.

Chalkiti, K., \& Sigala, M. (2008). Information sharing and knowledge creation in online forums: the case of the Greek online forum 'DIALOGOI'. Current Issues in Tourism, 11(5), 381-406.

Charmaz, K. (2014). Constructing grounded theory. Sage Publications Ltd. London.

Chatterjee, S., Xiao, X., Elbanna, A., \& Saker, S. (2017). The Information Systems Artifact: A Conceptualization Based on General Systems Theory. Proceedings of the 50th Hawaii International Conference on System Sciences. Hawaii, USA.

Chen, W. (2015). Mediatizing the network model of cultural capital: Network diversity, media use, and cultural knowledge along and across ethnic boundaries. Social Networks, 40, 185-196.

Chen, W., \& Choi, A. (2011). Leveraging computer-mediated communication for social support in immigrants' intercultural adaptation. Cross-Cultural Communication, 7(3), $167-176$.

Cheng, J. L. (2007). Critical issues in international management research: an agenda for future advancement. European Journal of International Management, 1(1-2), 23-38.

Cheng, J. L., Guo, W., \& Skousen, B. (2011). Advancing new theory development in the field of international management. Management International Review, 51(6), 787-802. 
Chew, J. (2004). Managing MNC expatriates through crises: A challenge for international human resource management. Research and Practice in Human Resource Management, 12(2), 1-30.

Chib, A., Wilkin, H. A., \& Hua, S. R. M. (2013). International migrant workers' use of mobile phones to seek social support in Singapore. Information Technologies \& International Development, 9(4), 19-34.

Chien, E. (2005). Informing and involving newcomers online: Users' perspectives of Settlement.Org. Master Thesis, University of Toronto.

Cho, J. Y., \& Lee, E. H. (2014). Reducing confusion about grounded theory and qualitative content analysis: Similarities and differences. The Qualitative Report, 19(32), 1-20.

Choldin, H. M. (1973). Kinship networks in the migration process. The International Migration Review, 7(2), 163-175.

Chu, C. M. (1999). Immigrant children mediators (ICM): Bridging the literacy gap in immigrant communities. New Review of Children's Literature and Librarianship, 5, 8594.

Chu, K. M. (2009). A study of members' helping behaviors in online community. Internet Research, 19(3), 279-292.

Chu, S. K. W., Kwan, A. C., \& Warning, P. (2012). Blogging for Information Management, Learning, and Social Support during Internship. Educational Technology \& Society, 15(2), $168-178$.

Chung, J. E. (2013). Social interaction in online support groups: Preference for online social interaction over offline social interaction. Computers in Human Behavior, 29(4), 1408-1414.

Cohen, S., \& Wills, T. A. (1985). Stress, social support, and the buffering hypothesis. Psychological bulletin, 98(2), 310-357

Coles, B. A., \& West, M. (2016). Trolling the trolls: Online forum users constructions of the nature and properties of trolling. Computers in Human Behavior, 60(July), 233-244.

Connor, P., \& Koenig, M. (2013). Bridges and barriers: religion and immigrant occupational attainment across integration contexts. International Migration Review, 47(1), 3-38.

Corbin, J., \& Strauss, A. (2008). Basics of qualitative research: Techniques and procedures for developing grounded theory ( $3^{\text {rd }}$ ed.). Thousand Oaks, CA: Sage Publications Inc.

Coursaris, C. K., \& Liu, M. (2009). An analysis of social support exchanges in online HIV/AIDS self-help groups. Computers in Human Behavior, 25(4), 911-918.

Courtright, C. (2005). Health information-seeking among Latino newcomers: An exploratory study. Information Research, 10(2). Retrieved from http://www.informationr.net/ir/10-2/paper224.html 
Cox, J. B. (2004). The role of communication, technology, and cultural identity in repatriation adjustment. International Journal of Intercultural Relations, 28(3), 201-219.

Crowley-Henry, M., O'Connor, E., \& Al Ariss, A. (2016). Portrayal of Skilled Migrants' Careers in Business and Management Studies: A Review of the Literature and Future Research Agenda. European Management Review. May, 1-20. Retrieved from http://onlinelibrary.wiley.com /doi/10.1111/emre.12072/pdf

Cuesta, Y. J. (1990). From survival to sophistication. Library Journal, 115(9), 26-28.

Cutrona, C. E. (1990). Stress and social support - In search of optimal matching. Journal of social and clinical Psychology, 9(1), 3-14.

Cutrona, C. E., \& Russell, D. W. (1990). Type of social support and specific stress: Toward a theory of optimal matching. In B. R. Sarason, I. G. Sarason, \& G. R. Pierce (Eds.), Social support: An interactional view (pp. 319-366). Oxford: John Wiley \& Sons.

Darrow, J. H. (2015). Getting refugees to work: A street-level perspective of refugee resettlement policy. Refugee Survey Quarterly, 34(2), 78-106.

Davies, J., \& Graff, M. (2005). Performance in e-learning: online participation and student grades. British Journal of Educational Technology, 36(4), 657-663.

Davoine, E., \& Ravasi, C. (2013). The relative stability of national career patterns in European top management careers in the age of globalisation: A comparative study in France/Germany/Great Britain and Switzerland. European Management Journal, 31(2), 152-163.

DeAndrea, D. C. (2015). Testing the proclaimed affordances of online support groups in a nationally representative sample of adults seeking mental health assistance. Journal of health communication, 20(2), 147-156.

DeAndrea, D. C., \& Anthony, J. C. (2013). Online peer support for mental health problems in the United States: 2004-2010. Psychological medicine, 43(11), 2277-2288.

Dechief, D. Y. (2006). Recent immigrants as an" alternate civic core": providing internet services, gaining" Canadian experiences" (Master Thesis, Concordia University). Retrieved from http://spectrum.library.concordia.ca/9042/1/MR20677.pdf

DelCampo, R. G., Jacobson, K. J., Van Buren III, H. J., \& Blancero, D. M. (2011). Comparing immigrant and US born Hispanic business professionals: insights on discrimination. Cross Cultural Management: An International Journal, 18(3), 327-350.

Delios, A., \& Bjorkman, I. (2000). Expatriate staffing in foreign subsidiaries of Japanese multinational corporations in the PRC and the United States. International Journal of Human Resource Management, 11(2), 278-293.

DeSanctis, G., Fayard, A. L., Roach, M., \& Jiang, L. (2003). Learning in online forums. European Management Journal, 21(5), 565-577.

Dictionary (2017). Retrieved December 20, 2017, from http://www.dictionary.com/ 
Dietz, J. (2010). Introduction to the special issue on employment discrimination against immigrants. Journal of Managerial Psychology, 25(2), 104-112.

Dietz, J., Joshi, C., Esses, V. M., Hamilton, L. K., \& Gabarrot, F. (2015). The skill paradox: explaining and reducing employment discrimination against skilled immigrants. The International Journal of Human Resource Management, 26(10), 1318-1334.

Doh, J. P. (2015a). From the Editor: Why we need phenomenon-based research in international business. Journal of World Business, 4(50), 609-611.

Doh, J. P. (2015b). From the Editor: Celebrating the past, looking to the future. Journal of World Business, 4(50), 1-2.

Doh, J. P. (2017). Phenomenon-Based Research in International Business: Making IB Relevant Again. AIB Insights, 17(2), 14-16

Doh, J. P., Luthans, F., \& Slocum, J. (2016). The world of global business 1965-2015: Perspectives on the 50th anniversary issue of the Journal of World Business: Introduction to the special issue. Journal of World Business, 51(1), 1-5.

Downe-Wamboldt, B. (1992). Content analysis: method, applications, and issues. Health care for women international, 13(3), 313-321.

Downie, M. (2010). Immigrants as Innovators Boosting Canada's Global Competitiveness. Conference Board of Canada. Retrieved from http://www.peelnewcomer.org/site/peel_newcomer_strategy_group/assets/pdf/11-074immigrantsasinnovators-web.pdf

Du, J. T. \& Haines, J. (2017). Indigenous Australians' information behaviour and Internet use in everyday life: an exploratory study. Information Research, 22(1), paper 737. Retrieved from http://InformationR.net/ir/22-1/paper737.html

Eastin, M. S., \& LaRose, R. (2005). Alt. support: modeling social support online. Computers in Human Behavior, 21(6), 977-992.

Edmondson, A. C., \& McManus, S. E. (2007). Methodological fit in management field research. Academy of management review, 32(4), 1246-1264.

Eisenhardt, K. M. (1989). Building theories from case study research. Academy of management review, 14(4), 532-550.

Ellis, R. A., Goodyear, P., O'hara, A., \& Prosser, M. (2007). The University Student Experience of Face-to-Face and Online Discussions: Coherence, Reflection and Meaning. ALT-J: Research in Learning Technology, 15(1), 83-97.

Elo, S., \& Kyngäs, H. (2008). The qualitative content analysis process. Journal of advanced nursing, 62(1), 107-115.

Esquivel, A., Meric-Bernstam, F., \& Bernstam, E. V. (2006). Accuracy and self correction of information received from an internet breast cancer list: content analysis. BMJ, 332(7547), 939-942. 
Eyou, M. L., Adair, V., \& Dixon, R. (2000). Cultural identity and psychological adjustment of adolescent Chinese immigrants in New Zealand. Journal of Adolescence, 23(5), 531543.

Eysenbach, G., \& Köhler, C. (2002). How do consumers search for and appraise health information on the world wide web? Qualitative study using focus groups, usability tests, and in-depth interviews. BMJ: British Medical Journal, 324(7337), 573-577.

Falco, C., \& Rotondi, V. (2016). Political Islam, Internet Use and Willingness to Migrate: Evidence from the Arab Barometer. Peace Economics, Peace Science and Public Policy, 22(1), 73-95.

Fan, Y. W., Wu, C. C., \& Chiang, L. C. (2009). Knowledge sharing in virtual community: The comparison between contributors and lurkers. In The 9th international conference on electronic business. Macau (pp. 661-668). Retrieved from https://pdfs.semanticscholar.org/4e6a/0dfadf6f284552f4cdd4dac096fc54192d32.pdf

Fang, T., Samnani, A. K., Novicevic, M. M., \& Bing, M. N. (2013). Liability-offoreignness effects on job success of immigrant job seekers. Journal of World Business, 48(1), 98-109.

Fang, T., Zikic, J., \& Novicevic, M. M. (2009). Career success of immigrant professionals: stock and flow of their career capital. International Journal of Manpower, 30(5), 472-488.

Faraj, S., \& Azad, B. (2012). The materiality of technology: An affordance perspective. In P. M. Leonardi, B. A. Nardi, \& J. Kallinikos (Eds.), Materiality and organizing: Social interaction in a technological world (pp. 237-258). Oxford: Oxford University Press.

Farh, C. I., Bartol, K. M., Shapiro, D. L., \& Shin, J. (2010). Networking abroad: A process model of how expatriates form support ties to facilitate adjustment. Academy of Management Review, 35(3), 434-454.

Feldman, D. C., \& Klaas, B. S. (2002). Internet job hunting: A field study of applicant experiences with on-line recruiting. Human resource management, 41(2), 175-192.

Feng, B., \& Hyun, M. J. (2012). The influence of friends' instant messenger status on individuals' coping and support-seeking. Communication Studies, 63(5), 536-553.

Feng, B., Li, S., \& Li, N. (2016). Is a profile worth a thousand words? How online supportseeker's profile features may influence the quality of received support messages. Communication Research, 43(2), 253-276.

Figer, R. C. (2014). Internet Use and Social Capital: The Case of Filipino Migrants in Japan. Online Journal of Communication and Media Technologies, 4(3), 101-123.

Figer, R. C., \& de Torres, C. (2012). The Technology and Diaspora: Investigating Immigration Issues in Timog Online. Online Journal of Communication and Media Technologies, 2(2), 79-102.

Fisher, K., Durrance, J. C., \& Bouch Hinton, M. (2004a). Information grounds and the use of needs-based services by immigrants in Queens, New York: A context-based, outcome 
evaluation approach. Journal of the American Society for Information Science and Technology, 55(8), 754-766.

Fisher, K. E., Marcoux, E., Miller, L. S., Sánchez, A., \& Cunningham, E. R. (2004b). Information behaviour of migrant Hispanic farm workers and their families in the Pacific Northwest. Information Research, 10(1) paper 199. Retrieved from informationr.net/ir/101/paper199.html

Flickinger, T. E., DeBolt, C., Waldman, A. L., Reynolds, G., Cohn, W. F., Beach, M. C., ... \& Dillingham, R. (2017). Social support in a virtual community: analysis of a clinicaffiliated online support group for persons living with HIV/AIDS. AIDS and Behavior, 21(11), 3087-3099.

Fountain, C. (2005). Finding a job in the internet age. Social Forces, 83(3), 1235-1262.

Fox, S. (2011). Peer-to-Peer Health Care. Pew Research Center Internet \& Technology. Retrieved April 6, 2017 from http://www.pewinternet.org/2011/02/28/peer-to-peer-healthcare-2/

Fox, S., and Duggan, M. (2013). Peer-to-Peer Health Care. Pew Research Center Internet \& Technology. Retrieved April 6, 2017 from http://www.pewinternet.org/2013/01/15/peer-to-peer-health-care/

Frank, K. (2013). Immigrant employment success in Canada: Examining the rate of obtaining a job match. International Migration Review, 47(1), 76-105.

Frenette, M., \& Morissette, R. (2005). Will They Ever Converge? Earnings of Immigrant and Canadian-born Workers over the Last Two Decades. International Migration Review, 39(1), 228-257.

Frijters, P., Shields, M. A., \& Price, S. W. (2005). Job Search Methods and Their Success: A Comparison of Immigrants and Natives in the UK. The Economic Journal, 115(507), F359-F376.

Fu, L. Y., Zook, K., Spoehr-Labutta, Z., Hu, P., \& Joseph, J. G. (2016). Search Engine Ranking, Quality, and Content of Web Pages That Are Critical Versus Noncritical of Human Papillomavirus Vaccine. Journal of Adolescent Health, 58(1), 33-39.

Fukkink, R. (2011). Peer counseling in an online chat service: A content analysis of social support. Cyberpsychology, behavior, and social networking, 14(4), 247-251.

Gale, N. K., Heath, G., Cameron, E., Rashid, S., \& Redwood, S. (2013). Using the framework method for the analysis of qualitative data in multi-disciplinary health research. BMC medical research methodology, 13(1), 117. Retrieved April 15, 2017 from https://bmcmedresmethodol.biomedcentral.com/articles/10.1186/1471-2288-13-117

Gao, F., Zhang, T., \& Franklin, T. (2013). Designing asynchronous online discussion environments: Recent progress and possible future directions. British Journal of Educational Technology, 44(3), 469-483. 
Gao, J., \& Zhou, T. (2017). Evaluating user reputation in online rating systems via an iterative group-based ranking method. Physica A: Statistical Mechanics and its Applications, 473(May), 546-560.

Genova, E. (2017). 'Between a rock and a hard place': Bulgarian highly skilled migrants' experiences of external and internal stereotypes in the context of the European crisis. National Identities, 19(1), 33-51.

George, U. (2002). A needs-based model for settlement service delivery for newcomers to Canada. International Social Work, 45(4), 465-480.

George, U., \& Mwarigha, M. S. (1999). Consultation on settlement programming for African newcomers: Final reportfor Citizenship and Immigration Canada, Ontario Administration of Settlement and Integration Services. Toronto: Center for Applied Social Research.

George, U., \& Tsang, A. K. T. (2000). Newcomers to Canada from former Yugoslavia: Settlement issues. International Social Work, 43(3), 381-393.

Gioia, D. A., Corley, K. G., \& Hamilton, A. L. (2013). Seeking qualitative rigor in inductive research: Notes on the Gioia methodology. Organizational Research Methods, 16(1), 15-31.

Gligor, D. M., Esmark, C. L., \& Gölgeci, I. (2016). Building international business theory: A grounded theory approach. Journal of International Business Studies, 47(1), 93-111.

Golding, S. A. (2014). Moving narratives: Using online forums to study amenity outmigration in the American Midwest. Journal of Rural Studies, 33(January), 32-40.

Goldsmith, D. J., \& Albrecht, T. L. (2011). Social support, social networks, and health. In T. L. Thompson, R. Parrott, \& J. F. Nussbaum (Eds.), The Routledge handbook of health communication (pp. 335-348). New York: Routledge.

Government of Canada. (2014). Facts and figures 2014 - Immigration overview: Permanent residents. Retrieved from http:/www.cic.gc.ca/english/pdf/2014-FactsPermanent.pdf

Government of Canada. (2016). Notice - Supplementary Information 2017 Immigration Levels Plan. Retrieved from http://www.cic.gc.ca/english/department/media/notices/201610-31.asp

Government of Canada. (2017a). 2017 Annual Report to Parliament on Immigration. Retrieved from https://www.canada.ca/content/dam/ircc/migration/ircc/english/pdf/pub/annual-report2017.pdf

Government of Canada. (2017b). Glossary. Retrieved from http://www.cic.gc.ca/english/helpcentre/glossary.asp

Government of Canada. (2017c). Welcome Refugees: Key figures. Retrieved from https:/www.canada.ca/en/immigration-refugees-citizenship/services/refugees/welcomesyrian-refugees/key-figures.html 
Graneheim, U. H., \& Lundman, B. (2004). Qualitative content analysis in nursing research: concepts, procedures and measures to achieve trustworthiness. Nurse education today, 24(2), 105-112.

Green-Hamann, S., \& Sherblom, J. C. (2014). The influences of optimal matching and social capital on communicating support. Journal of health communication, 19(10), 11301144.

Griesbaum, J., Mahrholz, N., von Löwe Kiedrowski, K., \& Rittberger, M. (2015). Knowledge generation in online forums: a case study in the German educational domain. Aslib Journal of Information Management, 67(1), 2-26.

Guarnizo, L. E., Portes, A., \& Haller, W. (2003). Assimilation and Transnationalism: Determinants of Transnational Political Action among Contemporary Migrants 1. American journal of sociology, 108(6), 1211-1248.

Gudykunst, W. B. (2005). An anxiety/uncertainty management (AUM) theory of strangers' intercultural adjustment. In W. B. Gudykunst (Ed.), Theorizing about intercultural communication (pp. 419-457). Thousand Oaks, Calif.: Sage

Guo, C., \& Al Ariss, A. (2015). Human resource management of international migrants: Current theories and future research. The International Journal of Human Resource Management, 26(10), 1287-1297

Haberstroh, S., \& Moyer, M. (2012). Exploring an online self-injury support group: Perspectives from group members. The Journal for Specialists in Group Work, 37(2), 113132.

Hagen-Zanker, J. (2008). Why do people migrate? A review of the theoretical literature. Maastrcht Graduate School of Governance, MPRA Paper No. 28197. Retrieved from https://mpra.ub.uni-muenchen.de/28197/1/MPRA_paper_28197.pdf

Hajli, M. N., Sims, J., Featherman, M., \& Love, P. E. (2015). Credibility of information in online communities. Journal of Strategic Marketing, 23(3), 238-253.

Hajro, A., Gibson, C. B., \& Pudelko, M. (2017a). Knowledge exchange processes in multicultural teams: Linking organizational diversity climates to teams' effectiveness. Academy of Management Journal, 60(1), 345-372.

Hajro, A., Zilinskaite, M., \& Stahl, G. (2017b). Acculturation of Highly-Qualified Migrants at the Workplace: The Importance of Individual Coping Strategies and Organizational Climate for Inclusion, Academy of Management Meeting, Atlanta, USA, 48 August.

Hall, H., \& Graham, D. (2004). Creation and recreation: motivating collaboration to generate knowledge capital in online communities. International Journal of Information Management, 24(3), 235-246.

Hambrick, D. C. (2007). The field of management's devotion to theory: Too much of a good thing?. Academy of Management Journal, 50(6), 1346-1352. 
Hamilton, D. L., \& Trolier, T. K. (1986). Stereotypes and stereotyping: An overview of the cognitive approach. In J. F. Dovidio \& S. L. Gaertner (Eds.), Prejudice, discrimination, and racism (pp. 127-163). San Diego, CA, US: Academic Press.

Hansen, R. (2012). The Centrality of Employment in Immigrant Integration in Europe. Washington DC: Migration Policy Institute. Retrieved from http://www.issuelab.org/resources/12668/12668.pdf

Harris, H., \& Brewster, C. (2002). An integrative framework for pre-departure preparation. In Brewster, C. and Harris, H. (Eds.) International HRM: Contemporary issues in Europe (pp. 223-240). Routledge, New York, NY.

Harvey, M., Buckley, M., \& Novicevic, M. (2007). The role of realistic job previews in expectation lowering procedures for expatriate assignments. Journal of Diversity Management, 2(3), 13-22.

Harvey, M., Buckley, M. R., Richey, G., Moeller, M., \& Novicevic, M. (2012). Aligning expatriate managers' expectations with complex global assignments. Journal of Applied Social Psychology, 42(12), 3026-3050.

Hawthorne, L. (2008). The impact of economic selection policy on labour market outcomes for degree-qualified migrants in Canada and Australia. IRPP choices, 14(5), 1-52.

Haythornthwaite, C., Kazmer, M. M., Robins, J., \& Shoemaker, S. (2000). Community development among distance learners: Temporal and technological dimensions. Journal of Computer-Mediated Communication, 6(1). Retrieved from http://onlinelibrary.wiley.com/doi/10.1111/j.1083-6101.2000.tb00114.x/full

Helfat, C. E. (2007). Stylized facts, empirical research and theory development in management. Strategic Organization, 5(2), 185-192.

Hernandez, E. (2014). Finding a home away from home: Effects of immigrants on firms' foreign location choice and performance. Administrative Science Quarterly, 59(1), 73-108.

Hertlein, K. M. (2012). Digital dwelling: Technology in couple and family relationships. Family Relations, 61(3), 374-387.

Hewitt, J. (2005). Toward an understanding of how threads die in asynchronous computer conferences. The journal of the learning sciences, 14(4), 567-589.

High, A. C., \& Solomon, D. H. (2011). Locating computer-mediated social support within online communication environments. In K. B. Wright, \& L. M. Webb (Eds.), Computermediated communication in personal relationships (pp. 119-136). Peter Lang Inc., International Academic Publishers.

Hiller, H. H., \& Franz, T. M. (2004). New ties, old ties and lost ties: the use of the internet in diaspora. New Media \& Society, 6(6), 731-752.

Holbrey, S., \& Coulson, N. S. (2013). A qualitative investigation of the impact of peer to peer online support for women living with polycystic ovary syndrome. BMC women's health, 13(1), 1-9. 
Hoogeveen, D., Wang, L., Baldwin, T., \& Verspoor, K. M. (2018). Web Forum Retrieval and Text Analytics: A Survey. Foundations and Trends ${ }^{\circledR}$ in Information Retrieval, 12(1), $1-163$.

Howe-Walsh, L., \& Schyns, B. (2010). Self-initiated expatriation: implications for HRM. The International Journal of Human Resource Management, 21(2), 260-273.

Hoye, G., Hooft, E. A., \& Lievens, F. (2009). Networking as a job search behaviour: A social network perspective. Journal of Occupational and Organizational Psychology, 82(3), 661-682.

Hrastinski, S. (2008). Asynchronous and synchronous e-learning. Educause quarterly, 31(4), 51-55.

Hsieh, H. F., \& Shannon, S. E. (2005). Three approaches to qualitative content analysis. Qualitative health research, 15(9), 1277-1288

Hurn, B. J. (2007). Pre-departure training for international business managers. Industrial and Commercial Training, 39(1), 9-17.

Hwang, Y. H., Jani, D., \& Jeong, H. K. (2013). Analyzing international tourists' functional information needs: A comparative analysis of inquiries in an on-line travel forum. Journal of Business Research, 66(6), 700-705.

Hynie, M., Crooks, V. A., \& Barragan, J. (2011). Immigrant and refugee social networks: determinants and consequences of social support among women newcomers to Canada. CJNR (Canadian Journal of Nursing Research), 43(4), 26-46.

Im, E. O., \& Chee, W. (2006). An online forum as a qualitative research method: Practical issues. Nursing research, 55(4), 267-273.

Im, E. O., \& Chee, W. (2012). Practical guidelines for qualitative research using online forums. Computers, informatics, nursing: CIN, 30(11), 604-611.

International Organization for Migration. (2017). Key Migration Terms. Retrieved March 10, 2017 from https://www.iom.int/key-migration-terms

Internet Live Stats. (2016). Canada Internet Users. Retrieved February 2, 2017 from http://www.internetlivestats.com/internet-users/canada/

Irving, P. G., \& Montes, S. D. (2009). Met expectations: The effects of expected and delivered inducements on employee satisfaction. Journal of Occupational and Organizational Psychology, 82(2), 431-451.

Jahnke, J. (2010). Student Perceptions of the Impact of Online Discussion Forum Participation on Learning Outcomes. Journal of Learning Design, 3(2), 27-34.

Jansen, N. A., \& Saint Onge, J. M. (2015). An internet forum analysis of stigma power perceptions among women seeking fertility treatment in the United States. Social Science \& Medicine, 147(December), 184-189.

Janta, H., \& Ladkin, A. (2013). In search of employment: online technologies and Polish migrants. New Technology, Work and Employment, 28(3), 241-253. 
Jean Harrison-Walker, L. (2001). E-complaining: A content analysis of an Internet complaint forum. Journal of Services Marketing, 15(5), 397-412.

Jensen, B. (2002). Service to day laborers: A job libraries have left undone. Reference \& User Services Quarterly, 41(3), 228-233.

Jeong, W. (2004). Unbreakable ethnic bonds: Information-seeking behaviour of Korean graduate students in the United States. Library \& Information Science Research, 26(3), 384-400.

Johannesson, P., \& Perjons, E. (2014). Research Paradigms. In An Introduction to Design Science (pp. 167-179). Springer International Publishing.

Johnson, H. (2007). Dialogue and the construction of knowledge in E-learning: Exploring students' perceptions of their learning while using Blackboard's asynchronous discussion board. European Journal of Open, Distance and E-Learning, 10(1). Retrieved from http://www.eurodl.org/?p=archives \&year $=2007 \& \&$ article $=251$

Johnson, H. H., \& Johnson, M. D. (2017). Influence of event characteristics on assessing credibility and advice-taking. Journal of Managerial Psychology, 32(1), 89-103.

Joyce, E., \& Kraut, R. E. (2006). Predicting continued participation in newsgroups. Journal of Computer-Mediated Communication, 11(3), 723-747.

Kaczmarek, L. D., \& Drążkowski, D. (2014). MMORPG escapism predicts decreased wellbeing: examination of gaming time, game realism beliefs, and online social support for offline problems. Cyberpsychology, Behavior, and Social Networking, 17(5), 298-302.

Kaiser, C., \& Bodendorf, F. (2012). Mining consumer dialog in online forums. Internet Research, 22(3), 275-297.

Kalman, Y. M. (2007). Silence in text-based computer mediated communication: the invisible component. (Doctoral Dissertation, University of Haifa). Retrieved from http://www.kalmans.com/YMKDissertation.pdf

Karanfil, G. (2007). Satellite television and its discontents: Reflections on the experiences of Turkish-Australian lives. Continuum: Journal of Media and Cultural Studies, 21(1), 5969.

Katila, S., \& Wahlbeck, Ö. (2012). The role of (transnational) social capital in the start-up processes of immigrant businesses: The case of Chinese and Turkish restaurant businesses in Finland. International Small Business Journal, 30(3), 294-309.

Keeling, D., Khan, A., \& Newholm, T. (2013). Internet forums and negotiation of healthcare knowledge cultures. Journal of Services Marketing, 27(1), 59-75.

Kehoe, T. (2015). I am Tibetan? An exploration of online identity constructions among Tibetans in China. Asian Ethnicity, 16(3), 314-333.

Kennedy, P. (2004). Making global society: Friendship networks among transnational professionals in the building design industry. Global Networks, 4(2), 157-179. 
Khan, C. (2007). The closed door: Credentialized society and immigrant experiences. Canadian Issues, Spring, 63-66.

Khoir, S., Du, J. T., \& Koronios, A. (2015). Everyday information behaviour of Asian immigrants in South Australia: A mixed-methods exploration. Information Research, 20(3), paper 687. Retrieved from http://InformationR.net/ir/20-3/paper687.html

Khoir, S., Du, J. T., \& Koronios, A. (2015b). Linking everyday information behaviour and Asian immigrant settlement processes: Towards a conceptual framework. Australian Academic \& Research Libraries, 46(2), 86-100.

Khoir, S., Du, J. T., Davison, R. M., \& Koronios, A. (2017). Contributing to social capital: An investigation of Asian immigrants' use of public library services. Library \& Information Science Research, 39(1), 34-45.

Kilpatrick, S., Johns, S., Vitartas, P., \& Homisan, M. (2011). Mobile skilled workers: making the most of an untapped rural community resource. Journal of Rural Studies, 27(2), 181-190.

Kilpatrick, S., Johnson, L., King, T. J., Jackson, R., \& Jatrana, S. (2015). Making connections in a regional city: Social capital and the primary social contract. Journal of Sociology, 51(2), 207-220.

Kim, H. D., \& Tung, R. L. (2013). Opportunities and challenges for expatriates in emerging markets: An exploratory study of Korean expatriates in India. The International Journal of Human Resource Management, 24(5), 1029-1050.

Kim, H. S., \& Sundar, S. S. (2016). Motivating contributions to online forums: can locus of control moderate the effects of interface cues?. Health communication, 31(5), 583-595.

Kim, H., Ray, C. D., \& Veluscek, A. M. (2017). Complementary Support from Facilitators and Peers for Promoting mHealth Engagement and Weight Loss. Journal of health communication, 22(11), 905-912.

Kim, K. H., Yun, H., \& Yoon, Y. (2009). The Internet as a facilitator of cultural hybridization and interpersonal relationship management for Asian international students in South Korea. Asian Journal of Communication, 19(2), 152-169.

Kim, S., \& Yoon, J. (2012). The use of an online forum for health information by married Korean women in the United States. Information Research, 17(2), 1-18.

Kim, Y. Y. (2008). Intercultural personhood: Globalization and a way of being. International journal of intercultural relations, 32(4), 359-368.

Kling, R., \& Courtright, C. (2003). Group behavior and learning in electronic forums: A sociotechnical approach. The Information Society, 19(3), 221-235.

Kogan, I. (2011). New immigrants—old disadvantage patterns? Labour market integration of recent immigrants into Germany. International Migration, 49(1), 91-117. 
Kondracki, N. L., Wellman, N. S., \& Amundson, D. R. (2002). Content analysis: review of methods and their applications in nutrition education. Journal of nutrition education and behavior, 34(4), 224-230.

Korpi, T. (2001). Accumulating disadvantage. Longitudinal analyses of unemployment and physical health in representative samples of the Swedish population. European Sociological Review, 17(3), 255-273.

Kozinets, R. V. (2002). The field behind the screen: Using netnography for marketing research in online communities. Journal of marketing research, 39(1), 61-72.

Kraimer, M., Bolino, M., \& Mead, B. (2016). Themes in expatriate and repatriate research over four decades: What do we know and what do we still need to learn?. Annual Review of Organizational Psychology and Organizational Behavior, 3(1), 83-109.

Krause, K. \& T. Liebig (2011). The Labour Market Integration of Immigrants and their Children in Austria. OECD Social, Employment and Migration Working Papers, No. 127, OECD Publishing, Paris. Retrieved from https://www.oecd.org/migration/49205671.pdf

Krippendorff, K. (2012). Content analysis: An introduction to its methodology. Beverly Hills, CA: Sage.

Kroft, K., \& Pope, D. G. (2014). Does online search crowd out traditional search and improve matching efficiency? Evidence from Craigslist. Journal of Labor Economics, 32(2), 259-303.

Kuckartz, U. (2014). Qualitative text analysis: A guide to methods, practice and using software. Sage.

Kuhn, P., \& Mansour, H. (2014). Is internet job search still ineffective?. The Economic Journal, 124(581), 1213-1233.

Kuhn, P., \& Skuterud, M. (2000). Job search methods: Internet versus traditional. Monthly Labor Review, 123(October), 3-11.

Kuhn, P., \& Skuterud, M. (2005). Internet Job Search and Unemployment Durations. American Economic Review, 94(1), 218-232

Kustec, S., Thompson, E., \& Li, X. (2007). Foreign credentials: The tools for research. Canadian Issues, 26(Spring), 26-30.

Lakey, B., \& Cohen, S. (2000). Social Support and Theory. In S. Cohen, L. G. Underwood, \& B. H. Gottlieb (Eds.), Social support measurement and intervention: A guide for health and social scientists, (pp. 29-52). London, UK: Oxford University Press.

Lampe, C., Wash, R., Velasquez, A., \& Ozkaya, E. (2010, April). Motivations to participate in online communities. In Proceedings of the SIGCHI conference on Human factors in computing systems (pp. 1927-1936). ACM.

Lampe, C., Wohn, D. Y., Vitak, J., Ellison, N. B., \& Wash, R. (2011). Student use of Facebook for organizing collaborative classroom activities. International Journal of Computer-Supported Collaborative Learning, 6(3), 329-347. 
Lee, C. (2004). Korean immigrants' viewing patterns of Korean satellite television and its role in their lives. Asian Journal of Communication, 14(1), 68-90.

Lee, M. (2017). Don't Give Up! A Cyber-ethnography and Discourse Analysis of an Online Infertility Patient Forum. Culture, Medicine, and Psychiatry, 41(3), 341-367.

Lee, S., Chung, J. E., \& Park, N. (2016). Linking cultural capital with subjective well-being and social support: The role of communication networks. Social Science Computer Review, 34(2), 172-196.

Leonardi, P. M., Materiality, Sociomateriality, and Socio-Technical Systems: What Do These Terms Mean? How are They Related? Do We Need Them? (2012). In P. M. Leonardi, B. A. Nardi, \& J. Kallinikos (Eds.), Materiality and Organizing: Social Interaction in a Technological World (pp. 25-48). Oxford: Oxford University Press.

Lewis, C. E., Thompson, L. F., Wuensch, K. L., Grossnickle, W. F., \& Cope, J. G. (2004). The impact of recipient list size and priority signs on electronic helping behavior. Computers in human behavior, 20(5), 633-644.

Li, P. S. (2001). The market worth of immigrants' educational credentials. Canadian Public Policy/Analyse de Politiques, 27(1), 23-38.

Li, Q. (2004). Knowledge building community: Keys for using online forums. TechTrends, 48(4), 24-29.

Li, X., \& Cox, A. M. (2016). A comparative study of knowledge construction within online user support discussion forums in Chinese and English-language cultural contexts. Telematics and Informatics, 33(4), 1048-1056.

Lim, V. K., Teo, T. S., \& Zhao, X. (2013). Psychological costs of support seeking and choice of communication channel. Behaviour \& Information Technology, 32(2), 132-146.

Lin, W., \& Song, H. (2006). Geo-ethnic storytelling: An examination of ethnic media content in contemporary immigrant communities. Journalism, 7(3), 362-388.

Lin, X., \& Yang, X. (2017). From human capital externality to entrepreneurial aspiration: Revisiting the migration-trade linkage. Journal of World Business, 52(3), 360-371.

Lin, X., Zhang, D., \& Li, Y. (2016). Delineating the dimensions of social support on social networking sites and their effects: A comparative model. Computers in human behavior, 58(May), 421-430.

Lincoln, Y. S., Lynham, S. A., \& Guba, E. G. (2011). Paradigmatic controversies, contradictions, and emerging confluences, revisited. In N. K. Denzin \& Y. S. Lincoln (Eds.), The Sage handbook of qualitative research, $4^{\text {th }}$ edition, 97-128. Thousand Oaks, Sage.

Littrell, L. N., Salas, E., Hess, K. P., Paley, M., \& Riedel, S. (2006). Expatriate preparation: A critical analysis of 25 years of cross-cultural training research. Human Resource Development Review, 5(3), 355-388. 
Liu, C. Y., \& Yu, C. P. (2013). Can Facebook use induce well-being?. Cyberpsychology, Behavior, and Social Networking, 16(9), 674-678.

Loncar, M., Barrett, N. E., \& Liu, G. Z. (2014). Towards the refinement of forum and asynchronous online discussion in educational contexts worldwide: Trends and investigative approaches within a dominant research paradigm. Computers \& Education, 73(April), 93-110.

Luca, J., \& McLoughlin, C. (2004). Using online forums to support a community of learning. In World Conference on Educational Multimedia, Hypermedia and Telecommunications, (June), 1468-1474.

Lucić, L. (2016). Changing landscapes, changing narratives: socio-cultural approach for teaching global migrants. Pedagogy, Culture \& Society, 24(2), 221-237.

Lundborg, P. (2013). Refugees' employment integration in Sweden: Cultural distance and labor market performance. Review of International Economics, 21(2), 219-232.

MacGeorge, E. L., Feng, B., \& Guntzviller, L. M. (2016). Advice: Expanding the communication paradigm. Annals of the International Communication Association, 40(1), 213-243.

Macnamara, J. R. (2005). Media content analysis: Its uses, benefits and best practice methodology. Asia-Pacific Public Relations Journal, 6(1), 1-34.

MacPherson, S. (2010). Teachers' collaborative conversations about culture: Negotiating decision making in intercultural teaching. Journal of Teacher Education, 61(3), 271-286.

Magsamen-Conrad, K., \& Greene, K. (2014). Technology addiction's contribution to mental wellbeing: The positive effect of online social capital. Computers in human behavior, 40, 23-30.

Mahajan, A., \& Toh, S. M. (2014). Facilitating expatriate adjustment: The role of adviceseeking from host country nationals. Journal of World Business, 49(4), 476-487.

Mähönen, T. A., Leinonen, E., \& Jasinskaja-Lahti, I. (2013). Met expectations and the wellbeing of diaspora immigrants: A longitudinal study. International Journal of Psychology, 48(3), 324-333.

Majchrzak, A., Faraj, S., Kane, G. C., \& Azad, B. (2013). The contradictory influence of social media affordances on online communal knowledge sharing. Journal of ComputerMediated Communication, 19(1), 38-55.

Makwarimba, E., Stewart, M., Simich, L., Makumbe, K., Shizha, E., \& Anderson, S. (2013). Sudanese and Somali refugees in Canada: Social support needs and preferences. International Migration, 51(5), 106-119.

Mao, Y. (2015). Investigating Chinese Migrants' Information-Seeking Patterns in Canada: Media Selection and Language Preference. Global Media Journal, 8(2), 113-131. 
Mark, G., Gonzalez, V. M., \& Harris, J. (2005, April). No task left behind?: examining the nature of fragmented work. In Proceedings of the SIGCHI conference on Human factors in computing systems (pp. 321-330). ACM.

Marra, R. M., Moore, J. L., \& Klimczak, A. K. (2004). Content analysis of online discussion forums: A comparative analysis of protocols. Educational Technology Research and Development, 52(2), 23-40.

Massey, D. S., Arango, J., Hugo, G., Kouaouci, A., Pellegrino, A., \& Taylor, J. E. (1993). Theories of international migration: A review and appraisal. Population and development review, 19(3), 431-466.

Mattingly, D. J. (1999). Job search, social networks, and local labor-market dynamics: The case of paid household work in San Diego, California. Urban Geography, 20(1), 46-74.

McKenzie, P. J. (2003). A model of information practices in accounts of everyday-life information seeking. Journal of Documentation, 59(1), 19-40.

McKiernan, A., Ryan, P., McMahon, E., \& Butler, E. (2017). Qualitative Analysis of Interactions on an Online Discussion Forum for Young People with Experience of Romantic Relationship Breakup. Cyberpsychology, Behavior, and Social Networking, 20(2), 78-82.

Mehra, B., \& Papajohn, D. (2007). "Glocal" patterns of communication-information convergences in Internet use: Cross cultural behaviour of international teaching assistants in a culturally alien information environment. International Information \& Library Review, $39(1), 12-30$.

Meissner, R. (2016). The relevance of social theory in the practice of environmental management. Science and engineering ethics, 22(5), 1345-1360.

Merriam-Webster Dictionary (2017). Retrieved December 20, 2017, from https://www.merriam-webster.com/

Metoyer-Duran, C. (1991). Information-seeking behavior of gatekeepers in ethnolinguistic communities: Overview of taxonomy. Library \& Information Science Research, 13(4), 319-346.

Metoyer-Duran, C. (1993). Information gatekeepers. Annual Review of Information Science and Technology, 28, 111-150.

Mezias, J. M., \& Scandura, T. A. (2005). A needs-driven approach to expatriate adjustment and career development: A multiple mentoring perspective. Journal of International Business Studies, 36(5), 519-538.

Mikal, J. P., Rice, R. E., Abeyta, A., \& DeVilbiss, J. (2013). Transition, stress and computer-mediated social support. Computers in Human Behavior, 29(5), A40-A53.

Mikal, J. P., Yang, J., \& Lewis, A. (2015). Surfing USA: How Internet use prior to and during study abroad affects Chinese students' stress, integration, and cultural learning while in the United States. Journal of Studies in International Education, 19(3), 203-224. 
Miles, M. B., \& Huberman, A. M. (1994). Qualitative data analysis: An expanded sourcebook. Sage.

Miles, M. B., Huberman, A. M., \& Saldaña, J. (2014). Qualitative data analysis: A methods sourcebook. Thousand Oaks, California.

Miller, D. (2007). Paradigm prison, or in praise of atheoretic research. Strategic Organization, 5(2), 177-184.

Mitra, A. (2006). Towards finding a cybernetic safe place: Illustrations from people of Indian origin. New Media \& Society, 8(2), 251-268.

Miyazoe, T., \& Anderson, T. (2010). Learning outcomes and students' perceptions of online writing: Simultaneous implementation of a forum, blog, and wiki in an EFL blended learning setting. System, 38(2), 185-199.

Mo, P. K., \& Coulson, N. S. (2008). Exploring the communication of social support within virtual communities: a content analysis of messages posted to an online HIV/AIDS support group. Cyberpsychology \& behavior, 11(3), 371-374.

Mo, P. K., \& Coulson, N. S. (2010). Empowering processes in online support groups among people living with HIV/AIDS: A comparative analysis of 'lurkers' and 'posters'. Computers in Human Behavior, 26(5), 1183-1193.

Momeni, E., Cardie, C., \& Diakopoulos, N. (2016). A survey on assessment and ranking methodologies for user-generated content on the web. ACM Computing Surveys (CSUR), 48(3), Article No. 41

Moon, S., \& Park, C. Y. (2007). Media effects on acculturation and biculturalism: A case study of Korean immigrants in Los Angeles' Koreatown. Mass Communication and Society, 10(3), 319-343.

Moore, D., \& Ayers, S. (2017). Virtual voices: social support and stigma in postnatal mental illness Internet forums. Psychology, health \& medicine, 22(5), 546-551.

Mudry, T. E., \& Strong, T. (2013). Doing recovery online. Qualitative Health Research, 23(3), 313-325.

Murray, A. (2010). The State of Knowledge on the Role and Impact of Labour Market Information: A Survey of the Canadian Evidence (No. 2010-04). Centre for the Study of Living Standards. Retrieved from http://www.csls.ca/reports/csls2010-04.pdf

Mwarigha M.S. (2002). Towards a framework for local responsibility: Taking action to end the current limbo in immigrant settlement - Toronto. Toronto: The Maytree Foundation. Retrieved from https://pdfs.semanticscholar.org/9f7d/57717c4f9d5253389869fd8a6e4083340309.pdf

Nambisan, P. (2011). Information seeking and social support in online health communities: impact on patients' perceived empathy. Journal of the American Medical Informatics Association, 18(3), 298-304. 
Nandy, B. R., \& Sarvela, P. D. (1997). Content analysis reexamined: A relevant research method for health education. American Journal of Health Behavior, 21(3), 222-234.

Nardon, L., \& Aten, K. (2016). Making sense of a foreign culture through technology: Triggers, mechanisms, and introspective focus in newcomers' blogs. International Journal of Intercultural Relations, 54, 15-20.

Nardon, L., Aten, K., \& Gulanowski, D. (2015). Expatriate adjustment in the digital age: The co-creation of online social support resources through blogging. International Journal of Intercultural Relations, 47, 41-55.

Naslund, J. A., Aschbrenner, K. A., Marsch, L. A., \& Bartels, S. J. (2016). The future of mental health care: peer-to-peer support and social media. Epidemiology and psychiatric sciences, 25(2), 113-122.

Netmarketshare.com. Desktop Search Engine Market Share. (2016, February). Retrieved from https://www.netmarketshare.com/search-engine-marketshare. aspx ?qprid $=4 \&$ qpcustomd $=0 \&$ qpsp $=205 \&$ qpnp $=1 \&$ qptimeframe $=M$

Newell, B. C., Gomez, R., \& Guajardo, V. E. (2016). Information seeking, technology use, and vulnerability among migrants at the United States-Mexico border. The Information Society, 32(3), 176-191.

Noh, S., \& Avison, W. R. (1996). Asian immigrants and the stress process: A study of Koreans in Canada. Journal of health and social behavior, 37(2), 192-206.

Nonaka, I. (1994). A dynamic theory of organizational knowledge creation. Organization science, 5(1), 14-37.

Nonnecke, B., Preece, J., \& Andrews, D. (2004). What lurkers and posters think of each other. Proceedings of the 37th Annual Hawaii International Conference on System Sciences. Retrieved from http://www.socs.uoguelph.ca/ nonnecke/research/WhatLurkersandPostersThinkofEachO ther.pdf

Noorani, N. (2017, May). Global Mobility in the Digital Age. Conference Board of Canada. Retrieved from http://www.conferenceboard.ca/Libraries/CONF_PRES_PUBLIC/170065_b2_noorani.sflb

Nor, N., Razak, N., \& Aziz, J. (2010). E-learning: Analysis of online discussion forums in promoting knowledge construction through collaborative learning. WSEAS Transactions on Communication, 9(1), 53-62.

Oh, H. J., Ozkaya, E., \& LaRose, R. (2014). How does online social networking enhance life satisfaction? The relationships among online supportive interaction, affect, perceived social support, sense of community, and life satisfaction. Computers in Human Behavior, 30, 69-78.

Oliver, L. W., \& Spokane, A. R. (1988). Career-intervention outcome: What contributes to client gain?. Journal of Counseling Psychology, 35(4), 447. 
Oliver, M. (2005). The problem with affordance. E-Learning and Digital Media, 2(4), 402413.

Omidvar, A., Garakani, M., \& Safarpour, H. R. (2014). Context based user ranking in forums for expert finding using WordNet dictionary and social network analysis. Information Technology and Management, 15(1), 51-63.

Orlikowski, W. J., \& Gash, D. C. (1994). Technological frames: making sense of information technology in organizations. ACM Transactions on Information Systems (TOIS), 12(2), 174-207.

Pan, W., Shen, C., \& Feng, B. (2017). You Get What You Give: Understanding Reply Reciprocity and Social Capital in Online Health Support Forums. Journal of health communication, 22(1), 45-52.

Paul, K. I., \& Moser, K. (2009). Unemployment impairs mental health: Metaanalyses. Journal of Vocational behavior, 74(3), 264-282.

Pearson, J., Hammond, M., Heffernan, E., \& Turner, T. (2012). Careers and talents not to be wasted: Skilled immigrants' journeys through psychological states en route to satisfying employment. Journal of Management development, 31(2), 102-115.

Pendry, L. F., \& Salvatore, J. (2015). Individual and social benefits of online discussion forums. Computers in Human Behavior, 50, 211-220.

Pennebaker, J. W., Boyd, R. L., Jordan, K., \& Blackburn, K. (2015). The development and psychometric properties of LIWC2015. Austin, TX: University of Texas at Austin.

Petersen, L. E., \& Dietz, J. (2005). Prejudice and Enforcement of Workforce Homogeneity as Explanations for Employment Discrimination. Journal of Applied Social Psychology, 35(1), 144-159.

Pettigrew, K. E. (1999). Waiting for chiropody: Contextual results from an ethnographic study of the information behaviour among attendees at community clinics. Information Processing \& Management, 35(6), 801-817.

Pholphirul, P., \& Rukumnuaykit, P. (2016). Does Immigration always Promote Innovation? Evidence from Thai Manufacturers. Journal of International Migration and Integration, 18(1), 1-28.

Picot, W. G., Hou, F., \& Coulombe, S. (2007). Chronic low income and low-income dynamics among recent immigrants. Ottawa: Statistics Canada. Retrieved from http://www.statcan.gc.ca/pub/11f0019m/11f0019m2007294-eng.htm

Pittaway, E. E., Bartolomei, L., \& Doney, G. (2016). The glue that binds: An exploration of the way resettled refugee communities define and experience social capital. Community Development Journal, 51(3), 401-418.

Podsiadlowski, A., Vauclair, C. M., Spiess, E., \& Stroppa, C. (2013). Social support on international assignments: The relevance of socioemotional support from locals. International Journal of Psychology, 48(4), 563-573. 
Pohlmann, C. (2017). Meeting Canada's Labour Market Needs: Small Business Perspective. Conference Board of Canada (May 2017) Retrieved from http://www.conferenceboard.ca/Libraries/CONF_PRES_PUBLIC/170065_d3_pohlmann.sflb

Pokorny, R. E. (2003). Library services to immigrants and non-native speakers of English: From our past to our present. Bookmobile \& Outreach Services, 6(2), 21-34.

Polanyi, M., \& Sen, A. (2009). The tacit dimension. University of Chicago press.

Porter, L. W., \& Steers, R. M. (1973). Organizational, work, and personal factors in employee turnover and absenteeism. Psychological bulletin, 80(2), 151.

Preece, J., Nonnecke, B., \& Andrews, D. (2004). The top five reasons for lurking: improving community experiences for everyone. Computers in human behavior, 20(2), 201-223.

Prock, A. (2003). Serving the invisible population: Library outreach for migrant farm workers. Bookmobile \& Outreach Services, 6(1), 37-51.

Puck, J. F., Kittler, M. G., \& Wright, C. (2008). Does it really work? Re-assessing the impact of pre-departure cross-cultural training on expatriate adjustment. The International Journal of Human Resource Management, 19(12), 2182-2197.

Puck, J., Holtbrügge, D., \& Raupp, J. (2017). Expatriate Adjustment: A Review of Concepts, Drivers, and Consequences. In Bader B., Schuster T., Bader A. (Eds) Expatriate Management (pp. 297-336). Palgrave Macmillan, UK.

Qureshi, M. A., Shah, S. M. M., Mirani, M. A., \& Tagar, H. K. (2017). Towards an Understanding of Expatriate Job Performance: A Conceptual Paper. International Journal of Academic Research in Business and Social Sciences, 7(9), 320-332.

Rabbany, R., Elatia, S., Takaffoli, M., \& Zaïane, O. R. (2014). Collaborative learning of students in online discussion forums: A social network analysis perspective. In Educational data mining (pp. 441-466). Springer International Publishing.

Rader, C. A., Larrick, R. P., \& Soll, J. B. (2017). Advice as a form of social influence: Informational motives and the consequences for accuracy. Social and Personality Psychology Compass, 11(8), 1-17.

Rains, S. A. (2016). Language style matching as a predictor of perceived social support in computer-mediated interaction among individuals coping with illness. Communication Research, 43(5), 694-712.

Rains, S. A., \& Keating, D. M. (2011). The social dimension of blogging about health: Health blogging, social support, and well-being. Communication Monographs, 78(4), 511534.

Rains, S. A., \& Tsetsi, E. (2017). Social support and digital inequality: Does Internet use magnify or mitigate traditional inequities in support availability?. Communication Monographs, 84(1), 54-74. 
Rains, S. A., \& Wright, K. B. (2016). Social support and computer-mediated communication: A state-of-the-art review and agenda for future research. Annals of the International Communication Association, 40(1), 175-211.

Rains, S. A., Brunner, S. R., Akers, C., Pavlich, C. A., \& Tsetsi, E. (2016). The Implications of Computer-Mediated Communication (CMC) for Social Support Message Processing and Outcomes: When and Why Are the Effects of Support Messages Strengthened During CMC?. Human Communication Research, 42(4), 553-576.

Rains, S. A., Peterson, E. B., \& Wright, K. B. (2015). Communicating social support in computer-mediated contexts: A meta-analytic review of content analyses examining support messages shared online among individuals coping with illness. Communication Monographs, 82(4), 403-430.

Rains, S. A., \& Young, V. (2009). A meta-analysis of research on formal computermediated support groups: Examining group characteristics and health outcomes. Human communication research, 35(3), 309-336.

Ramboarison-Lalao, L., Al Ariss, A., \& Barth, I. (2012). Careers of skilled migrants: understanding the experiences of Malagasy physicians in France. Journal of Management Development, 31(2), 116-129.

Reitz, J. G. (2001). Immigrant skill utilization in the Canadian labour market: Implications of human capital research. Journal of International Migration and Integration, 2(3), 347378.

Reitz, J. G. (2005). Tapping immigrants' skills: New directions for Canadian immigration policy in the knowledge economy. IRPP Choices, 11(1), 1-20.

Reitz, J. G. (2007a). Immigrant employment success in Canada, Part I: Individual and contextual causes. Journal of International Migration and Integration, 8(1), 11-36.

Reitz, J. G. (2007b). Immigrant employment success in Canada, part II: Understanding the decline. Journal of International Migration and Integration, 8(1), 37-62.

Reitz, J. G. (2011). Taxi driver syndrome. Literary review of Canada, 19(2), 20-22.

Reitz, J. G., Curtis, J., \& Elrick, J. (2014). Immigrant skill utilization: Trends and policy issues. Journal of International Migration and Integration, 15(1), 1-26.

Reitz, J. M. (2004). Dictionary for library and information science. Libraries Unlimited. Westport.

Ring, D. M., \& Oei, S. Y. (2016). The Tax Lives of Uber Drivers: Evidence from Online Forums. Columbia Journal of Tax Law, 8(1), 56.

Rising, C. J., Bol, N., Burke-Garcia, A., Rains, S., \& Wright, K. B. (2017). Perceived Stress in Online Prostate Cancer Community Participants: Examining Relationships with Stigmatization, Social Support Network Preference, and Social Support Seeking. Journal of Health Communication, 22(6), 469-476. 
Road to Canada. (2017). Road to Canada Forums. Retrieved January 2017 from http://www.roadtocanada.com/forums/index.php

Rodriguez, M. A. (2014). Content analysis as a method to assess online discussions for learning. SAGE Open, 4(4), 1-13

Rolls, K., Hansen, M., Jackson, D., \& Elliott, D. (2016). How health care professionals use social media to create virtual communities: An integrative review. Journal of medical Internet research, 18(6).

Ruhleder, K. (2002). Understanding on-line community: The affordances of virtual space. Information Research, 7(3). Retrieved from http://InformationR.net/ir/73/paper132.html

Russell, C., Dickson, T., \& McKeganey, N. (2017). Advice From Former-Smoking ECigarette Users to Current Smokers on How to Use E-Cigarettes as Part of an Attempt to Quit Smoking. Nicotine \& Tobacco Research. Published online: 3 August 2017, ntx176, https://doi.org/10.1093/ntr/ntx176

Saade, G. R., \& Huang, Q. (2009). Meaningful learning in discussion forums: Towards discourse analysis. Issues in Informing Science and Information Technology, 6(1), 87-99.

Salaff, J., Greve, A., \& Ping, L. X. L. (2002). Paths into the economy: Structural barriers and the job hunt for skilled PRC migrants in Canada. International Journal of Human Resource Management, 13(3), 450-464.

Salgado, J. F., \& Bastida, M. (2017). Predicting expatriate effectiveness: The role of personality, cross-cultural adjustment, and organizational support. International Journal of Selection and Assessment, 25(3), 267-275.

Sambasivan, M., Sadoughi, M., \& Esmaeilzadeh, P. (2017). Investigating the factors influencing cultural adjustment and expatriate performance: The case of Malaysia. International Journal of Productivity and Performance Management, 66(8), 1002-1019.

Sandberg, J. (2005). How do we justify knowledge produced within interpretive approaches?. Organizational research methods, 8(1), 41-68.

Savolainen, R. (1995). Everyday life information seeking: Approaching information seeking in the context of "way of life." Library \& Information Science Research, 17(3), 259-294.

Savolainen, R. (2006). Time as a context of information seeking. Library \& Information Science Research, 28(1), 110-127.

Savolainen, R. (2007). Information behavior and information practice: Reviewing the umbrella concepts of information-seeking studies. Library Quarterly, 77(2), 109-132.

Savolainen, R. (2008). Everyday information practices: A social phenomenological perspective. Toronto: Scarecrow Press. 
Savolainen, R. (2016). Approaches to socio-cultural barriers to information seeking. Library \& Information Science Research, 38(1), 52-59.

Schau, H. J., Dang, Y. M., \& Zhang, Y. G. (2017). Learning to navigate the American retail servicescape: Online forums as consumer acculturation platforms and consumer gift systems. Journal of Business Research, 72(March), 178-188.

Schreier, M. (2012). Qualitative content analysis in practice. Sage Publications.

Seethamraju, R. (2014). Effectiveness of using online discussion forum for case study analysis. Education Research International, Volume 2014, 1-10. Retrieved from https://www.hindawi.com/journals/edri/2014/589860/

Seraj, M. (2012). We create, we connect, we respect, therefore we are: intellectual, social, and cultural value in online communities. Journal of Interactive Marketing, 26(4), 209222.

Shahiri, H., \& Osman, Z. (2015). Internet Job Search and Labor Market Outcome. International Economic Journal, 29(1), 161-173.

Shapiro, J. M., Ozanne, J. L., \& Saatcioglu, B. (2008). An interpretive examination of the development of cultural sensitivity in international business. Journal of International Business Studies, 39(1), 71-87.

Sheng, M., \& Hartono, R. (2015). An exploratory study of knowledge creation and sharing in online community: A social capital perspective. Total Quality Management \& Business Excellence, 26(1-2), 93-107.

Shenkar, O. (2004). One more time: International business in a global economy. Journal of International Business Studies, 35(2), 161-171.

Shoham, S., \& Rabinovich, R. (2008). Public library services to new immigrants in Israel: The case of immigrants from the Former Soviet Union and Ethiopia. The International Information \& Library Review, 40(1), 21-42.

Shoham, S., \& Strauss, S. (2007). Information needs of North American immigrants to Israel. Journal of Information, Communication \& Ethics in Society, 5(2/3), 185-205.

Sidani, Y., \& Al Ariss, A. (2014). Institutional and corporate drivers of global talent management: Evidence from the Arab Gulf region. Journal of World Business, 49(2), $215-$ 224.

Silvanto, S., Ryan, J., \& McNulty, Y. (2015). An empirical study of nation branding for attracting internationally mobile skilled professionals. Career Development International, 20(3), 238-258.

Silvio, D. H. (2006). The information needs and information seeking behaviour of immigrant southern Sudanese youth in the city of London, Ontario: An exploratory study. Library Review, 55(4), 259-266. 
Simich, L., Beiser, M., \& Mawani, F. N. (2003). Social support and the significance of shared experience in refugee migration and resettlement. Western journal of nursing research, 25(7), 872-891.

Singh, J. S. K., \& Mahmood, N. H. N. (2017). Emotional Intelligence and Expatriate Job Performance in the ICT Sector: The Mediating Role of Cultural Adjustment. Global Business and Management Research, 9(1s), 230-243.

Sirikul, P., \& Dorner, D. (2016). Thai immigrants' information seeking behaviour and perception of the public library's role during the settlement process. Library Review, 65(8/9), 535-548.

Sobre-Denton, M., \& Hart, D. (2008). Mind the gap: Application-based analysis of cultural adjustment models. International Journal of Intercultural Relations, 32(6), 538-552.

Srinivasan, R. (2007). Ethnomethodological architectures: Information systems driven by cultural and community visions. Journal of the American Society for Information Science and Technology, 58(5), 723-733.

Srinivasan, R., \& Pyati, A. (2007). Diasporic information environments: Re-framing information behavior research. Journal of the American Society for Information Science and Technology, 58(12), 1734-1744.

Statista. (2016). Worldwide desktop market share of leading search engines. Retrieved August 1, 2016 from https://www.statista.com/statistics/216573/worldwide-market-shareof-search-engines/

Statista. (2017). Internet usage frequency in Canada as of January 2017. Retrieved March 15, 2017 from https://www.statista.com/statistics/686835/canada-internet-usagefrequency/

Statistics Canada. (2013). Immigration and ethnocultural diversity in Canada. Retrieved from http://www12.statcan.gc.ca/nhs-enm/2011/as-sa/99-010-x/99-010-x2011001eng.pdf

Statistics Canada. (2016). 150 years of immigration in Canada. Retrieved from http://www.statcan.gc.ca/pub/11-630-x/11-630-x2016006-eng.htm

Steuber, K. R., \& Haunani Solomon, D. (2008). Relational uncertainty, partner interference, and infertility: A qualitative study of discourse within online forums. Journal of Social and Personal Relationships, 25(5), 831-855.

Stevenson, B. (2009). The Internet and job search. Studies of Labor Market Intermediation, 2, 67-86. Retrieved from http://www.nber.org/books/auto07-1

Stewart, M., Anderson, J., Beiser, M., Mwakarimba, E., Neufeld, A., Simich, L., \& Spitzer, D. (2008). Multicultural meanings of social support among immigrants and refugees. International Migration, 46(3), 123-159. 
Stewart Loane, S., Webster, C. M., \& D’Alessandro, S. (2015). Identifying consumer value co-created through social support within online health communities. Journal of Macromarketing, 35(3), 353-367.

Stroppa, C., \& Spieß, E. (2011). International assignments: The role of social support and personal initiative. International Journal of Intercultural Relations, 35(2), 234-245.

$\mathrm{Su}, \mathrm{S}$. S., \& Conaway, C. W. (1995). Information and a forgotten minority: Elderly Chinese immigrants. Library \& Information Science Research, 17(1), 69-86.

Sun, N., Rau, P. P. L., \& Ma, L. (2014). Understanding lurkers in online communities: A literature review. Computers in Human Behavior, 38, 110-117.

Sundararajan, B. (2010). Emergence of the most knowledgeable other (mko): Social network analysis of chat and bulletin board conversations in a CSCL system. Electronic Journal of e-Learning, 8(2), 191-208.

Suvankulov, F., Chi Keung Lau, M., \& Ho Chi Chau, F. (2012). Job search on the internet and its outcome. Internet research, 22(3), 298-317.

Syed, J. (2008). Employment prospects for skilled migrants: A relational perspective. Human Resource Management Review, 18(1), 28-45.

Syed, J., \& Murray, P. (2009). Combating the English language deficit: The labour market experiences of migrant women in Australia. Human Resource Management Journal, 19(4), 413-432.

Tabor, A. S., \& Milfont, T. L. (2013). We are all in the same boat: How online communities facilitate the process of migration. New Zealand Journal of Psychology, 42(1), 31-35.

Takeda, A. (2013). Weblog narratives of Japanese migrant women in Australia: Consequences of international mobility and migration. International Journal of Intercultural Relations, 37(4), 415-421.

Takeuchi, R. (2010). A critical review of expatriate adjustment research through a multiple stakeholder view: Progress, emerging trends, and prospects. Journal of Management, 36(4), 1040-1064.

Tan, S. C., \& Seah, L. H. (2011). Exploring relationship between students' questioning behaviors and inquiry tasks in an online forum through analysis of ideational function of questions. Computers \& Education, 57(2), 1675-1685.

Tang, X., \& Yang, C. C. (2012). Ranking user influence in healthcare social media. ACM Transactions on Intelligent Systems and Technology (TIST), 3(4), Article No. 73.

Tanis, M. A. (2008). What makes the internet a place to seek social support? In E. A. Konijn, S. Utz, M. Tanis, \& S. B. Barnes (Eds.), Mediated interpersonal communication (pp. 290-308). New York: Routledge Taylor \& Francis Group.

Tarique, I., \& Schuler, R. S. (2010). Global talent management: Literature review, integrative framework, and suggestions for further research. Journal of World Business, 45(2), 122-133. 
Tatli, A., Vassilopoulou, J., Ariss, A. A., \& Özbilgin, M. (2012). The role of regulatory and temporal context in the construction of diversity discourses: The case of the UK, France and Germany. European Journal of Industrial Relations, 18(4), 293-308.

Taylor, E. J. (1999). The new economics of labour migration and the role of remittances in the migration process. International migration, 37(1), 63-88.

Ter Bush, R. F. (2006, January). Silence, attribution accuracy and virtual environments: Implications for developers and facilitators. In System Sciences, 2006. HICSS'06. Proceedings of the 39th Annual Hawaii International Conference on (Vol. 1, pp. 17b-17b). IEEE.

Tharenou, P. (2015). Researching expatriate types: the quest for rigorous methodological approaches. Human Resource Management Journal, 25(2), 149-165.

The Region of Peel and The Diversity Institute. (2009). The Peel Immigration Labour Market Survey Findings. Retrieved from http://www.ryerson.ca/content/dam/diversity/reports/PeelReport_2010.pdf

The University of New South Wales. (2017). Blog, Wiki or Forum - which should you use?. Retrieved from https://teaching.unsw.edu.au/assessment-blog-wiki-or-forum-whichshould-you-use

Thomas, D. R. (2006). A general inductive approach for analyzing qualitative evaluation data. American journal of evaluation, 27(2), 237-246.

Thomsen, S. L., \& Wittich, M. (2010). Which one to choose? Evidence on the choice and success of job search methods. Schmollers Jahrbuch, 130(4), 445-483.

To, T. (1995). Survey on the library needs of and library use by the Chinese language readers in Fairfield, New South Wales: Preliminary report. Public Library Quarterly, 14(4), 27-50.

Treem, J. W., \& Leonardi, P. M. (2012). Social media use in organizations: Exploring the affordances of visibility, editability, persistence, and association. Communication Yearbook 36(1), 143-189.

Trepte, S., Dienlin, T., \& Reinecke, L. (2015). Influence of social support received in online and offline contexts on satisfaction with social support and satisfaction with life: A longitudinal study. Media Psychology, 18(1), 74-105.

Treurnicht, I. (2017, May). Keynote Presentation: Innovation at 150 and Beyond. Conference Board of Canada. Retrieved from http://www.conferenceboard.ca/Libraries/CONF_PRES_PUBLIC/170065_p3_treurnicht.sflb

Tung, R. L. (2016). New perspectives on human resource management in a global context. Journal of World Business, 51(1), 142-152.

Turchick Hakak, L., \& Al Ariss, A. (2013). Vulnerable work and international migrants: A relational human resource management perspective. The International Journal of Human Resource Management, 24(22), 4116-4131. 
Turchick Hakak, L., Holzinger, I., \& Zikic, J. (2010). Barriers and paths to success: Latin American MBAs' views of employment in Canada. Journal of Managerial Psychology, 25(2), 159-176.

Uchino, B. N. (2004). Social support and physical health: Understanding the health consequences of relationships. New Haven, CT: Yale University Press.

UN International Migration Report 2017. (2017). Retrieved from http://www.un.org/en/development/desa/population/migration/publications/migrationrepo rt/docs/MigrationReport2017.pdf

UN International Migration Report 2017: Highlights. (2017). Retrieved from http://www.un.org/en/development/desa/population/migration/publications/migrationrepo rt/docs/MigrationReport2017_Highlights.pdf

UN International Migration Wallchart 2017. (2017). Retrieved from http://www.un.org/en/development/desa/population/migration/publications/wallchart/doc s/MigrationWallChart2017.pdf

UNHCR. (2017). A Syrian Family Finds Acceptance for their Disabled Children through Canadian Resettlement. Retrieved from https://www.unhcr.ca/news/syrian-familycanadian-resettlement/

Vacca, R., Solano, G., Lubbers, M. J., Molina, J. L., \& McCarty, C. (2016). A personal network approach to the study of immigrant structural assimilation and transnationalism. Social Networks. Retrieved from http://www.raffaelevacca.com/wpcontent/uploads/2015/07/Vacca-et-al.-A-personal-network-approach-to-the-study-ofimmigr.pdf

Vaiman, V., Haslberger, A., \& Vance, C. M. (2015). Recognizing the important role of self-initiated expatriates in effective global talent management. Human Resource Management Review, 25(3), 280-286.

van Bakel, M., van Oudenhoven, J. P., \& Gerritsen, M. (2017). Expatriate contact with a local host: an intervention to increase social support. Human Resource Development International, 20(3), 215-235.

van Berkel, J. J., Lambooij, M. S., \& Hegger, I. (2015). Empowerment of patients in online discussions about medicine use. BMC medical informatics and decision making, 15(1), 19.

van der Laken, P., van Engen, M., van Veldhoven, M., \& Paauwe, J. (2016). Expatriate support and success: A systematic review of organization-based sources of social support. Journal of Global Mobility: The Home of Expatriate Management Research, 4(4), 408-431.

van Mierlo, T. (2014). The $1 \%$ rule in four digital health social networks: an observational study. Journal of medical Internet research, 16(2). e33. doi:10.2196/jmir.2966 
Van Rooy, D. L., Alonso, A., \& Fairchild, Z. (2003). In with the new, out with the old: Has the technological revolution eliminated the traditional job search process?. International journal of selection and assessment, 11(2-3), 170-174.

Vanable, P. A., Carey, M. P., Blair, D. C., \& Littlewood, R. A. (2006). Impact of HIVrelated stigma on health behaviors and psychological adjustment among HIV-positive men and women. AIDS and Behavior, 10(5), 473-482.

Veronis, L., \& Ahmed, R. (2015). The role of multicultural media in connecting municipal governments with ethnocultural and immigrant communities: The case of Ottawa. Global Media Journal, 8(2), 73-95.

Vilhelmson, B., \& Thulin, E. (2013). Does the Internet encourage people to move? Investigating Swedish young adults' internal migration experiences and plans. Geoforum, Volume 47, 209-216.

Von Krogh, G., Rossi-Lamastra, C., \& Haefliger, S. (2012). Phenomenon-based research in management and organisation science: When is it rigorous and does it matter?. Long Range Planning, 45(4), 277-298.

Wald, S., \& Fang, T. (2008). Overeducated immigrants in the Canadian labour market: Evidence from the workplace and employee survey. Canadian Public Policy, 34(4), 457479.

Wanberg, C. R. (2012). The individual experience of unemployment. Annual review of psychology, 63, 369-396.

Wang, Q., \& Woo, H. L. (2008). The Affordances of Weblogs and Discussion Forums for Learning: A Comparative Analysis. Educational Technology, 48(5), 34-38.

Wang, X., \& Sangalang, P. J. (2005). Work adjustment and job satisfaction of Filipino immigrant employees in Canada. Canadian Journal of Administrative Sciences, 22(3), 243-254.

Ward, C., Okura, Y., Kennedy, A., \& Kojima, T. (1998). The U-curve on trial: A longitudinal study of psychological and sociocultural adjustment during cross-cultural transition. International Journal of Intercultural Relations, 22(3), 277-291.

Watt, D., \& Bloom, M. (2001). Exploring the Learning Recognition Gap in Canada. Phase 1 Report. Recognizing Learning: The Economic Cost of Not Recognizing Learning and Learning Credentials in Canada. Conference Board of Canada. Retrieved from http://www.hireimmigrants.ca/wp-content/uploads/Exploring-the-learning-recognitiongap.pdf

Weber, R. (2004). Editor's comments: the rhetoric of positivism versus interpretivism: a personal view. MIS quarterly, 28(1), 3-12.

Weber, R. P. (1990). Basic content analysis. Beverly Hills, CA: Sage.

Wenjing, X. (2005). Virtual space, real identity: Exploring cultural identity of Chinese diaspora in virtual community. Telematics \& Informatics, 22(4), 395-404. 
Whiston, S. C., Sexton, T. L., \& Lasoff, D. L. (1998). Career-intervention outcome: A replication and extension of Oliver and Spokane (1988). Journal of Counseling Psychology, 45(2), 150-165.

Wong, S. L., \& Salaff, J. W. (1998). Network capital: emigration from Hong Kong. British journal of sociology, 49(3), 358-374.

Wright, K. B., \& Bell, S. B. (2003). Health-related support groups on the Internet: Linking empirical findings to social support and computer-mediated communication theory. Journal of Health Psychology, 8(1), 39-54.

Wright, K. B., Rosenberg, J., Egbert, N., Ploeger, N. A., Bernard, D. R., \& King, S. (2013). Communication competence, social support, and depression among college students: a model of Facebook and face-to-face support network influence. Journal of Health Communication, 18(1), 41-57.

Wrona, T., \& Gunnesch, M. (2016). The one who sees more is more right - How theory enhances the 'repertoire to interpret' in qualitative case study research. Journal of Business Economics, 86(7), 723-749.

Xie, B. (2008). Multimodal Computer-Mediated Communication and Social Support among Older Chinese Internet Users. Journal of Computer-Mediated Communication, 13(3), 728-750.

Yang, X., Li, G., \& Huang, S. S. (2017). Perceived online community support, member relations, and commitment: Differences between posters and lurkers. Information \& Management, 54(2), 154-165.

Ye, J. (2006). Traditional and online support networks in the cross-cultural adaptation of Chinese international students in the United States. Journal of Computer-Mediated Communication, 11(3), 863-876.

Yechiam, E., \& Barron, G. (2003). Learning to ignore online help requests. Computational \& Mathematical Organization Theory, 9(4), 327-339.

Yin, H. (2015). Chinese-language cyberspace, homeland media and ethnic media: A contested space for being Chinese. New Media \& Society, 17(4), 556-572.

Yli-Uotila., T., Rantanen, A., \& Suominen, T. (2014). Online social support received by patients with cancer. CIN: Computers, Informatics, Nursing, 32(3), 118-126.

Yoon, K. (2017). Korean Migrants' Use of the Internet in Canada. Journal of International Migration and Integration, 18(2), 547-562.

Yoon, J., \& Chung, E. (2017). International Students' Information Needs and Seeking Behaviours throughout the Settlement Stages. Libri, 67(2), 119-128.

Zainol, H., Tambi, A. M. A., \& Aziz, A. R. A. (2013). The preparedness of Malaysian multinational construction companies (MNCCs) in providing pre-departure and nontechnical trainings for their expatriates. World Applied Sciences Journal, 25(3), 391-398. 
Zhai, C., \& Massung, S. (2016). Text data management and analysis: a practical introduction to information retrieval and text mining. ACM and Morgan \& Claypool Publishers.

Zhang, R. (2017). The stress-buffering effect of self-disclosure on Facebook: An examination of stressful life events, social support, and mental health among college students. Computers in Human Behavior, 75(1), 527-537.

Zhang, Z. (2010). Feeling the sense of community in social networking usage. IEEE Transactions on Engineering Management, 57(2), 225-239.

Zhao, X., \& Basnyat, I. (2018). Online social support for "Danqin Mama": A case study of parenting discussion forum for unwed single mothers in China. Computers in Human Behavior, 80(March), 12-21.

Zhou, T. (2011). Understanding online community user participation: a social influence perspective. Internet research, 21(1), 67-81.

Zhu, E. (2006). Interaction and cognitive engagement: An analysis of four asynchronous online discussions. Instructional Science, 34(6), 451-480.

Zikic, J. (2015). Skilled migrants' career capital as a source of competitive advantage: implications for strategic HRM. The International Journal of Human Resource Management, 26(10), 1360-1381.

Zikic, J., Bonache, J., \& Cerdin, J. L. (2010). Crossing national boundaries: A typology of qualified immigrants' career orientations. Journal of Organizational Behavior, 31(5), 667686.

Zikic, J., \& Richardson, J. (2016). What happens when you can't be who you are: Professional identity at the institutional periphery. Human Relations, 69(1), 139-168. 


\section{Appendices:}

\section{Appendix A. Relational perspective on newcomers' capital mobilization}

International business and management literature concerning labour market integration of newcomers primarily focus on newcomers' motivations and career outcomes and macrocontextual matters, such as brain drain and brain gain (Al Ariss and Syed, 2011; Cerdin et al., 2014; Dietz et al., 2015; Guo and Al Ariss, 2015; Reitz et al., 2014). The literature also tends to focus on the human capital theory, which suggests that newcomers' skills play a key role in newcomers' employment success in the destination country's labour market, and that more skilled newcomers enjoy better jobs and career mobility in the labour market (Bahn, 2015; Lin and Yang, 2017; Silvanto et al., 2015).

Recent perspectives (Al Ariss and Syed, 2011; Syed, 2008) on employee integration challenge the notion of the human capital theory and suggest that it does not fully explain the differences in employment outcomes and career mobility between skilled newcomers and equally skilled locals. They also argue that there are other types of capital available in addition to the human capital. Al Ariss and Syed (2011) propose a relational perspective framework on newcomers' capital mobilization, suggesting that newcomers may use multiple types of capital (social, cultural, economic, and symbolic) in their efforts to integrate in the local labour market.

Social capital refers to the resources that are accumulated from one's relationships, such as family support, personal contacts, friends, and professional and educational networks (Al Ariss and Syed, 2011). Research has shown that newcomers' social networks in the destination country can be invaluable sources of local knowledge (Reitz et al., 2014; 
Turchick Hakak and Al Ariss, 2013). The relationships may inform newcomers about employment opportunities and local labour market environment, as well as introduce and connect newcomers to relevant information sources and influential others (Fang, 2013; Farh et al., 2010; Vacca et al., 2016).

Cultural capital refers to individual competencies such as prior knowledge of the new culture, academic qualifications, and language skills (Al Ariss and Syed, 2011). Lack of knowledge of the local culture and local information environment are significant barriers to newcomers' labour market integration (Caidi et al., 2010; Savolainen, 2016). Newcomers need to understand the local culture (e.g., how to communicate and function in the society) and local information environment (e.g., what sources of information are available, where and how to search needed information, whom to ask) to fully integrate in the destination country's labour market and society (Guo and Al Ariss, 2015; Takeda, 2013).

Economic capital refers to economic resources available to undertake international mobility, such as financial resources (e.g., savings), financial support from friends and family, and scholarships (Al Ariss and Syed, 2011). Economic capital is - in most cases the outcome of labour market integration as employment allows newcomers to support themselves and their families and to fully function in the new society. Economic capital can also often be exchanged into or used to acquire social and cultural capital (Al Ariss and Syed, 2011). For example, greater economic capital (e.g., money) allows an individual to attend universities, and attain higher levels of education and language skills (i.e., cultural capital) and develop professional networks of relationships (i.e., social capital) (Al Ariss 
et al., 2013). Economic capital also allows newcomers to wait for a better job opportunity and not to accept the first survival job that becomes available.

Symbolic capital refers to "a reflected power gained by individuals through the mobilization of their economic, cultural or social capital valued by society" (Al Ariss and Syed, 2011: 295). Symbolic capital has both objective and subjective properties. A subjective symbolic capital is the value that newcomers perceive about their various types of capitals (e.g., social, cultural, and economic), whereas an objective symbolic capital is the collective shared meaning that others (e.g., local employers) have about the value of newcomer's various capitals (Al Ariss and Syed, 2011). In addition, the subjective perceptions newcomers have about the value of their symbolic capital can vary substantially from the objective perceptions others have about the value of newcomers' various capitals. For instance, by possessing various forms of capital, such as social capital (e.g., local personal contacts in Canada) and cultural capital (e.g., education and ten years of work experience in Germany), a newcomer can perceive himself/herself to be able to work in Canada. However, local employers may perceive newcomer's capitals as insufficient to secure a relevant employment (e.g., they may discount newcomer's foreign education and experience).

The four forms of capital are interdependent and overlapping. For example, the level of support from friends and family (social capital) may impact the level of financial resources available (economic capital), which in turn may impact the level of education an individual may pursue (cultural capital) (Al Ariss and Syed, 2011). 
Research suggests that newcomers typically have limited access to the various types of capitals. For example, they often lack local networks of relationships (i.e., social capital), knowledge of the local culture and informational environment (i.e., cultural capital), and financial resources (i.e., economic capital) (Dietz et al., 2015; Fang et al., 2013; Reitz et al., 2014, Turchick Hakak and Al Ariss, 2013; Syed, 2008). This is especially true for refugees who typically lack all forms of capital (Alam and Imran, 2015; Bevelander and Pendakur, 2014). In addition, newcomers' foreign academic qualifications, experience and skills are often undervalued and underutilized (i.e., perception of symbolic capital) (Dietz et al., 2015; Ramboarison-Lalao et al., 2012).

This framework was not used because only cultural capital was present in the examined online discussion forums. In addition, examination of the online discussions suggested users were exchanging social support resources, which required a revision of the conceptual framework. 
Appendix B. Examples of types of support provided in the 41 providing initial posts

\begin{tabular}{|c|c|}
\hline $\begin{array}{l}\text { Type of } \\
\text { support } \\
\text { provided }\end{array}$ & Examples \\
\hline $\begin{array}{l}\text { Information } \\
31 \text { posts } \\
76 \%\end{array}$ & $\begin{array}{l}\text { "Ijust heard an interview on the news radio about Shopify setting up a } \\
\text { cell phone charging station and recruiting booth in Confederation Park } \\
\text { in Ottawa tomorrow. Apparently, there are multiple "poke-stops" in the } \\
\text { park, so they are hoping to capitalize on the number of tech } \\
\text { savvy/passionate people in the area and engage people in conversations } \\
\text { about employment. Note, Shopify is difficult to get into and they use } \\
\text { various out of the box strategies for recruiting. this one seems pretty } \\
\text { brilliant and I hope results in some good hires!!! They didn't provide } \\
\text { times, so perhaps the information is available on their website or } \\
\text { somewhere else on google." (CV21_195) } \\
\text { "Hi guys, our aerospace company is looking for experienced Quality } \\
\text { technicians for Cambridge, Ontario Location. If someone is interested, } \\
\text { please send your resume to..." (CV21_281) } \\
\text { "I came to Canada in } 2011 \text { on safety officer job through a consultant } \\
\text { in Firdous Mkt. Lahore, Pakistan. They told me that pay will } 25 \$ \text { per } \\
\text { hour but my company is paying only } 16 \$ \text {. Canadian companies are also } \\
\text { not offering over time to safety officer so remember, if you are coming } \\
\text { to Canada for safety officer job, you'll have } 16 \text { to 18\$ per hour, that's } \\
\text { all, No over time, no accommodation, no food." (CV24_6) }\end{array}$ \\
\hline $\begin{array}{l}\text { Advice } \\
5 \text { posts } \\
12 \%\end{array}$ & $\begin{array}{l}\text { "Having been through hell and having spoken to many others sailing in } \\
\text { the same boat, here's a word of sincere advice for Newcomers applying } \\
\text { for registration as a Professional Engineer to the Professional } \\
\text { Engineers Association of Ontario (PEO). Here goes: Before you decide } \\
\text { to apply to PEO, STOP and research the Registration Process for P. } \\
\text { Eng. designation in all the other provinces of Canada to enable you to } \\
\text { make a decision as to which province has a process that suits you. It is } \\
\text { immaterial as to which Province you live in. You can apply for } \\
\text { registration to any provincial association..." (CV21_9) } \\
\text { "Hi All, I am a new immigrant and have landed here with a job by god's } \\
\text { grace. I am an ITprofessional. In my attempt to help all new immigrants } \\
\text { and future immigrants I am posting job postings which I receive in the } \\
\text { mail. As a thumb rule the following points may help you get a job soon, } \\
\text { this is what I personally did and Ifound } 2 \text { jobs one as soon as I landed } \\
\text { last year to complete my landing formalities and another recently which } \\
\text { I have taken up. I. Create a Canadian format CV - This is super } \\
\text { important, most people from India and other Asian counties have CVS } \\
\text { which run into pages and also include a lot of unnecessary info such as }\end{array}$ \\
\hline
\end{tabular}




\begin{tabular}{|c|c|}
\hline & $\begin{array}{l}\text { Date of Birth, religion, father's name, marital status, name of school, } \\
\text { college etc. Get rid of all these junk data from your CV. Here in Canada } \\
\text { nobody is interested in these details, all they want to know is are you } \\
\text { qualified to do the job? do you have relevant experience in a similar } \\
\text { job? are you able to articulate your skills clearly on your CV? that's all. } \\
\text { remember your CV is like a movie poster, looking at the poster you } \\
\text { should want to watch the movie, if the poster itself is boring then there } \\
\text { is a good chance nobody will watch the movie!! 2. If you are coming } \\
\text { from the middle east then please lower your expectations, the economy } \\
\text { of the middle east is flush with oil money and companies there will often } \\
\text { pay you a lot of money for jobs like administrative officer or secretarial } \\
\text { jobs. In Canada and the real world such is not the case..." (CV21_135) } \\
\text { "Hello everyone, it has been a while since I posted on here, I'm a new } \\
\text { immigrant as well to Canada and I have been here for } 2 \text { months now. I } \\
\text { would like to share my person advice and experience while I have been } \\
\text { here and how I had few job offers and landed a good job. Things to do } \\
\text { once you land. I) I opened a bank account with scotia and immediately } \\
\text { got a credit card to pay for things instead of cash and just transfer the } \\
\text { money over to my credit card on a regular basis. Also, if you do go with } \\
\text { scotia make sure you get a scene card as you collect points and can go } \\
\text { see movies at the cinema for free. You can join TD or any other bank if } \\
\text { you wish. 2) Health card. People will tell you that you need to go and } \\
\text { apply for it as soon as you land as it takes } 3 \text { months to receive it, well } \\
\text { you don't exactly need to collect it on the same day you can even go a } \\
\text { month later because regardless of the day you go the health card starts } \\
\text { the 3-month period from the day you land and not the day you walk in } \\
\text { to register. 3) Exchange your driver's license to get a Canadian as Ijust } \\
\text { gave them mine and they gave me a G license as a lot of jobs will ask if } \\
\text { you have your license..." (CV21_296) }\end{array}$ \\
\hline $\begin{array}{l}\text { Instrumental } \\
5 \text { posts } \\
12 \%\end{array}$ & $\begin{array}{l}\text { "Hi, just wanted to know if anyone moving into Canada on PR, in the } \\
\text { next few months between August - November and would be in the IT } \\
\text { industry, please don't hesitate to contact me on this post. Please leave } \\
\text { your email ID and what kind of skill set you have and years of } \\
\text { experience. I can see if I can help you out." (CV21_52) } \\
\text { "Hello Friends, if you are in IT (Java,.NET, UI) and have experience } \\
\text { around } 7 / 8 \text { years. I have roles for them in Citi Canada. send me your } \\
\text { resume... or give me a call or WhatsApp on..." (CV21_153) } \\
\text { "Farm job in CANADA, interested applicant should send their nice } \\
\text { cover letter and cv. send to this email... places available are just 10. I } \\
\text { will present it to the company for screening. The candidate should have } \\
\text { farm work experience" (CV21_187) }\end{array}$ \\
\hline
\end{tabular}




\section{Appendix C. Examples of types of support needs requested in the 533 requesting initial posts}

\begin{tabular}{|c|c|}
\hline $\begin{array}{l}\text { Types of } \\
\text { support } \\
\text { requested }\end{array}$ & Examples \\
\hline $\begin{array}{l}\text { Information } \\
383 \text { posts } \\
72 \%\end{array}$ & $\begin{array}{l}\text { "Hi, I have a question, for the Egyptian bachelor degree of } \\
\text { Mechanical Engineer (From Alexandria University, Egypt). do they } \\
\text { need a license to work as an engineer in Ontario?? If yes, can anyone } \\
\text { tell me where I can find more information about that?? and, can they } \\
\text { work as engineer assistance till they got the license?? appreciate } \\
\text { your help" (CV21_145) } \\
\text { "Hi!! I wanted to know about career opportunities for doctors since } \\
\text { I am a clinical oncologist in Pakistan and have applied for } \\
\text { immigration in the family group. Any immigrants who can share } \\
\text { their experience Thanks" (CV21_31) } \\
\text { "What is the process for parents of a permanent residents to apply } \\
\text { for work under super visa entry to Canada or while the PR } \\
\text { application for family class sponsorship is under process?" } \\
\text { (CV21_259) } \\
\text { "Hey everyone. does anyone hear about something like Self- } \\
\text { Employment work permit? is such work permit exists, that enables } \\
\text { me to come to Canada and work a self-employed, even if I did not } \\
\text { apply to immigrate as a self-employed?" (CV22_37) }\end{array}$ \\
\hline $\begin{array}{l}\text { Advice } \\
144 \text { posts } \\
27 \%\end{array}$ & $\begin{array}{l}\text { "Has anyone taken the CSC course to get in the banking field in } \\
\text { Canada? I heard it is very helpful to inquire information on the } \\
\text { Canadian market for those who are in the financial field. I am in } \\
\text { corporate banking as a relationships manager over } 10 \text { yrs. } \\
\text { experience. Will this course help? Or is it a waste of time and } \\
\text { money? Thanks" (CV21_21) } \\
\text { "I am 31, Mechanical Engineer living and working in Japan. My } \\
\text { work experience is so-so in terms of competency and skills. I have } \\
\text { PR and I am planning out strategies that would help me settle down } \\
\text { in Canada. Can you advise of some short-term courses ranging from } \\
3 \text { months to a year which could help me land me a Job in Canada?" } \\
\text { (CV21_19) } \\
\text { "Hello, could anyone give me some advice on the best places to find } \\
\text { a job in engineering in Canada?" (CV21_48) }\end{array}$ \\
\hline
\end{tabular}




\begin{tabular}{|c|c|}
\hline & Examples \\
\hline & $\begin{array}{l}\text { "Hello Everyone, I've been in Canada since January 23. I'm an } \\
\text { Environmental Engineer that's got } 4 \text { years' work experience with a } \\
\text { global firm in both the UK and UAE. I'm currently in Ontario and } \\
\text { I'm struggling to find any work. It's been a real headache. I would } \\
\text { really appreciate if anyone has any sort of advice for me? I really } \\
\text { like living here and I do not regret my decision but the job hunt is } \\
\text { getting me stressed!" (CV21_193) }\end{array}$ \\
\hline $\begin{array}{l}\text { Instrumental } \\
5 \text { posts } \\
0.9 \%\end{array}$ & $\begin{array}{l}\text { "Could anyone please share a C++ Software Engineer } \\
\text { chronological resume after removing your personal details." } \\
\text { (CV21_121) } \\
\text { "Hi, I am a self-employed photographer/videographer based in } \\
\text { Riyadh, Saudi Arabia. I have an experience of } 4 \text { years. I need to } \\
\text { collect work experience letters from the people I have worked for, } \\
\text { but what exactly should they mention in the letters that they will give } \\
\text { me so I can provide my work experience to the Canadian } \\
\text { immigration? if anybody can send me a sample letter of how exactly } \\
\text { it should look and be written, the format etc. that will be an awesome } \\
\text { help! thank you" (CV21_126) } \\
\text { "Here is my situation, I only need an employer who can offer me a } \\
\text { job, an offer can't hurt because they will not be going to pay } \\
\text { anything, they just going to offer me a job for me get a big chance } \\
\text { for successful process of my application as a permanent residency in } \\
\text { Canada, please help me to get a job offer." (CV21_229) }\end{array}$ \\
\hline $\begin{array}{l}\text { Companionship } \\
1 \text { post } \\
0.2 \%\end{array}$ & $\begin{array}{l}\text { "hi to all forum participants. dear friends, I found this forum } \\
\text { amazing for friendship. I am looking for friends. I would share my } \\
\text { bio with friends, no problem. please answer." (CV21_132) }\end{array}$ \\
\hline
\end{tabular}




\section{Appendix D. Initial 24 and final 10 categories of topics}

\begin{tabular}{|l|l|}
\hline$\#$ & Initial categories of Topics \\
\hline $\mathbf{1}$ & About process \\
\hline $\mathbf{2}$ & About opportunities \\
\hline $\mathbf{3}$ & Applying for jobs \\
\hline $\mathbf{4}$ & Business start \\
\hline $\mathbf{5}$ & Business practices \\
\hline $\mathbf{6}$ & Business opportunities \\
\hline $\mathbf{7}$ & Education \\
\hline $\mathbf{8}$ & Finding work \\
\hline $\mathbf{9}$ & Find resources \\
\hline $\mathbf{1 0}$ & Immigration and settlement \\
\hline $\mathbf{1 1}$ & Job application questions \\
\hline $\mathbf{1 2}$ & Job search tools and services \\
\hline $\mathbf{1 3}$ & Labour market in Canada \\
\hline $\mathbf{1 4}$ & Qualification questions \\
\hline $\mathbf{1 5}$ & Resources \\
\hline $\mathbf{1 6}$ & Salary \\
\hline $\mathbf{1 7}$ & Seek others' experiences \\
\hline $\mathbf{1 8}$ & Self-employed immigration \\
\hline $\mathbf{1 9}$ & Starting groups \\
\hline $\mathbf{2 0}$ & Taxes \\
\hline $\mathbf{2 1}$ & Technical question \\
\hline $\mathbf{2 2}$ & Visa questions \\
\hline $\mathbf{2 3}$ & Work permit \\
\hline $\mathbf{2 4}$ & Work practice in Canada \\
\hline
\end{tabular}

\begin{tabular}{|l|l|}
\hline$\#$ & Final categories of topics \\
\hline $\mathbf{1}$ & Business \\
\hline $\mathbf{2}$ & Education and qualification \\
\hline $\mathbf{3}$ & Finding and applying for jobs \\
\hline $\mathbf{4}$ & Job opportunities \\
\hline $\mathbf{5}$ & Living in Canada \\
\hline $\mathbf{6}$ & Others' experiences \\
\hline $\mathbf{7}$ & Resources \\
\hline $\mathbf{8}$ & Starting groups \\
\hline $\mathbf{9}$ & Visa and work permit \\
\hline $\mathbf{1 0}$ & Work practices in Canada \\
\hline
\end{tabular}


Appendix E. Examples for topics requested in the 380 initial posts requesting information

\begin{tabular}{|c|c|}
\hline $\begin{array}{l}\text { Type of } \\
\text { information } \\
\text { Needs }\end{array}$ & Examples \\
\hline $\begin{array}{l}\text { Job } \\
\text { opportunities } \\
90 \text { posts } \\
23.7 \%\end{array}$ & 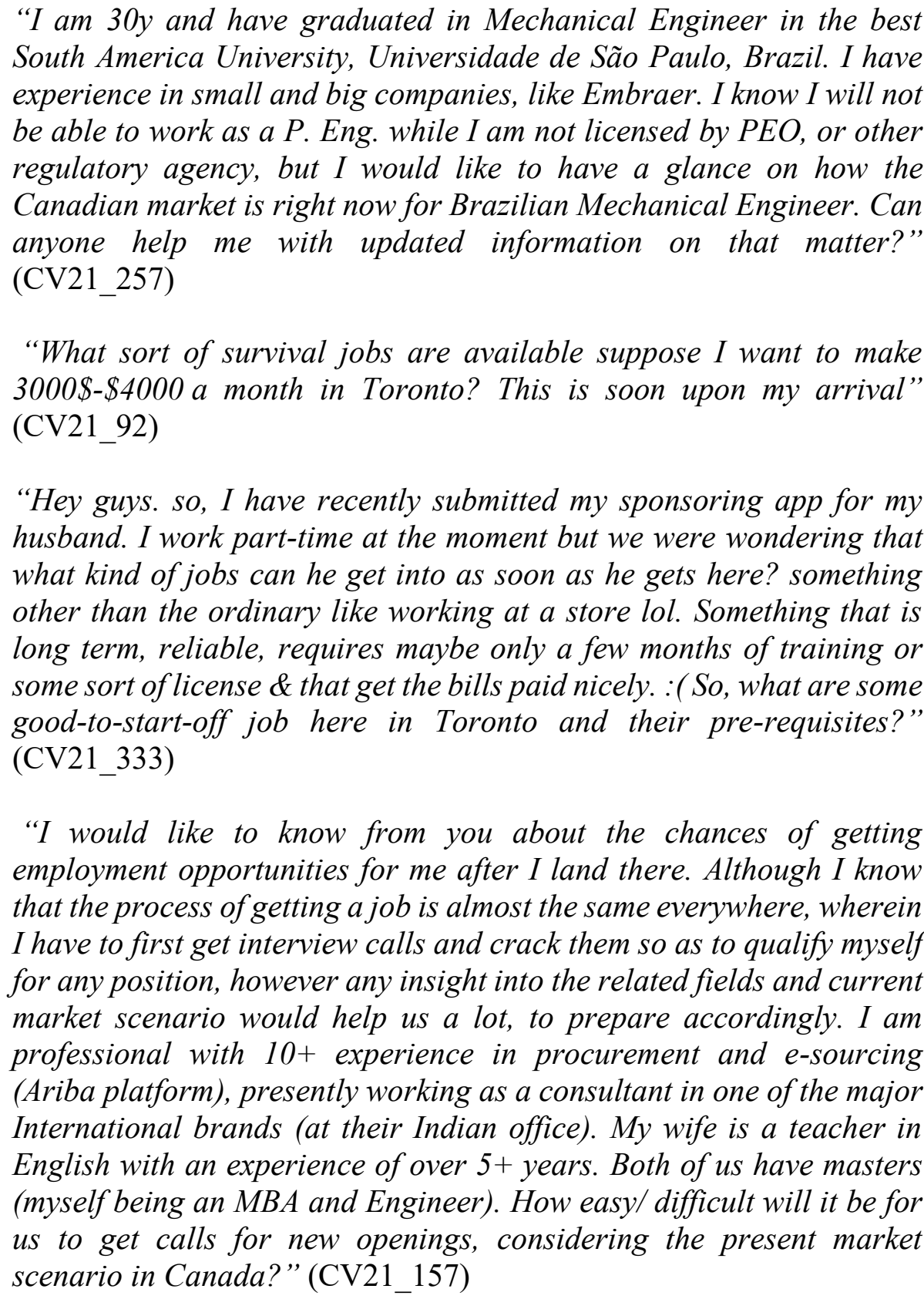 \\
\hline $\begin{array}{l}\text { Visa and } \\
\text { work permit } \\
84 \text { posts } \\
22.1 \% \\
\end{array}$ & $\begin{array}{l}\text { "Hi, I am an IT professional and have } 11 \text { years of experience. I want to } \\
\text { work and live in Canada. I want to know how much the processing time } \\
\text { for is getting work visa in Canada, assuming I have received the offer } \\
\text { letter." (CV21_72) }\end{array}$ \\
\hline
\end{tabular}




\begin{tabular}{|c|c|}
\hline & $\begin{array}{l}\text { "Hi, I'm a 29-year-old in Vancouver, BC. I moved in with my girlfriend } \\
\text { here two months ago. I have a Bachelor's degree in political science } \\
\text { and over four years of administrative / clerical experience. As far as I } \\
\text { can tell, I am not a "skilled worker", and none of my previous } \\
\text { occupations seem to align with what would qualify for an open work } \\
\text { permit. Am I mistaken? Is there another way to qualify for a work } \\
\text { permit? Do I have a decent chance of getting a job and receiving } \\
\text { sponsorship from them?" (CV24_1) } \\
\text { "I would like to ask what jobs are considered as LMIA jobs? I am } \\
\text { moving with my family to Canada in July I got temporary job in factory } \\
\text { but I would like to know which jobs are considered under LMIA?" } \\
\text { (CV21_297) } \\
\text { "What is the process for parents of a permanent residents to apply for } \\
\text { work under supervisa entry to Canada or while the PR application for } \\
\text { family class sponsorship is under process?" (CV21_259) }\end{array}$ \\
\hline $\begin{array}{l}\text { Finding and } \\
\text { applying for } \\
\text { jobs } \\
49 \text { posts } \\
12.9 \%\end{array}$ & $\begin{array}{l}\text { "I am working in IT around } 12 \text { years in Teamcenter, Java, J2EE, C++, } \\
\text { C skill sets in India. Is it possible to search job in Canada from India? } \\
\text { I am applying for a Canadian PR." (CV21_300) } \\
\text { "I have a question for people already in Canada looking for a job or } \\
\text { already working. when I applying for a job does the cv or resume should } \\
\text { include a photo or not? I heard is not always a good idea, but others } \\
\text { say that it does not matter." (CV21_151) } \\
\text { "we are moving Canada in first week of November. Do my husband } \\
\text { needs reference letter from their office for getting job in Canada. Do } \\
\text { Indian job experience really works there? He has more than } 12 \text { yrs. of } \\
\text { experience in a prestigious insurance company. And what else they } \\
\text { need...salary slip" (CV21_91) } \\
\text { "I am an international student looking for a part time job in the } \\
\text { Mississauga area or near Humber Lakeshore campus for January, } \\
\text { 2016. I have } 14 \text { years experiencing in banking which also includes } \\
\text { customer service." (CV21_420) }\end{array}$ \\
\hline $\begin{array}{l}\text { Others' } \\
\text { experiences } \\
33 \text { posts } \\
8.7 \%\end{array}$ & $\begin{array}{l}\text { "Anyone who had already landed in Saskatoon or Regina, please share } \\
\text { the real-time experiences in terms of job search, weather, atmosphere, } \\
\text { housing, etc." (CV21_156) } \\
\text { "Hi guys. Is there anyone on this forum who specializes in } \\
\text { Instrumentation \& Control and was able to land a decent job in } \\
\text { Canada? Can theyplease share their experience?"(CV21_351) }\end{array}$ \\
\hline
\end{tabular}




\begin{tabular}{|c|c|}
\hline & $\begin{array}{l}\text { "Hi there. Are there any HR among newcomers who were able to find } \\
\text { a job in HR successfully? What did you dofor this? I have been sending } \\
\text { a lot of resumes for Recruiter and Compensation Analyst roles, but had } \\
\text { only } 3 \text { face-to-face interviews and } 3 \text { phone interviews..." (CV21_276) } \\
\text { "I am curious on the chances of either new Canadians or PRs in } \\
\text { landing a government job; either at federal, provincial or municipal } \\
\text { level. Can fellow users of this forum share any relevant piece of } \\
\text { information or experience they had? Both positive and negative } \\
\text { please?" (CV21_40) }\end{array}$ \\
\hline $\begin{array}{l}\text { Business } \\
31 \text { posts } \\
8.2 \%\end{array}$ & $\begin{array}{l}\text { "I am planning to open a Latin-grocery store in Alberta, and I don't } \\
\text { have a clue from where to start. I do have my vendors already, but how } \\
\text { to set up the company, CRA, etc... so if anyone can give me a hand } \\
\text { would be greatly appreciated." (CV22_49) } \\
\text { "Hi, my wife has education and experience in making bakery items we } \\
\text { want to open a bakery in Canada after landing... we have fund for } \\
\text { initial investment but not sure how much to commit" (CV22_33) } \\
\text { "I just arrived in Canada and I'm thinking about open a business. It's } \\
\text { in the signage field. Is it normal and should I have some problems in } \\
\text { walk ins some stores and leave a flyer about my products? Just a small } \\
\text { talk and leave a flyer with a business card. It's not in the mall. Just on } \\
\text { street stores. Thanks!!" (CV22_32) } \\
\text { "I am an international student in MB, and I own a local Chinese forum } \\
\text { and a mobile APP. Now, they are totally free, but I wish if I can get } \\
\text { some income from the Ads on my forum or APP. The problem is I am } \\
\text { not PR and I did not want to get trouble in the trade, which will affect } \\
\text { my immigrant in the future. So, I wonder if I can start a business } \\
\text { (Partnerships or Corporations) during my university. Do the deal } \\
\text { within the company and standard agreement. I have SIN which begins } \\
\text { with 9, but I do not have off-campus work permit. Well there are very } \\
\text { limited information for the international student and I wish someone } \\
\text { can help me out. In addition, it seems that I can start a business with } \\
\text { PR or Citizen partner, so is there requirement for the share for this } \\
\text { Partner?" (CV22_59) }\end{array}$ \\
\hline $\begin{array}{l}\text { Work } \\
\text { practices in } \\
\text { Canada } \\
24 \text { posts } \\
6.3 \%\end{array}$ & $\begin{array}{l}\text { "I just have a question about some companies that are not paying their } \\
\text { employees when they do OT. In some industry, it happens a lot. I was } \\
\text { thinking if it's that even legal at all. Some companies tell you work } 10 \\
\text { to } 12 \text { hrs. a day to meet the deadline without even paying you OT. Worse } \\
\text { case is you need to work free on weekend as well. This happens when }\end{array}$ \\
\hline
\end{tabular}




\begin{tabular}{|c|c|}
\hline & $\begin{array}{l}\text { deadline is on the edge. I'm just curious if this situation is normal at } \\
\text { all." (CV23_7) } \\
\text { "My wife and I (and our } 3 \text { young kids) are looking to move to the } \\
\text { Calgary/Airdrie area from the UK around August 2018, we are just } \\
\text { starting the process now. One question I have though is, I understand } \\
\text { you only get } 2 \text { weeks' holiday entitlement in Canada once you have } \\
\text { worked a year for a company, but if you are happy to take the financial } \\
\text { impact, are you able to take unpaid leave? I currently get } 27 \text { days } \\
\text { holiday in the UK, which is great and I except I won't get that in } \\
\text { Canada, but could I get that if I was prepare to take the holiday time } \\
\text { unpaid? } 2 \text { weeks holiday a year sounds like a very bad work/life } \\
\text { balance to me, so do people in Canada take unpaid leave instead to get } \\
\text { more time off or is it really all work and no play?" (CV23_3) } \\
\text { "So, I'm working in this small company and I believe that I'm doing } \\
\text { well and finish all the job on time. I'm in a contract that expires early } \\
\text { next year and also my probation period is done as well. But for some } \\
\text { reason they fire me without any notice at all. Same day when they msg. } \\
\text { me to have a talk. After the I immediately packed my stuff and leave the } \\
\text { same day." (CV23_08) } \\
\text { "In my home-town, we have high season to search job after new year } \\
\text { and after summer (Around Oct - Nov). Do we have same or similar in } \\
\text { Toronto (or GTA)?" (CV21_44) }\end{array}$ \\
\hline $\begin{array}{l}\text { Education } \\
\text { and } \\
\text { qualifications } \\
23 \text { posts } \\
6.1 \%\end{array}$ & $\begin{array}{l}\text { "My wife is a bio-medical engineer in India, she works at a hospital } \\
\text { supporting patient diagnosing and treatment by installing, testing, } \\
\text { calibrating, and repairing biomedical equipment, training users, etc. } \\
\text { (We are already in the pool, expecting ITA very soon) Are there any } \\
\text { mandatory certifications/exams she has to pass in order to } \\
\text { find/apply/practice this occupation. If Yes, what are they." (CV21_18) } \\
\text { "I am interested to see whether my profession - Biologist is regulated } \\
\text { or not since Ifind contradictory statement. Somewhere on Canada Visa } \\
\text { it says it not regulated, except in BC and in the CICIC search engine it } \\
\text { says it is, for example also in Ontario." (CV21_143) } \\
\text { "I am finalizing my MBA with Roehampton University Online program } \\
\text { in the UK. I am wondering if my MBA from UK will be accepted in } \\
\text { Canada?" (CV21_228) } \\
\text { "Hi I have my PR and want to move to BC. I am a Professor in India. } \\
\text { Do the colleges/ universities recognize the education qualifications } \\
\text { from other countries?" (CV21_217) }\end{array}$ \\
\hline
\end{tabular}




\begin{tabular}{|c|c|}
\hline $\begin{array}{l}\text { Resources } \\
23 \text { posts } \\
6.1 \%\end{array}$ & $\begin{array}{l}\text { "Hi Anyone help in finding resources to pass written examination for } \\
\text { license exam of physiotherapist in Canada" (CV24_13) } \\
\text { "I'm currently studying TV production at a CalState and I was } \\
\text { wondering if somebody could refer me to any recruitment agencies that } \\
\text { I can send my resume to which specialize in my industry my NOC is } \\
5131 \text { I I know I'm still a college student (or should I rather say university } \\
\text { student) but it would help me a lot if anyone has some useful resources } \\
\text { here or outside the forum to make the search a bit easier since I notice } \\
\text { a lot of us on here are in a IT/CS/business/engineering related } \\
\text { industry." (CV21_57) } \\
\text { "Does anyone have any recommended, trustworthy job recruitment } \\
\text { companies/website in Canada? Inever know who to contact, or who to } \\
\text { give my money to :( Thanks!" (CV21_247) } \\
\text { "Any one knows about work at home web sites. like data entry work." } \\
\text { (CV21_66) }\end{array}$ \\
\hline $\begin{array}{l}\text { Living in } \\
\text { Canada } \\
14 \text { posts } \\
3.7 \%\end{array}$ & $\begin{array}{l}\text { "I was reading through one website and it was mentioned that we need } \\
\text { to have Driving License G1 first, then G2 and then G. G1 (learner's) } \\
\text { allows the driver to drive with a fully-licensed driver My question is, If } \\
\text { Iam immigrating to Canada and am alone, how can Idrive my car with } \\
\text { G1? is it possible to get Full-License (G Level) in first attempt?" } \\
\text { (CV24_41) } \\
\text { "From what I understand, there is a 3-month waiting period for a new } \\
\text { resident of Ontario to quality for OHIP. And I also am aware that you } \\
\text { need to spend } 153 \text { of the first } 183 \text { days in Ontario to also qualify. My } \\
\text { question is for those first } 3 \text { months before you can qualify, do you need } \\
\text { to spend all days of those } 3 \text { months in Ontario otherwise the waiting } \\
\text { period resets? For example, if someone becomes a permanent resident } \\
\text { and settles in Ontario, they can't leave for the first } 90 \text { days if they want } \\
\text { to qualify for OHIP?" (RC_7) } \\
\text { "Suppose I get a job that pays me \$60000 CAD per year in Toronto. } \\
\text { How much would my take home salary be after federal and provincial } \\
\text { tax deductions? How much is needed in hand to live comfortably for a } \\
\text { family of } 3 \text { in Toronto?" (CV21_242) } \\
\text { "Hi all, Quick question, I have interviewed for a job in Vancouver and } \\
\text { been advised the salary is } 80 k \text { CAD. I'm currently on £30k in Scotland } \\
\text { in a very similar job. Is this salary enough to live reasonably in } \\
\text { Vancouver?" (CV21_313) }\end{array}$ \\
\hline
\end{tabular}




\begin{tabular}{|l|l|}
\hline $\begin{array}{l}\text { Starting } \\
\text { groups } \\
2.4 \%\end{array}$ & $\begin{array}{l}\text { "Hi to all nurses planning to land in Toronto or even the Toronto } \\
\text { nurses. Let's share here guys for the benefit of others and for us also." } \\
\text { (CV21_364) }\end{array}$ \\
"Guys, all those who have contacts with people working with \\
$\begin{array}{l}\text { Canadian public sector at either municipal/provincial/federal level, } \\
\text { pleas drop in your contact num. I will create a WhatsApp grp for } \\
\text { networking and to discuss the process to get govt jobs. Thanks } \\
\text { (CV24_15) } \\
\text { "Hellofriends, this thread has been createdfor all IT People especially } \\
\text { dealing with NOC 2281. Let's network together and help each other in } \\
\text { getting a dream Job." (CV21_207) } \\
\text { "People with mainframe work experience please network here. } \\
\text { experience with Cobol, DB2, VSAM, CICS, IMS, SAS, REXX skills." } \\
\text { (CV21_368) }\end{array}$
\end{tabular}


Appendix F. Examples for topics requested in the 144 initial posts requesting advice

\begin{tabular}{|c|c|}
\hline $\begin{array}{l}\text { Type of } \\
\text { advice needs }\end{array}$ & Examples \\
\hline $\begin{array}{l}\text { Finding and } \\
\text { applying for } \\
\text { jobs } \\
59 \text { posts } \\
41 \%\end{array}$ & $\begin{array}{l}\text { "Hello, I've been searching for a job in the last three months, mainly in } \\
\text { Montreal, Ottawa and Toronto, but to no avail. I'm growing more } \\
\text { desperate now. I have a degree in Computer Engineering and advanced } \\
\text { degrees in Electrical Engineering, but I cannot find a job neither in the } \\
\text { industry nor in the academia. They all need 5+ years of experience on } \\
\text { average, and I have non, which makes it even harder. Any advice? } \\
\text { Thanks" (CV21_96) } \\
\text { "Hello Everyone, I've been in Canada since January 23. I'm an } \\
\text { Environmental Engineer that's got } 4 \text { years' work experience with a } \\
\text { global firm in both the UK and UAE. I'm currently in Ontario and I'm } \\
\text { struggling to find any work. It's been a real headache. I would really } \\
\text { appreciate if anyone has any sort of advice for me? I really like living } \\
\text { here and I do not regret my decision but the job hunt is getting me } \\
\text { stressed!" (CV21_193) } \\
\text { "Hi, I have submitted my profile into express entry and have registered } \\
\text { into the job bank. But I have not got a single job match. I have Masters } \\
\text { in Electrical Engineering, USA with eight years of experience. } \\
\text { Suggestions on job search would be highly appreciated. I have only } 403 \\
\text { CRS points." (CV21_124) } \\
\text { "hello, I am PR of Canada and looking for the job of a sonographer } \\
\text { (one who does ultrasound examination). I am certified with the } \\
\text { American registry (which all jobs want) and have been applying for the } \\
\text { jobs but I don't get any interviews. I happen to talk with one of the } \\
\text { recruiters and she says that I don't have Canadian work experience } \\
\text { though I do have about 5-6 years' experience from my home country. I } \\
\text { am kind of disheartened. how to crack the ice?" (CV21_400) } \\
\text { applications online require a Canadian address???" (CV21_93) } \\
\text { "I am a Chartered Accountant from India having } 3 \text { years of experience } \\
\text { in internal audit, SOX Compliance and internal controls. I wish to seek } \\
\text { in India before migrating to Canada? } 2 . \text { What is the best way to go about } \\
\text { Appreciate all your help" (CV21_387) }\end{array}$ \\
\hline
\end{tabular}




\begin{tabular}{|c|c|}
\hline $\begin{array}{l}\text { Education } \\
\text { and } \\
\text { qualifications } \\
20 \text { posts } \\
13.9 \%\end{array}$ & $\begin{array}{l}\text { "Hello Everyone, I am posting this in "Finding Work" forum because I } \\
\text { want to look at it from job perspective. I am not in Canada yet, but soon } \\
\text { will be (if I get PR). I already have a } 4 \text { years Engineering degree from } \\
\text { another country (assessed by WES to be equivalent to } 4 \text { years } \\
\text { Canadian bachelor's degree). I also have 5+ years' experience in } \\
\text { Web/Software Development. If I want to add Canadian education to my } \\
\text { resume, which is better: Degree or Diploma? - Degree has more worth } \\
\text { probably, but more expensive and time-consuming to obtain - Diploma } \\
\text { is cheaper and faster to obtain - What is the general opinion on online } \\
\text { degrees/diplomas from Canadian colleges/universities? I am just } \\
\text { planning ahead for worst and expecting to have hard time finding job } \\
\text { without Canadian education (after reading stories of many other } \\
\text { people). So, I am expecting that I will have to start working towards } \\
\text { Canadian Degree/Diploma after landing. All of your suggestions are } \\
\text { welcome. Many Thanks" (CV21_29) } \\
\text { "Hello guys, kindly advise on best school option for a management } \\
\text { program based on my below criteria, am new to this forum I will really } \\
\text { need you guys' advice to apply for my January (2017) session } \\
\text { admission. Cheap tuition fee Availability of job while schooling in the } \\
\text { province No interest in writing GMAT, TOEFL etc. First degree holder } \\
\text { (Second Class lower division) ..." (CV21_312) } \\
\text { "Hello, I've done my bachelors in Commerce with 80\% in 2014- HYD, } \\
\text { India. Since then I've worked as senior CSA at Amazon.com for around } \\
\text { 15 months and Network Operations Specialist (Logistics) for a period } \\
\text { of } 6 \text { months... As I understand with these limited qualifications, there } \\
\text { wouldn't be many options available to me. I'd like to inquire, what are } \\
\text { the courses that I can do, here in India, in order to get a job in Canada. } \\
\text { know which course can fetch me a job in Canada. Like I believe a CFA } \\
\text { course can get me a job there, however, I'd like to be sure on that. Also, } \\
\text { it would be great if you can advise, the other courses/qualifications } \\
\text { needed to get a job in Canada. Please advise." (CV24_24) }\end{array}$ \\
\hline $\begin{array}{l}\text { Visa and } \\
\text { work permit } \\
21 \text { posts } \\
14.6 \%\end{array}$ & $\begin{array}{l}\text { "Please note I am holding a multiple entry visit visa (v1) which is valid } \\
\text { until Nov } 2017 \text {. I have an active express entry profile and have a CSC } \\
\text { score of } 382 \text { points. I will get a job in Mississauga once I landed. So } \\
\text { please advise is it legal to work in Canada on V1 visa and while working } \\
\text { I can apply for my PR. Also, please advise the procedure to get work } \\
\text { permit too. I can come to Canada in February since my UAE residence } \\
\text { visa is valid until Feb 10th." (CV21_416) } \\
\text { "Hi Everyone, I need advice under what category should I do my } \\
\text { application for PR visa. I'm currently running a Tyre retreading } \\
\text { company. Before this I was running an electronics store, I have more }\end{array}$ \\
\hline
\end{tabular}




\begin{tabular}{|c|c|}
\hline & $\begin{array}{l}\text { than } 10 \text { years of experience in business. Please advise me under which } \\
\text { category do I fall... and under which program should I do my } \\
\text { application. Thanking you in advance for your advice." (RC_1) } \\
\text { "Hi, I received AOR on 23rd June 2016. And I'm processing my } \\
\text { application under LMIA and job offer. Employer gave me the Offer of } \\
\text { Employment mentioning the commencement date as 01st August } 2016 . \\
\text { Since it takes around } 6 \text { months PR evaluation process, what should I } \\
\text { do? In this case will they give priority to my application and process? } \\
\text { If I am not getting any update before the commencement date (01 Aug) } \\
\text { in the employment agreement, do I need to ask for a new agreement by } \\
\text { extending the commencement date..." (CV23_17) }\end{array}$ \\
\hline $\begin{array}{l}\text { Job } \\
\text { opportunities } \\
17 \text { posts } \\
11.8 \%\end{array}$ & $\begin{array}{l}\text { "I am a Semi Qualified Chartered Accountant (CA inter qualified, Final } \\
\text { remaining) from India. I have 2+ years of work ex in addition to } 3 \text { years } \\
\text { of internship in Audit firms. I am currently working in FIS global } \\
\text { business solutions as a Finance controller (engaged with the Statutory } \\
\text { reporting and audit team). Prior to this, I was working with SG } \\
\text { Analytics as an Analyst in investment research domain using IFRS and } \\
\text { US GAAP skills to analyze Financial Statements Besides I am also } \\
\text { pursuing CPA (US Chartered Accountant) and has certifications in } \\
\text { merger and acquisition from New York institute of finance. What are } \\
\text { my prospects of getting a job in Canada and which province / territory } \\
\text { should I go for?" (CV24_5) } \\
\text { "Hi, how are the opportunities for Science (Physics and Chemistry) } \\
\text { teachers in Canada. Which province will be the best suit for me." } \\
\text { (CV21_220) } \\
\text { "Hello, if you can guide please which city in Canada has more jobs in } \\
\text { IT Support and bit quicker to find than other cities with } 7 \text { years' } \\
\text { experience in Ireland. Thanks" (CV21_154) } \\
\text { "I am confused about my decision. Me \& my wife both having } \\
\text { Government Job in India, having Rs. 80,000/-permonth family income. } \\
\text { Also have PR in Canada. We have 4-year-old daughter. According to } \\
\text { facts seen, that future in Canada secure for children. It's really tough } \\
\text { for me to choose the right one (INDIA or CANADA). Please suggest me } \\
\text { expert advice, what is best for me \& my family. Right now, we both are } \\
\text { 32 and have Bachelor's Degree in Electronic \& Electrical } \\
\text { Engineering." (CV21_340) }\end{array}$ \\
\hline $\begin{array}{l}\text { Business } \\
10 \text { posts } \\
6.9 \%\end{array}$ & $\begin{array}{l}\text { "I have landed in Canada and not able get a good job yet, anyhow, I } \\
\text { have a good saving from my previous job so start to think about private } \\
\text { business, can anyone advise me on small business idea that cost less } \\
\text { than 150k, thanks all" (CV21 338) }\end{array}$ \\
\hline
\end{tabular}




\begin{tabular}{|c|c|}
\hline & $\begin{array}{l}\text { "Hi I am looking some business idea in Quebec. Montreal with a little } \\
\text { investment for small return on investment. Any experience person } \\
\text { please feel free to reply. Thanks" (CV22_46) } \\
\text { "I am an international student in Manitoba, I have a valid study permit } \\
\text { and sin number. Am I allowed to open a business while studying (by } \\
\text { partnership with one of my friend who is Canadian citizen)? Are there } \\
\text { any paper works I need to know? I am thinking of opening an online } \\
\text { store, what is the requirement for starting a business as an international } \\
\text { student? Any advice and suggest? I don't want to be in trouble with the } \\
\text { laws..." (CV22_71) }\end{array}$ \\
\hline $\begin{array}{l}\text { Work } \\
\text { practices in } \\
\text { Canada } \\
9 \text { posts } \\
6.3 \%\end{array}$ & $\begin{array}{l}\text { "What happens if my employer never paid me either the salary he } \\
\text { declared he would pay me on the LMO nor the 6\% vacation? I received } \\
\text { my PR a month ago, I asked for my first-year vacation that was never } \\
\text { paid and mentioned the LMO subject to him. A month later he laid me } \\
\text { off saying there is no work for me, when clearly, we have houses to } \\
\text { frame and lack of man power. He never gave me a two week notice after } \\
\text { working for } 21 / 2 \text { years for him. Just told me to grab my things and go } \\
\text { (he used the words laid off though). A day later I find a new job a and } \\
\text { when I asked for my record of employment he says I should help frame } \\
\text { those houses at least for } 2 \text { weeks??? what should I do? thank you" } \\
\text { (CV23_15) } \\
\text { "Hello, I had a one-year contract with a company. Almost two months } \\
\text { prior to the termination date, I signed another one-year contact with } \\
\text { them. A few days before the termination date of the first contact, the } \\
\text { company downsized its operation and I was laid off. A new opening has } \\
\text { opened up and the Manager of that position has called me and asked if } \\
\text { Iwas willing to sign a } 6 \text {-month contact for thatposition. Upon agreeing, } \\
\text { I received a call from the recruitment agency to ask for my approval } \\
\text { before drafting the contact. A week later, I was advised that the HR } \\
\text { rejected me on the grounds that I was among those who were laid off } \\
\text { and that rehiring me would pose a conflict of interest. Is it legal to deny } \\
\text { me this position, despite the desire of the manager to rehire me, on the } \\
\text { above-mentioned grounds? Please Advise." (CV23_16) } \\
\text { "I recently signed a job in Canada from oversea and didn't ask them to } \\
\text { pay for my moving cost (I know, I should have asked before signing but } \\
\text { regardless I would still have signed even they didn't provide any support } \\
\text { for my moving cost). Is it appropriate to ask now? and if so how should } \\
\text { I ask without coming off too unprofessional or inappropriate?" } \\
\text { (CV21_25) }\end{array}$ \\
\hline
\end{tabular}




\begin{tabular}{|c|c|}
\hline $\begin{array}{l}\text { Living in } \\
\text { Canada } \\
6 \text { posts } \\
4.2 \%\end{array}$ & $\begin{array}{l}\text { "Hi my Friends I was being away from this amazing website, right now } \\
\text { it is for a while I have lived in Canada. I have lived in } 3 \text { major cities in } \\
\text { Canada. My question is which of the cities in Canada are best to live in } \\
\text { warm weather. By my friend's advice I have lived in } 3 \text { different cities } \\
\text { Windsor, Montreal and Toronto and none of them were warm.by being } \\
\text { warm I mean no -20 Celsius over there. I experienced -39 in Windsor } \\
\text { which by internet data was one of the warmest and frequent -20 by wind } \\
\text { chill was there in Windsor, it was a cheap city but no jobs over there. I } \\
\text { wonder which place is best to ask this question. to me it is also crucial } \\
\text { to find a place which life is more affordable as well and I can apply for } \\
\text { jobs (reasonable job market)." (CV21_198) } \\
\text { "Hello Every, I am a newly arrived Immigrant currently living in } \\
\text { Ottawa. I want to find out which is the best place to live \& work in } \\
\text { Canada for PHYSIOTHERAPISTS. I am a physiotherapist back home } \\
\text { and now I arrived here and I am planning to take my exam and then } \\
\text { settle in life. As I am still single I want to know more information } \\
\text { whether to settle here in Ottawa or move to Toronto for future life. I am } \\
\text { hoping people from the Canada Visa Forum will help me in giving me } \\
\text { the correct answer. Thankyou..." (CV21_405) } \\
\text { "Hi all, since I am travelling to Vancouver(sabbatical) next June I am } \\
\text { curious to know which district/part of Vancouver is the most practical } \\
\text { to live in regarding commuting to work. Although I am searching for a } \\
\text { job now, I assume that I will only find one once I have arrived in } \\
\text { Vancouver. So, I am searching for a place from which a have the most } \\
\text { reach to possible job locations within a timely manner. Given the nature } \\
\text { of my visit, the type of job can vary widely. Thanks!" (CV21_295) }\end{array}$ \\
\hline $\begin{array}{l}\text { Resources } \\
2 \text { posts } \\
1.4 \%\end{array}$ & $\begin{array}{l}\text { "Hello all Just received my COPR and my visa stamped and was } \\
\text { wondering if you would advise some recruitment websites that could } \\
\text { help find a job in pharmaceutical field before moving to Canada?" } \\
\text { (CV21_231) } \\
\text { "Hello, could anyone give me some advice on the best places } \\
\text { (resources) to find a job in engineering in Canada? Thanks." } \\
\text { (CV21 48) }\end{array}$ \\
\hline
\end{tabular}




\begin{tabular}{|c|c|}
\hline $\begin{array}{l}\text { Types of } \\
\text { outcomes }\end{array}$ & Examples \\
\hline $\begin{array}{l}\text { Yes } \\
314 \\
\text { threads } \\
60 \%\end{array}$ & $\begin{array}{l}\text { Example 1. Initial post (CV21_7) } \\
\text { "I am planning to register to APEGBC, and their requirement is that } \\
\text { transcripts to be sent in a sealed envelope to their office by the University. } \\
\text { I want to know if they require certified / attested copies from my university } \\
\text { or they are asking for original transcripts to be sent by my University. If } \\
\text { anyone has experience with APEGBC, kindly shed some light." } \\
\text { Reply } \\
\text { "First you need to apply for transcripts at the university from where you } \\
\text { obtained your degree, go to the university, fill the prescribed form, pay the } \\
\text { nominal charges, the clerk will tell you the time to come to receive } \\
\text { transcripts as it takes } 2 \text { to } 3 \text { weeks to prepare them. Don't give them extra } \\
\text { charges to get it immediately. Then go there at mentioned time, and receive } \\
\text { transcripts, which will be sealed by the university. Then send it through } \\
\text { courier to the destination." } \\
\text { Example 2. Initial post (CV21_379) } \\
\text { "I am a US citizen and am planning on coming Toronto for work under a } \\
\text { NAFTA work visa. Iaccepted a job with a company that knew this and was } \\
\text { going to sponsor me. This job has raised several red flags (took over a } \\
\text { month to get me the offer letter after they said they were going to make one, } \\
\text { has done nothing toward lining up the work visa even after they said they } \\
\text { would, etc.) and to be honest, my patience has pretty much run out for } \\
\text { them. I pretty much feel that the original employer is being unprofessional } \\
\text { and I question their ability to get the visa at all, and my happiness in this } \\
\text { environment. Another job offer has found me, and I would like to rescind } \\
\text { my original job offer and accept the new one instead. Are there typically, } \\
\text { any legal concerns with rescinding a job offer after it has been accepted?" } \\
\text { Reply } \\
\text { "Typically - no. But it would depend on the contract you signed (if any)." } \\
\text { Example } 3 \text {. Initial post (CV22 30) } \\
\text { "I part own an incorporation in Canada. I am on a business visitor's visa. } \\
\text { Reply } \\
\text { No }\end{array}$ \\
\hline $\begin{array}{l}\text { Partial } \\
40 \text { threads } \\
7.6 \%\end{array}$ & $\begin{array}{l}\text { Example 1. Initial post (CV24_43) } \\
\text { "Hi I will belong from USA to Canada. USA is known for low expenses and } \\
\text { low taxes while Canada has high living expenses and taxes. If I am not }\end{array}$ \\
\hline
\end{tabular}




\begin{tabular}{|c|c|}
\hline & $\begin{array}{l}\text { wrong, tax is } 45 \text { percent and living is twice as expensive than USA. So, } \\
\text { when you got a job, did I get twice the salary you were getting in USA? } \\
\text { How did your new offer compared to USA? Are u making money or losing } \\
\text { money in Canada?" } \\
\text { Reply } \\
\text { "As to tax, see here: http://www.cra-arc.gc.ca/tx/ndvdls/fq/txrts-eng.html } \\
\text { As for salaries, I don't know." } \\
\text { Example 2. Initial post (CV21_37) } \\
\text { "I want to know about SEO jobs. I have an experience in SEO and I am } \\
\text { looking for some opportunities in Canada along with studies." } \\
\text { Reply } \\
\text { "I assume you mean with SEO search engine optimization. If that is the } \\
\text { case then I think you should be searching studies regarding } \\
\text { marketing/internet marketing because usually SEO will be taught along } \\
\text { those programs. But I am not sure about job situation regarding SEO." } \\
\text { Example } 3 . \text { Initial post (CV24_37) } \\
\text { "I am at my final stage of immigration... will be moving to Calgary in next } \\
2 \text {-3 months. . I am a flight operation officer/Load Controller.... I want to } \\
\text { apply for the same job at Calgary Airport... Anyone has any idea where to } \\
\text { apply for this job and what is the average salary for this position?" } \\
\text { Reply } \\
\text { Try at WestJet, they are planning a bit more over there I guess. }\end{array}$ \\
\hline $\begin{array}{l}\text { More } \\
\text { questions } \\
43 \text { threads } \\
8.2 \%\end{array}$ & $\begin{array}{l}\text { Example 1. Initial post (CV21_54) } \\
\text { "Hi. I will soon be getting my PR to come to Canada. I have done my } \\
\text { masters from India in biotech. I will be going to Vancouver, so I was } \\
\text { wondering how the job market is for international Biotech background } \\
\text { immigrants. Is it recommended to get my credentials evaluated? And, which } \\
\text { job boards might be useful for me relating to my biotech career? And, what } \\
\text { other fields can I look into if biotech careers are not surplus? Thankyou." } \\
\text { Reply } \\
\text { "Any luck on getting a Biotech Job in Vancouver, my wife is also searching } \\
\text { for an opening in Biotech as she as a Masters in Biotech from India. Any } \\
\text { help/insights here would be great." } \\
\text { Example 2. Initial post (CV21_131) } \\
\text { "I got admission in university of Alberta. Branch is master of civil } \\
\text { engineering. So, I am wondering about job opportunities after the course } \\
\text { please can anyone help me with this. It would be very helpful for me." }\end{array}$ \\
\hline
\end{tabular}




\begin{tabular}{|c|c|}
\hline & $\begin{array}{l}\text { Reply } \\
\text { "Did you join University of Alberta already? Are you considering PhD } \\
\text { degree?" } \\
\text { Example 3. Initial post (CV22_5) } \\
\text { "I currently have a valid work permit for } 2 \text { years in Canada but as a non- } \\
\text { Canadian resident, am I able to set up my own business and work as a } \\
\text { freelancer? If yes, how would I go about registering the business? Would I } \\
\text { need to sort out tax declarations? I was reading on the Canadian Revenue } \\
\text { Agency website that if you earn less than } \$ 30,000 \text { over each business } \\
\text { quarter you do not have to submit for the GST/HST, is this correct?" } \\
\text { Reply } \\
\text { "I am really interested to know the answers of your question from any } \\
\text { candidate or expert that face similar situation" }\end{array}$ \\
\hline $\begin{array}{l}\text { No reply } \\
127 \\
\text { threads } \\
24.2 \%\end{array}$ & $\begin{array}{l}\text { Example 1. Initial post (CV21_367) } \\
\text { "Hi there Has anyone applied for federal internships from the government? } \\
\text { Are they paid? Are they hard to get?" } \\
\text { No reply } \\
\text { Example 2. Initial post (CV21_405) } \\
\text { "Hello Every, I am a newly arrived Immigrant currently living in Ottawa. } \\
\text { I want to find out which is the best place to live \& work in Canada for } \\
\text { PHYSIOTHERAPISTS. I am a physiotherapist back home and now I } \\
\text { arrived here and I am planning to take my exam and then settle in life. As I } \\
\text { am still single I want to know more information whether to settle here in } \\
\text { Ottawa or move to Toronto for future life." } \\
\text { No reply } \\
\text { Example } 3 \text {. Initial post (CV21_392) } \\
\text { "I have completed my Computer and Network support from Humber } \\
\text { college and have } 3 \text { months' experience working as Technical Project } \\
\text { Admin with Rogers (It was contract-based job through an agency). Could } \\
\text { you all please help me just by referring any websites, job board, any } \\
\text { company, any agency or any other tips on how to find job now? I request } \\
\text { all reader to share something good they have done and that can help others } \\
\text { here. All the replies will be much appreciated.I am specifically looking for } \\
\text { Technical Support Analyst/IT Technician/Help Desk positions" } \\
\text { No reply }\end{array}$ \\
\hline
\end{tabular}

